\title{
Functional domain contributions to signaling specificity between the non-receptor tyrosine kinases c-Src and c-Yes
}

Justin Matthew Summy

West Virginia University

Follow this and additional works at: https://researchrepository.wvu.edu/etd

\section{Recommended Citation}

Summy, Justin Matthew, "Functional domain contributions to signaling specificity between the nonreceptor tyrosine kinases c-Src and c-Yes" (2001). Graduate Theses, Dissertations, and Problem Reports. 1447.

https://researchrepository.wvu.edu/etd/1447

This Dissertation is protected by copyright and/or related rights. It has been brought to you by the The Research Repository @ WVU with permission from the rights-holder(s). You are free to use this Dissertation in any way that is permitted by the copyright and related rights legislation that applies to your use. For other uses you must obtain permission from the rights-holder(s) directly, unless additional rights are indicated by a Creative Commons license in the record and/ or on the work itself. This Dissertation has been accepted for inclusion in WVU Graduate Theses, Dissertations, and Problem Reports collection by an authorized administrator of The Research Repository @ WVU.

For more information, please contact researchrepository@mail.wvu.edu. 


\title{
Functional Domain Contributions to Signaling Specificity Between the Non-Receptor Tyrosine Kinases c-Src and c-Yes
}

\author{
Justin Matthew Summy \\ Dissertation submitted to the School of Medicine At West Virginia University \\ in partial fulfillment of the requirements for the degree of
}

Doctor of Philosophy

in

Biological Science

Daniel Flynn, Ph.D., Chair

Thomas Elliott, Ph.D.

Stephen Graber, Ph.D.

Bing-Hua Jiang, Ph.D.

Lisa Salati, Ph.D.

Department of Microbiology, Immunology, and Cell Biology

Morgantown, WV

2001

Key Words: Src, Yes, SH4, SH3, SH2, Unique domain, lipid rafts, signaling specificity, substrate selection, stable complex formation, Heme Oxygenase I 


\title{
Abstract
}

\section{Functional Domain Contributions to Signaling Specificity Between the Non-Receptor Tyrosine Kinases c-Src and c-Yes}

\begin{abstract}
Justin Summy
c-Src and c-Yes are two widely expressed and highly homologous members of the Src family of non-receptor tyrosine kinases and are involved in a diverse range of cellular signaling pathways. They are frequently activated in human cancers, and thus represent potential targets for anti-tumor drug design. The high level of homology between these two kinases includes not only sequence similarity, but also overlapping regulation and function. Despite the redundancies between c-Src and c-Yes, however, specificity in signaling has been demonstrated between the two proteins. It was hypothesized in these studies that differences in the signaling capacities of c-Src and c-Yes could be attributed to functional domain differences. In order to test this hypothesis, chimeric proteins were created in which the SH4, Unique, SH3, or SH2 domains of c-Src or the constitutively activated $\mathrm{Src}^{527 \mathrm{~F}}$, were replaced by those of c-Yes, either individually or in combinations. Differences in the signaling capacities of these proteins were assessed at the levels of protein/protein interactions, downstream gene induction, and cell biology. It was demonstrated that both the $\mathrm{SH} 3$ and $\mathrm{SH} 2$ domains were capable of directing differential protein/protein interactions between c-Src and c-Yes. While no differences in substrate selection were evident, the c-Yes SH3 domain failed to efficiently bind the Src SH3 binding partner AFAP-110 and several additional tyrosine-phosphorylated binding partners. Additionally, the c-Yes SH2 domain facilitated stable complex formation between $\mathrm{Src}^{527 \mathrm{~F}} / \mathrm{c}$-Yes chimeras and an unidentified $87 \mathrm{kDa}$ tyrosine-phosphorylated protein, pp87. Differences in downstream gene induction and cell biology were mediated by the amino terminal region (including the SH4 and Unique domains), as $\mathrm{Src}^{527 \mathrm{~F}} / \mathrm{c}-\mathrm{Y}$ es amino terminal chimeras failed to induce efficient upregulation of Heme Oxygenase 1 expression and were unable to induce actin filament rearrangement or changes in cell morphology upon expression in chicken embryo fibroblasts. These results occurred concomitant with a failure of these chimeras to induce activation of the PI3K/Akt pathway and inactivation of RhoA. Taken together, these results indicate that each of the non-catalytic functional domains may contribute to signaling specificity between c-Src and c-Yes. These results may contribute to the overall knowledge of biological differences between c-Src and c-Yes and how Src family kinases in general are able to achieve signaling specificity.
\end{abstract}




\section{Table of Contents}

Functional Domain Contributions to Signaling

Specificity Between the Non-Receptor Tyrosine

Kinases c-Src and c-Yes............................i

Abstract............................................ii

Acknowledgements..............................vi

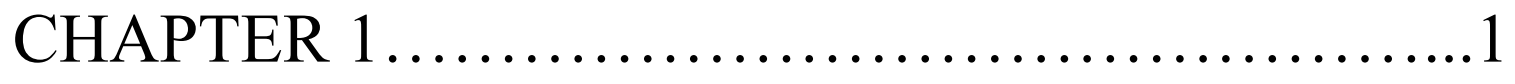

Introduction and Review of Literature................1

I. Introduction and Significance.............................................2

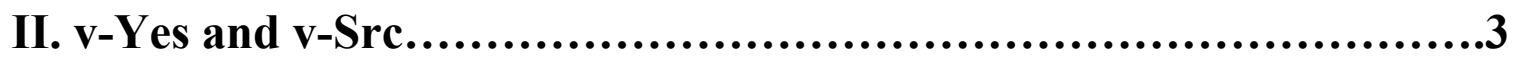

III. c-Yes Expression Patterns: Comparison and Contrast to c-Src.......5

IV. Involvement of c-Yes in Cellular Signaling Pathways...................6

V. Specificity in Signaling Between c-Yes and Other Src Family Kinases

[.........................................................................7

VI. c-Yes in Cancer and Disease......................................11

VII. Contributions of the c-Yes Functional Domains to Signaling

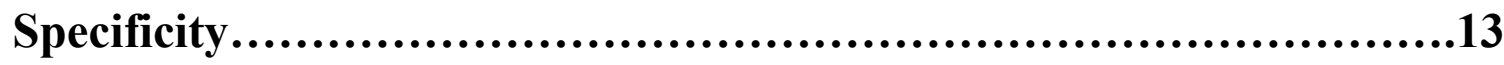

VIII. Summary and Goals.........................................20

References..........................................................22

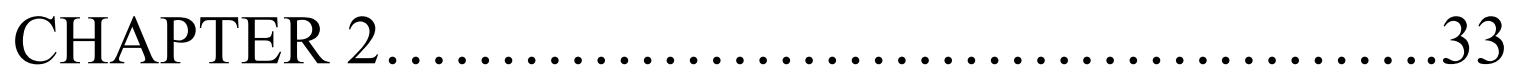

The SH3 and SH2 Domains Are Capable of Directing Specificity in Protein Interactions Between the Non- 
Receptor Tyrosine Kinases c-Src and c-Yes........33

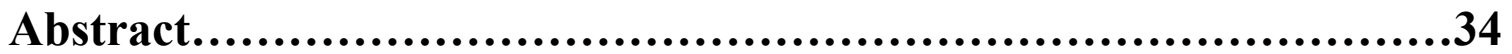

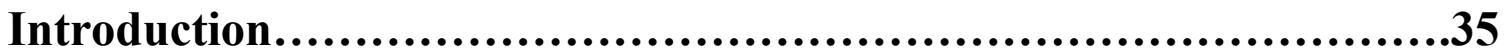

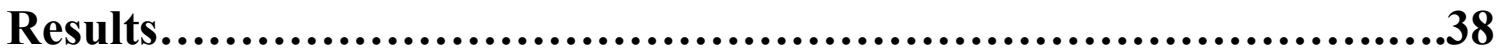

Discussion............................................................43

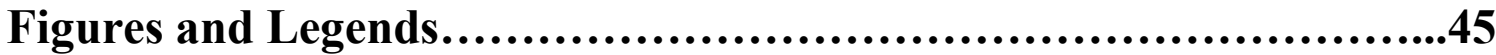

References..................................................................54

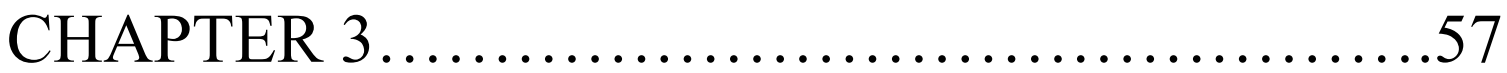

Chimeric Constructs Containing the SH4/Unique

Domains of c-Yes Can Restrict the Ability of $\mathrm{Src}^{527 \mathrm{~F}}$

to Upregulate Heme Oxygenase-1 Expression

Efficiently...................................57

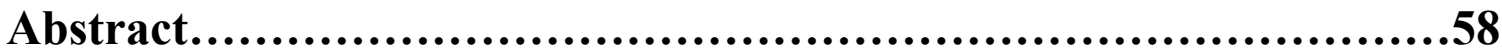

Introduction..............................................................59

Materials and Methods....................................................62

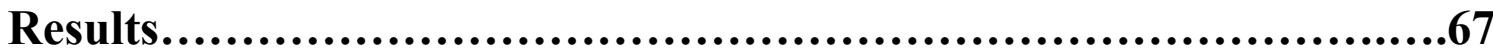

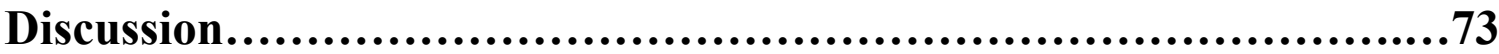

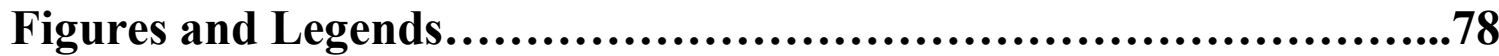

References..................................................................87

CHAPTER 4.......................................89

The c-Yes Amino Terminal SH4 and Unique

Domains Prevent Actin Filament Rearrangement and

Phosphatidylinositol-3-Kinase Activation by 
$\mathrm{Src}^{527 \mathrm{~F}} / \mathrm{c}-$ Yes Chimeric Proteins....................89

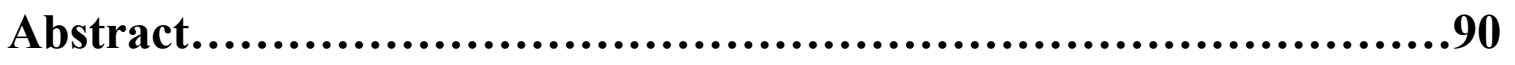

Introduction..........................................................91

Materials and Methods...............................................95

Results.................................................................100

Discussion..........................................................110

Figures and Legends...............................................116

References.........................................................133

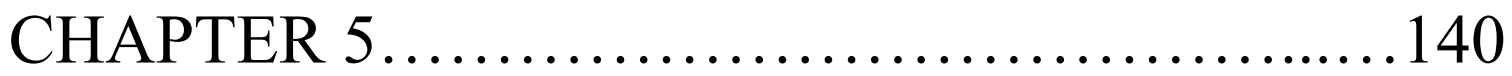

General Discussion..............................140

Figures and Legends.................................................167

References............................................................182

Curriculum Vitae...............................191 


\section{Acknowledgements}

I would like to express my most profound appreciation and thanks to my advisor, Dr. Daniel Flynn, for his support and guidance throughout my graduate career. Dr. Flynn allowed me to take on a project that represented a new direction for the lab and gave me considerable leeway in developing the direction it should take. This has been a wonderful experience in my development as a scientist. Dr. Flynn has also made my graduate career fun and enjoyable. He kept science interesting, and for that I will always be grateful.

I would like to express my sincere thanks and appreciation to the members of my committee, past and present, including Dr. Thomas Elliott, Dr. Stephen Graber, Dr. BingHua Jiang, Dr. Lisa Salati, and Dr. Eric Westin. Their advice has helped me out with experimentation, drawing conclusions, and presentation of data.

I would like to thank the Arlen G. and Louise Stone Swiger Pre-Doctoral Fellowship Foundation for providing me with funding during my second, third, and fourth years.

I would like to thank all of my colleagues in the Flynn lab, including Anne Guappone Koay, Dr. Yong Qian, Amanda Gatesman, Joe Baisden, Lidia Cherezova, Itishaam Qazi, Carrie Marshall, Thomas Brown, Andy Clump, Lanette Murphy, Helen $\mathrm{Vu}$, and Dr. Tracy Weimer. They have given me technical advice and experimental help when necessary, along with friendship, support, and entertainment that have helped make this a rich and rewarding experience.

Finally, I'd like to thank all my friends and family who have supported me throughout the years. Their love and support has helped see me through the challenges and hard times. 


\section{Chapter 1}

\section{Introduction and Review of Literature}




\section{Introduction and Significance}

p62 c-Yes and p60 c-Src are two of the nine members of the Src family of nonreceptor tyrosine kinases (c-Src, c-Yes, Fyn, Lyn, Lck, Hck, Blk, Fgr, and Yrk). Src family kinases are linked by a common structural architecture, each with four Src homology domains (SH1-4) and a Unique domain. The Src family kinases have been implicated in signaling pathways that regulate a vast array of cellular processes, including cytokine and growth factor responses, cytoskeleton dynamics, cell proliferation, survival and differentiation (Rev. in Thomas and Brugge, 1997). While c-Src has been extensively studied, comparatively little is known of the biological functions of c-Yes. cYes and c-Src are two of the most widely expressed and homologous members of the Src family. Both kinases are present in many of the same tissues and are activated in response to many of the same stimuli. The frequent activation of c-Src and c-Yes in human cancers, coupled with the tumorigenic potential of their viral homologues, v-Src and v-Yes, suggests that they may contribute to the onset or progression of the malignant phenotype. Thus c-Src and c-Yes represent potential targets for rational drug design. In order to optimize the value of these kinases as chemotherapeutic targets, it will not only be important to understand the biological functions of c-Yes and c-Src, both in normal and cancerous tissues, but also to understand how they are capable of sending specific signals. As the biology and functions of c-Src have been extensively studied and reported, this literature review will focus on the functions of c-Yes and how c-Yes may be able to participate in specific signaling pathways. 


\section{II. v-Yes and v-Src}

The Yes kinase was originally discovered as the oncogenic protein encoded by the Yamaguchi 73 and Esh sarcoma viruses (Ghysdael et al., 1981; Rev. in Toyoshima et al., 1987; Wang and Hanafusa, 1988). Initial interest in v-Yes arose as a result of its similarity to v-Src. Both oncoproteins are tyrosine kinases capable of inducing sarcomas in chickens and transforming fibroblasts in culture (Toyoshima et al., 1987). v-Src and v-Yes are $82 \%$ homologous, with particularly strong homology $(90 \%)$ within the tyrosine kinase domain (Kitamura et al., 1982). The amino acid homology between the two kinases allows immunorecognition of v-Yes by monoclonal antibodies raised against vSrc (McCarley et al., 1987), and the two proteins release overlapping subsets of tyrosinephosphorylated peptides upon tryptic digestion and two-dimensional electrophoresis (Erikson and Erikson, 1983). In addition to their structural homology, biochemical and functional similarities have been observed between v-Src and v-Yes in chicken embryo fibroblast culture. Both proteins fractionate with the detergent-insoluble cytoskeleton and localize to focal contacts, where the cell and extracellular matrix meet (Loeb et al., 1987; Gentry and Rohrschneider, 1984). Many of the same proteins are phosphorylated in cells transformed by either v-Src or v-Yes (Kamps and Sefton, 1988; Kanner et al., 1990). v-Src and v-Yes also appear to utilize shared downstream signaling pathways, as both proteins induce activation of PI3 kinase and require the activator protein 1 (AP-1) transcription factor complex (composed of heterodimers of various isoforms of the c-Jun and c-Fos transcription factors) for cell transformation (Fukui et al., 1991; Suzuki et al., 1994).

Homology between v-Src and v-Yes can be extended further to include the 
mechanisms by which these kinases have been rendered transformation-competent. Both kinases are constitutively active due to loss or replacement of sequence in their carboxytermini (Rev. in Brown and Cooper, 1996). Src family kinases contain a conserved tyrosine residue ( $\mathrm{Tyr}^{527}$ in c-Src, $\mathrm{Tyr}^{535}$ in c-Yes) in their carboxy-terminal tail sequence. This tyrosine residue is phosphorylated by members of the Csk (C-terminal Src kinase) family and forms an intramolecular interaction with the SH2 domain (Okada et al., 1991). The SH2/tail interaction forms the linchpin of the "closed" or "assembled" conformation (Xu et al., 1997; Sicheri et al., 1997). The SH3 domain contributes to the stability of the closed conformation through formation of an intramolecular interaction with the kinase linker, a short stretch of amino acids bridging the $\mathrm{SH} 2$ and kinase domains (Xu et al., 1997; Sicheri et al., 1997). In the assembled state, the conformation of the kinase active site is such that ATP and substrates are prevented from entering, resulting in repressed kinase activity (Xu et al., 1999). Although recent evidence indicates that autophosphorylation within the active site ( $\mathrm{Tyr}^{416}$ in $\mathrm{Src} \mathrm{Tyr}^{424}$ in Yes) may allow kinase activity in the presence of phosphorylation at the regulatory tyrosine (Sun et al., 1998; Xu et al., 1999), Src family kinases must be released from the closed conformation in order to achieve their full transforming potential. The ability of v-Src, v-Yes, Src ${ }^{527 \mathrm{~F}}$ (in which $\mathrm{Tyr}^{527}$ is mutated to Phe), and various SH3 and SH2 domain mutants of c-Src to transform cells illustrates this point (O'brien et al., 1990; Superti-Furga et al., 1993; Brown and Cooper, 1996). 


\section{III. c-Yes Expression Patterns: Comparison and Contrast with c-Src}

The c-yes gene, localized to chromosome 18 at locus q21.3 in humans (Yoshida et al., 1985), was discovered as the cellular homologue of the v-yes oncogene (Yoshida et al., 1980; Sukegawa et al., 1987; Sudol et al., 1988b). The c-yes gene encodes a 62 kDa tyrosine kinase that displays extensive homology with the c-Src protein and, like c-Src, is expressed across a wide range of normal cells and tissues (Sudol and Hanafusa, 1986). cYes expression is found in epithelial tissues (lung, kidney, gastrointestine, liver, skin, etc.), connective tissue, vascular endothelial cells, and smooth muscle; expression levels are particularly high in platelets, neurons (particularly Purkinje cells of the cerebellum), and spermatid acrosomes (Sudol et al., 1989; Zhao et al., 1990; Sugawara et al., 1991; Zhao et al., 1991; Walaas et al., 1993). While c-Src is also expressed in many of these tissues, the expression patterns of the two proteins are not identical, thus providing evidence that c-Yes may perform functions unique from those of c-Src. Gessler and Barnekow observed that the c-yes and c-src genes were differentially expressed during chicken embryogenesis (Gessler and Barnekow, 1984). In these studies, c-src message was expressed at high levels in brain throughout embryogenesis and displayed an agedependent decrease in muscle tissue. Message levels of c-yes were initially low in brain, muscle, and heart, but increased throughout embryogenesis. Bixby and Jhabvala noted differential developmental expression of c-Src and c-Yes in the brain (Bixby and Jhabvala, 1993). Peak c-Src expression was observed between days 10 and 12, followed by a gradual decrease in expression, whereas c-Yes expression did not peak until day 20 and remained at high levels into adulthood. Sudol et al. noted a similar age-dependent decrease in chicken cerebellar c-Src expression, in contrast to increased c-Yes expression 
(Sudol et al., 1988a). Collectively, these data imply that c-Src and c-Yes may perform different functions in the developing embryo and adult.

\section{Involvement of c-Yes in Cellular Signaling Pathways}

While c-Yes has not been studied as exhaustively as c-Src, several studies over the past decade have examined the biological functions of cellular Yes. The ability of vYes to induce cellular transformation suggests that c-Yes may be involved in the control of cell proliferation. However, the fact that many of the cells in which c-Yes is highly expressed are post-replicative (i.e. neurons, platelets) and fully differentiated suggests a possible role in differentiation or the facilitation of cell-specific processes. In fact, evidence exists for involvement of c-Yes, and Src family kinases in general, in a variety of signal transduction pathways, including those that regulate cell division, differentiation, survival, motility, adhesion, spreading, and vesicular transport (Thomas and Brugge, 1997). In serum-starved NIH 3 T3 fibroblasts, serum stimulation results in activation of c-Yes, along with c-Src and Fyn, during the G2/M cell cycle transition (Roche et al., 1995). c-Yes and c-Src are both activated during proliferation and differentiation of rat trophoblast cells (Kamei et al., 1997). In keratinocytes, calcium treatment results in decreased c-Yes kinase activity, coinciding with a shift from cellular proliferation to differentiation (Zhao et al., 1993). Owens et al. demonstrated that, upon calcium treatment of epithelial cells, c-Yes, c-Src, and Fyn localize to sites of cell/cell contact, where their kinase activity is necessary for disruption of cell/cell junctions (Owens et al., 2000). In cultured neuronal cells, c-Yes, c-Src, and Fyn are concentrated and activated in growth cones (Meyerson and Pahlman, 1993). c-Yes is also activated in response to stimulation of receptor tyrosine kinases (PDGF-R, CSF-1-R, Neu, FGF-R, 
Sky, Flt 1) (Kypta et al., 1990; Courtneidge et al., 1993; Muthuswamy and Muller, 1995;

Landgren et al., 1995; Toshima et al., 1995; Waltenberger et al., 1994), G-protein coupled receptors (angiotensin II receptor, thrombin receptor, endothelin receptor) (Tsygankova et al., 1998; Chen et al., 1994; Kovacic et al., 1998), cytokine receptors (oncostatin M, interleukin-11, GM-CSF) (Schieven et al., 1992; Fuhrer and Yang, 1996a; Corey et al., 1993), the FceRI receptor, and the polyimmunoglobulin (pIg) receptor (Eiseman and Bolen, 1992; Luton et al., 1999).

\section{Specificity in Signaling Between c-Yes and Other Sre Family Kinases}

While the above list represents what is likely to be only a sampling of the pathways in which c-Yes is involved, it illustrates the potential for diversity in the function of this kinase. However, as c-Src and other Src family kinases are activated in response to many of the same cellular signals, it is not always clear where c-Yes performs unique functions and where it functions redundantly with other Src family kinases. The answer appears to vary from system to system. c-Yes may function redundantly with cSrc and Fyn in serum-induced fibroblast cell cycle progression. Microinjection of antibodies immunoreactive against all three proteins induces a cell cycle block at the G2/M phase transition, whereas microinjection of a c-Src-specific antibody does not interfere with cell cycle progression unless no other Src family kinases are expressed (Roche et al., 1995). c-Yes may also function redundantly with c-Src and Fyn in PDGFreceptor signaling (Mori et al., 1993; Twamley-Stein et al., 1993).

The phenotypes of the Src family kinase knockout mice provide further evidence for shared functions between Src family members. Whereas c-src -/-, fyn -/-, and c-yes -/individual knockout mice develop distinct phenotypes, they typically survive for 
extended periods after birth. The loss of both the c-src and c-yes genes, however, invariably leads to perinatal lethality (Stein et al., 1994). Mice lacking both the fyn and c-yes genes develop degenerative renal damage, leading to diffuse segmental glomerulosclerosis (Stein et al., 1994). Interestingly, mice harboring a disruption of the c-yes gene do not display significant abnormalities in the cells or tissues in which c-Yes is most highly expressed (platelets, neurons, and spermatid acrosomes), suggesting that cSrc and/or Fyn are capable of compensating for the lack of c-Yes activity in these cells.

Despite the evidence for functional overlap, data also exist that indicate c-Yesspecific signaling. Much of this data is obtained from studies of c-src -/- mice and cells derived from them. Several of these studies indicate that c-Yes is unable to compensate for $\mathrm{c}-\mathrm{Src}$ in processes that are dependent on the dynamic regulation of the actin cytoskeleton. Osteoclasts from c-src -/- mice are unable to reabsorb bone, resulting in an osteopetrotic phenotype (Soriano et al., 1991). This deficiency correlates with an inability of the osteoclasts to form membrane ruffles and actin ring structures (Boyce $e t$ al., 1992). Additionally, cells from the c-src -/- mice fail to spread properly on fibronectin and demonstrate reduced motility (Kaplan et al., 1995; Hall et al., 1996). Neuronal cells derived from c-src -/- mice are deficient in neurite extension on NCAML1 (Ignelzi, Jr. et al., 1994). Mice lacking the c-src gene also fail to develop Middle T antigen-induced mammary tumors, whereas c-yes -/- mice develop mammary tumors at a normal rate (Guy et al., 1994). Despite the apparent deficiency of c-Yes in eliciting these actin-dependent processes, active variants of Yes are localized to detergent insoluble cytoskeletal fractions (Loeb et al., 1987). It is possible that c-Yes may associate with and/or regulate other components of the cytoskeleton. Indeed, it was observed by 
Ciesielski-Treska et al. that c-Yes co-localizes specifically with vimentin intermediate filaments in amoeboid microglia (Ciesielski-Treska et al., 1995).

The inability of c-Yes to function as a "molecular backup" for c-Src is not limited exclusively to regulation of the actin cytoskeleton. In rat aortic smooth muscle cells, cSrc specifically is necessary for angiotensin II-induced phosphorylation of p120 Ras GAP and p190 Rho GAP (Schieffer et al., 1996). In rat ventricular myocytes, c-Yes, cSrc, and Fyn are activated in response to endothelin, however, only c-Src is able to drive elevated transcription from the atrial natriuretic peptide promoter, a hallmark of hypertrophy in ventricular cardiomyocytes (Kovacic et al., 1998). c-Src and c-Yes also differ in their respective abilities to participate in the hypoxia response. Of the three ubiquitously expressed Src family members, c-Src exclusively is activated under hypoxic conditions (Mukhopadhyay et al., 1995). This is in agreement with recent data that indicates that $\mathrm{Src}^{527 \mathrm{~F}} / \mathrm{c}$-Yes chimeras with the $\mathrm{c}-\mathrm{Yes} \mathrm{SH} 4$ and Unique domains are deficient in upregulation of Heme Oxygenase 1 expression, as normally occurs in response to cellular stresses, including hypoxia (Hoey et al., 2000).

Specificity between c-Yes and c-Src is not limited to pathways in which c-Yes fails to compensate for c-Src. While both c-Yes and c-Src are able to induce phosphorylation of the adapter protein Cbl when overexpressed in COS cells, only c-Yes is able to efficiently co-immunoprecipitate with Cbl (Feshchenko et al., 1998). During trophoblast cell proliferation, c-Yes associates with several tyrosine-phosphorylated proteins that are not found in complex with other Src family kinases (Kamei et al., 1997). As mentioned above, c-Yes is inactivated in keratinocytes upon calcium and phorbol ester treatment (Zhao et al., 1993). In this system, c-Yes inactivation correlates with 
association with unknown proteins of 110 and $220 \mathrm{kDa}$ (Zhao et al., 1993). In 3T3 L1 mouse pre-adipocytes, both c-Src and c-Yes are activated upon IL-11 stimulation; however, only c-Yes is detected in a receptor-associated signaling complex including JAK2, PP2A, and gp130 (Fuhrer and Yang, 1996b). In angiotensin II-treated pulmonary vein endothelial cells, of the three ubiquitously expressed Src family kinases, only c-Yes induces phosphorylation of and associates with the calcium-sensitive kinase Pyk2 (Tang et al., 2000). Unfortunately, the importance of co-association between c-Yes and the proteins mentioned above remains unknown. They do however, illustrate that c-Yes is capable of forming distinct protein/protein interactions and is thus capable of initiating or participating in unique signaling pathways.

In addition to differences in intermolecular interactions, signaling specificity between c-Src and c-Yes has been observed at the level of kinase activation. c-Yes is the predominant Src family kinase activated upon engagement of the Fce receptor in the TF1 mast cell line (Eiseman and Bolen, 1992) and upon stimulation of neutrophils with oncostatin M (Schieven et al., 1992). By virtue of its localization to lipid raft fractions, c-Yes may be selectively involved in the renal tubular cell internalization of Shiga toxin (Stx), produced by Shigella dysenteriae and enterohemorrhagic Escherichia coli. c-Yes associates with the globotriaosylceramide Gb3, to which Stx binds. Association of Stx with Gb3 induces c-Yes-specific kinase activation (Katagiri et al., 1999). The importance of c-Yes activity for Stx entry was not determined. In rat liver epithelial cells, c-Yes and Fyn are specifically activated in response to angiotensin II (Tsygankova et al., 1998). In this system, c-Yes and Fyn are essential for the induction of DNA synthesis and c-Fos expression, as both responses are inhibited by microinjection of 
antibodies against either protein (Tsygankova et al., 1998). Both c-Src and c-Yes, but not Fyn, appear to be required for VEGF-induced vascular permeability in mice, as cells lacking either protein are deficient in this response (Eliceiri et al., 1999). Finally, c-Yes specifically associates with the pIg receptor and is activated upon receptor engagement (Luton et al., 1999). c-Yes appears to be required for pIg receptor-mediated transcytosis, as mice lacking the c-yes gene are deficient in transcytosis of IgA (Luton et al., 1999). Taken together, these results indicate that in normal cells, c-Yes is able to send unique signals.

\section{VI. c-Yes in Cancer and Disease}

The ability of v-Yes to induce cell transformation piqued interest in the study of the normal cellular homologue, as it was inferred that c-Yes might be involved in the onset or progression of human cancers. As with c-Src, several lines of evidence have in fact pointed to this possibility. The evidence is largely circumstantial, however, and consists primarily of observations that c-Yes is activated in several transforming, cancerous, and pre-cancerous conditions. Nevertheless, the data discussed below have laid the groundwork for future studies of c-Yes in human cancers. Both c-Yes and c-Src are frequently activated in human colon carcinoma cells and pre-malignant lesions of the colon (Cartwright et al., 1989; Park et al., 1993; Cartwright et al., 1994; Pena et al., 1995). The degree of c-Yes and/or c-Src kinase activation in these cells correlates with their malignant potential (Cartwright et al., 1994; Pena et al., 1995). In colorectal carcinoma liver metastases, the kinase activity of either c-Src or c-Yes decreases relative to the parent tumor (Han et al., 1996). However, activation of c-Yes in colon carcinoma liver metastases is associated with more aggressive disease and a poorer prognosis than c- 
Src activation (Han et al., 1996). Interestingly, Park and Cartwright demonstrated that while c-Src activity increases during mitosis of human colon carcinoma cells, c-Yes protein expression and activation decrease (Park and Cartwright, 1995). c-Yes protein levels and kinase activity are elevated 5-10 fold in malignant melanoma cells, in comparison to normal melanocytes, whereas c-Src activity and expression are unchanged (Loganzo, Jr. et al., 1993). c-Yes kinase activity correlates with the brain metastatic potential of melanoma cell lines, as the most highly metastatic melanoma cell lines display the highest levels of c-Yes kinase activity (Marchetti et al., 1998). c-Yes activity is further elevated upon stimulation with NGF or neurotrophin 3 (Marchetti et al., 1998). The neurotrophin-induced activation is specific for c-Yes, as c-Src activity is not affected. Despite the apparent dispensability of c-Yes kinase activity for Middle T antigen-induced murine breast tumors, the ability of Middle $\mathrm{T}$ to transform cells correlates well with its ability to associate with and activate both c-Src and c-Yes (Courtneidge, 1985; Kornbluth et al., 1987; Kornbluth et al., 1990; Glenn and Eckhart, 1993). While c-Yes activity does not appear to be necessary for transformation of fibroblasts by Middle T, it is important for Middle T-induced transformation of endothelial cells (Reported in Guy et al., 1994). In human breast cancer cells, overexpression of members of the EGFR family, specifically erbB-2 (Neu), is associated with poor clinical prognosis. When expressed in mice, under control of the mouse mammary tumor virus (MMTV) promoter, the Neu protein induces transformation of breast epithelial cells. In this system, the Neu protein associates with and activates both c-Src and c-Yes through SH2 domain interactions (Muthuswamy and Muller, 1995). Moasser et al. demonstrated up-regulation of c-Src and/or c-Yes kinase activity in a panel 
of human breast cancer cell lines, and inhibition of Src family kinase activity in this system resulted in cell cycle arrest during mitotic prophase (Moasser et al., 1999). Together, the above data illustrate that not only is c-Yes activated in select human cancers, but its contributions to the transformed phenotype may differ from those of cSrc. Furthermore, the differential activation of c-Yes and c-Src in some human cancers suggests that it may be beneficial to selectively target these kinases individually using rational drug design. In order to accomplish this, however, it is necessary to understand how these kinases send specific signals.

\section{Contributions of the c-Yes Functional Domains to Signaling Specificity}

As a member of the Src family, c-Yes shares the functional domain architecture common to all Src family kinases. As mentioned above, this consists of four homologous domains and a Unique domain. While the c-Yes functional domains, specifically, have not been studied extensively, a great deal has been learned about the roles of Src family functional domains in general, and this knowledge will be important in the elucidation of how the c-Yes functional domains are likely to contribute to signaling specificity.

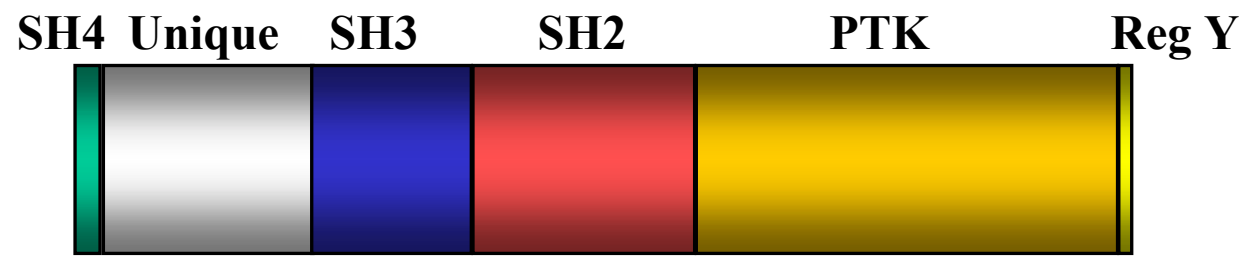

\section{A Prototypical Src Family Kinase Sub-Divided into the Functional Domains}




\section{VII.A. SH4 Domain}

The amino terminal 7-14 amino acids are referred to as the SH4 domain (Rev. in Resh, 1994). This region is necessary and sufficient for localization to cellular membranes. All Src family members contain a glycine in the second position from the amino terminus. This glycine is myristoylated co-translationally and targets Src family members to cellular membranes. While the addition of myristic acid is necessary for membrane localization, it is not sufficient (Resh, 1994). All Src family members, with the exception of c-Src and Blk, additionally undergo palmitoylation at one or more cysteine residues downstream of the myristoylation site (Resh, 1994). Palmitoylation occurs post-translationally, and potentially spontaneously, as cysteine-acylation has been shown to occur spontaneously in the presence of acyl-CoA in vitro (Bano et al., 1998). However, prior myristoylation is required for palmitoylation (Koegl et al., 1994). It has been suggested that palmitoylation is a dynamic process and may serve as a means of regulating the sub-cellular localization of Src family members and their access to substrates (Yurchak and Sefton, 1995). Palmitoylation targets Src family members to lipid rafts, regions of the plasma membrane rich in glycolipids, sphingolipids, cholesterol, and glycosylphosphatidyl inositol-linked proteins, that can be isolated by flotation on sucrose gradients (Shenoy-Scaria et al., 1993; Robbins et al., 1995). The importance of the SH4 domain in raft localization has not been demonstrated specifically for c-Yes but has been shown for other Src family members, including Lck and Hck (Shenoy-Scaria et al., 1993). However, since c-Yes is palmitoylated and is found in lipid rafts (Sargiacomo et al., 1993; Arreaza et al., 1994), it is likely that palmitoylation also serves to target cYes to these membrane microdomains. 
Several recent studies have revealed the importance of palmitoylation and lipid raft localization in Src family kinase signaling. A functional palmitoylation signal is required for the ability of Src family kinases to efficiently transduce signals from the T cell receptor and Fc receptors (Kabouridis et al., 1997; Honda et al., 2000; Suzuki et al., 2000). It has been speculated that the presence of c-Yes in lipid raft fractions in MDCK cells may be indicative of a role for c-Yes in vesicular trafficking or proper sorting of GPI-linked proteins (Sargiacomo et al. 1993; Arreaza et al., 1994).

\section{VII.B. Unique Domain}

Following the SH4 domain is the Unique domain, a 60 to 90 amino acid sequence that is completely heterogeneous across the Src family. Very little is known about the role of the Unique domain in c-Yes signaling, and due to the lack of sequence homology in this region, it is difficult to infer a function for the c-Yes Unique domain based upon what is known of other Src family kinases. c-Src is phosphorylated on serine and threonine residues in the Unique domain during mitosis, and these phosphorylation events correlate with elevated kinase activity (Gould and Hunter, 1988; Morgan et al., 1989; Shenoy et al., 1989). Upon stimulation of the PDGF receptor in fibroblasts, Fyn is phosphorylated on tyrosine residues in its Unique domain, via both autophosphorylation and PDGF receptor phosphorylation (Hansen et al., 1997). As with the c-Src Unique domain, phosphorylation of the Fyn Unique domain also correlates with increased kinase activity. An in vitro autophosphorylation site was mapped to tyrosine 32 in the c-Yes Unique domain, however, the importance of this phosphorylation event remains unclear (Ariki et al., 1997). Phosphorylation of Unique domain residues may serve to facilitate protein/protein interactions or to alter the global conformation of the protein in such a 
fashion that the inactive "closed" conformation is destabilized, thus increasing kinase activity. In addition to serving as a site of phosphorylation, the Unique domain may also direct protein/protein interactions. The Unique domain is responsible for association of Lck with CD4 and CD8 in T cells, and association of Lyn with the Fce receptor (Shaw et al., 1989; Vonakis et al., 1997).

\section{VII.C. SH3 Domain}

Following the Unique domain are two modular domains that serve to direct protein/protein interactions: the $\mathrm{SH} 3$ and $\mathrm{SH} 2$ domains. There are several ways in which protein/protein interactions mediated by the $\mathrm{SH} 3$ and $\mathrm{SH} 2$ domains may direct c-Yesspecific signaling. SH3 and SH2 domain binding partners may disrupt the intramolecular interactions maintaining the protein in the assembled or inactive conformation.

Destabilization of the closed conformation enhances the accessibility of the kinase active site for ATP and substrates, thus increasing the specific activity of the kinase (Alonso et al., 1995; Moarefi et al., 1997). Additionally, association of c-Yes with $\mathrm{SH} 3$ or SH2 domain binding partners may serve to present these proteins for tyrosine phosphorylation. Thus the SH3 and SH2 domains may contribute to signaling specificity through differential substrate selection and presentation for processive phosphorylation (Kanner et al., 1991; Mayer and Baltimore, 1994; Weng et al., 1994; Guappone and Flynn, 1997; Pellicena et al., 1998). Finally, stable association between c-Yes and SH3 or SH2 domain binding partners may allow the formation of c-Yes-specific signaling complexes that serve as sites of activation or inactivation of downstream signaling pathways or target c-Yes to distinct sub-cellular localizations (Fukui et al., 1991).

The SH3 domain is approximately 60 amino acids in length and directs 
protein/protein interactions through association with left-handed type II helical prolinerich sequences within SH3 domain binding partners (Yu et al., 1992; Yu et al., 1994; Rev. in Brown and Cooper, 1996). Domain swapping studies and in vitro binding assays have demonstrated overlapping ligand specificity between Src family SH3 domains (Weng et al., 1994; Erpel et al., 1996). However, these studies have also illustrated differences in Src family kinase SH3 domain specificity. Studies utilizing phage display analysis have revealed subtle differences in the ligands selected by Src family kinase SH3 domains, including c-Src and c-Yes (Rickles et al., 1995; Sparks et al., 1996). It is important to note, however, that actual SH3 domain binding partners do not always contain the consensus binding motifs defined by peptide-binding assays. In support of the peptide-binding data, however, differential protein binding has been demonstrated between the c-Yes and c-Src SH3 domains in vitro and in vivo. In comparison to the cSrc SH3 domain, the c-Yes SH3 domain is deficient in binding the $110 \mathrm{kDa}$ actin filament associated protein (AFAP-110) in vitro (Summy et al., 2000). In agreement with the in vitro binding data, $\mathrm{Src}^{527 \mathrm{~F}} / \mathrm{c}-$ Yes chimeras with the c-Yes $\mathrm{SH} 3$ domain were deficient in stable complex formation with AFAP-110 in vivo, as demonstrated by a lack of co-immunoprecipitation between the proteins (Summy et al., 2000). Conversely, the c-Yes SH3 domain readily binds the $65 \mathrm{kDa}$ Yes Associated Protein (YAP 65), a weak c-

Src SH3 domain binding partner (Sudol, 1994). Association of c-Yes with YAP 65 appears to contribute to the apical localization of c-Yes in airway epithelia, through association with EBP50 (Mohler et al., 1999).

\section{VII.D. SH2 Domain}

Immediately following the $\mathrm{SH} 3$ domain is the $\mathrm{SH} 2$ domain. The $\mathrm{SH} 2$ domain is 
comprised of 90-100 amino acids that form a modular phosphotyrosine-binding motif (Rev. in Brown and Cooper, 1996). SH2 domain interactions are high affinity, with dissociation constants in the nanomolar range. The SH2 domain is comprised of a central $\beta$-barrel structure, flanked by two $\alpha$-helices and a smaller $\beta$-sheet (Waksman et al., 1992; Eck et al., 1993). The tertiary structure of the SH2 domain forms two binding pockets, the first for phosphotyrosine and the second for the $\mathrm{pY}+3$ amino acid (Waksman et al., 1992; Eck et al., 1993). SH2 domain binding specificity is dictated by the sequence of amino acids surrounding the phosphorylated tyrosine residue, particularly those on the carboxy-terminal side (Bibbins et al., 1993; Songyang et al., 1993). The optimal c-Yes SH2 domain ligand sequence has not been specifically determined, however, all Src family SH2 domains appear to select the sequence pYEEI with maximal affinity (Songyang et al., 1993). In support of the peptide-binding data, SH2 domain redundancy has also been demonstrated with regard to full-length protein binding. c-Src, Fyn, and cYes bind the same sites within the PDGF and CSF-1 receptors via their SH2 domains (Alonso et al., 1995), and the c-Yes and c-Src SH2 domains appear to bind the same sites within the Neu protein (Muthuswamy and Muller, 1995).

Little data exists to suggest signaling specificity between Src family members at the level of the SH2 domain, however, it was recently noted that $\mathrm{Src}^{527 \mathrm{~F}} / \mathrm{c}$-Yes chimeras with the c-Yes SH2 domain display enhanced co-immunoprecipitation with an unknown phosphoprotein of approximately $87 \mathrm{kDa}$ (pp87) (Summy et al., 2000). As the identity of this protein is currently unknown, the significance of complex formation between pp 87 and the c-Yes SH2 domain is unclear. It does illustrate, however, that c-Yes-specific signaling events may be generated through $\mathrm{SH} 2$ domain interactions. A recent study by 
Bradshaw et al. revealed that SH2 domain specificity between Src family members may arise as a result of differences within the phosphotyrosine binding pocket (Bradshaw et al., 1999). It was noted in this study that the amino acid in the $\beta C 3$ position of the pTyrbinding pocket contributes considerable energy to phosphotyrosine binding. c-Src contains a cysteine in this position, whereas all other Src family kinases, including c-Yes, contain a serine in this position. Mutation of the cysteine to serine resulted in a four-fold increase in binding affinity for $\mathrm{pTyr}$. This may have implications for the relative abilities of Src family kinase SH2 domains to associate with their cognate regulatory phosphotyrosines or intermolecular binding partners.

\section{VII.E. SH2/Kinase Linker}

Following the SH2 domain is a short stretch of 15 amino acids that spans the gap between the $\mathrm{SH} 2$ and tyrosine kinase domains, referred to as the $\mathrm{SH} 2 /$ kinase linker. The primary function of the linker sequence is association with the $\mathrm{SH} 3$ domain in the closed conformation. In the closed conformation, the linker takes on the left-handed helical structure characteristic of SH3 domain binding partners. Mutations in this region can enhance kinase activity through destabilization of the closed conformation (Briggs and Smithgall, 1999). Thus any contributions to signaling specificity made by the linker sequence would likely be reflected in the ease of enzymatic activation. Only one amino acid difference exists between the linker sequences of c-Yes and c-Src: the fourth position in the sequence is occupied by a serine residue in c-Src and a valine in c-Yes. The role of this amino acid in maintenance of the closed conformation has not been investigated, and thus, at this point no accurate assessment of its contribution to c-Yes signaling specificity can be made. 


\section{VIIf. Tyrosine Kinase Domain}

Following the linker sequence is the tyrosine kinase domain. This is the most

highly conserved region across the Src family. As mentioned above, the kinase domains of c-Yes and c-Src are approximately $90 \%$ homologous. The extremely high homology between c-Yes and c-Src, and members of the Src family in general, in the kinase domain suggests that this region contributes little to signaling specificity. Differences in the optimal substrate sequences phosphorylated by Src and Lck have been demonstrated (Songyang et al., 1995), however, these differences were subtle, and Src and Hck have been demonstrated to select the same peptide sequences for phosphorylation in vitro (Sicilia et al., 1998).

\section{Summary and Goals}

While the information available on c-Yes still lags behind that of c-Src and other members of the Src family, over the past decade, knowledge of the regulation and functions of the c-Yes tyrosine kinase have increased dramatically. It has become clear that c-Yes is capable of sending specific signals, however, the manner by which c-Yes accomplishes this remains a mystery. The work presented in this dissertation has begun to investigate the issue of signaling specificity between c-Src and c-Yes, with particular emphasis placed on the contributions of the functional domains to specificity in signaling between these closely related proteins. The studies presented in this thesis have focused on the roles of the non-catalytic functional domains in signaling specificity between c-Src and c-Yes at three levels: (1) protein/protein interactions, including substrate selection and stable complex formation, (2) downstream gene activation, as determined by differential display analysis, and (3) cell biology, with emphasis placed on understanding 
why c-Yes is apparently unable to compensate for c-Src in regulation of the actin cytoskeleton. The overriding hypothesis driving these studies was that differences in signaling specificity between c-Src and c-Yes could be attributed to individual functional domains, and that utilization of Src/Yes chimeric constructs would allow determination of the contributions of the various functional domains to signaling events or pathways that were representative of the three general categories listed above. These studies may shed light, not only on the biology of c-Yes, but also on how specificity is generated between Src family kinases. Knowledge of the roles of the functional domains in directing c-Yes signaling specificity may contribute to the design of inhibitory drugs, which selectively disrupt signals sent by c-Yes, as opposed to other Src family members. Such compounds would not only aid in the elucidation of c-Yes-specific signaling pathways but could potentially be of therapeutic use in the treatment of cancers in which c-Yes is abnormally activated. 


\section{References}

Alonso, G., Koegl, M., Mazurenko, N., and S.A. Courtneidge. 1995. Sequence requirements for binding of Src family tyrosine kinases to activated growth factor receptors. J. Biol. Chem. 270:9840-9848.

Ariki, M., Tanabe, O., Usui, H., Hayashi, H., Inoue, R., Nishito, Y., Kagamiyama, H., and M. Takeda. 1997. Identification of autophosphorylation sites in c-Yes purified from rat liver plasma membranes. J. Biochem. 121:104-11.

Arreaza, G., Melkonian, K.A., LaFevre-Bernt, M., and D.A. Brown. 1994. Triton X100-resistant membrane complexes from cultured kidney epithelial cells contain the Src family protein tyrosine kinase p62 ${ }^{\text {yes }}$. J. Biol. Chem. 269:19123-19127.

Bano, M.C., Jackson, C.S., and A.I. Magee. 1998. Pseudo-enzymatic S-acylation of a myristoylated Yes protein tyrosine kinase peptide in vitro may reflect non-enzymatic Sacylation in vivo. Biochem. J. 330:723-731.

Bibbins, K.B., Boeuf, H., and H.E. Varmus. 1993. Binding of the Src SH2 domain to phosphopeptides is determined by residues in both the $\mathrm{SH} 2$ domain and the phosphopeptides. Mol. Cell. Biol. 13:7278-7287.

Bixby, J.L., and P. Jhabvala. 1993. Tyrosine phosphorylation in early embryonic growth cones. J. Neurosci. 13:3421-3432.

Boyce, B.F., Yoneda, T., Lowe, C., Soriano, P., and Mundy, G.R. 1992. Requirement of pp60 ${ }^{\text {c-src }}$ expression for osteoclasts to form ruffled borders and resorb bone in mice. J. Clin. Invest. 90:1622-1627.

Bradshaw, J.M., Mitaxov, V., and G. Waksman. 1999. Investigation of phosphotyrosine recognition by the SH2 domain of the Src kinase. J. Mol. Biol. 293:971-985.

Briggs, S.D. and T.E. Smithgall. 1999. SH2-kinase linker mutations release Hck tyrosine kinase and transforming activities in Rat-2 fibroblasts. J. Biol. Chem. 274:26579-26583.

Brown, M.T. and J.A. Cooper. 1996. Regulation, substrates and functions of Src. Biochem. Biophys. Acta. 1287:121-149.

Cartwright, C.A., Coad, C.A., and B.M. Egbert. 1994. Elevated c-Src tyrosine kinase activity in premalignant epithelia of ulcerative colitis. J. Clin. Invest. 93:509-515.

Cartwright, C.A., Kamps, M.P., Meisler, A.I., Pipas, J.M., and W. Eckhart. 1989. p60 ${ }^{c-s r c}$ activation in human colon carcinoma. J. Clin. Invest. 83:2025-2033.

Chen, Y. Pouyssegur, J., Courtneidge, S.A., and E.Van Obberghen-Schilling. 1994. 
Activation of Src family kinase activity by the G protein-coupled thrombin receptor in growth-responsive fibroblasts. J. Biol. Chem. 269:27372-27377.

Ciesielski-Treska, J., Ulrich, G., Chasserot-Golaz, S., and D. Aunis. 1995. Immunocytochemical localization of protein kinases Yes and Src in amoeboid microglia in culture: association of Yes kinase with vimentin intermediate filaments. Eur. J. Cell Biol. 68:369-376.

Corey, S., Eginoa, A., Puyana-Theall, Bolen, J.B., Cantley, L., Mollinedo, F., Jackson, T.R., Hawkins, P.T., and L.R. Stephens. 1993. Granulocyte macrophage-colony stimulating factor stimulates both association and activation of phosphoinositide $3 \mathrm{OH}-$ kinase and $s r c$-related tyrosine kinase(s) in human myeloid derived cells. EMBO J. 12:2681-2690.

Courtneidge, S.A. 1985. Activation of the pp60 ${ }^{\mathrm{c}-s r c}$ kinase by middle T antigen binding or by dephosphorylation. EMBO J. 4:1471-1477.

Courtneidge, S.A., Dhand, R., Pilat, D., Twamley, G.M., Waterfield, M.D., and M.F. Roussel. 1993. Activation of Src family kinases by colony stimulating factor-1, and their association with its receptor. EMBO J. 12:943-950.

Eck, M.J., Shoelson, S.E., and S.C. Harrison. 1993. Recognition of a high-affinity phosphotyrosyl peptide by the Src homology-2 domain of p56 ${ }^{l c k}$. Nature. 362:87-91.

Eiseman, E. and J.B. Bolen. 1992. Engagement of the high-affinity IgE receptor activates src protein-related tyrosine kinases. Nature. 355:78-80.

Eliceiri, B.P., Paul, R., Schwartzberg, P.L., Hood, J.D., Leng, J., and D.A. Cheresh. 1999. Selective requirement for Src kinases during VEGF-induced angiogenesis and vascular permeability. Mol. Cell. 4:915-924.

Erikson, E. and R.L. Erikson. 1983. Antigenic and structural studies on the transforming proteins of Rous sarcoma virus and Yamaguchi 73 Avian sarcoma virus. Virology. 130:221-226.

Erpel, T., Alonso, G., Roche, S., and S.A. Courtneidge. 1996. The Src SH3 domain is required for DNA synthesis induced by platelet-derived growth factor and epidermal growth factor. J. Biol. Chem. 271:16807-16812.

Feshchenko, E.A., Langdon, W.Y., and A.Y. Tsygankov. 1998. Fyn, Yes, and Syk phosphorylation sites in c-Cbl map to the same tyrosine residues that become phosphorylated in activated T cells. J. Biol. Chem. 273:8323-8331.

Fuhrer, D.K. and Y. Yang. 1996a. Activation of Src-family protein tyrosine kinases and phosphatidylinositol 3-kinase in 3T3-L1 mouse preadipocytes by interleukin-11. Exp. Hematol. 24:195-203. 
Fuhrer, D.K. and Y. Yang. 1996b. Complex formation of JAK2 with PP2A, PI3K, and Yes in response to the hematopoietic cytokine interleukin-11. Biochem. Biophys. Res. Comm. 224:289-296.

Fukui, Y., O’Brien, M.C., and H. Hanafusa. 1991. Deletions in the SH2 domain of p60 ${ }^{\mathrm{v}-}$ ${ }^{s r c}$ prevent association with detergent-insoluble cellular matrix. Mol. Cell. Biol. 11:1207-1213.

Gentry, L.E. and L.R. Rohrschneider. 1984. Common features of the yes and src gene products defined by peptide-specific antibodies. J. Virol. 51:539-546.

Gessler, M. and A. Barnekow. 1984. Differential expression of the cellular oncogenes csrc and c-yes in embryonal and adult chicken tissues. Biosci. Rep. 4:757-770.

Ghysdael, J., Neil, J.C., and P.K. Vogt. 1981. A third class of avian sarcoma viruses, defined by related transformation-specific proteins of Yamaguchi 73 and Esh sarcoma viruses. Proc. Natl. Acad. Sci. USA. 78:2611-2615.

Glenn, G.M. and W. Eckhart. 1993. Mutation of a cysteine residue in polyomavirus middle T-antigen abolishes interactions with protein phosphatase $2 \mathrm{~A}, \mathrm{pp} 60^{\mathrm{c}-s r c}$, and phosphatidylinositol-3 kinase, activation of c-fos expression, and cellular transformation. J. Virol. 67:1945-1952.

Gould, K.L. and T. Hunter. 1988. Platelet-derived growth factor induces multisite phosphorylation of pp $60^{\mathrm{c}-s r c}$ and increases its protein-tyrosine kinase activity. Mol. Cell. Biol. 8:3345-3356.

Guappone, A.C. and D.C. Flynn. 1997. The integrity of the SH3 binding motif of AFAP-110 is required to facilitate tyrosine phosphorylation by, and stable complex formation with, Src. Mol. Cell. Biochem. 175:243-252.

Guy, C.T., Muthuswamy, S.K., Cardiff, R.D., Soriano, P., and W.J. Muller. 1994. Activation of the c-Src tyrosine kinase is required for the induction of mammary tumors in transgenic mice. Genes Dev. 8:23-32.

Hall, C.L., Lange, L.A., Prober, D.A., Zhang, S., and E.A. Turley. 1996. pp60(c-src) is required for cell locomotion regulated by the hyaluronan receptor RHAMM. Oncogene. $13: 10$.

Han, N.M., Curley, S.A., and G.E. Gallick. 1996. Differential activation of pp60 ${ }^{\mathrm{c}-s r c}$ and pp62 $2^{\text {c-yes }}$ in human colorectal carcinoma liver metastases. Clin. Can. Res. 2:1397-1404.

Hansen, K., Alonso, G., Courtneidge, S.A., Ronnstrand, L., and C. Heldin. 1997. PDGFinduced phosphorylation of Tyr28 in the N-terminus of Fyn affects Fyn activation. Biochem. Biophys. Res. Comm. 241:355-362. 
Hoey, J.G., Summy, J., and D.C. Flynn. 2000. Chimeric constructs containing the $\mathrm{SH} 4 /$ Unique domains of cYes can restrict the ability of $\mathrm{Src}^{527 \mathrm{~F}}$ to upregulate heme oxygenase-1 expression efficiently. Cell. Signal. 12:691-701.

Honda, Z., Suzuki, T., Kono, H., Okada, M., Yamamoto, T., Ra, C., Morita, Y., and K. Yamamoto. 2000. Sequential requirements of the N-terminal palmitoylation site and $\mathrm{SH} 2$ domain of Src family kinases in the initiation and progression of FceRI signaling. Mol. Cell. Biol. 20:1759-1771.

Ignelzi, Jr., M.A., Miller, D.R., Soriano, P., and P.F. Maness. 1994. Impaired neurite outgrowth of $s r c$-minus cerebellar neurons on the cell adhesion molecule L1. Neuron. $12: 873-884$.

Kabouridis, P.S., Magee, A.I., and S.C. Ley. 1997. S-Acylation of LCK protein tyrosine kinase is essential for its signalling function in T lymphocytes. EMBO J. 16:4983-4998.

Kamei, T., Hamlin, G.P., Chapman, B.M., Burkhardt, A.L., Bolen, J.B., and M.J. Soares. 1997. Signaling pathways controlling trophoblast cell differentiation: src family protein tyrosine kinases in the rat. Biol. Reprod. 57:1302-1311.

Kamps, M.P. and B.M. Sefton. 1988. Identification of multiple novel polypeptide substrates of the v-src, v-yes, v-fps, v-ros, and v-erb-B oncogenic tyrosine protein kinases utilizing antisera against phosphotyrosine. Oncogene. 2:305-315.

Kanner, S.B., Reynolds, A.B., Bines, R.R., and J.T. Parsons. 1990. Monoclonal antibodies to individual tyrosine-phosphorylated protein substrates of oncogene-encoded tyrosine kinases. Proc. Natl. Acad. Sci. USA. 87:3328-3332.

Kanner, S.B., Reynolds, A.B., Wang, H.R., Vines, R.R., and J.T. Parsons. 1991. The $\mathrm{SH} 2$ and $\mathrm{SH} 3$ domains of $\mathrm{pp} 60^{\mathrm{src}}$ direct stable association with tyrosine phosphorylated proteins p130 and p110. EMBO J. 10:1689-1698.

Kaplan, K.B., Swedlow, J.R., Morgan, D.O., and H.E. Varmus. 1995. c-Src enhances the spreading of $s r c$-/- fibroblasts on fibronectin by a kinase-independent mechanism. Genes Dev. 9:1505-1517.

Katagiri, Y.U., Mori, T., Nakajima, H., Katagiri, C., Taguchi, T., Takeda, T., Kiyokawa, N., and J. Fujimoto. 1999. Activation of Src family kinase Yes induced by Shiga toxin binding to Globotriaosyl ceramide (Gb3/CD77) in low density, detergent-insoluble microdomains. J. Biol. Chem. 274:35278-35282.

Kitamura, N., Kitamura, A., Toyoshima, K., Hirayama, Y., and M. Yoshida. 1982. Avian sarcoma virus Y73 genome sequence and structural similarity of its transforming gene product to that of Rous sarcoma virus. Nature. 297:205-208. 
Koegel, M., Zlatkine, P., Ley, S.C., Courtneidge, S.A., and A.I. Magee. 1994. Palmitoylation of multiple Src-family kinases at a homologous N-terminal motif. Biochem. J. 303:749-753.

Kornbluth, S., Cheng, S.H., Markland, W., Fukui, Y., and H. Hanafusa. 1990. Association of ${ }^{\text {p62c-yes }}$ with polyomavirus middle T-antigen mutants correlates with transforming ability. J. Virol. 64:1584-1589.

Kornbluth, S., Sudol, M., and H. Hanafusa. 1987. Association of the polyomavirus middle-T antigen with c-yes protein. Nature. 325:171-173.

Kovacic, B., Ilic, D., Damsky, C.H., and D.G. Gardner. 1998. c-Src activation plays a role in endothelin-dependent hypertrophy of the cardiac myocyte. J. Biol. Chem. 273:35185-35193.

Kypta, R.M., Goldberg, Y., Ulug, E.T., and S.A. Courtneidge. 1990. Association between the PDGF receptor and members of the src family of tyrosine kinases. Cell. 62:481-492.

Landgren, E., Blume-Jensen, P., Courtneidge, S.A., and L. Claesson-Welsh. 1995. Fibroblast growth factor receptor-1 regulation of Src family kinases. Oncogene. 10:2027-2035.

Loeb, D.M., Woolford, J., and K. Beemon. 1987. pp60 ${ }^{\mathrm{c}-s r c}$ has less affinity for the detergent-insoluble cellular matrix than do $\mathrm{pp} 60^{\mathrm{v}-s r c}$ and other viral protein-tyrosine kinases. J. Virol. 61:2420-2427.

Loganzo, Jr., F., Dosik, J.S., Zhao, Y., Vidal, M.J., Nanus, D.M., Sudol, M., and A.P. Albino. 1993. Elevated expression of protein tyrosine kinase c-Yes, but not c-Src, in human malignant melanoma. Oncogene. 8:2637-2644.

Luton, F., Verges, M., Vaerman, J.P., Sudol, M., and K.E. Mostov. 1999. The SRC family protein tyrosine kinase p62yes controls polymeric IgA transcytosis in vivo. Mol. Cell. 4:627-632.

Marchetti, D., Parikh, N., Sudol, M., and G.E. Gallick. 1998. Stimulation of the protein tyrosine kinase c-Yes but not c-Src by neurotrophins in human brain-metastatic melanoma cells. Oncogene. 16:3253-3260.

Mayer, B.J. and D. Baltimore. 1994. Mutagenic analysis of the roles of SH2 and SH3 domains in regulation of the Abl tyrosine kinase. Mol. Cell. Biol. 14:2883-2894.

McCarley, D.J., Parsons, J.T., Benjamin, D.C., and S.J. Parsons. 1987. Inhibition of the tyrosine kinase activity of $\mathrm{v}-s r c, \mathrm{v}-f g r$, and $\mathrm{v}-y e s$ gene products by a monoclonal antibody which binds both amino and carboxy peptide fragments of pp60 ${ }^{\mathrm{v}-s r c}$. J. Virol. 61:19271937. 
Meyerson, G. and S. Pahlman. 1993. pp59 fyn and pp62 $2^{\mathrm{c}-\mathrm{yes}}$ are enriched in SH-SY5Y neuroblastoma growth cones but do not associate to the $38 \mathrm{kDa}$ protein which complexes with pp60 $0^{\mathrm{c}-\mathrm{src}}$ and pp60 $0^{\mathrm{c}-\mathrm{srcN}}$. FEBS. 332:27-30.

Moarefi, I., LaFevre-Bernt, M., Sicheri, F., Huse, M., Lee, C., Kuriyan, J., and W.T. Miller. 1997. Activation of the Src-family tyrosine kinase Hck by SH3 domain displacement. Nature. 385:650-653.

Moasser, M.M., Srethapakdi, M., Sachar, K.S., Kraker, A.J., and N. Rosen. 1999. Inhibition of Src kinases by a selective tyrosine kinase inhibitor causes mitotic arrest. Canc. Res. 59:6145-6152.

Mohler, P.J., Kreda, S.M., Boucher, R.C., Sudol, M., and M.J. Stutts. 1999. YesAssociated Protein 65 localizes p $62^{\mathrm{c}-\mathrm{Yes}}$ to the apical compartment of airway epithelia by association with EBP50. J. Cell Biol. 147:879-890.

Morgan, D.O., Kaplan, J.M., Bishop, J.M., and H.E. Varmus. 1989. Mitosis-specific phosphorylation of $\mathrm{p} 60^{\mathrm{c}-s r c}$ by $\mathrm{p} 34^{c d c 2}$-associated protein kinase. Cell. 57:775-786.

Mori, S., Ronnstrand, L., Yokote, K., Engstrom, A., Courtneidge, S.A., Claesson-Welsh, L., and C.H. Heldin. 1993. Identification of two juxtamembrane autophosphorylation sites in the PDGF $\beta$-receptor; involvement in the interaction with Src family tyrosine kinases. EMBO J. 12:2257-2264.

Mukhopadhyay, D., Tsiokas, L., Zhou, X., Foster, D., Brugge, J.S., and V.P. Sukhatme. 1995. Hypoxic induction of human vascular endothelial growth factor expression through c-Src activation. Nature. 375:577-581.

Muthuswamy, S.K. and W.J. Muller. 1995. Activation of Src family kinases in Neuinduced mammary tumors correlates with their association with distinct sets of tyrosine phosphorylated proteins in vivo. Oncogene. 11:1801-1810.

O'Brien, M.C., Fukui, Y., and H. Hanafusa. 1990. Activation of the proto-oncogene p60 ${ }^{\mathrm{c}-s r c}$ by point mutations in the SH2 domain. Mol. Cell. Biol. 10:2855-2862.

Okada, M., Nada, S., Yamanashi, Y., Yamamoto, T., and H. Nakagawa. 1991. CSK: a protein-tyrosine kinase involved in regulation of $\operatorname{src}$ family kinases. J. Biol. Chem. 266:24249-24252.

Owens, D.W., McLean, G.W., Wyke, A.W., Paraskeva, C., Parkinson, E.K., Frame, M.C., and V.G. Brunton. 2000. The catalytic activity of the Src family kinases is required to disrupt cadherin-dependent cell-cell contacts. Mol. Biol. Cell. 11:51-64.

Park, J. and C.A. Cartwright. 1995. Src activity increases and Yes activity decreases during mitosis of human colon carcinoma cells. Mol. Cell. Biol. 15:2374-2382. 
Park, J., Meisler, A.I., and C.A. Cartwright. 1993. c-Yes tyrosine kinase activity in human colon carcinoma. Oncogene. 8:2627-2635.

Pellicena, P., Stowell, K.R., and W.T. Miller. 1998. Enhanced phosphorylation of Src family kinase substrates containing SH2 domain binding sites. J. Biol. Chem. 273:15325-15328.

Pena, S.V., Melhem, M.F., Meisler, A.I., and C.A. Cartwright. 1995. Elevated c-Yes tyrosine kinase activity in premalignant lesions of the colon. Gastroenterology. 108:117124.

Resh, M.D. 1994. Myristylation and palmitylation of Src family members: the fats of the matter. Cell. 76:411-414.

Rickles, R.J., Botfield, M.C., Zhou, X., Henry, P.A., Brugge, J.S., and M.J. Zoller. 1995. Phage display selection of ligand residues important for Src homology 3 domain binding specificity. Proc. Natl. Acad. Sci. USA. 92:10909-10913.

Robbins, S.M., Quintrell, N.A., and J.M. Bishop. 1995. Myristoylation and differential palmitoylation of the HCK protein tyrosine-kinases govern their attachment to membranes and association with caveolae. Mol. Cell. Biol. 15:3507-3515.

Roche, S., Fumagalli, S., and S.A. Courtneidge. 1995. Requirement for Src family protein tyrosine kinases in $\mathrm{G}_{2}$ for fibroblast cell division. Science. 269:1567-1569.

Sargiacomo, M., Sudol, M., Tang, Z., and M.P. Lisanti. 1993. Signal transducing molecules and glycosyl-phosphatidylinositol-linked proteins form a caveolin-rich insoluble complex in MDCK cells. J. Cell Biol. 122:789-807.

Schieffer, B., Paxton, W.G., Chai, Q., Marrero, M.B., and K.E. Bernstein. 1996. Angiotensin II controls p21 ${ }^{\text {ras }}$ activity via pp60 ${ }^{\mathrm{c}-s r c}$. J. Biol. Chem. 271:10329-10333.

Schieven, G.L., Kallestad, J.C., Brown, T.J., Ledbetter, J.A., and P.S. Linsley. 1992. Oncostatin $\mathrm{M}$ induces tyrosine phosphorylation in endothelial cells and activation of p62 $2^{\text {yes }}$ tyrosine kinase. J. Immunol. 149:1676-1682.

Shaw, A.S., Amrein, K.E., Hammond, C., Stern, D.F., Sefton, B.M., and J.K. Rose. 1989. The $l c k$ tyrosine protein kinase interacts with the cytoplasmic tail of the CD4 glycoprotein through its unique amino-terminal domain. Cell. 59:627-636.

Shenoy, S., Choi, J., Bagrodia, S., Copeland, T.D., Maller, J.L., and D. Shalloway. 1989. Purified maturation promoting factor phosphorylates $\mathrm{pp} 60^{\mathrm{c}-s r c}$ at the sites phosphorylated during fibroblast mitosis. Cell. 57:763-774.

Shenoy-Scaria, A.M., Dietzen, D.J., Kwong, J., Link, D.C., and D.M. Lublin. 1994. 
Cysteine 3 of Src family protein tyrosine kinase determines palmitoylation and localization in caveolae. J. Cell Biol. 126:353-363.

Sicheri, F., Moarefi, I., and J. Kuriyan. 1997. Crystal structure of the Src family tyrosine kinase Hck. Nature. 385:602-609.

Sicilia, R.J., Hibbs, M.L., Bello, P.A., Bjorge, J.D., Fujita, D.J., Stanley, I.J., Dunn, A.R., and H. Cheng. 1998. Common in vitro substrate specificity and differential Src homology domain 2 accessibility displayed by two members of the Src family o f proteintyrosine kinases, c-Src and Hck. J. Biol. Chem. 273:16756-16763.

Songyang, Z., Gish, G., Mbamalu, G., Pawson, T., and L.C. Cantley. 1995. A single point mutation switches the specificity of group III Src Homology (SH) 2 domains to that of group I SH2 domains. J. Biol. Chem. 270:26029-26032.

Songyang, Z., Shoelson, S.E., Chaudhuri, M., Gish, G., Pawson, T. Haser, W.G., King, F., Roberts, T., Ratnofsky, S., Lechleider, R.J., Neel, B.G., Birge, R.B., Fajardo, J.E., Chou, M.M., Hanafusa, H., Schaffhausen, B., and L.C. Cantley. 1993. SH2 domains recognize specific phosphopeptide sequences. Cell. 72:767-778.

Soriano, P., Montgomery, C., Geske, R., and A. Bradley. 1991. Targeted disruption of the c-src proto-oncogene leads to osteopetrosis in mice. Cell. 64:693-702.

Sparks, A.B., Rider, J.E., Hoffman, N.G., Fowlkes, D.M., Quilliam, L.A., and B.K. Kay. 1996. Distinct ligand preferences of Src homology 3 domains from Src, Yes, Abl, Cortactin, p53bp2, PLC $\gamma$, Crk, and Grb2. Proc. Natl. Acad. Sci. USA. 93:1540-1544.

Stein, P.L., Vogel, H., and P. Soriano. 1994. Combined deficiencies of Src, Fyn, and Yes tyrosine kinases in mutant mice. Genes Dev. 8:1999-2007.

Sudol, M. 1994. Yes-Associated Protein (YAP65) is a proline-rich phosphoprotein that binds to the SH3 domain of the Yes proto-oncogene product. Oncogene. 9:2145-2152.

Sudol, M., Alvarez-Buylla, A., and H. Hanafusa. 1988a. Differential developmental expression of cellular Yes and cellular Src proteins in cerebellum. Onc. Res. 2:345-355.

Sudol, M. and H. Hanafusa. 1986. Cellular proteins homologous to the viral yes gene product. Mol. Cell. Biol. 6:2839-2846.

Sudol, M., Kieswetter, C., Zhao, Y., Dorai, T., Wang, L.H., and H. Hanafusa. 1988b. Nucleotide sequence of a cDNA for the chick yes proto-oncogene: comparison with the viral yes gene. Nuc. Acids Res. 16:9876.

Sudol, M., Kuo, C.F., Shigemitsu, L., and A. Alvarez-Buylla. 1989. Expression of the yes proto-oncogene in cerebellar Purkinje cells. Mol. Cell. Biol. 9:4545-4549. 
Sugawara, K., Sugawara, I., Sukegawa, J., Akatsuka, T., Yamamoto, T., Morita, M., Mori, S., and K. Toyoshima. 1991. Distribution of c-yes-1 gene product in various cells and tissues. Br. J. Cancer. 63:508-513.

Sukegawa, J., Semba, K., Yamanashi, Y., Nishizawa, M., Miyajima, N., Yamamoto, T., and K. Toyoshima. 1987. Characterization of cDNA clones for the human c-yes gene. Mol. Cell. Biol. 7:41-47.

Summy, J.M., Guappone, A.C., Sudol, M., and D.C. Flynn. 2000. The SH3 and SH2 domains are capable of directing specificity in protein interactions between the nonreceptor tyrosine kinases cSrc and cYes. Oncogene. 19:155-160.

Sun, G., Sharma, A.K., and R.J.A. Budde. 1998. Autophosphorylation of Src and Yes blocks their inactivation by CSK phosphorylation. Oncogene. 17:1587-1595.

Superti-Furga, G., Fumagalli, S., Koegl, M., Courtneidge, S.A., and G. Draetta. 1993. Csk inhibition of c-Src activity requires both the SH2 and SH3 domains of src. EMBO J. $12: 2625-2634$.

Susa, M., Luong-Nguyen, N., Crespo, J., Maier, R., Missbach, M., and G. McMaster. 2000. Active recombinant human tyrosine kinase c-Yes: expression in Baculovirus system, purification, comparison to c-Src, and inhibition by a c-Src inhibitor. Protein Expr. Purif. 19:99-106.

Suzuki, T., Kono, H., Hirose, N., Okada, M., Yamamoto, T., Yamamoto, K. and Z. Honda. 2000. Differential involvement of Src family kinases in Fc $\gamma$ receptor-mediated phagocytosis. J. Immunol. 165:473-482.

Suzuki, T., Murakami, M., Onai, N., Fukuda, E., Hashimoto, Y., Sonobe, M.H., Kameda, T., Ichinose, M., Miki, K., and H. Iba. 1994. Analysis of AP-1 function in cellular transformation pathways. J. Virol. 68:3527-3535.

Tang, H., Zhao, Z.J., Landon, E.J., and T. Inagami. 2000. Regulation of calciumsensitive tyrosine kinase Pyk2 by Angiotensin II in endothelial cells. J. Biol. Chem. 275:8389-8396.

Thomas, S.M. and J.S. Brugge. 1997. Cellular functions regulated by Src family kinases. Annu. Rev. Cell Dev. Biol. 13:513-609.

Toshima, J., Ohashi, K., Iwashita, S., and K. Mizuno. 1995. Autophosphorylation activity and association with Src family kinase of Sky receptor tyrosine kinase. Biochem. Biophys. Res. Comm. 209:656-663.

Toyoshima, K., Yamamoto, T., Kawai, S., and M. Yoshida. 1987. Viral oncogenes, vyes and v-erbB, and their cellular counterparts. Adv. Viral Res. 32:97-127. 
Tsygankova, O.M., Peng, M., Maloney, J.A., Hopkins, N., and J.R. Williamson. 1998. Angiotensin II induces diverse signal transduction pathways via both $\mathrm{G}_{\mathrm{q}}$ and $\mathrm{G}_{\mathrm{i}}$ proteins in liver epithelial cells. J. Cell. Biochem. 69:63-71.

Twamley-Stein, G.M., Pepperkok, R., Ansorge, W., and S.A. Courtneidge. 1993. The Src family tyrosine kinases are required for platelet-derived growth factor-mediated signal transduction in NIH 3 T3 cells. Proc. Natl. Acad. Sci. USA. 90:7696-7700.

Vonakis, B.M., Chen, H., Haleem-Smith, H., and H. Metzger. 1997. The Unique domain as the site on Lyn kinase for its constitutive association with the high affinity receptor for IgE. J. Biol. Chem. 272:24072-24080.

Waksman, G., Kominos, D., Robertson, S.C., Pant, N., Baltimore, D., Birge, R.B., Cowburn, D., Hanafusa, H., Mayer, B.J., Overduin, M., Resh, M.D., Rios, C.B., Silverman, L., and J. Kuriyan. 1992. Crystal structure of the phosphotyrosine recognition domain $\mathrm{SH} 2$ of v-src complexed with tyrosine-phosphorylated peptides. Nature. 358:646-653.

Walaas, S.I., Zhao, Y., and M. Sudol. Neuronal localization of the tyrosine-specific protein kinase $\mathrm{p} 62^{\mathrm{c}-\mathrm{yes}}$ in rat basal ganglia. Neurochem. Res. 18:43-46.

Waltenberger, J., Claesson-Welsh, L., Siegbahn, A., Shibuya, M., and C. Heldin. 1994. Different signal transduction properties of KDR and Flt1, two receptors for vascular endothelial growth factor. J. Biol. Chem. 269:26988-26995.

Wang, L. and H. Hanafusa. 1988. Avian sarcoma viruses. Virus Res. 9:159-203.

Weng, Z., Thomas, S.M., Rickles, R.J., Taylor, J.A., Brauer, A.W., Seidel-Dugan, C., Michael, W.M., Dreyfuss, G., and J.S. Brugge. 1994. Identification of Src, Fyn, and Lyn SH3-binding proteins: implications for a function of SH3 domains. Mol. Cell. Biol. 14:4509-4521.

Xu, W., Doshi, A., Lei, M., Eck, M.J., and S.C. Harrison. 1999. Crystal structures of cSrc reveal features of its autoinhibitory mechanism. Mol. Cell. 3:629-638.

Xu, W., Harrison, S.C., and M.J. Eck. 1997. Three-dimensional structure of the tyrosine kinase c-Src. Nature. 385:595-602.

Yoshida, M., Kawai, S., and K. Toyoshima. 1980. Uninfected avian cells contain structurally unrelated progenitors of viral sarcoma genes. Nature. 287:653-654.

Yoshida, M.C., Sasaki, M., Mise, K., Semba, K., Nishizawa, M., Yamamoto, T., and K. Toyoshima. 1985. Regional mapping of the human proto-oncogene c-yes-1 to chromosome 18 at band q21.3. Jpn. J. Cancer Res. 76:559-562. 
Yu, H., Chen, J.K., Feng, S., Dalgarno, D.C., Brauer, A.W., and S.L. Schreiber. 1994. Structural basis for the binding of proline-rich peptides to SH3 domains. Cell. 76:933945.

Yu, H., Rosen, M.K., Shin, T.B., Seidel-Dugan, C., Brugge, J.S., and S.L. Schreiber. 1992. Solution Structure of the SH3 domain of Src and identification of its ligandbinding site. Science. 258:1665-1668.

Yurchak, L.K., and B.M. Sefton. 1995. Palmitoylation of either Cys-3 or Cys-5 is required for the biological activity of the Lck tyrosine protein kinase. Mol. Cell. Biol. 15:6914-6922.

Zhao, Y., Baker, H., Walaas, S.I., and M. Sudol. 1991. Localization of $\mathrm{p} 62^{\mathrm{c}-y e s}$ protein in mammalian neural tissues. Oncogene. 6:1725-1733.

Zhao, Y., Krueger, J.G., and M. Sudol. 1990. Expression of cellular-yes in mammalian tissues. Oncogene. 5:1629-1635.

Zhao, Y., Uyttendaele, H., Krueger, J.G., Sudol, M., and H. Hanafusa. 1993. Inactivation of c-Yes tyrosine kinase by elevation of intracellular calcium levels. Mol. Cell. Biol. 13:7507-7514. 


\title{
Chapter 2
}

\section{The SH3 and SH2 Domains Are Capable of Directing Specificity In Protein} Interactions Between the Non-Receptor Tyrosine Kinases c-Src and c-Yes

\author{
Justin M. Summy ${ }^{1}$, Anne C. Guappone ${ }^{1}$, Marius Sudol ${ }^{2}$, and Daniel C. Flynn ${ }^{1} *$
}

1 The Mary Babb Randolph Cancer Center and the Department of Microbiology and Immunology, P.O. Box 9300, West Virginia University, Morgantown, WV 26506-93001

2 Department of Biochemistry, Mount Sinai School of Medicine, New York, NY $10029^{2}$

This report was published in the journal Oncogene, Vol. 19 (2000) 155-160.

(C) 2000 Macmillan Publishers Ltd. All rights reserved. 


\section{Abstract}

The c-src and c-yes proto-oncogenes encode 60,000 and 62,000 Dalton nonreceptor tyrosine kinases of the Src family, $\mathrm{pp} 60^{\mathrm{c}-\mathrm{src}}$ and $\mathrm{pp} 62^{\mathrm{c}-\mathrm{yes}}$, respectively. These kinases are over $80 \%$ homologous outside of their unique amino termini, yet several studies suggest that differences exist in the regulation, activation, and function of c-Src and c-Yes. The determinants of specificity in signaling between these proteins, however, remain unclear. In order to investigate the roles of the Src Homology (SH) 3 and 2 domains in mediating signaling specificity between c-Src and c-Yes, chimeras were created in which the SH3 and/or SH2 domains of c-Src or the fully activated variant $\mathrm{Src}^{527 \mathrm{~F}}$ were replaced by the corresponding domains of $\mathrm{c}-\mathrm{Yes}$. These constructs were used to assess the effects of the c-Yes $\mathrm{SH} 3$ and $\mathrm{SH} 2$ domains on the ability of activated Src to form stable complexes with and induce tyrosine phosphorylation of c-Src SH3 and SH2 domain binding partners in vivo. Differences were demonstrated between c-Src and cYes in the specificity of both the SH3 and SH2 domains. The c-Yes SH3 domain was unable to affinity absorb the Src SH3/SH2 binding partner AFAP-110 from COS-1 cell lysates, and chimeric constructs of $\mathrm{Src}^{527 \mathrm{~F}}$ containing the c-Yes SH3 domain were unable to efficiently co-immunoprecipitate with AFAP-110 from chicken embryo fibroblasts. Interactions with the Src SH2 binding partner pp130cas were unaffected. Additionally, only chimeras containing the c-Yes SH2 domain were able to co-immunoprecipitate with an unidentified $87 \mathrm{kDa}$ tyrosine-phosphorylated protein. These results indicate that the SH3 and SH2 domains are capable of directing specificity in substrate binding between cSrc and c-Yes, indicating potential mechanisms for generating specificity in signaling between these two highly related non-receptor tyrosine kinases. 


\section{Introduction}

The Src family of non-receptor tyrosine kinases is comprised of nine members (cSrc, c-Yes, Fgr, Fyn, Lyn, Lck, Hck, Blk, and Yrk) that share amino acid homology and a common domain architecture, consisting of four regions of Src homology (SH1-4) and a Unique domain (Brickell, 1992). Src family kinases are involved in many signal transduction pathways, influencing such diverse cellular processes as cell division, differentiation, survival, adhesion, and motility (Thomas and Brugge, 1997). pp60 ${ }^{\text {c-src }}$ and pp $62^{\text {c-yes }}$ are of particular interest due to their frequent activation in several human cancers, most notably colon carcinoma, in which the activity of both kinases is commonly up-regulated (Cartwright et al., 1994; Cartwright et al., 1989; Park et al., 1993; Pena et al., 1995). pp60 ${ }^{\mathrm{c}-\mathrm{Src}}$ and pp62-yes are two of the most highly homologous members of the Src family. They share greater than $80 \%$ amino acid homology outside of their Unique domains (Erikson and Erikson, 1983; Kitamura et al., 1982; Sudol et al., 1988b) and are both expressed throughout several vertebrate tissues, with particularly high levels in brain and platelets (Bixby and Jhabvala, 1993; Brown and Cooper, 1996; Gessler and Barnekow, 1984; Horne et al., 1992; Sugawara et al., 1991; Zhao et al., 1990). c-Src and c-Yes are also activated in response to many of the same extracellular stimuli (Courtneidge et al., 1993; Di Domenico et al., 1996; Eiseman and Bolen, 1992; Fuhrer and Yang, 1996; Kypta et al., 1990; Muthuswamy and Muller, 1995; Schieffer et al., 1996; Tsygankova et al., 1998), at the same points in the cell cycle (Roche et al., 1995), and are at least partially able to functionally compensate for each other in the event that one of the kinases is missing or non-functional (Roche et al., 1995; Stein et al., 1994). 
Despite the similarities between c-Src and c-Yes, differences in expression, regulation, and function have been demonstrated between the two proteins (Fuhrer and Yang, 1996; Loganzo et al., 1993; Marchetti et al., 1998; Park and Cartwright, 1995; Zhao et al., 1993). Single gene knockouts of either the c-src or c-yes gene in mice provide strong evidence for specific roles performed by c-Src and c-Yes, as the loss of either gene results in a unique phenotype. The loss of the c-src gene results in osteopetrosis due to a defect in the ability of the osteoclasts to reabsorb bone (Soriano et al., 1991), and the loss of the c-yes gene results in a reduction in IgA levels in secreted fluids, as c-Yes has been demonstrated to play a key role in IgA transcytosis mediated by the polyimmunoglobulin receptor (Luton et al., 1998).

To date, the establishment of functional and regulatory differences between c-Src and c-Yes have not revealed which functional domain or domains are responsible for directing signaling specificity between these two highly related, non-receptor tyrosine kinases. Two potential candidates for mediating specificity in signaling between c-Src and c-Yes are the $\mathrm{SH} 3$ and $\mathrm{SH} 2$ domains. The $\mathrm{SH} 3$ domain directs specific interactions by binding to proline-rich sequences in target proteins, while the $\mathrm{SH} 2$ domain recognizes a phosphotyrosine moiety and the surrounding 3 or 4 amino acids (Anderson et al., 1990; Moran et al., 1990; Pawson and Scott, 1997; Ren et al., 1993; Songyang et al., 1992; Sudol et al., 1998). It has been demonstrated that c-Src will phosphorylate many substrates on tyrosine residues that represent potential SH2 binding motifs, indicating that c-Src may select substrates for stable complex formation ( Songyang et al., 1995; Zhou and Cantley, 1995). Weng et al. demonstrated that phosphorylation of some SH3 domain binding partners was dependent upon a functional $\mathrm{Src}$ SH3 domain, indicating a potential 
role for SH3 interactions in presenting substrates for tyrosine phosphorylation (Weng et al., 1994).

The Src-binding partners pp130cas and AFAP-110 are two well-characterized tyrosine phosphorylated substrates that form a stable complex with activated forms of Src, e.g., Src ${ }^{527 F}$ (Schaller et al., 1993). Stable complex formation between pp130cas and activated forms of Src are dependent upon the integrity of the SH2 domain (Kanner et al., 1991; Sakai et al., 1994). However, interactions between AFAP-110 and $\mathrm{Src}^{527 \mathrm{~F}}$ are modulated by both the $\mathrm{SH} 3$ and $\mathrm{SH} 2$ domains, and disruption of either interaction is sufficient to abrogate stable complex formation between these two proteins (Reynolds et al., 1989; Kanner et al., 1991; Guappone and Flynn, 1997; Guappone et al., 1998). Additionally, deletions in the SH2 domain of Src can inhibit phosphorylation of pp130cas (Kanner et al., 1991), while mutations in the Src SH3 domain or the SH3-binding motif of AFAP-110 inhibit phosphorylation of AFAP-110 by Src in vivo (Kanner et al., 1991; Guappone and Flynn, 1997). v-Yes is unable to induce high levels of phosphorylation of either of these proteins in vivo (Kanner et al., 1990), and thus one possible explanation of this data is that v-Yes is unable to form sufficiently high affinity $\mathrm{SH} 3$ and/or SH2 domain interactions with AFAP-110 and pp130cas to allow efficient substrate presentation in vivo. 


\section{Results}

In order to explore this possibility, the relative affinities of the c-Src and c-Yes SH3 domains for AFAP-110 were compared, in vitro. The SH3 and SH2 domains are well conserved between c-Yes and v-Yes, thus the c-Yes SH3 and SH2 domains were used throughout this report. Lysates from Cos-1 cells overexpressing AFAP-110 were incubated with GST, GST-SH3 ${ }^{\text {Src }}$ or GST-SH3 ${ }^{\text {Yes }}$ fusion proteins immobilized on glutathione-coated sepharose beads. AFAP-110 was efficiently absorbed by GST-SH3 ${ }^{\text {Src }}$, however, the levels of AFAP-110 absorbed by GST-SH3 ${ }^{\text {Yes }}$ more closely approximated background levels absorbed by GST alone (Figure 1A). c-Src and c-Yes SH3 absorbtions were performed from aliquots of the same cell lysates, thus differences in the amount of AFAP-110 absorbed were not due to differences in AFAP-110 expression. In contrast, tyrosine phosphorylated AFAP-110 from Cos-1 cell lysates overexpressing AFAP-110 and $\mathrm{Src}^{527 \mathrm{~F}}$ was efficiently affinity absorbed by both GST- SH2 $2^{\mathrm{Src}}$ and GST$\mathrm{SH} 2{ }^{\text {Yes }}$ (Figure 1A). These data indicate that $\mathrm{c}-$ Yes has the potential to bind AFAP-110 through SH2, but not SH3 interactions. Fusion proteins were quantitated via Coomassie staining to verify that equal amounts were used in the absorptions. In order to confirm that the inability of the c-Yes SH3 domain to absorb AFAP-110 reflected differential specificity and not a defect in the folding or function of the GST-SH3 ${ }^{\text {Yes }}$ construct, western blot analysis with an antibody directed against the c-Yes SH3 binding partner p65 YAP was performed (Sudol 1994). p65 YAP was identified through the use of an anti-idiotypic antibody and was subsequently demonstrated to bind to the c-Yes $\mathrm{SH} 3$ domain in vitro (Sudol 1994). However, p65 YAP is not a tyrosine-phosphorylated substrate and is not readily co-immunoprecipitated with c-Yes in vivo (Sudol, Unpubl. 
Data). Western blot analysis confirmed that p65 YAP was specifically absorbed by the cYes SH3 domain and not the c-Src SH3 domain or GST alone (Figure 1B). Thus, the inability of the c-Yes SH3 domain to affinity absorb AFAP-110 did not appear to be due to a functional defect in the GST-SH3 ${ }^{\mathrm{Yes}}$ construct. These results demonstrate that there is ligand specificity between the c-Src and c-Yes $\mathrm{SH} 3$ domains and raises the possibility that SH3 domain selectivity may serve as a general mechanism for directing signaling specificity between c-Src and c-Yes.

In order to assess the ability of the $\mathrm{SH} 3$ or $\mathrm{SH} 2$ domains to affect substrate selection, chimeric $\mathrm{Src}^{527 \mathrm{~F}}$ constructs were created in which the c-Src SH3 domain $\left(\mathrm{Y}^{527 \mathrm{~F}}\right)$, SH2 domain $\left(\mathrm{Y}^{527 \mathrm{~F}}\right)$ or both domains $\left(\mathrm{Y} 32^{527 \mathrm{~F}}\right)$, were replaced by the corresponding domains of c-Yes. These same chimeras were also generated within the context of c-Src (Y3, Y2 and Y32). Swapping of functional domains was enabled by the generation of novel restriction sites that define the boundaries separating the $\mathrm{SH} 3$ and SH2 domains. Point mutations were verified, and DNA sequence analysis confirmed that no secondary mutations were encumbered. These chimeras were expressed in CEF cells using the Rous Sarcoma Virus vector, along with c-Src and $\operatorname{Src}^{527 F}$ (Figure 2). Relative expression levels were determined by western blot analysis of whole cell lysates with the rabbit anti-Src antibody that recognizes a common epitope in the carboxy terminus of cSrc or $\mathrm{Src}^{527 \mathrm{~F}}$. As shown in Figures 3A and 3B, all constructs were expressed at comparable levels. The inclusion of normal CEF cell lysates in these and all subsequent western blots demonstrated the contribution of the overexpressed proteins to the observed results, as compared to endogenous Src family kinases. Western blots of total cell lysates were also probed with a polyclonal anti-Yes antibody (Figure 3C and 3D). This antibody 
showed strong reactivity with the $\mathrm{Y} 3, \mathrm{Y} 32, \mathrm{Y} 3^{527 \mathrm{~F}}$, and $\mathrm{Y} 32^{527 \mathrm{~F}}$ constructs and some limited cross-reactivity with constructs containing the c-Src SH3 domain. The anti-Yes antibody was raised against a region of Yes encompassing the $\mathrm{SH} 3$ and $\mathrm{SH} 2$ domains and appears to have specificity for the c-Yes SH3 domain (Sudol and Hanafusa, 1986). No antibody was available to discriminate between the c-Src and c-Yes SH2 domains, however, restriction enzyme digests of the plasmid cDNA's encoding these constructs, as well as sequence analysis, verified the presence of the c-Yes SH2 domain coding sequence (data not shown). These data demonstrate that the c-Src/c-Yes and the $\mathrm{Src}^{527 \mathrm{~F}} / \mathrm{c}-$ Yes chimeras can be expressed in CEF cells by Rous sarcoma virus.

In order to explore the possibility that $\mathrm{SH} 3$ and/or SH2 domain interactions may have been responsible for the previously observed inefficient phosphorylation of AFAP110 and pp130cas by v-Yes, the ability of activated Src with the c-Yes SH3 and/or SH2 domains to form stable complex with and induce tyrosine-phosphorylation of these proteins was analyzed. The steady-state levels of pp130cas and AFAP-110 tyrosinephosphorylation were assessed from lysates of cells expressing $\mathrm{Src}^{527 \mathrm{~F}}$ and the corresponding chimeras. As seen in Figure 4, $\mathrm{Src}^{527 \mathrm{~F}}$ and each of the $\mathrm{Src}^{527 \mathrm{~F}} / \mathrm{c}$-Yes chimeras induced comparable levels of pp130cas and AFAP-110 tyrosine phosphorylation (Figure 4A and 4B, top panels). In order to assess the effects of the cYes SH3 domain on the ability of $\mathrm{Src}^{527 \mathrm{~F}}$ chimeras to form stable complex with either AFAP-110 or pp130cas, in vivo, $\mathrm{Src}^{527 \mathrm{~F}} / \mathrm{c}-$ Yes chimeras were immunoprecipitated with the $\mathrm{mAb}$ EC10 and western blot analysis was performed with monoclonal antibodies directed against either pp130cas (anti-pp130cas) or AFAP-110 (mAb 4C3). Although no significant reduction in pp130cas binding to the $\mathrm{Src}^{527 \mathrm{~F}} / \mathrm{c}-$ Yes chimeras was detected 
(Figure 4C, top panel), $\mathrm{Y} 3^{527 \mathrm{~F}}$ and $\mathrm{Y} 32^{527 \mathrm{~F}}$, demonstrated a 2.5 fold reduction in their ability to co-immunoprecipitate with AFAP-110, compared to $\mathrm{Src}^{527 \mathrm{~F}}$ and $\mathrm{Y} 2^{527 \mathrm{~F}}$ (Fig. 4D, top panel). This correlated well with previous data that indicated SH3 interactions are necessary for stable complex formation between $\mathrm{Src}^{527 \mathrm{~F}}$ and AFAP-110 (Kanner et al., 1991; Reynolds et al., 1989, Guappone and Flynn, 1997). These results indicate that differential SH3 domain specificity can direct differences in steady-state levels of stable complex formation between AFAP-110 and c-Src and c-Yes, in vivo. These results also indicate that the previously observed inefficient tyrosine-phosphorylation of AFAP-110 and pp130cas by v-Yes do not appear to be the result of inefficient SH3 or SH2 domain mediated substrate presentation, as these proteins were efficiently phosphorylated in vivo by the $\mathrm{Y} 3^{527 \mathrm{~F}}, \mathrm{Y} 2^{527 \mathrm{~F}}$ and $\mathrm{Y} 32^{527 \mathrm{~F}}$ chimeras. This result is particularly interesting in the case of AFAP-110, as SH3 domain interactions have been demonstrated to be required for phosphorylation of AFAP-110 by Src in vivo, and the c-Yes SH3 domain clearly demonstrates a low affinity for AFAP-110, both in vitro and via co-immunoprecipitation. However, even the low affinity of the c-Yes SH3 domain for AFAP-110 may allow a transient interaction between the $\mathrm{Y}^{527 \mathrm{~F}}$ and $\mathrm{Y} 32^{527 \mathrm{~F}}$ chimeras and AFAP-110 in vivo that, coupled with the overexpression of the chimeras in comparison to AFAP-110, may be sufficient to achieve stoichiometric levels of phosphorylation in vivo.

In order to assess the roles of the $\mathrm{SH} 3$ and $\mathrm{SH} 2$ domains in directing binding to additional substrates, the profile of tyrosine-phosphorylated proteins in complex with $\mathrm{Src}^{527 \mathrm{~F}}$ and each of the $\mathrm{Src}^{527 \mathrm{~F}} / \mathrm{c}-$ Yes chimeras was examined. $\mathrm{Src}^{527 \mathrm{~F}}, \mathrm{Y}^{527 \mathrm{~F}}, \mathrm{Y}^{527 \mathrm{~F}}$, and Y32 $2^{527 F}$ were immunoprecipitated with the rabbit anti-Src antibody, and coimmunoprecipitating tyrosine-phosphorylated proteins were resolved by SDS-PAGE and 
visualized by western blotting with an antibody directed against phosphotyrosine. As seen in Figure 5, a phosphorylated protein of approximately $87 \mathrm{kDa}$ specifically coimmunoprecipitated with constructs containing the c-Yes SH2 domain, Y2 $2^{527 \mathrm{~F}}$ and $\mathrm{Y} 32^{527 \mathrm{~F}}$, while the presence of the $\mathrm{c}-\mathrm{Y}$ es $\mathrm{SH} 3$ domain in the $\mathrm{Y} 3^{527 \mathrm{~F}}$ construct did not permit binding of pp87. Thus, the c-Yes SH2 domain may also direct specificity in binding cellular proteins. 


\section{Discussion}

The data presented here indicate that specificity exists between both the SH3 and SH2 domains of c-Src and c-Yes. It is not surprising that differences were observed in the ligand specificity of the c-Src and c-Yes SH3 domain in regard to their ability to bind to AFAP-110. Previous reports by others indicate differences in the ligand binding capacities of Src family members. In vitro analyses of the optimal peptide sequences bound by SH3 domains of multiple Src family members, including c-Src and c-Yes, have revealed subtle differences in the sequences surrounding the core PXXP motif preferred by each family member (Rickles et al., 1994; Rickles et al., 1995; Sparks et al., 1996). Weng et al. demonstrated that the c-Src, Fyn, and Lyn SH3 domains bound overlapping yet distinct profiles of proteins in vitro (Weng et al., 1995). It has also been shown that the Lck SH3 domain is unable to functionally compensate for the c-Src SH3 domain in allowing c-Src to transduce signals from the PDGF receptor that result in DNA synthesis (Erpel et al. 1996). Thus, there is precedent for differential SH3 domain specificity between Src family members. Little prior data existed however, to suggest differences in the binding specificity of the $\mathrm{SH} 2$ domains of Src family members. In vitro studies have shown that Src family members optimally bind cognate ligands having the sequence pYEEI (Songyang et al., 1993; Sicilia et al., 1998). However, this is merely an optimized sequence obtained using short peptides as cognate ligands, and thus cannot take into account how the sequence is presented in the context of a complete protein. The ability of both the c-Yes and c-Src SH2 domains to efficiently bind AFAP-110 in vitro, and the ability of the $\mathrm{Y} 2^{527 \mathrm{~F}}$ and $\mathrm{Y} 32^{527 \mathrm{~F}}$ constructs to co-immunoprecipitate with AFAP110 and pp130cas suggests that there is functional redundancy between the c-Src and c- 
Yes SH2 domains. However, the fact that pp87 co-immunoprecipitates only with constructs with the c-Yes SH2 domain suggests strongly that it is associated, either directly or indirectly, with the c-Yes but not the c-Src SH2 domain. This in turn points toward ligand specificity between the c-Src and c-Yes SH2 domains. Future studies will determine the significance of stable complex formation with AFAP-110 and pp87, and if the differential abilities of activated Src and Yes to associate with these proteins correlates with any of the known functional differences between c-Src and c-Yes. The molecular determinants of specificity between the SH3 and SH2 domains of c-Src and cYes, and the remaining Src family members, remain unclear. Elucidation of the contribution of specific amino acids toward SH3 and SH2 domain specificity between cSrc and c-Yes may lead to the design of rational drugs capable of specifically blocking the unique signaling pathways utilized by these kinases. Such drugs would be ideal for studying the biological pathways affected by individual Src family members and may prove beneficial in the treatment of cancers in which c-Src or c-Yes is abnormally activated, as they could avoid the potentially deleterious effects of inhibiting the function of multiple Src family members.

\section{Acknowledgements}

DCF was supported by the NIH grant CA60731and a grant from the Emmett G. and Brownie E. McDowell Fund supported this work. JMS was supported by the Arlen G. and Louise Stone Swiger Pre-doctoral Fellowship. MS was supported by NIH grants CA45757 and CA01605. 
Absorptions

Anti-AFAP-110 Western Blot

Cos Cell Lysates

AFAP-110

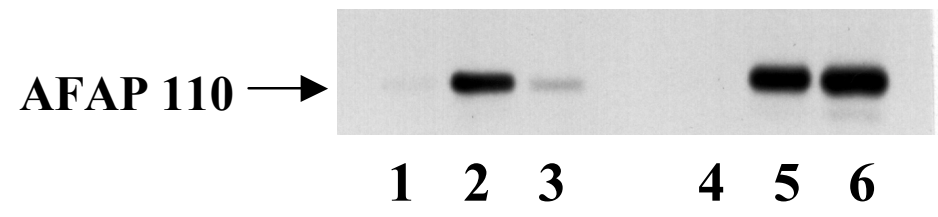

Cos Cell Lysates

AFAP-110+Src ${ }^{527 F}$

B

GST-SH3 Absorption

From CEF Cell Lysates

Anti-p65 YAP Western Blot

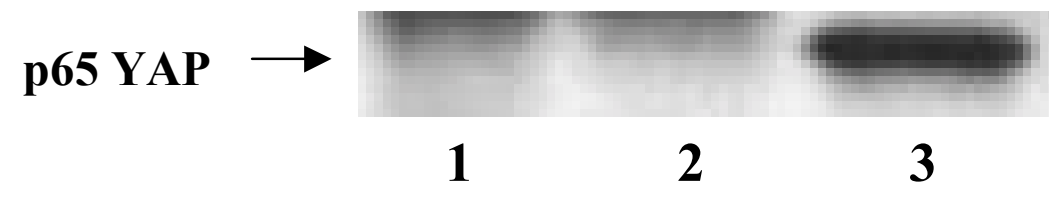

Figure 1. Affinity absorption of AFAP-110 by fusion proteins expressing the c-Src or cYes $\mathrm{SH} 3$ or SH2 domains. (A). Cos-1 cells transiently expressing AFAP-110 or tyrosine phosphorylated AFAP-110 (co-expressed with Src $^{527 F}$ ) were grown to confluence and lysed in RIPA buffer. Twenty $\mu \mathrm{g}$ of GST, GST-SH3 ${ }^{\mathrm{Src}}$ or GST-SH3 ${ }^{\text {Yes }}$ were incubated with $250 \mu \mathrm{g}$ of Cos- 1 cell lysates containing AFAP-110, while GST, GST-SH2 ${ }^{\mathrm{Src}}$, and GST-SH2 ${ }^{\text {Yes }}$ were incubated with $250 \mu \mathrm{g}$ of Cos- 1 cell lysates containing tyrosine phosphorylated AFAP-110, as previously described (Guappone et al., 1996). Bound proteins were eluted by boiling in Laemmli's sample buffer, resolved by $8 \%$ SDS-PAGE, and subjected to western blot analysis with the polyvalent anti-AFAP-110 antibody F1 
(Guappone et al., 1996). Lanes 1 and 4 = GST; Lane $2=$ GST-SH3 ${ }^{\text {Src }}$; Lane $3=$ GST$\mathrm{SH} 3^{\mathrm{Yes}}$; Lane $5=\mathrm{GST}-\mathrm{SH} 2^{\mathrm{Src}}$; Lane $6=\mathrm{GST}-\mathrm{SH} 2^{\mathrm{Yes}}$ (B) Affinity absorption from 500 $\mu \mathrm{g}$ of CEF cellular lysates with GST, GST-SH3 ${ }^{\mathrm{Src}}$ or GST-SH3 ${ }^{\text {Yes }}$, followed by western blot analysis with an anti-p65YAP polyclonal antibody. Lane $1=$ GST; Lane $2=$ GST$\mathrm{SH}^{\text {Src }}$; Lane 3 = GST-SH3 ${ }^{\text {Yes }}$. 
Construction of Src/Yes chimeras

SH3 SH2 PTK
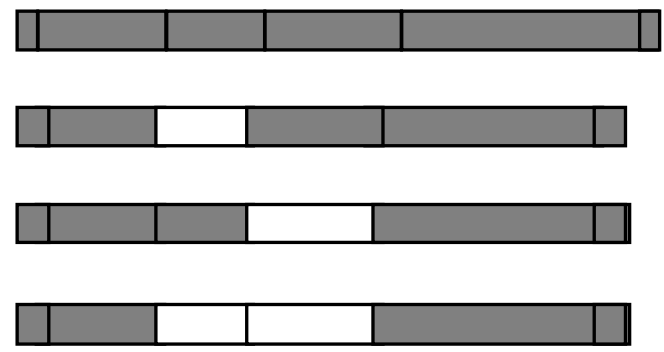

c-Yes Domain

$\begin{array}{ccc}-- & \text { c-Src } & \text { Src }^{527 F} \\ \text { SH3 } & \text { Y3 } & Y^{527 F} \\ \text { SH2 } & \text { Y2 } & Y^{527 F} \\ \text { SH3/SH2 } & \text { Y32 } & \text { Y32 }\end{array}$

Figure 2. Generation of Src/Yes chimeras. An Acy I site was engineered into the avian c-yes gene $\left(\mathrm{GGT}^{\mathrm{Gly} 90} \mathrm{GTT}^{\mathrm{Va} 191} \rightarrow \mathrm{GGC}\right.$ GTC) immediately 5 ' to the $\mathrm{SH} 3$ domain coding sequence. This matched a pre-existing site in the avian c-src gene $\left(\mathrm{GGC}^{\mathrm{Gly} 82} \mathrm{GTC}^{\mathrm{Val} 83}\right)$. A PinA I restriction site was engineered into both the c-src $\left(\mathrm{ACG}^{\mathrm{Thr} 129} \mathrm{GGC}^{\mathrm{Gly} 130} \rightarrow \mathrm{ACC}\right.$ GGT) and c-yes $\left(\mathrm{ACA}^{\mathrm{Thr} 137} \mathrm{GGC}^{\mathrm{Gly} 138} \rightarrow \mathrm{ACC}\right.$ GGT) genes, immediately 3' to the SH3 domain coding sequences. An Mlu I site was engineered into the c-yes gene 3' to the SH2 domain and kinase linker coding sequence $\left(\mathrm{GAT}^{\mathrm{Asp} 267} \mathrm{GCC}^{\mathrm{Ala} 268} \mathrm{TGG}^{\mathrm{Trp} 269} \rightarrow \mathrm{GAC}\right.$

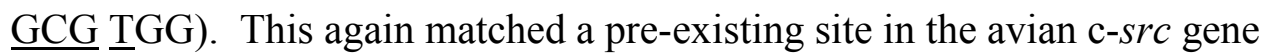
$\left(\underline{G A C}^{\mathrm{Asp} 258} \underline{\mathrm{GCG}}^{\mathrm{Ala} 259} \underline{\mathrm{TGG}}^{\mathrm{Trp} 260}\right)$. Mutations were engineered using the Quickchange Site-directed Mutagenesis kit (Stratagene). All mutations were engineered such that the corresponding amino acid sequence remained intact. All sequences were verified, along with the absence of second site mutations, by DNA sequencing. The newly engineered restriction enzyme sites were used to facilitate sub-cloning of the $\mathrm{SH} 3$ and $\mathrm{SH} 2$ domain coding sequences of c-yes into the c-src or $\mathrm{Src}^{527 \mathrm{~F}}$ backbone. The SH3, $\mathrm{SH} 2$, or SH3 and 
SH2 domains of c-Src and $\mathrm{Src}^{527 \mathrm{~F}}$ were replaced with those of c-Yes, resulting in constructs of c-Src, c-Src/c-Yes SH3 (Y3), c-Src/c-Yes SH2 (Y2), c-Src/c-Yes SH3/SH2 (Y32), $\mathrm{Src}^{527 \mathrm{~F}}, \mathrm{Src}^{527 \mathrm{~F}} / \mathrm{c}-\mathrm{Yes} \mathrm{SH3}\left(\mathrm{Y3}^{527 \mathrm{~F}}\right), \mathrm{Src}^{527 \mathrm{~F}} / \mathrm{c}-\mathrm{Yes} \mathrm{SH} 2\left(\mathrm{Y}^{527 \mathrm{~F}}\right)$, and $\mathrm{Src}^{527 \mathrm{~F}} / \mathrm{c}-$ YesSH3/SH2 (Y32 $\left.2^{527 \mathrm{~F}}\right)$. Gray boxes: c-Src domains; White boxes: c-Yes domains. 


\section{Cell lysates}

\section{Rabbit Anti-Src Blot}

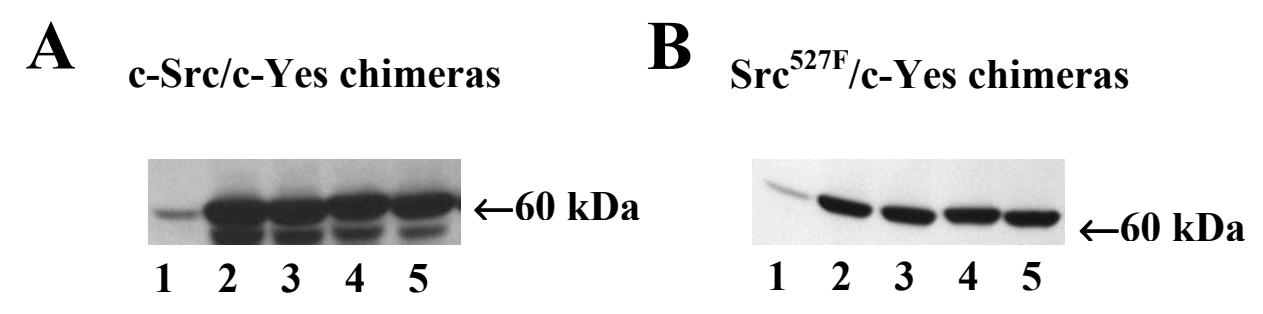

Cell lysates

Anti-Yes Blot

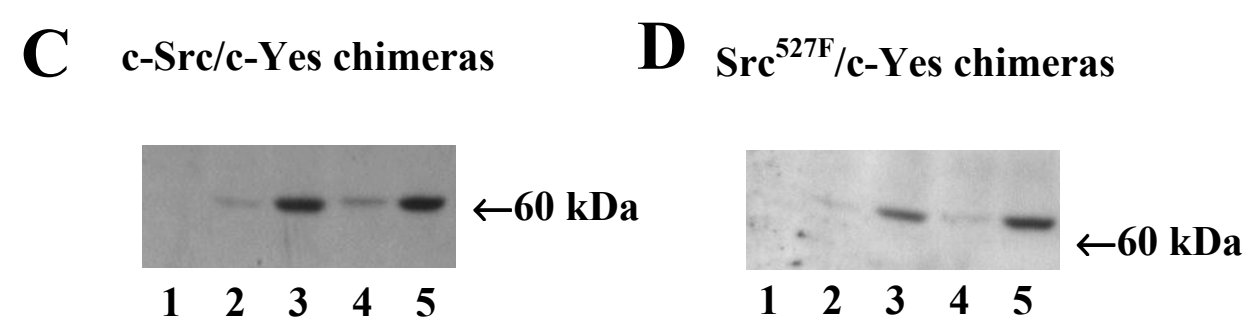

Figure 3. Expression levels of chimeric constructs. Mock transfected CEF cells, as well as $\mathrm{CEF}$ cells expressing the c-Src/c-Yes chimeras (A and C) or $\mathrm{Src}^{527 \mathrm{~F}} / \mathrm{c}-Y$ es chimeras (B and D) were lysed in NP40 or RIPA buffer, respectively, and $25 \mu \mathrm{g}$ total cell proteins were resolved by $8 \%$ SDS-PAGE. Western blot analysis with the rabbit anti-Src antibody (1:1000 dil.), reactive against a conserved domain in the carboxy-terminus of Src, common to all constructs, was used to demonstrate the expression levels of (A) cSrc, Y3, Y2 and Y32, (B) as well as Src ${ }^{527 F}, Y^{527 F}, Y^{527 F}$ and $Y^{227 F}$. Western blot analysis with the rabbit anti-Yes antibody (1:2000), that recognizes a motif specific to the c-Yes SH3 domain, was used to demonstrate the identity of the chimeric constructs (C) 
$\mathrm{Y} 3$ and $\mathrm{Y} 32,(\mathrm{D})$ as well as the $\mathrm{Y}^{527 \mathrm{~F}}$ and $\mathrm{Y} 32^{527 \mathrm{~F}}$ constructs. (A and C) Lane $1=\mathrm{CEF}$;

Lane 2 = c-Src; Lane 3 = Y3; Lane $4=\mathrm{Y} 2$; Lane $5=\mathrm{Y} 32$. (B and D) Lane $1=\mathrm{CEF}$;

Lane $2=\mathrm{Src}^{527 \mathrm{~F}}$; Lane $3=\mathrm{Y} 3^{527 \mathrm{~F}}$; Lane $4=\mathrm{Y} 2^{527 \mathrm{~F}}$; Lane $5=\mathrm{Y} 32^{527 \mathrm{~F}}$. Results are representative of three independent experiments. 
A

\section{IP: Anti-CAS}

Blot: Anti-pTyr

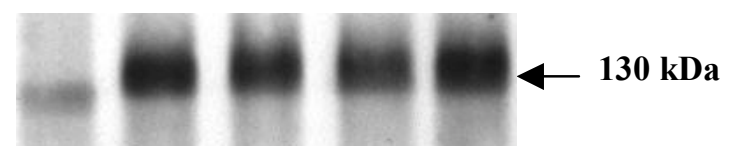

Blot: Anti-CAS
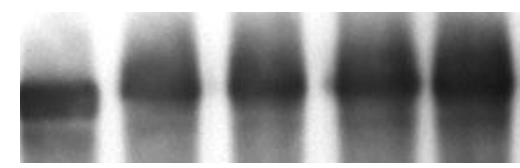

$\begin{array}{lllll}1 & 2 & 3 & 4 & 5\end{array}$

C

IP: Anti-Src

Blot: Anti-CAS

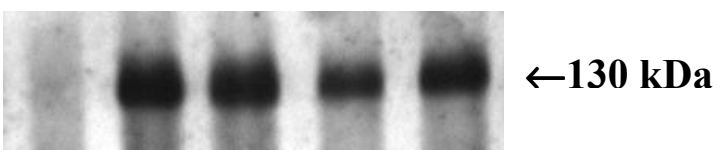

Blot: Anti-Src

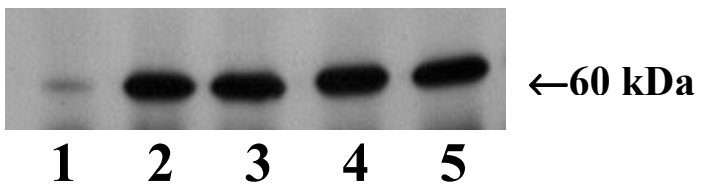

B

IP: Anti-AFAP-110

Blot: Anti-pTyr

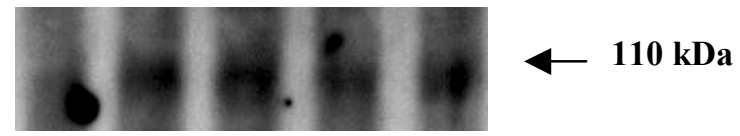

Blot: Anti-AFAP-110

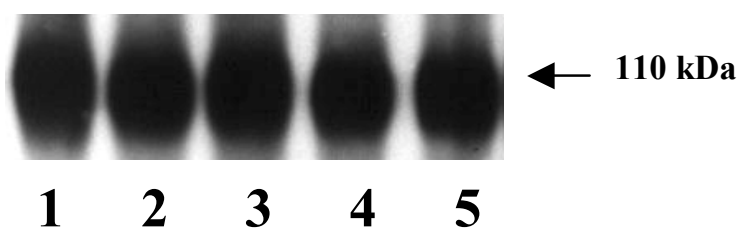

D

IP: Anti-Src

Blot: Anti-AFAP-110

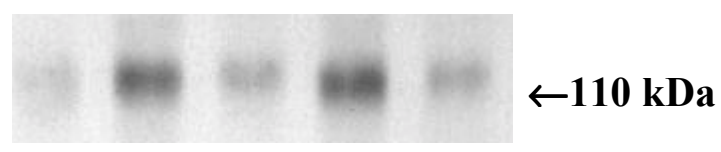

Blot: Anti-Src

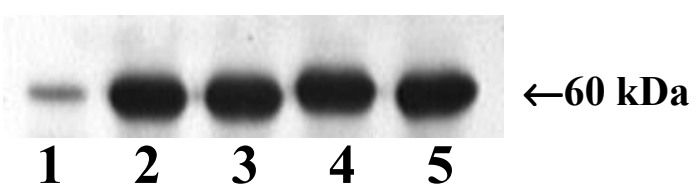

Figure 4. Effects of the c-Yes SH3 and SH2 domains on in vivo steady-state tyrosine phosphorylation levels and stable complex formation with pp130cas and AFAP-110 from lysates of cells expressing Src ${ }^{527 F} / \mathrm{c}-Y$ es chimeras. Five hundred $\mu \mathrm{g}$ of CEF lysates from mock-transfected cells or cells expressing Src ${ }^{527 \mathrm{~F}}, \mathrm{Y}^{527 \mathrm{~F}}, \mathrm{Y}^{527 \mathrm{~F}}$ or $\mathrm{Y} 32^{527 \mathrm{~F}}$ were immunoprecipitated with either a polyclonal anti-pp130cas antibody (1:300 dil.) (A) or 
the polyclonal anti-AFAP-110 antibody F1 (B). Bound proteins were eluted by boiling in Laemmli's sample buffer and resolved by $8 \%$ SDS-PAGE. Immunoprecipitated proteins were subjected to western blot analysis using a polyvalent antibody against phosphotyrosine (A and B, top panels). The blot was stripped and re-probed with the anti-pp130cas antibody (A, bottom panel) or the anti-AFAP-110 antibody (B, bottom panel). C and D: Stable complex formation between $\mathrm{Src}^{527 \mathrm{~F}} / \mathrm{c}$-Yes chimeras and pp130cas or AFAP-110. Five hundred $\mu \mathrm{g}$ of CEF lysates from mock-transfected cells or cells expressing Src ${ }^{527 \mathrm{~F}}, \mathrm{Y}^{527 \mathrm{~F}}, \mathrm{Y}^{527 \mathrm{~F}}$, or $\mathrm{Y} 32^{527 \mathrm{~F}}$ were immunoprecipitated with $\mathrm{mAb} \mathrm{EC} 10$. Bound proteins were eluted by boiling in Laemmli's sample buffer and resolved by $8 \%$ SDS-PAGE. Immunoprecipitated proteins were subjected to western blot analysis using a polyvalent antibody against $\mathrm{p} 130 \mathrm{cas}(\mathrm{C}$, top panel) or anti-AFAP-110 monoclonal antibody 4C3 (1:2000 dil.) (D, top panel). The anti-pp130cas blot and AFAP-110 blots were stripped and reprobed with rabbit anti-Src antibodies (C and D, bottom panels). (AD) Lane $1=\mathrm{CEF}$; Lane $2=\mathrm{Src}^{527 \mathrm{~F}}$; Lane $3=\mathrm{Y}^{527 \mathrm{~F}}$; Lane $4=\mathrm{Y} 2^{527 \mathrm{~F}}$; Lane $5=\mathrm{Y} 32^{527 \mathrm{~F}}$. Results are representative of two independent experiments. Western blots were quantitated using the Stratagene Eagle Eye II scanning densitometry software. 


\section{IP: Anti-Src \\ Blot: Anti-pTyr}

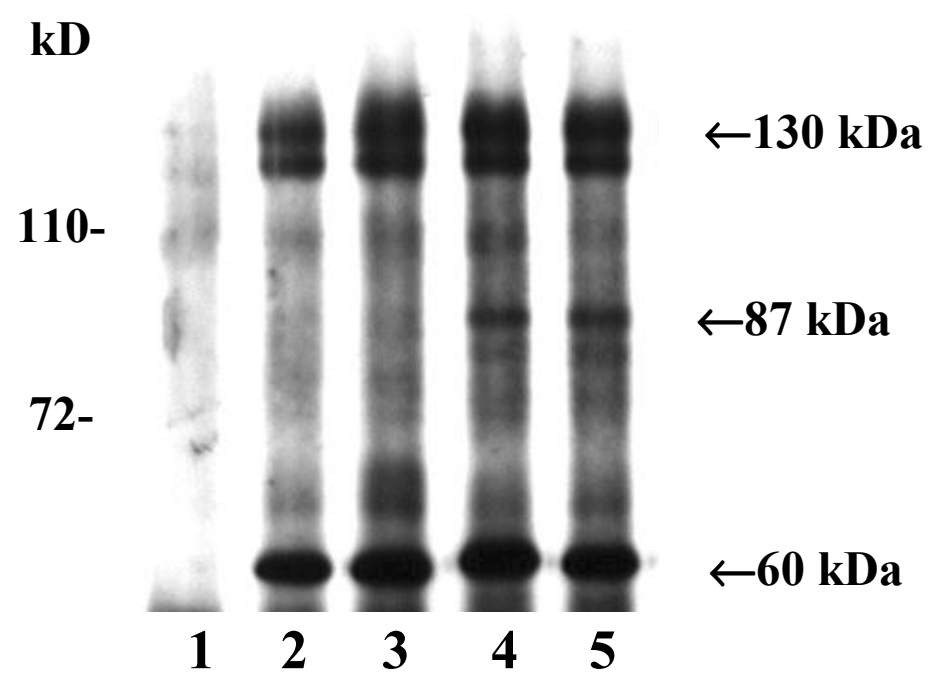

Figure 5. Stable complex formation between $\mathrm{Src}^{527 \mathrm{~F}} / \mathrm{c}-$ Yes chimeras and tyrosine phosphorylated proteins. Mock-transfected CEF, or CEF expressing Src ${ }^{527 F}, Y^{527 F}$, $\mathrm{Y} 2^{527 \mathrm{~F}}$, or $\mathrm{Y} 32^{527 \mathrm{~F}}$, were grown to confluence in $100 \mathrm{~mm}$ dishes and lysed in RIPA buffer. Five hundred $\mu \mathrm{g}$ of each cell lysate was immunoprecipitated with the rabbit antiSrc antibody. Co-immunoprecipitated proteins were eluted by boiling in Laemmli's sample buffer, resolved by $8 \%$ SDS-PAGE, and subjected to western blot analysis using a polyclonal antibody against phosphotyrosine. Lane $1=\mathrm{CEF}$; Lane $2=\mathrm{Src}^{527 \mathrm{~F}}$; Lane 3 $=\mathrm{Y} 3^{527 \mathrm{~F}} ;$ Lane $4=\mathrm{Y} 2^{527 \mathrm{~F}} ;$ Lane $5=\mathrm{Y} 32^{527 \mathrm{~F}}$. Results are representative of three independent experiments. 


\section{References}

1. Anderson D, Koch C, Grey L, Ellis C, Moran M and Pawson T. (1990). Science. 250, 979-982.

2. Bixby JL and Jhabvala P. (1993). J. Neuroscience. 13, 3421-3432.

3. Brickell PM. (1992). Crit. Rev. Onc. 3, 401-446.

4. Brown MT and Cooper JA. (1996). Biochem. Biophys. Acta. 1287, 121-149.

5. Boyce BF, Yoneda T, Lowe C, Soriano P and Mundy GR. (1992). J. Clin. Invest. 90, 1622-1627.

6. Cartwright CA, Coad CA and Egbert BM. (1994). J. Clin. Invest. 93, 509-515.

7. Cartwright CA, Kamps MP, Meisler AI, Pipas JM and Eckhart W. (1989). J. Clin. Invest. 83, 2025-2033.

8. Chen C, and Okayama H. (1987). Mol. Cell. Biol. 7, 2745-2752.

9. Courtneidge SA, Dhand R, Pilat D, Twamley GM, Waterfield MD and Roussel MF. (1993). EMBO J. 12, 943-950.

10. Di Domenico M, Castoria G, Bilancio A, Migliaccio A and Auricchio F. (1996). Cancer Res. 56, 4516-4521.

11. Eiseman E and Bolen JB. (1992). Nature 355, 78-80.

12. Erikson E and Erikson RL. (1983). Virology 130, 221-226.

13. Erpel T, Alonso G, Roche S, and Courtneidge SA. (1996). J. Biol. Chem. 271, 16807-16812.

14. Flynn DC, Leu T, Reynolds AB, and Parsons JT. (1993). Mol. Cell. Biol. 13, 78927900.

15. Fuhrer DK and Yang Y. (1996). Biochem. Biophys. Res. Comm. 224, 289-296.

16. Fuhrer DK and Yang Y. (1996). Exp. Hematol. 24, 195-203.

17. Fukui Y, O'Brien MC and Hanafusa H. (1991). Mol. Cell. Biol. 11, 1207-1213.

18. Gentry LE and Rohrschneider LR. (1984). J. Virol. 51, 539-546.

19. Gessler M and Barnekow A. (1984). Biosci. Rep. 4, 757-770.

20. Guappone AC, Qian Y, Weimer T, and Flynn DC. (1996). Meth. Cell Sci. 18, 1-11.

21. Guappone AC and Flynn DC. (1997). Mol. Cell. Biochem. 175, 243-252.

22. Guappone AC, Weimer T and Flynn DC. (1998) Mol Carcinog 22, 110-119.

23. Horne WC, Neff L, Chatterjee D, Lomri A, Levy JB and Baron R. (1992). J. Cell Biol. 119, 1003-1013.

24. Insogna KL, Sahni M, Grey AB, Tanaka S, Horne WC, Neff L, Mitnick M, Levy JB and Baron R. (1997). J. Clin. Invest. 100, 2476-2485.

25. Kanner SB, Reynolds AB, and Parsons JT. (1989). J. Immunol. Methods 120, 115124.

26. Kanner SB, Reynolds AB, Bines RR, and Parsons JT. (1990). Proc. Natl. Acad. Sci. USA. 87, 3328-3332.

27. Kanner SB, Reynolds AB, Wang H-CR, Vines RR and Parsons JT. (1991). EMBOJ. 10, 1689-1698.

28. Kaplan KB, Bibbins KB, Swedlow JR, Arnaud M, Morgan DO and Varmus HE. (1994). EMBO J. 13, 4745-4756.

29. Kaplan KB, Swedlow JR, Morgan DO, and Varmus HE. (1995). Genes Dev. 9, 1505-1517. 
30. Kefalas P, Brown TRP and Brickell PM. (1995). Int. J. Biochem. Cell Biol. 27, 551563.

31. Kitamura N, Kitamura A, Toyoshima K, Hirayama Y and Yoshida M. (1982). Nature 297, 205-208.

32. Kypta RM, Goldberg Y, Ulug ET, and Courtneidge SA. (1990). Cell 62, 481-492.

33. Loeb DM, Woolford J, and Beemon K. (1987). J. Virol. 61, 2420-2427.

34. Loganzo F Jr., Dosik JS, Zhao Y., Vidal MJ, Nanus DM, Sudol M, and Albino AP. (1993). Oncogene 8, 2637-2644.

35. Luton, F., Verges, M., and K.E. Mostov. (1998). (Abstract) Mol. Biol. Cell. 9, 259 a.

36. Marchetti D, Parikh N, Sudol M, and Gallick GE. (1998). Oncogene 16, 3253-3260.

37. Mayer, BJ and Baltimore D. (1994). Mol. Cell. Biol. 14, 2883-2894.

38. Moran MF, Koch CA, Anderson D, Ellis C, England L, Martin GS, and Pawson T. (1990). Proc. Natl. Acad. Sci. USA 87, 8622-8626.

39. Muthuswamy SK and Muller WJ. (1995). Oncogene 11, 1801-1810.

40. Noble MEM, Musacchio A, Saraste M, Courtneidge SA and Wierenga RK. (1993). EMBO J. 12, 2617-2624.

41. Okamura H and Resh MD. (1994). Oncogene 9, 2293-2303.

42. Park J and Cartwright CA. (1995). Mol. Cell. Biol. 15, 2374-2382.

43. Park J, Meisler AI and Cartwright CA. (1993). Oncogene 8, 2627-2635.

44. Parsons SJ, McCarley DJ, Raymond VW, and Parsons JT. (1984). J. Virol. 51, 272282.

45. Pawson T. (1995). Nature 373, 573-580.

46. Pawson T and Scott JD. (1997). Science 278, 2075-2080.

47. Pena SV, Melhem MF, Meisler AI, and Cartwright CA. (1995). Gastroenterology 108, 117-124.

48. Qian Y, Baisden JM, Westin EH, Guappone AC, Koay TC and Flynn DC. (1998) Oncogene 16, 2185-2195

49. Ren R, Mayer BJ, Cicchetti P, and Baltimore D. (1993). Science 259, 1157-1161.

50. Reynolds AB, Kanner SB, Wang H-CR and Parsons JT. (1989). Mol. Cell. Biol. 9, 3951-3958.

51. Rickles RJ, Botfield MC, Weng Z, Taylor JA, Green OM, Brugge JS and Zoller MJ. (1994). EMBO J. 13, 5598-5604.

52. Rickles RJ, Botfield MC, Zhou X, Henry PA, Brugge JS and Zoller MJ. (1995). Proc. Natl. Acad. Sci. USA. 92, 10909-10913.

53. Robbins SM, Quintrell NA and Bishop JM. (1995) Mol Cell Biol 15, 3507-3515.

54. Roche S, Fumagalli S and Courtneidge SA. (1995). Science 269, 1567-1569.

55. Sakai R, Iwamatsu A, Hirano N, Ogawa S, Tanaka T, Mano H, Yazaki Y and Hirai H. (1994). EMBO J. 13, 3748-3756.

56. Schaller MD, Bouton AH, Flynn DC and Parsons JT. (1993) Prog. Nucleic Acid Res. Mol. Biol. 44, 205-227.

57. Schieffer B, Paxton WG, Chai Q, Marrero MB, and Bernstein KE. (1996). J. Biol. Chem. 271, 10329-10333.

58. Schwartzberg PL, Xing L, Hoffmann O, Lowell CA, Garrett L, Boyce BF and Varmus HE. (1997). Gen. Dev. 11, 2835-2844.

59. Sicilia RJ, Hibbs ML, Bello PA, Bjorge JD, Fujita DJ, Stanley IJ, Dunn AR, and Cheng H. J. Biol. Chem. 273, 16756-16763. 
60. Smith DB and Johnson KS. (1988). Gene 67, :31-40.

61. Songyang Z, Shoelson SE, Chaudhuri M, Gish G, Pawson T, Haser WG, King F, Roberts T, Ratnofsky S, Lechleider RJ, Neel BG, Birge RB, Fajardo JE, Chou MM, Hanafusa H, Schaffhausen B, and Cantley LC. (1993). Cell 72, 767-778.

62. Songyang Z., Carraway III KL, Eck MA, Harrison SC, Feldman RA, Mohammadi M Schlessinger J, Hubbard SR, Smith DP, Eng C, Lorenzo MJ, Ponder BAJ, Mayer BJ, and Cantley LC. (1995) Nature 373, 536-539.

63. Soriano P, Montgomery C, Geske R, and Bradley A (1991). Cell 64, 693-702.

64. Sparks AB, Rider JE, Hoffman NG, Fowlkes DM, Quilliam LA, and Kay BK. (1996). Proc. Natl. Acad. Sci. USA. 93, 1540-1544.

65. Stein PL, Vogel H and Soriano P. (1994). Genes Dev. 8, 1999-2007

66. Sudol M and Hanafusa H (1986). Mol. Cell. Biol. 6, 2839-2846.

67. Sudol M, Alvarez-Buylla A and Hanafusa H. (1988a). Onc. Res. 2, 345-355.

68. Sudol M, Kieswetter C, Zhao Y, Thambi D, Wang L and Hanafusa H. (1988b). Nucl. Acids Res. 16, 9876.

69. Sudol M. (1994). Oncogene 9, 2145-2152.

70. Sudol M. (1998). Oncogene 17, 1469-1474.

71. Sugawara K, Sugawara I, Sukegawa J, Akatsuka T, Yamamoto T, Morita M, Mori S, and Toyoshima K. (1991). Br. J. Cancer 63, 508-513.

72. Thomas SM and Brugge JS. (1997). Annu. Rev. Cell Dev. Biol. 13, 513-609.

73. Tsukita Sa, Oishi K, Akiyama T, Yamanashi Y, Yamamoto T, and Tsukita Sh. (1991). J. Cell Biol. 113, 867-879.

74. Tsygankova OM, Peng M, Maloney JA, Hopkins N, and Williamson JR. (1998). J. Cell. Biochem. 69, 63-71.

75. Weng Z, Thomas SM, Rickles RJ, Taylor JA, Brauer AW, Seidel-Dugan C, Michael WM, Dreyfuss G, and Brugge JS. (1994). Mol. Cell. Biol. 14, 4509-4521.

76. Weng Z, Rickles RJ, Feng S, Richard S, Shaw AS, Schreiber SL, and Brugge JS. (1994). Mol. Cell. Biol. 15, 5627-5634.

77. Xu W, Harrison SC, and Eck MJ. (1997). Nature 385, 595-602.

78. Yu H, Rosen MK, Shin TB, Seidel-Dugan C, Brugge, JS, and Schreiber SL. (1992). Science 258, 1665-1668.

79. Zhao Y, Krueger JG, and Sudol M. (1990). Oncogene 5, 1629-1635.

80. Zhao Y, Sudol M, Hanafusa H, and Krueger J. (1992). Proc. Natl. Acad. Sci. USA. 89, 8298-8302.

81. Zhao Y, Uyttendaele H, Krueger JG, Sudol M and Hanafusa H. (1993). Mol. Cell. Biol. 13, 7507-7514.

82. Zhou S and Cantley L.C. (1995). Trends Biochem. Sci. 20:470-475. 


\title{
Chapter 3
}

Chimeric Constructs Containing the SH4/Unique Domains of c-Yes Can Restrict the Ability of $\mathrm{Src}^{527 \mathrm{~F}}$ to Upregulate Heme Oxygenase-1 Expression Efficiently.

\author{
${ }^{1}$ John G. Hoey ${ }^{\mathrm{a}, c,},{ }^{1}$ Justin M. Summy ${ }^{\mathrm{a}, \mathrm{b}}$, Daniel C. Flynn ${ }^{*}$,a,b
}

a 2822 Mary Babb Randolph Cancer Center, West Virginia University, Morgantown, WV 26506-9300, USA.

b Department of Microbiology and Immunology, West Virginia University, Morgantown, WV 26506-9177, USA.

c Department of Surgery, West Virginia University, Morgantown, WV 2506-9238, USA.

1 These two authors contributed equally to this report.

This manuscript was published in the journal Cellular Signalling, Vol. 12 (2000) 691701.

(C) 2000 Elsevier Science Inc. Al rights reserved. 


\begin{abstract}
c-Src and c-Yes are the two most homologous members of the Src family of nonreceptor tyrosine kinases. These kinases perform redundant signaling functions in cells; however, there is also evidence to support specificity in signaling. In this report, specificity in signaling between activated forms of the c-Src and c-Yes oncoproteins was examined at the level of downstream gene expression. Here, pp60c-src ${ }^{527 \mathrm{~F}}\left(\mathrm{Src}^{527 \mathrm{~F}}\right)$ and chimeric constructs of $\mathrm{Src}^{527 \mathrm{~F}}$ containing combinations of the SH4/Unique/SH3/SH2 domains of c-Yes were generated to determine whether the individual modular domains of c-Src or c-Yes could direct distinct cellular signals leading to differential gene expression. A biased, differential display analysis approach was used to analyze changes in gene expression. The data indicate that $\mathrm{Src}^{527 \mathrm{~F}}$ is capable of upregulating heme oxygenase-1 (HO-1) in CEF cells at the level of transcription and protein expression. Chimeric constructs containing the SH4/Unique domains of c-Yes were less efficient in upregulating HO-1 expression. Activation of c-Src and expression of the HO-1 gene product are each induced under conditions of hypoxia. We hypothesize that activated cSrc can direct upregulation of HO-1 while activated c-Yes may be less efficient in stimulating signal transduction pathways that direct expression of HO-1.
\end{abstract}




\section{Introduction}

The Src family of non-receptor tyrosine kinases comprises nine members ( $\mathrm{Src}$, Yes, Fgr, Fyn, Lyn, Lck, Hck, Blk, and Yrk), all of which share a common functional domain structure, consisting of four Src homology domains (SH1, SH2, SH3, and SH4) and a Unique domain [1]. The SH1 or tyrosine kinase domain provides the enzymatic function specific to these tyrosine kinases and is regulated via intramolecular interactions [2]. The kinase domain can be further segregated into 11 subdomains, which are highly conserved among all the non-receptor tyrosine kinases $[1,2]$. The amino terminal SH3 and $\mathrm{SH} 2$ domains appear to play a central role in substrate selection and kinase regulation $[3,4]$. The SH3 and SH2 domains form intramolecular interactions with Src family kinases when they are in the repressed or inactivated state. However, upon activation of the enzyme, the SH3 and SH2 domains are released from intramolecular binding, thus becoming accessible for modulation of protein-protein interactions with a variety of SH2/SH3 binding partners [2].

c-Src and c-Yes are the two most homologous members of the Src family [5-7]. There is very high homology within the $\mathrm{SH} 2$ and $\mathrm{SH} 3$ domains. In addition, the 11 subdomains within the SH1 domain that define its function are virtually identical between c-Yes and c-Src. It has been demonstrated that cellular and viral homologues of these two kinases phosphorylate many of the same substrates [8,9]. c-Src and c-Yes are expressed at relatively high levels in the same cell types and tissues [2,10-14], and they localize to the same subcellular region [10,15-18]. In addition, knockouts of either the cSrc or c-Yes gene are not embryonic-lethal; however, knocking out both genes is embryonic-lethal, indicating the capacity of these two genes to compensate for each other 
during development [19]. These data indicate that these two kinases may have redundant functions.

The most significant differences between c-Src and c-Yes exist in the SH4 and Unique domains. The amino terminal SH4 domain modulates interactions with the cytoplasmic face of the cell membrane [20]. The SH4 domains of c-Src and c-Yes are both myristoylated at $\mathrm{Gly}^{2}$ and this modification is important for membrane association. However, unlike c-Src, the $\mathrm{SH} 4$ domain of c-Yes is also palmitoylated at $\mathrm{Cys}^{3}$ [20]. It has been hypothesized that the additional palmitoylation signal in the amino terminus of c-Yes may help to direct it to specific subcellular membrane domains, such as caveolae [21]. The Unique domains share little conservation in primary amino acid sequence among Src family members and their function is poorly understood; however, there is evidence to indicate that the Unique domain of pp561ck can mediate protein interactions with the CD4 receptor or the CD45 tyrosine phosphatase [22-24]. Furthermore, the Unique domain of pp56lck can also mediate membrane-associated localization [25]. Therefore, the Unique domains of the Src family tyrosine kinases may function by facilitating protein interactions, which could influence subcellular membrane association.

There is some evidence for specificity in signaling between c-Src and c-Yes.

Although c-Src and c-Yes are expressed in many of the same cells and tissues, differences in expression can be documented over the course of development [17,26]. There is also some evidence for specificity in protein/protein interactions. Activated cYes will associate with an $87 \mathrm{kDa}$ protein by virtue of its $\mathrm{SH} 2$ domain [9]. Also, the SH3 domain of c-Yes fails to bind to the Src SH3 binding partner AFAP-110, and chimeric constructs containing the c-Yes SH3 domain fail to form a stable complex with AFAP- 
110 [9]. Specificity in signaling between c-Src and c-Yes is also evident in cells isolated from genetic knockout mice. The osteoclasts from c-src -/- mice show abnormalities in formation of lamellipodia $[27,28]$, and fibroblasts from c-src -/- mice are also deficient in cell spreading, despite normal expression levels of c-Yes [29]. Thus, c-Yes cannot compensate for the ability of c-Src to effect these cytoskeletal changes. In addition, c-yes -/- mice have deficiencies in the ability to transcytose IgA from the blood to the bile despite normal expression levels of c-Src [30].

In this report, we sought to determine whether specificity in signaling between cSrc and c-Yes could result in changes in transcriptional activation of specific gene products, and whether these changes could be attributed to a specific functional domain. Here, we demonstrate that signals modulated by activated $\mathrm{Src}_{\left(\mathrm{Src}^{527 \mathrm{~F}}\right)}$ direct upregulation of heme oxygenase 1 (HO-1) mRNA and protein levels; while chimeric constructs containing the c-Yes SH4/Unique domains within the context of $\mathrm{Src}^{527 \mathrm{~F}}$ were less efficient in stimulating an increase in $\mathrm{HO}-1$ expression. 


\section{Materials and Methods}

\section{Generation of Src/Yes chimeras}

Site-directed mutagenesis was used to generate restriction enzyme sites flanking the c-src and c-yes SH3 and SH2 domains. All mutations were designed so that the resulting amino acid sequences remained unchanged (see Table 1). These restriction sites resulted in $\mathrm{SH} 3$ and $\mathrm{SH} 2$ domain cassettes in c-Src and c-Yes that could be easily exchanged (Fig. 1). An Acy I site was introduced at position 393 in the chicken c-yes sequence, just 5' of the SH3 domain. This corresponded to a pre-existing Acy I site at position 355 in chicken c-src. Unique PinA I restriction sites were engineered at the 3' ends of the SH3 domains in c-src (position 496) and c-yes (position 534). The coding sequence for the c-src SH3 domain was replaced with that of c-yes via a two-part Acy I to PinA I ligation. To facilitate SH2 domain replacement, a unique Mlu I site was engineered at position 922 just downstream of the c-yes SH2 domain and kinase linker sequence. Again, this site corresponded to a pre-existing Mlu I site in c-src at position 884. All mutagenesis was performed using the Stratagene Quickchange Site-Directed Mutagenesis protocol and reagents. Prior to sub-cloning, DNA sequencing was performed after each round of mutagenesis in order to ensure that the desired mutation was present and to ensure that no second-site mutations had arisen. Restriction enzyme digests were performed to verify the presence of the correct sequence from c-yes. All $\mathrm{Src}^{527 \mathrm{~F}} / \mathrm{c}-$ Yes chimeras were created in the Rous Sarcoma Virus (RSV) Sac $\Delta$ vector, a deletion variant of RSV that lacks the Gag, Pol, and Env sequences [9]. Full-length RSV constructs encoding c-src with the c-yes $\mathrm{SH} 3$, c-yes $\mathrm{SH} 2$, or c-yes $\mathrm{SH} 3$ and $\mathrm{SH} 2$ domains 
were generated by linearizing the RSV Sac $\Delta$ vectors with $\operatorname{Sac}$ I and sub-cloning RSV digested with $S a c$ I, as previously described [9]. Fully activated versions of the c-src chimeras were generated by replacing the c-src kinase domain, from the Mlu I site mentioned above, to a Cla I site downstream of the c-src coding sequence in RSV, with that of $\mathrm{Src}^{527 \mathrm{~F}}$, a fully active $\mathrm{Src}$ variant in which the regulatory tyrosine residue has been mutated to phenylalanine. The nomenclature uses $\mathrm{Y}$ to represent $\mathrm{c}-\mathrm{Y}$ es sequence, $4=$ SH4 domain, 3 = SH3 domain, $2=\mathrm{SH} 2$ domain, and $\mathrm{U}=$ Unique domain (Fig. 1b). The superscript 527F indicates an activated tyrosine kinase analogous to $\mathrm{Src}^{527 \mathrm{~F}}$. Thus, $\mathrm{Y}_{32} 2^{527 \mathrm{~F}}$ indicates a chimera of $\mathrm{Src}^{527 \mathrm{~F}}$ containing $\mathrm{SH} 3 / \mathrm{SH} 2$ domains of c-Yes in place of the same domains found in c-Src. The SH1 or kinase domains are virtually identical between c-Src and c-Yes in the 11 subdomains that define a tyrosine kinase domain [9] and can be used interchangeably. Thus, Y4U32 $2^{527 \mathrm{~F}}$ would be analogous to activated cYes. Site-directed mutagenesis was used to change the $\mathrm{Cys}^{3} \rightarrow$ Ser and the $\mathrm{Ile}^{4} \rightarrow \mathrm{Ser}$, to create a c-Src SH4 domain using the $\mathrm{Y}_{4} \mathrm{U}^{527 \mathrm{~F}}$ construct, generating $\mathrm{YU}^{527 \mathrm{~F}}$. Conversely, the $\mathrm{Src}^{527 \mathrm{~F}} \mathrm{SH} 4$ domain was mutated by changing $\mathrm{Ser}^{3} \rightarrow \mathrm{Cys}$ and $\mathrm{Ser}^{4} \rightarrow$ Ile to represent the c-Yes SH4 domain, generating $4^{527 F}$.

\section{Cell culture, antibodies, and western blot analysis}

Chicken embryo fibroblasts (CEF) were prepared as described previously and cultured in 100-mm dishes in DMEM containing 4\% fetal calf serum, $1 \%$ chicken serum, $4 \%$ tryptose phosphate broth, $2 \mathrm{mM}$ glutamine, and 1\% penicillin/streptomycin. CEF were transfected via $\mathrm{CaCl}_{2}$ as described previously at $50 \%$ cell-confluence with $5 \mu \mathrm{g}$ of RSV plasmid DNA encoding $\mathrm{Src}^{527 \mathrm{~F}}$ or the $\mathrm{Src}^{527 \mathrm{~F}} / \mathrm{c}$-Yes chimeras and passaged 1:4 every $48 \mathrm{hr}$ with $0.25 \%$ trypsin. After 10-12 days, confluent plates were lysed with RIPA 
(1\% NP-40; $0.25 \%$ deoxycholate; $50 \mathrm{mM}$ Tris, $\mathrm{pH} 7.5,150 \mathrm{mM} \mathrm{NaCl} ; 2 \mathrm{mM}$ sodium vanadate; $2 \mathrm{mM}$ PMSF; $50 \mu \mathrm{g} / \mathrm{ml}$ aprotinin; $2 \mathrm{mM} \mathrm{EGTA),} \mathrm{and} \mathrm{total} \mathrm{cellular} \mathrm{proteins}$ were quantitated via the Bicinchoninic acid (BCA) assay (Pierce).

Western blot analysis was performed as described previously, using the antibody concentrations previously described and quantitated by chemiluminescence and scanning densitometry using the Stragene Eagle Eye II software [9]. Rabbit anti-Src is a polyclonal antibody raised against an epitope in the carboxy-terminus [9]. Rabbit antiSrc was used at a 1:1000 dilution for probing western blots. The anti-phosphotyrosine antibody is a polyclonal antibody from Transduction Laboratories $(250 \mu \mathrm{g} / \mathrm{ml})$ and was used for western blotting at a 1:1000 dilution. Anti-heme oxygenase- 1 antibodies specific for an amino terminal epitope in HO-1 and not immunoreactive with $\mathrm{HO}-2$ were obtained from StressGen (Vancouver, British Columbia) and used according to manufacturer's instructions.

\section{RNA isolation and Northern blot analysis}

Total RNA was isolated from cultured cells using TRI REAGENT (Molecular Research Center, Cincinnati, $\mathrm{OH}$ ) according to manufacturer's recommendations. Total RNA was fractionated on a $1 \%$ agarose/formaldehyde gel and transferred to a Zeta-probe GT membrane (Bio-Rad, Hercules, CA). Following UV cross-linking using the Stratalinker 2400 (Stratagene, La Jolla, CA), the membrane was hybridized to cDNA

probes random-prime labeled with $\left[\alpha-{ }^{32} \mathrm{P}\right]$ using the HotPrime kit (Genhunter, Nashville, $\mathrm{TN})$.

For removal of chromosomal DNA from total RNA, the MessageClean kit (Genhunter, Nashville, TN) was used according to the manufacturer's recommended 
protocol. Fifty $\mu \mathrm{g}$ total cellular RNA was incubated for $30 \mathrm{~min}$ at $37^{\circ} \mathrm{C}$ with 10 units of Dnase I in 10 X Reaction buffer consisting of 100 mM Tris-Cl, pH 8.4, $500 \mathrm{mM} \mathrm{KCl,} 15$ $\mathrm{mM} \mathrm{MgCl} 2$, and $0.01 \%$ gelatin. Following extraction with phenol $/ \mathrm{CHCl}_{3}$, the upper phase was ethanol precipitated by adding 0.1 vol $3 \mathrm{M} \mathrm{NaOAc}$ and 2.5 vol $100 \% \mathrm{EtOH}$. Following centrifugation at $4^{\circ} \mathrm{C}$, the RNA pellet was washed twice with $80 \% \mathrm{EtOH}$. The pellet was air dried and redissolved in Milli-Q $\mathrm{H}_{2} \mathrm{O}$. RNA concentration was determined using a GeneQuant II DNA/RNA calculator (Pharmacia Biotech, Inc.). RNA integrity was assessed by analyzing a $1 \mu \mathrm{g}$ aliquot on a $1 \%$ (TBE) agarose gel.

\section{Differential display PCR, cDNA amplification, cloning and sequence analysis}

Differential display was performed essentially as described [31,32], except that $0.2 \mu \mathrm{g}$ of total RNA was used for reverse transcription in a $20 \mu \mathrm{l}$ reaction volume. A two-base anchored oligodeoxy adenylic acid primer $\mathrm{T}_{11} \mathrm{AA}$ (Display Systems Biotech) was used to reverse transcribe total RNA into first-strand cDNA, which was subsequently amplified by PCR using the Zn2 upstream primer (5'-

GTCGTCGAATTCCA(CT)AC(ACT)GG(AG)GAAAAGCC-3') as previously described [33]. PCR conditions followed the suggested instructions in the Display Systems Differential Display Kit (Display Systems Biotech). PCR products were resolved on a $6 \%$ nondenaturing polyacrylamide gel (Gibco BRL, NY) using $\left[\alpha-{ }^{33} \mathrm{P}\right] \mathrm{dATP}(3000$ $\mathrm{Ci} / \mathrm{mmol})$.

For re-amplification of differentially expressed cDNAs, autoradiograms with cDNAs of interest (i.e., those with bands that appeared to be differentially expressed) were overlayed onto the dried gel. cDNA bands were cut from the dried gel using a sterile blade, and put into $100 \mu \mathrm{l}$ of sterile $\mathrm{H}_{2} \mathrm{O}$. Samples were boiled for $10 \mathrm{~min}$ and an 
aliquot was taken for PCR. The PCR primers used for reamplification were identical to those that generated the original differential display cDNA. The reamplified cDNA bands were subcloned into pCR 2.1 plasmid vector using the TA cloning kit (Invitrogen, San Diego, CA). Competent E. coli (INV $\left.\alpha F^{\prime}\right)$ were transformed by the heat shock method. Plasmids were sequenced using Sequenase 7-deaza-dGTP sequencing reagents with $\left[\alpha^{33} \mathrm{P}\right] \mathrm{dATP}(3000 \mathrm{Ci} / \mathrm{mmol})$ and vector-specific sequencing primers.

For preparation of mRNA and cloning by PCR amplification, poly (A)+ RNA was purified using the Poly(A) Pure mRNA preparation kit (Ambion, Austin, TX). Doublestrand cDNA synthesis was carried out with the Marathon cDNA amplification kit (Clontech Laboratories, Inc., Palo Alto, CA) according to the manufacturer's recommended protocol. The PCR amplification was carried out using a forward primer corresponding to the ligated adaptor in combination with a reverse primer, 5'GCTCCGGAGCTGCATAGTTCTGAGGCA-3' designed against the Zn2A-1 differential display PCR cDNA.

The PCR products were run on a 1\% (TAE) agarose gel. A 1.0-kb PCR product corresponding to the expected size of the full-length Zn2A-1 cDNA was cut from the gel and purified using the QIAquick gel extraction kit (Qiagen, Valencia, CA). The PCR product was ligated into pCR 2.1 vector (Invitrogen, San Diego, CA) using the TA cloning kit (Invitrogen, San Diego, CA) for sequence analysis using Sequenase 7-deazadGTP sequencing reagents with $\left[\alpha_{-}{ }^{33} \mathrm{P}\right] \mathrm{dATP}(3000 \mathrm{Ci} / \mathrm{mmol})$. The full-length $\mathrm{Zn} 2 \mathrm{~A}-1$ 5'RACE cDNA was sequenced using vector-specific and internal sequencing primers as shown diagrammatically in Fig. 4b. 


\section{Results}

\section{Expression of $\mathrm{Src}^{527 F} / \mathrm{c}$-Yes chimeric constructs in CEF cells}

Chimeric constructs were generated as described in materials and methods (Fig. 1a and $b$, Table1). The chimeras were expressed in CEF cells by transfection using the Rous Sarcoma Virus and lysed at confluence after 10-12 days in culture, as previously described [9]. Twenty-five $\mu \mathrm{g}$ of total cellular proteins were resolved by SDS-PAGE and transferred to PVDF. Relative expression levels were determined by western blot analysis with a polyclonal rabbit anti-Src antibody, which recognizes an epitope in the carboxy-terminus of c-Src and $\mathrm{Src}^{527 \mathrm{~F}}$ that is conserved among all chimeric constructs (Fig. 2a). Western blot analysis with anti-c-Yes specific antibodies confirmed the presence of the c-Yes SH3 domain [9]. The presence of the c-Yes SH2 domain was verified by cDNA restriction enzyme digest, as no antibody was available to discriminate between the c-Src and c-Yes SH2 domains. Most constructs were expressed at comparable levels; however, $\mathrm{Y} 4 \mathrm{U} 32^{527 \mathrm{~F}}$ and $\mathrm{Y} 4 \mathrm{U}^{527 \mathrm{~F}}$ demonstrated reduced expression levels relative to the other chimeric constructs. Western blot analysis of total cell lysates with polyclonal rabbit anti-phosphotyrosine demonstrated similar steady-state levels of tyrosine phosphorylation (Fig. 2B). These data indicate that the constructs were active and catalytic and that the chimeric constructs induced steady-state levels of tyrosine phosphorylation similar to $\mathrm{Src}^{527 \mathrm{~F}}$ and significantly higher than in untransfected CEF cells. 


\section{Differential display analysis}

CEF cells expressing the $\mathrm{Src}^{527 \mathrm{~F}}$, Y4U32 $2^{527 \mathrm{~F}}, \mathrm{Y} 32^{527 \mathrm{~F}}, \mathrm{Y} 2^{527 \mathrm{~F}}, \mathrm{Y} 3^{527 \mathrm{~F}}$, or mocktransfected CEF cells, were lysed and total RNA isolated as described in materials and methods. A biased, differential display analysis was applied whereby RT-PCR of the isolated poly A+ RNA was performed using primers that hybridized with the poly-A tail at the $3^{\prime}$ ' end of the transcripts, as well as a consensus 5' primer $(\mathrm{Zn} 2)$ for members of the $\mathrm{C}_{2} \mathrm{H}_{2}$ family of Zinc-finger transcription factors, as previously described [33]. The bias toward a $\mathrm{Zn}$-finger transcription factor was applied as a means to identify induction of related transcription factors. The $\left[{ }^{33} \mathrm{P}\right]$-labeled $\mathrm{PCR}$ products were resolved by $6 \%$ acrylamide gel electrophoresis and differential expression noted by changes in intensity of PCR products in each lane. As demonstrated in Fig. 3, a PCR product was identified (Zn2A-1) that was $325 \mathrm{bp}$ in size and was amplified from poly A+ RNA isolated from CEF cells expressing $\mathrm{Src}^{527 \mathrm{~F}}, \mathrm{Y} 32^{527 \mathrm{~F}}, \mathrm{Y}^{527 \mathrm{~F}}$, and $\mathrm{Y}^{527 \mathrm{~F}}$. However, this same $325-\mathrm{bp}$ RT-PCR product was less efficiently detected from CEF cells expressing Y4U32 ${ }^{527 F}$ or from untransfected CEF cells (Fig. 3a). Northern blot analysis using the Zn2A-1 PCR product as a probe confirmed the differential display results and indicated that $\mathrm{Zn} 2 \mathrm{~A}-1$ hybridizes to a $1.2-\mathrm{kb}$ poly A+ RNA product that could be detected in CEF cells expressing $\mathrm{Src}^{527 \mathrm{~F}}$ and $\mathrm{Y} 32^{527 \mathrm{~F}}$. The Zn2A-1 probe hybridized less efficiently with RNA from CEF cells expressing Y4U32 $2^{527 \mathrm{~F}}$, and was not able to detect this $1.2-\mathrm{kb}$ poly $\mathrm{A}+$ RNA in untransfected CEF cells (Fig. 3b). Analysis of ethidium bromide stained gels indicated equivalent loading efficiency (data not shown). 


\section{$\mathrm{Zn} 2 \mathrm{~A}-1$ is representative of $\mathrm{HO}-1$}

Sequence analysis of Zn2A-1 revealed a novel sequence that was not homologous with any known sequence in the cDNA databases. A 5' RACE strategy was employed to obtain additional sequence 5 ' and upstream of Zn2A-1 in order to identify this putative gene product (Fig. 4a). A 1.0-kb amplified cDNA product (called Zn2A-1 5'RACE) was isolated, cloned and the 5' and 3' ends sequenced. There was a 134-bp overlap between the 3' end of Zn2A-1 5'RACE and the 5' end of Zn2A-1, indicating that Zn2A-1 5'RACE product contained cDNA sequence that was identical to the 5' end of the Zn2A1 RT-PCR product (Fig. 4b). BLAST analysis [34] demonstrated that the 5' end of the Zn2A-1 5'RACE clone was 97\% homologous with the reported sequence for chicken heme oxygenase-1 (HO-1; Fig. 4c). This homologous sequence represented the region of HO-1 from bp 1 to 329. The 3' end of the original Zn2A-1 PCR product was not homologous with the reported cDNA sequence for HO-1. These data indicate that the Zn2A-1 5'RACE cDNA sequence may contain additional 3' sequence information from HO-1 that was not previously reported, or it could represent an alternatively processed form of HO-1.

To confirm that the Zn2A-1 5'RACE product was representative of the original Zn2A-1 PCR product identified by differential display, Northern analysis was also performed using the 1.0-kb Zn2A-1 5'RACE cDNA as a probe. The data indicated that a major 1.2-kb band was also detected among poly A+ RNAs isolated from CEF cells expressing $\mathrm{Src}^{527 \mathrm{~F}}, \mathrm{Y} 32^{527 \mathrm{~F}}, \mathrm{Y}^{527 \mathrm{~F}}, \mathrm{Y}^{527 \mathrm{~F}}$, and $\mathrm{Y} 4 \mathrm{U} 32^{527 \mathrm{~F}}$ (Fig. 5a). In untransfected CEF, significantly less HO-1 poly-A+ RNA was detected. The size of the poly A+ RNA was consistent with the reported size of the HO-1 message [35] and is consistent with the 
size of the poly A+ RNA that hybridized with Zn2A-1. In addition, Zn2A-1 5'RACE hybridized less efficiently to a second poly A+ RNA that was approximately $2.8 \mathrm{~kb}$ and was detected equally in each sample. $Y 2^{527 \mathrm{~F}}$ appeared to induce a higher level of the 1.2$\mathrm{kb}$ poly $\mathrm{A}+\mathrm{RNA}$. The reason for this increase in hybridization efficiency in that particular sample was not clear, and could represent either an increase in the ability to upregulate transcription or an anomaly of sample loading. These data demonstrate that like Zn2A-1, the Zn2A-1 5'RACE cDNA product also hybridized to a $\mathrm{Src}^{527 \mathrm{~F}}$-inducible 1.2-kb transcript. However, unlike the original Zn2A-1 cDNA, the Zn2A-1 5'RACE cDNA also efficiently hybridized to a $2.8-\mathrm{kb}$ transcript that was not induced by $\mathrm{Src}^{527 \mathrm{~F}}$ or the $\mathrm{Src}^{527 \mathrm{~F}} / \mathrm{c}-$-Yes chimeras. In order to calibrate the samples for loading efficiency, a cDNA representative of ubiquitin was used as a probe. The data indicated some differences in loading (Fig. $5 \mathrm{~b}$ and c). Densitometry analysis was performed to determine the relative amounts of the 1.2-kb poly A+ RNA compared to ubiquitin (Fig. 5c). When normalized to loading controls, densitometry analysis indicated that the 1.2kb poly A+ RNA isolated from CEF cells expressing Y4U $32^{527 F}$ was less efficiently induced, relative to $\mathrm{Src}^{527 \mathrm{~F}}$ or the other chimeras. Collectively, these data are consistent with the differential display and the Northern analysis using Zn2A-1 and indicate that (1) both the Zn2A-1 and Zn2A-1 5'RACE probes hybridize with an inducible 1.2-kb poly $\mathrm{A}+\mathrm{RNA}$, (2) the Y4U32 $2^{527 \mathrm{~F}}$ kinase is less efficient at inducing expression of this 1.2-kb RNA, (3) the 1.2-kb RNA is consistent with the size of the HO-1 transcript and (4) Zn2A-1 5'RACE contains sequence homologous to HO-1.

\section{$\mathrm{Src}^{527 F}$ induces HO-1 protein expression more efficiently than $\mathrm{Y}^{4} \mathrm{U}^{527 \mathrm{~F}}$ or $\mathrm{Y} 4 \mathrm{U} 32^{527 F}$.}


To determine whether the protein expression levels of HO-1 were affected, CEF cells expressing c-Src, c-Yes, Src ${ }^{527 \mathrm{~F}}, \mathrm{Y} 4 \mathrm{U} 32^{527 \mathrm{~F}}, \mathrm{Y}_{4} \mathrm{U}^{527 \mathrm{~F}}, \mathrm{Y}^{527 \mathrm{~F}}, \mathrm{YU}^{527 \mathrm{~F}}$, and $\mathrm{Y} 32^{527 \mathrm{~F}}$ were lysed and processed for western blot analysis using an antibody specific for the amino terminus of HO-1 (StressGen, Vancouver, BC). As demonstrated in Fig. 6, the protein expression levels of HO-1 were undetectable in CEF cells and very low in CEF cells expressing c-Src and c-Yes. Src ${ }^{527 \mathrm{~F}}$ induced relatively high expression levels of $\mathrm{HO}-1$, as did $\mathrm{Y} 32^{527 \mathrm{~F}}, \mathrm{Y} 4^{527 \mathrm{~F}}$, and $\mathrm{YU}^{527 \mathrm{~F}}$. However, Y4U32 $2^{527 \mathrm{~F}}$ and $\mathrm{Y}_{4 \mathrm{U}^{527 \mathrm{~F}}}$ were only able to induce relatively low levels of HO-1 protein compared to the other chimeras. Expression levels of $\mathrm{Src}^{527 \mathrm{~F}}$ and the chimeric constructs were also quantitated and matched to these lysates (see Fig. 2). The relative steady-state levels of tyrosine phosphorylation (see Fig. 2b), suggest that, although there were differences between expression levels of the chimeric constructs, each was capable of inducing comparable steady-state levels of tyrosine phosphorylation, indicating that the kinases were functional and equivalently catalytic. These data demonstrate that: (1) c-Src and c-Yes are unable to induce efficient upregulation of HO-1 expression; (2) although $\mathrm{Src}^{527 \mathrm{~F}}$ and Y4 $\mathrm{U}^{527 \mathrm{~F}}$ expression levels are equivalent, the expression levels of HO-1 are reduced for $\mathrm{Y} 4 \mathrm{U}^{527 \mathrm{~F}}$, as they are for $\mathrm{Y} 4 \mathrm{U} 32^{527 \mathrm{~F}}$, indicating that the c-Yes SH4/Unique domains, in the context of a fully activated Src, do not permit efficient upregulation of HO-1 protein expression by these chimeric constructs; (3) Y4U32 $2^{527 \mathrm{~F}}$ was also less efficient in upregulating expression of the 1.2-kb poly A+ RNA; and (4) $\mathrm{Y} 32^{527 \mathrm{~F}}$ induced relatively high expression levels of HO-1 indicating that the $\mathrm{SH} 3 / \mathrm{SH} 2$ domains of c-Yes are capable of transmitting cellular signals for these chimeric constructs that result in increased HO-1 expression. Collectively, these data indicate that $\mathrm{Src}^{527 \mathrm{~F}}$ can upregulate 
$\mathrm{HO}-1$ and that the presence of the c-Yes SH4/Unique domains restricts the ability of $\mathrm{Src}^{527 \mathrm{~F}}$ to upregulate $\mathrm{HO}-1$. 


\section{Discussion}

In an effort to elucidate mechanisms for specificity in signaling between c-Src and c-Yes, chimeric constructs containing the c-Yes SH4/Unique/SH3/SH2 domains were subcloned within the context of the $\mathrm{Src}^{527 \mathrm{~F}}$ tyrosine kinase. Each of these chimeric constructs contained the SH1, or tyrosine kinase domain, of $\mathrm{Src}^{527 \mathrm{~F}}$. In this study, we hypothesized that c-Src and c-Yes may modulate specific signaling cascades that the other could not activate and that a mechanism for differential signaling may be due to differences in the functional domains. These differences could direct these chimeric constructs to activate different signaling cascades, which could be qualitatively measured by differential gene expression. Here, a biased, differential display analysis was used as a technique to look for differences in gene expression between the chimeric constructs. One PCR product, Zn2A-1, was generated from poly A+ RNA isolated from cells expressing $\mathrm{Src}^{527 \mathrm{~F}}$ and was less prevalent in CEF cells expressing the $\mathrm{Y} 4 \mathrm{U} 32^{527 \mathrm{~F}}$ chimera, while undetected in untransfected CEF cells. Zn2A-1 was also detectable in the CEF cells expressing $\mathrm{Y} 32^{527 \mathrm{~F}}$, indicating that the $\mathrm{SH} 4$ and/or Unique domains may have prevented Y4U32 $2^{527 F}$ from efficiently inducing Zn2A-1.

Sequence analysis of Zn2A-lindicated that it was not homologous with any known sequences in the DNA database. A probe was created for a 5'RACE analysis using sequences within Zn2A-1 which resulted in the isolation of a 1-kb RT-PCR product, Zn2A-1 5'RACE. This Zn2A-1 5'RACE cDNA contained 5' cDNA sequence information that predicted an amino acid sequence that was $97 \%$ homologous to the chicken heme oxygenase-1 gene (HO-1) [35]; while the 3' sequence was identical to Zn2A-1. It is possible that Zn2A-1 sequence may represent previously unreported 3' 
avian HO-1 sequence or it could represent an alternatively processed variant of HO-1 with different 3' sequence. Although it is possible that the Zn2A-1 5'RACE product could represent a PCR artifact, we consider this to be less likely in light of the northern and western blot analysis. Northern analysis demonstrated that both the Zn2A-1 and Zn2A-1 5'RACE cDNA products were able to hybridize with a 1.2-kb poly A+ RNA, which is consistent with the reported size of the HO-1 mRNA [35]. However, unlike Zn2A-1, the Zn2A-1 5'RACE cDNA was also able to hybridize to a 2.8 -kb poly A+ RNA, which is inconsistent with the reported size of the HO-1 mRNA [35]. This indicates that there could be alternatively processed forms of HO-1 represented by both the 1.2 and $2.8 \mathrm{~kb}$ mRNAs. Western blot data demonstrated that $\mathrm{Src}^{527 \mathrm{~F}}$ could also induce expression of the HO-1 protein, as did most of the chimeric constructs. However, chimeric constructs containing the c-Yes SH4/Unique domains were unable to upregulate HO-1 protein levels efficiently, consistent with reduced detection of the 1.2-kb poly A+ RNA from Northern analysis with Zn2A-1 or Zn2A-1 5'RACE probes. These data indicate that these kinases, in the absence of the c-Yes SH4/Unique domains, may be able to effect expression of the HO-1 gene product at the level of transcription. It is clear that $\mathrm{Src}^{527 \mathrm{~F}}, \mathrm{Y} 4 \mathrm{U} 32^{527 \mathrm{~F}}$, and $\mathrm{Y}_{4} \mathrm{U}^{527 \mathrm{~F}}$ each induced equivalent levels of tyrosine phosphorylation. These data suggest that the presence of the c-Yes SH4/Unique domains do not position c-Yes or the chimeric constructs to upregulate expression of the HO-1 protein efficiently.

It has been shown that the SH4 domains of the Src family can effect subcellular localization along the cell membrane. Both c-Src and c-Yes are myristoylated at $\mathrm{Gly}^{2}$, which is required for membrane association; however, unlike c-Src, c-Yes is also 
palmitoylated at the $\mathrm{Cys}^{3}$ position [20]. Palmitoylation has been predicted to direct proteins to specific membrane microdomains such as caveolae [21]. Previously reported data indicate that palmitoylation influences the localization of the Src family member pp56lck. In NIH 3 T3 cells, pp56lck localized primarily with the plasma membrane; however, when $\mathrm{Cys}^{5}$ was mutated to lysine (abrogating one of two palmitoylation signals in pp561ck), pp561ck co-localized with both the plasma membrane and golgi region. Interestingly, mutations that changed the palmitoylation site at $\mathrm{Cys}^{3}$ to a Ser induced a subcellular localization that was indistinguishable from wild-type pp561ck, occurring primarily at the plasma membrane [25]. These data indicate that palmitoylation can regulate specific membrane associations in at least one Src family member.

Interestingly, expression of either the SH4 or Unique domain of c-Yes individually in the chimeric constructs $\mathrm{Y}^{527 \mathrm{~F}}$ or $\mathrm{YU}^{527 \mathrm{~F}}$ permitted intermediate expression levels of $\mathrm{HO}-1$, indicating that the $\mathrm{SH} 4 /$ Unique domains may operate cooperatively. It is possible that the Unique domain may direct specific protein interactions that assist in sequestering c-Yes away from signaling proteins that activate HO-1 expression. For example, pp56lck forms functional protein interactions via its Unique domain [22-24]. Also, Bijlmakers et al. demonstrated that the Unique domain of pp56lck, when tethered to green fluorescent protein (GFP), was able to target GFP to the cell membrane [25]. Although the work of Resh and colleagues have clearly demonstrated a role for myristoylation in targeting Src family kinases to the cell membrane [20], it is possible that the targeting of pp56lck to specific subcellular localizations along the cell membrane may be influenced by both palmitoylation in the SH4 domain and by protein interactions modulated by the Unique domain. Therefore, we 
hypothesize that it is also possible that specificity in signaling by c-Yes may be regulated by the SH4/Unique domains, and that these two domains may work cooperatively simply by positioning c-Yes in specific subcellular regions that do not permit it to interact efficiently with signaling proteins that modulate HO-1 expression. Conversely, these chimeric constructs may exist in subcellular domains concomitant with $\mathrm{Src}^{527 \mathrm{~F}}$; however, the SH4/Unique domains of c-Yes may modulate interactions with other signaling proteins, which in turn sequester the chimeras away and prevent them from activating signaling pathways that efficiently modulate $\mathrm{HO}-1$ expression.

Although this is the first report that we are aware of demonstrating that activated c-Src can upregulate expression of HO-1, several reports from other labs indirectly support this hypothesis. Under conditions of hypoxia, it has been demonstrated that c-Src becomes activated while c-Yes does not $[36,37]$. These data indicate that hypoxia directly affects upstream regulatory components that regulate c-Src activation. In addition, hypoxia results in the expression of HO-1 [38]. It has also been demonstrated that v-Src will induce expression of hypoxia-inducible transcription factor-1 (HIF-1) [39]. Ectopic expression of HIF-1 has been shown to upregulate HO-1 expression levels [40,41]. Lastly, Masuya et al. demonstrated that inhibitors of tyrosine kinases block the induction of HO-1 expression by hemin, sodium arsenite, or cadmium chloride [42]. Thus, the results presented in this report are consistent with a prediction that activated cSrc would be capable of upregulating HO-1 expression, possibly via a signal transduction cascade that includes HIF-1.

Several signal transducing proteins that become activated during hypoxia have been identified, and are also known to become activated or upregulated in response to 
activated c-Src. These include focal adhesion kinase [43], Ras [37], NFkB [44], MAP kinases [44,45], AP-1 [46], c-Fos [47], and HIF-1 [39]. It is possible that activated c-Src may modulate upregulation of HO-1 via one or more of these signaling proteins as part of a signal transduction cascade, and that activation of c-Yes is less efficient in modulating this same cascade. The ability of activated c-Src to upregulate HO-1 may enhance tumor cell survival under conditions of hypoxia. HO-1 can cleave heme into Fe, biliverdin, and CO. Biliverdin can provide some protection against oxidative damage [38], indicating that one function of HO-1 might be to aid cell survival in the face of oxidative stress. These data are consistent with a prediction that c-Yes might not become activated during hypoxia simply because it is unable to efficiently modulate signal transduction pathways necessary to effect changes in gene expression that are required for survival under conditions of cellular stress.

\section{Acknowledgments}

This work was supported by a grant from the National Cancer Institute CA60731 (DCF) and by a grant from the Arlen G. and Louise Stone Swiger Pre-doctoral Fellowship Program (JMS). 
Table 1

Engineered restriction sites do not alter amino acid sequences in cSre or cYes

IA - Acy / site: This restriction site exists at the second and third residues for the c.Sre and $\mathrm{c}$ Ves $\mathrm{SH} 3 \mathrm{domains}$. Each SH3 doenain begims with Gly" (for cSre) or Gly" (for cYes).

1) eSre Gly" $\mathrm{Val}^{3} \mathrm{Thr}^{34}$

2) cYes Gly" Val" Thr" Gly" Val" Thr" $\frac{\text { GGC GTC ACT }}{\text { Ary } ?}$ GGT GTT ACT $\rightarrow$ GGC GTC ACC Acy $?$

$1 B$ - PinA $l$ site: This restrietion site was engineered near the end of the $\mathrm{SH} 3$ domain, which terminates with the codon encoding Ser ${ }^{12}$ in Sre and Ser in eVes.

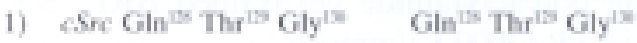

$$
\text { CAGACGGGC } \rightarrow \text { CAG ACC GGT }
$$

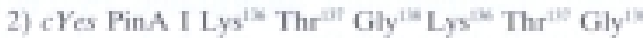
A.A ACA GGC $\rightarrow$ AAA $\frac{\text { ACC GGT }}{\text { PinAl }}$

1C. Mha $I$ site: The SH2 domain ends in eSre with the codon encoding Asn ${ }^{20}$ and in eYes at Thr ${ }^{31}$. The Mir $I$ site exists 3 of the sequences

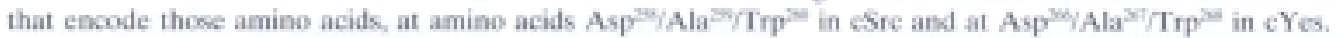

1) CSre TRPo Asp $\mathrm{Ala}^{20} \mathrm{Trp}^{20}$

2) CYes Asp $^{32} \quad$ Ala $\operatorname{Trp}^{3 \times}$ Asp Ala $^{20}$

GAC GOG TGC

GAT GCC TGG $\rightarrow$ GAC GCG TGE

Mhin $I$

Min $?$ 


\section{Generation of $\mathrm{Src}^{527 \mathrm{~F}} / \mathrm{cYes}$ chimeric constructs}

A.

A. Evisting restriction sites in $\mathrm{c}$ Sr and eYes

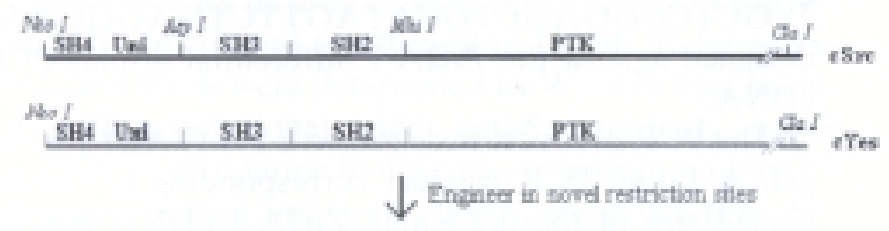

B. efre and $e$ Yes whth engineered restriction sites form cassettes

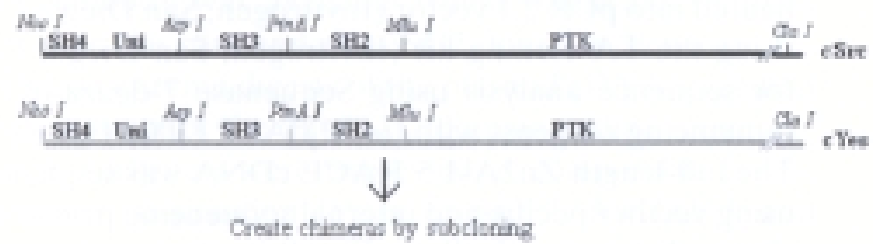

B.

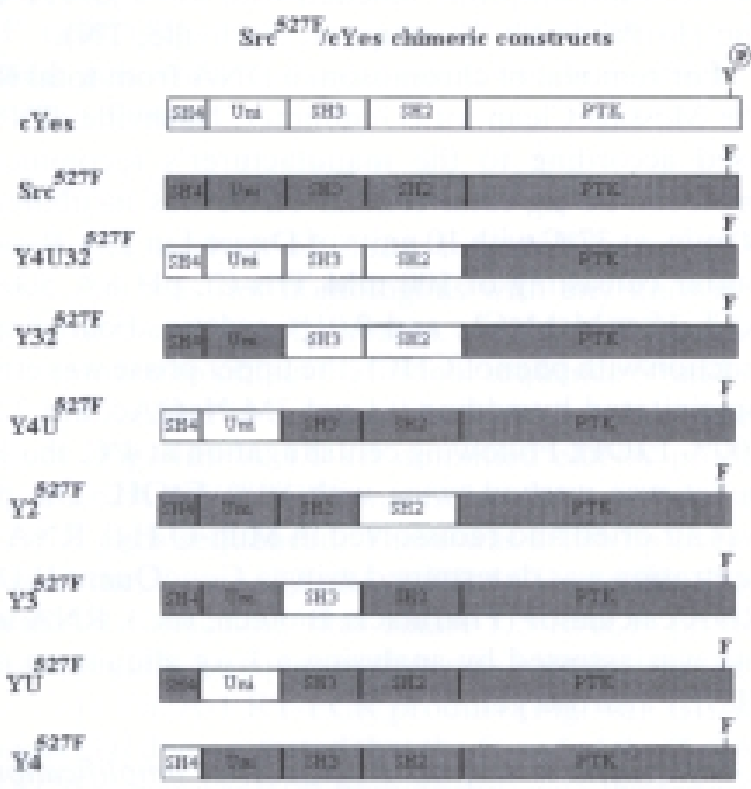

Figure 1. Engineering of restriction sites into c-Src and c-Yes for generation of chimeras. (A) Pre-existing restriction sites in the c-src cDNA include the Nco I, Acy I, and Mlu I sites, as shown. The c-yes cDNA had an analogous Nco I restriction site. Matching sites were engineered into the cDNAs to permit swapping of sequences encoding the modular domains, as detailed in materials and methods. (B) Nomenclature for chimeric constructs, as detailed in materials and methods. Y indicates c-Yes sequence and the following 4, 3, 2 and/or U indicate the $\mathrm{SH} 4, \mathrm{SH} 3, \mathrm{SH}$, and Unique domains derived from c-Yes and placed within the context of $\mathrm{Src}^{527 \mathrm{~F}}$. White boxes indicate c-Yes sequence; shaded boxes indicate $\mathrm{Src}^{527 \mathrm{~F}}$ derived sequences. 


\section{Western Blot}

A.
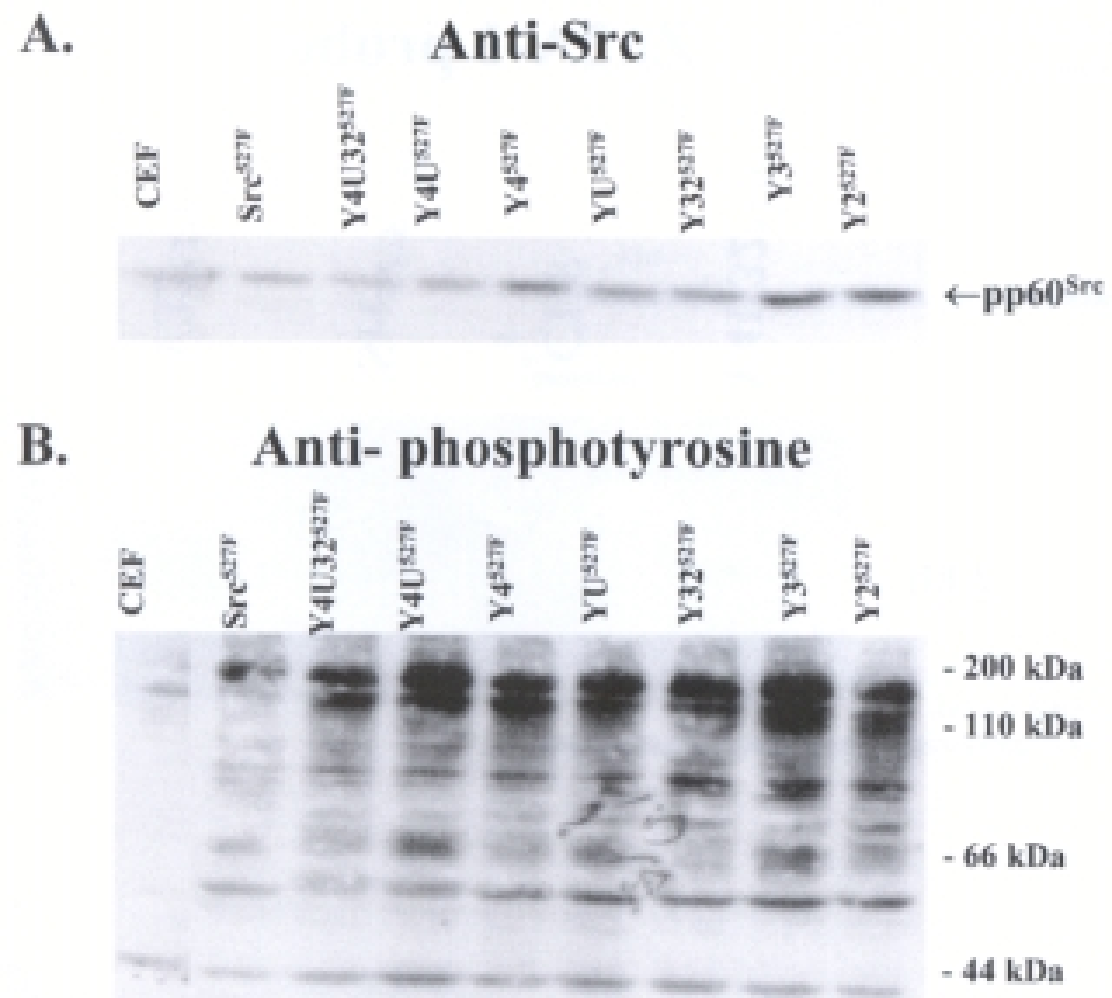

Figure 2. Expression of chimeric constructs in CEF cells and analysis of steady-state levels of tyrosine phosphorylation. (A) Twenty-five $\mu \mathrm{g}$ of CEF lysates expressing the chimeric constructs were resolved by SDS PAGE and western blot analysis performed using a rabbit anti-Src antibody that reacts with a conserved epitope in the carboxy terminus. (B) Twenty-five $\mu \mathrm{g}$ of CEF lysates expressing the chimeric constructs were resolved by SDS-PAGE and western blot analysis performed using the rabbit antiphosphotyrosine antibody. Results are representative of three independent experiments. 


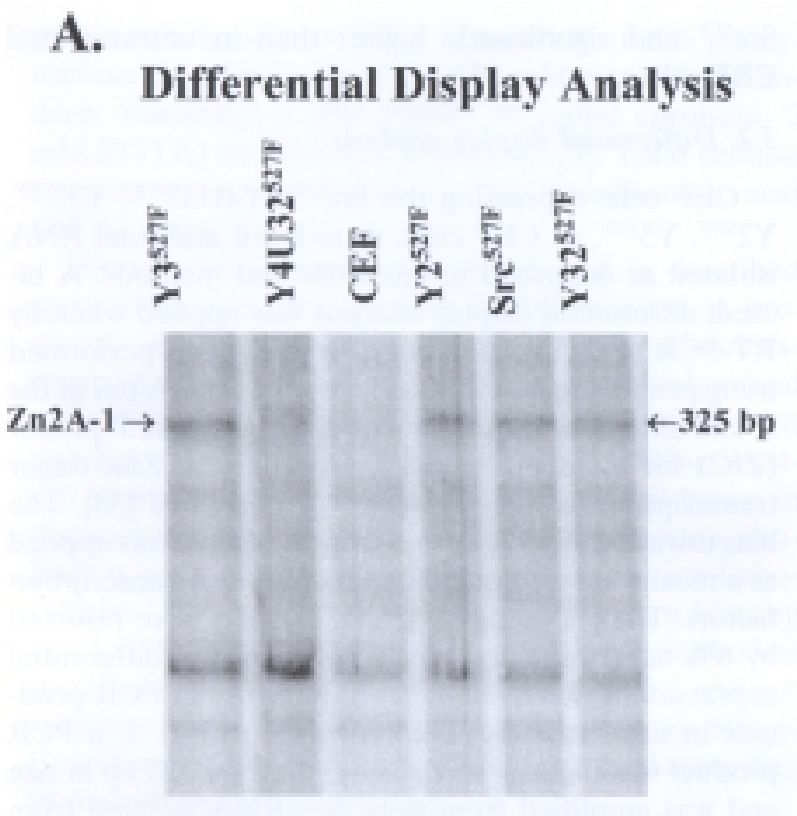

B.

Northern Blot Analysis Zn2A-1 probe

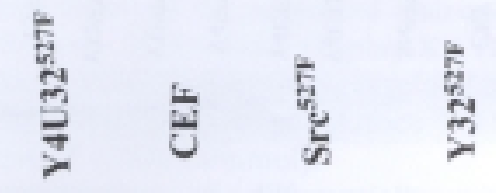

$1.2 \mathrm{~kb} \rightarrow$

Figure 3. $\mathrm{Src}^{527 \mathrm{~F}}$ induces expression of a 1.2-kb poly A+ RNA from CEF cells. (A) Differential display analysis. Resolution of amplified cDNAs demonstrate a $325 \mathrm{bp}$, $\left[{ }^{33} \mathrm{P}\right]$-labeled PCR product, called Zn2A-1, that is detected from amplified mRNAs isolated from $\mathrm{Src}^{527 \mathrm{~F}}, \mathrm{Y}^{527 \mathrm{~F}}, \mathrm{Y}^{527 \mathrm{~F}}$, and $\mathrm{Y}^{52} 2^{527 \mathrm{~F}}$, but not identified in $\mathrm{Y} 4 \mathrm{U} 32^{527 \mathrm{~F}}$ expressing CEF cells or CEF cells alone. (B) Northern analysis with Zn2A-1. The Zn2A-1 probe was used to hybridize against poly A+ RNA from CEF cells expressing $\mathrm{Src}^{527 \mathrm{~F}}, \mathrm{Y} 4 \mathrm{U} 32^{527 \mathrm{~F}}, \mathrm{Y} 32^{527 \mathrm{~F}}$, or CEF cells alone. 
A.

5 'gtcgtcgaaticcataccggagaanagcctcaaaccaacagccasagagctgcagtfaftcta cagagtatcfgcasaaatcccacaggafgagaaasgcagctitgacaccfgtcttgectcaga actatgcagctccggagctoctoctgtggctategaactgitttatatgacoctagcaggtctgtg thaatcticticcaatcattittcttctttttttaagagatgatggttgttgaagatacagtgitcgittcttt atctgatcatataattlatatacataataasagtcaatgtasagcgttasasaasasa 3

B.

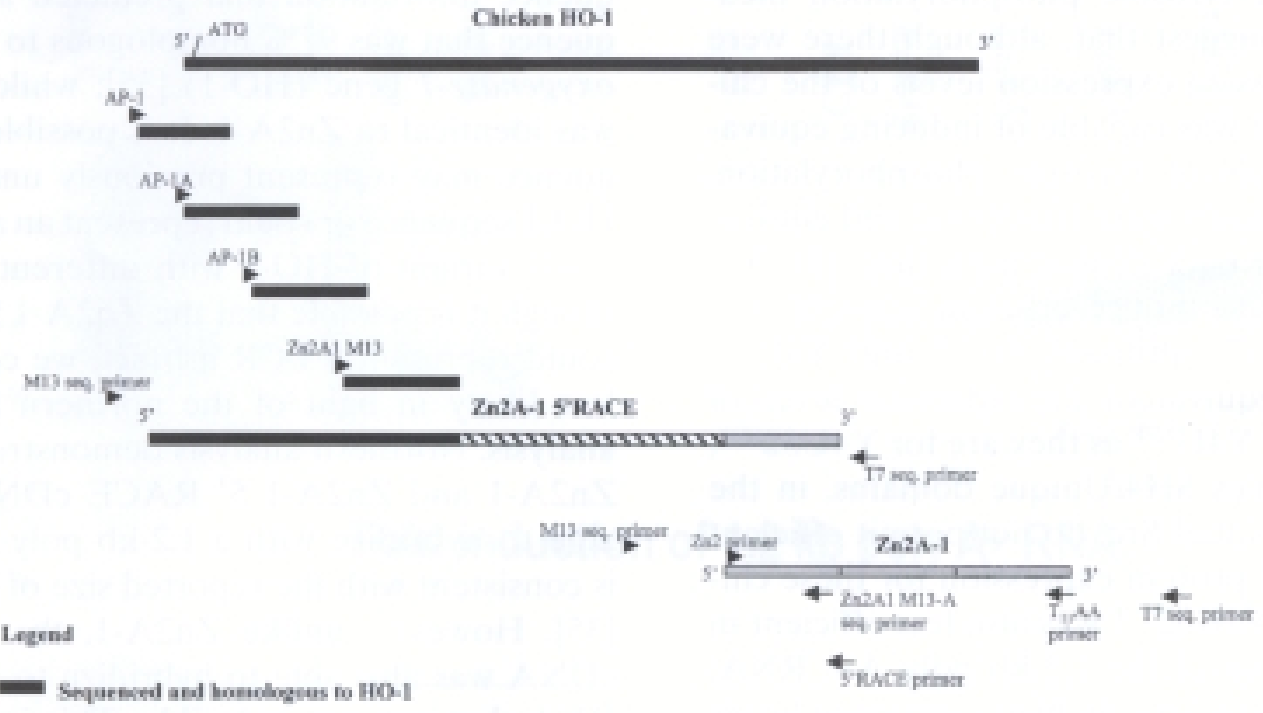

was Uesegarened

$\square$ Sequesexd and sot heanelegoes to HO-1

C.

Hemology between Zn2A-1 S' RACE sequence and avian HO-1

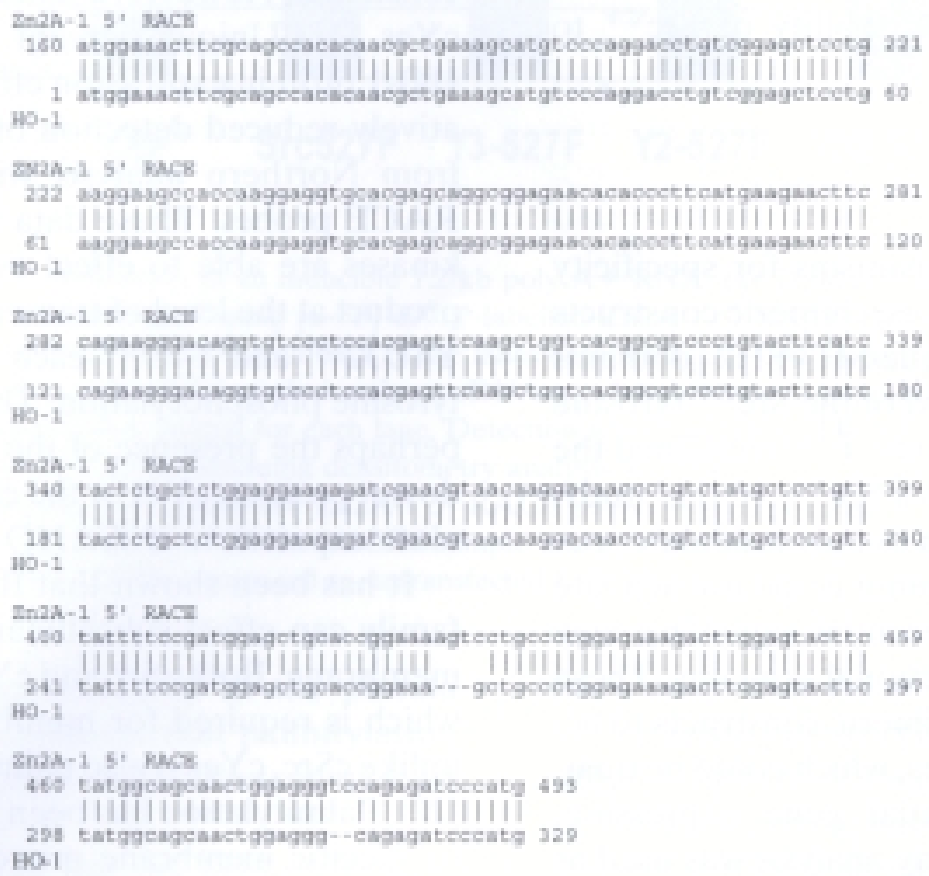


Figure 4. cDNA sequence generated upstream of $\mathrm{Zn} 2 \mathrm{~A}-1$ is homologous to heme oxygenase-1. (A) Sequence analysis of 325 bp Zn2A-1 differential display PCR product. The underlined sequences are those used as primers for the differential display PCR. The double underlined region corresponds to the putative poly $\mathrm{A}+$ signal sequence. For 5'RACE PCR, a 27-bp antisense primer (5'

ACGGAGTCTTGATACGTCGAGGCCTCG 3') was designed against the region shown by bold type. (B) 5'RACE using a primer generated from Zn2A-1 sequence. A primer designed from Zn2A-1 was used for 5'RACE as a technique to identify upstream 5' sequence. The diagram shows the relationship between the reported avian HO-1 sequence compared to the Zn2A-1 PCR product generated by differential display (Zn2A1) and Zn2A-1 5'RACE product sequences. Dark shaded areas indicate sequences that are identical to the avian HO-1 sequence. Hatched boxes indicate unsequenced cDNA and the gray-shaded boxes indicate identity between the Zn2A-1 clone used for differential display and the Zn2A-1 5'RACE cDNA. The arrows indicate sites for primers used for sequencing and for the 5'RACE PCR. (C) The 5' end of the Zn2A-1 5'RACE cDNA product exhibits significant homology with the reported avian HO-1 sequence. Blast analysis showing the alignment between HO-1 cDNA sequence and the 5'RACE product. The Zn2A-1 5'RACE product exhibits 97\% homology with 2\% gaps to a portion of the reported chicken heme oxygenase 1 sequence (gi: 62923; embl: X56201.1). 


\section{Northern Blot Analysis}

\section{A. Zn2A-1 5'-PCR probe B. ubiquitin probe}

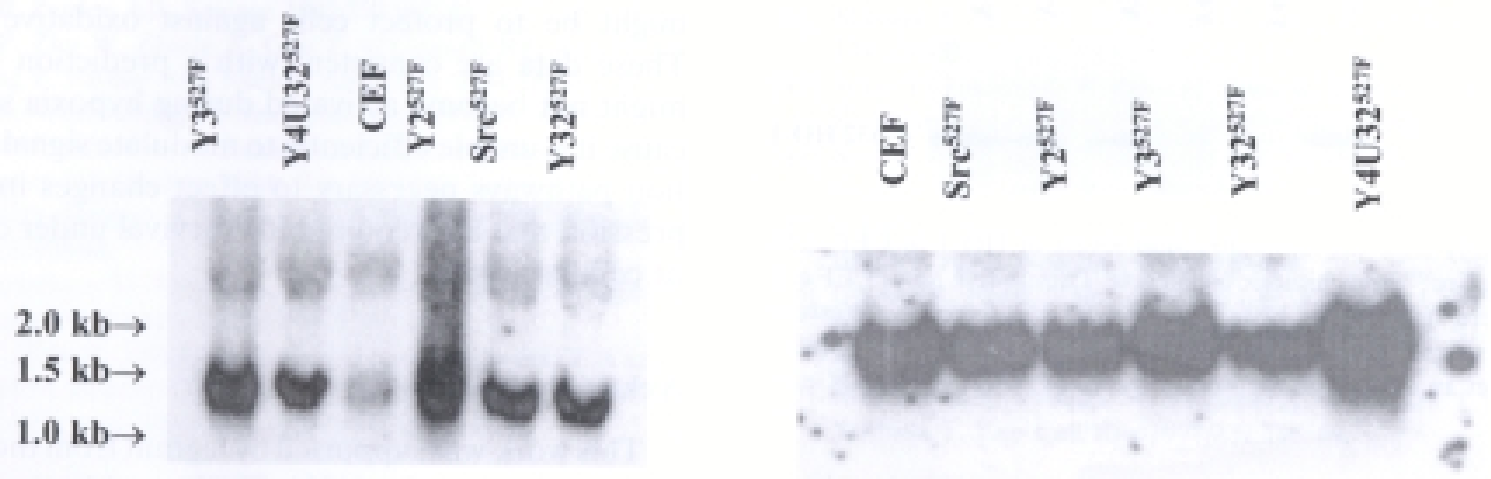

C.

Fold induction of $1.2 \mathrm{~kb}$ poly A+ RNA

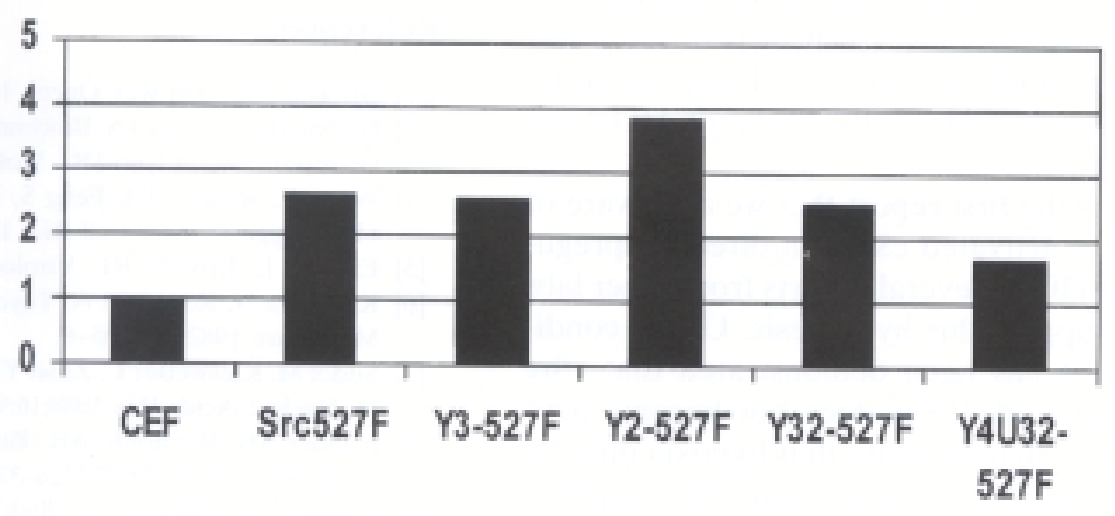

Figure 5. Zn2A-1 5'RACE cDNA also hybridizes to an inducible 1.2-kb poly A+ RNA. (A) Total cellular RNA was isolated from the cell lines indicated, and Northern blot analysis performed using $\left[\alpha^{32} \mathrm{P}\right]$ dATP-labeled Zn2A-1 5'RACE cDNA as a probe. A major poly A+ RNA of approximately 1.2-kb hybridizes to the labeled cDNA in each of the lanes except the lane containing CEF RNA, while a minor $2.8-\mathrm{kb}$ message was also detected. (B) Loading control of Northern analysis using a cDNA which hybridizes to ubiquitin. $\left[\alpha-{ }^{32} \mathrm{P}\right]$ dATP-labeled ubiquitin probe was used to quantitate the amounts of 
RNA loaded for each construct. Detection was accomplished by autoradiogram. (C) Relative amounts of the 1.2-kb poly A+ RNA representative of HO-1. Scanning densitometry analysis was performed by quantitating the relative amount of the $1.2-\mathrm{kb}$ poly A+ RNA detected and shown in (A), with the Zn2A-1 5'RACE probe, divided by the densitometric analysis of ubiquitin shown in (B). The quotients were normalized to "1" for the CEF sample and all other quotients normalized against the CEF sample, giving a relative induction of the $1.2-\mathrm{kb}$ poly $\mathrm{A}+\mathrm{RNA}$ compared to untransfected $\mathrm{CEF}$ cells. 


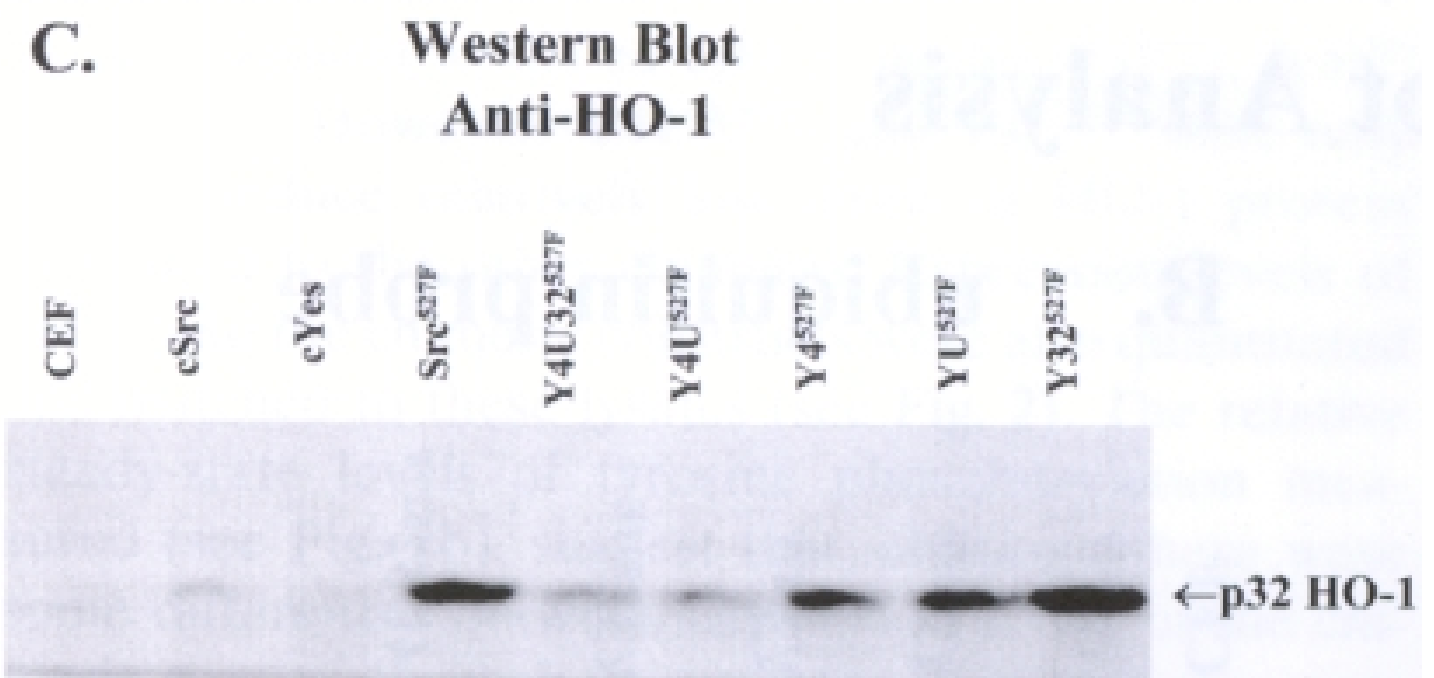

Figure 6. Steady-state protein expression levels of HO-1 in CEF cells expressing $\mathrm{Src}^{527 \mathrm{~F}}$ and chimeric constructs. Twenty-five $\mu \mathrm{g}$ of CEF cell lysates were resolved by $12 \%$ SDS PAGE, transferred to PVDF membrane, and probed with an antibody raised against an epitope in the amino terminus of HO-1 (StressGen). Results are representative of two independent experiments. 


\section{References}

[1] Brickell PM. Crit Rev Oncog 1992;3:401-46.

[2] Brownn MT, Cooper JA. Biochim Biophys Acta 1996;1287:121-49.

[3] Guappone AC, Flynn DC. Mol Cell Biochem 1997;175:243-52.

[4] Weng Z, Rickles RJ, Feng S, Richard S, Shaw AS, Schreiber SL, Brugge JS. Mol Cell Biol 1995;15:5627-34.

[5] Erikson E, Erikson RL. Virology 1983;130221-6.

[6] Kitamura N, Kitamura A, Toyoshima K, Hirayama Y, Yoshida, M Nature 1982;297:205-8.

[7] Sudol M, Kieswetter C, Zhao YH, Dorai T, Wang LH, Hanafusa H. Nucleic Acids Res 1988;16:9876.

[8] Kanner SB, Reynolds AB, Bines RR, Parsons JT. Proc Natl Acad Sci USA 1990;119:3328-32.

[9] Summy JM, Guapppone AC, Sudol M, Flynn DC. Oncogene 2000;19:155-160.

[10] Bixby JL, Jhabvala P. J Neuroscience 1993;13:3421-32.

[11] Gessler M, Barnekow A. Biosci Rep 1984;4:757-70.

[12] Horne WC, Neff L, Chatterjee D, Lomri A, Levy JB, Baron R. J Cell Biol 1992;119:1003-13.

[13] Sugawara K, Sugawara I, Sukegawa J, Akatsuka T, Yamamoto T, Morita M, Mori S, Toyoshima K. Br J Cancer 1991;63:508-13.

[14] Zhao Y, Krueger JG, Sudol M. Oncogene 1990;5:1629-35.

[15] Gentry LE, Rohrschneider LR. J Virol 1984;51:539-46.

[16] Loeb DM, Woolford J, Beemon K. J Virol 1987;61:2420-7.

[17] Sudol M, Alvarez-Buylla A, Hanafusa H. Onc Res 1988;2:345-55.

[18] Tsukita SA, Oishi K, Akiyama T, Yamanashi Y, Yamamoto T, Tsukita SH. J Cell

Biol 1991;113-867-79.

[19] Stein PL, Vogel H, Soriano P. Genes Dev 1994;8:1999-2007.

[20] Resh MD. Cell 1994;76:411-3.

[21] Brown DA, London E. Biochem Biophys Res Commun 1997;240:1-7.

[22] Shaw AS, Amrein KE, Hammond C, Stern DF, Sefton BM, Rose JK. Cell 1989;59:627-36.

[23] Gervais FG, Veillette A. Mol Cell Biol 1995;15:2393-401.

[24] Ng DH, Watts JD, Aebersold R, Johnson P. J Biol Chem 1996;271:1295-300.

[25] Bijlmakers MJ, Isobe-Nakamura M, Ruddock LJ, Marsh M. J Cell Biol 1997; 137:1029-40.

[26] Barnekow A, Bauer H. Biochim Biophys Acta 1984;782:94-102.

[27] Boyce BF, Yoneda T, Lowe C, Soriano P, Mundy GR. J Clin Invest 1992;90:16227.

[28] Insogna KL, Sahni M, Grey AB, Tanaka S, Horne WC, Neff L, Mitnick M, Levy JB, Baron R. J Clin Invest 1997;100:2476-85.

[29] Kaplan KB, Bibbins KB, Swedlow JR, Arnaud M, Morgan DO, Varmus HE. EMBO J 1994;13:4745-56. 
[30] Luton F, Verges M, Vaerman J-P, Sudol M, Mostov KE. Mol Cell 1999;4:627-32.

[31] Liang P, Pardee AB. Science 1992;257:967-71.

[32] Liang P, Zhu W, Zhang X, Guo Z, O'Connell RP, Averbouck L, Wang F, Pardee AB. Nucleic Acids Res 1994;22:5763-4.

[33] Stone B, Wharton W. Nucleic Acids Res 1994;22:2612-8.

[34] Altschul SF, Madden TL, Schaffer AA, Zhang J, Zhang Z, Miller W, Lipman DJ. Nucleic Acids Res 1997;25:3389-402.

[35] Evans CO, Healey JF, Greene Y, Bonkovsky HL. Biochem J 1991;273:659-66.

[36] Mukhopadhyay D, Tsiokas L, Zhou X-M, Foster D, Brugge JS, Sukhatme VP. Nature 1995;375:577-81.

[37] Seko Y, Tobe K, Takahashi N, Kaburagi Y, Kadowaki T, Yazaki Y. Biochem Biophys Res Commun 1996;226:530-5.

[38] Maines MD. Ann Rev Pharm Tox 1997;37:517-54.

[39] Jiang B-H, Agani F, Passaniti A, Semenza GL. Cancer Res 1997;57:5328-35.

[40] Lee PJ, Jiang B-H, Chin BY, Iyer NV, Alam J, Semenza GL, Choi AM. J Biol Chem 1997;272:5375-81.

[41] Hartsfield CL, Alam J, Choi AM. Am J Physiol 1999;277:L1133-41.

[42] Masuya Y, Hioki K, Tokunaga R, Taketani S. J Biochem 1998;124:628-33.

[43] Seko Y, Takahashi N, Sabe H, Tobe K, Kadowaki T, Nagai R. Biochem Biophys Res Commun 1999;262:290-6.

[44] Koong AC, Chen EY, Mivechi NF, Denko NC, Stambrook P, Giaccia AJ. Cancer Res 1994;54:5273-9.

[45] Seko Y, Yakahashi N, Tobe K, Kadowaki T, Yazaki Y. Bioxhem Biophys Res Commun 1997;239:840-4.

[46] Birchenall-Roberts MC, Ruscetti FW, Kasper J, Lee HD, Friedman R, Geiser A, Sporn MB, Roberts AB, Kim SJ. Mol Cell Biol 1990;4978-83.

[47] Numazawa S, Yamada H, Furusho A, Nakahara T, Oguro T, Yoshida T. Exp Cell Res 1997;237:434-44. 


\section{Chapter 4}

The c-Yes Amino Terminal SH4 and Unique Domains Prevent Actin Filament Rearrangement and Phosphatidylinositol-3-Kinase Activation by $\mathrm{Src}^{527 \mathrm{~F}} / \mathrm{c}-\mathrm{Yes}$ Chimeric Proteins.

Justin M. Summy ${ }^{1}$, Bing-Hua Jiang ${ }^{1}$, and Daniel C. Flynn ${ }^{1}$

${ }^{1}$ Dept. of Microbiology, Immunology, and Cell Biology and Mary Babb Randolph Cancer Center.

West Virginia University School of Medicine. PO Box 9300. Morgantown WV 26506. 


\begin{abstract}
c-Src and c-Yes are highly homologous members of the Src family of nonreceptor tyrosine kinases. The sequence similarity between c-Src and c-Yes allows them to perform overlapping functions. However, the phenotypes of the c-src and c-yes knockout mice, and cells derived from them, are quite different, suggesting functional specificity between the two proteins. In particular, c-src -/- cells are deficient in several processes that require dynamic regulation of the actin cytoskeleton. In order to begin to understand why c-Yes is unable to compensate for c-Src in the regulation of the actin cytoskeleton, we have utilized a series of Src/Yes chimeras in which the non-catalytic functional domains of $\mathrm{Src}^{527 \mathrm{~F}}$ were replaced by those of c-Yes. Using $\mathrm{Src}^{527 \mathrm{~F}}$-induced chicken embryo fibroblast (CEF) cytoskeletal rearrangements as a model system, our results indicate that the c-Yes amino terminus, including the $\mathrm{SH} 4$ and Unique domains, is sufficient to inhibit the ability of $\operatorname{Src}^{527 \mathrm{~F}}$ to alter cell morphology and induce actin filament rearrangements. Furthermore, we have found that the inability of chimeric proteins with the c-Yes amino terminus to induce the cytoskeletal rearrangements and changes in cell morphology that occur concomitant with cell transformation correlates with an inability to induce activation of the downstream Src effector, phosphatidylinositol-3-kinase (PI3K).
\end{abstract}




\section{Introduction}

The Src family of non-receptor tyrosine kinases is composed of nine members: cSrc, c-Yes, Fyn, Lyn, Lck, Hck, Blk, Fgr, and Yrk. Src family kinases make important contributions to a variety of cellular signal transduction pathways, including those that govern such diverse processes as cell division, differentiation, survival, motility, and vesicular trafficking (Thomas and Brugge, 1997). Members of the Src family are defined by their amino acid homology and functional domain architecture. All Src family members are comprised of an amino-terminal membrane-localization domain (Src Homology 4 or SH4 domain), a poorly conserved Unique domain, an SH3 domain, an SH2 domain, a tyrosine kinase or SH1 domain, and a short carboxy-terminal regulatory sequence (Thomas and Brugge, 1997). c-Src and c-Yes are two of the most ubiquitously expressed and highly homologous members of the Src family (Sudol and Hanafusa, 1986; Sudol et al., 1988; Zhao et al., 1990; Sugawara et al., 1991), sharing over 80\% homology outside of their Unique domains (Kitamura et al., 1982).

Given the high homology between these two kinases and their widely overlapping tissue distributions, it is of little surprise that they are capable of performing redundant functions. c-Src and c-Yes are both activated downstream of a variety of cell surface receptors, including receptor tyrosine kinases, G-protein-coupled receptors, and cytokine receptors (Kypta et al., 1990; Courtneidge et al., 1993; Waltenberger et al., 1994; Muthuswamy and Muller, 1995; Landgren et al., 1995; Fuhrer and Yang, 1996a). Additionally, both kinases are activated during the cell cycle transition from G2 to M phase. Roche et al. provided strong evidence for functional overlap between c-Src, cYes, and Fyn, in demonstrating that inhibition of all three Src family kinases blocked cell 
cycle progression at the G2/M transition (Roche et al., 1995). Inhibition of c-Src alone did not block cell cycle progression unless c-Src was the only Src family member expressed (Roche et al., 1995). Further evidence for functional redundancy between cSrc and c-Yes has been derived from the c-src and c-yes knockout mice. While the loss of neither gene individually is embryonic lethal, mice lacking both genes fail to survive after birth (Stein et al., 1994).

Despite the evidence for functional overlap, several studies have also indicated specificity between c-Src and c-Yes. The two kinases differ in their sub-cellular localization (Sargiacomo et al., 1993; Zhao et al., 1993; Arreaza et al., 1994; CiesielskiTreska et al., 1995), intermolecular binding partners (Fuhrer and Yang, 1996b; Kamei et al., 1997; Feshchenko et al., 1998; Tang et al., 2000), activation in response to cellular stimulation (Schieven et al., 1992; Zhao et al., 1993; Mukhopadhyay et al., 1995; Park and Cartwright, 1995; Marchetti et al., 1998; Tsygankova et al., 1998), and ability to mediate downstream signaling (Schieffer et al., 1996; Kovacic et al., 1998).

The inactivation of the c-src and c-yes genes has provided the most compelling evidence for functional specificity. The c-yes -/- mice display no overt phenotype, however, mice lacking the c-src gene develop osteopetrosis due to an inability of the osteoclasts to reabsorb bone (Soriano et al., 1991). The only observed deficiency in cells from c-yes -/- mice is reduced efficiency in transcytosis of the polyimmunoglobulin (pIg) receptor (Luton et al., 1999). Cells from c-src -/- mice display a host of deficiencies, including inefficient motility (Hall et al., 1996), fibroblast spreading (Kaplan et al., 1995), neurite extension (Ignelzi, Jr. et al., 1994), and formation of membrane ruffles and actin ring structures in osteoclasts (Boyce et al., 1992). Additionally, induction of 
mammary tumors by middle T antigen is impaired in c-src-/- cells, whereas tumor formation occurs normally in c-yes -/- mice (Guy et al., 1994). A common feature of the cellular processes mentioned above is their shared requirement for dynamic regulation of the actin cytoskeleton. Given that c-Yes is present in c-src-/- cells, we hypothesize that c-Yes is unable to compensate for c-Src in signaling pathways that control these cytoskeletal processes as a result of functional domain differences between the two proteins.

Each functional domain may contribute to signaling specificity between c-Src and c-Yes, and functional domain specificity may result from subtle differences in amino acid composition. Previous studies have indicated minor differences in the ligand specificity of the c-Src and c-Yes SH3 domains in vitro (Rickles et al., 1995; Sparks et al., 1996). Data obtained in our laboratory indicate that the c-Yes SH3 domain is incapable of efficiently binding several c-Src SH3 domain binding partners, including the actin filament associated protein AFAP-110 (Summy et al., 2000 and unpublished data). In contrast to the SH3 domain, little data exists to suggest specificity between c-Src and cYes, or other Src family members, at the level of the SH2 domain. However, we recently demonstrated co-immunoprecipitation of an $87 \mathrm{kDa}$ tyrosine-phosphorylated protein (pp87) with $\mathrm{Src}^{527 \mathrm{~F}} / \mathrm{c}-$ Yes chimeras containing the c-Yes SH2 domain, indicating that specificity between the two kinases may also be derived from $\mathrm{SH} 2$ domain differences (Summy et al., 2000).

Several recent studies have pointed to the role of the Src family amino terminus in dictating signaling specificity. All Src family members with the exception of c-Src and Blk contain one or more cysteine residues downstream of the myristoylated glycine 
residue at amino acid position two (Resh, 1994). These cysteine residues are sites of palmitoylation, and incorporation of one or more palmitate residues facilitates localization to detergent-resistant membrane fractions, also known as lipid rafts (ShenoyScaria et al., 1994; Resh, 1994; Robbins et al., 1995). Localization to lipid rafts is important for Src family kinase participation in Fce receptor and $\mathrm{T}$ cell receptor signaling (Kabouridis et al., 1997; Honda et al., 2000; Suzuki et al., 2000). Hoey et al. recently demonstrated that replacement of the $\mathrm{Src}^{527 \mathrm{~F}}$ amino terminus (including the SH4 and Unique domains) with that of c-Yes prevented upregulation of heme oxygenase 1 (HO-1) message and protein (Hoey et al., 2000). Thus it is evident that multiple functional domains may contribute to specificity in signaling, and hence function, between c-Src and c-Yes. In the present study, we have sought to gain a better understanding of why cYes is unable compensate for c-Src in the dynamic regulation of the actin cytoskeleton. In order to accomplish this, we have replaced the non-catalytic functional domains of $\mathrm{Src}^{527 \mathrm{~F}}$ with those of c-Yes and assessed the ability of the resulting chimeras to induce the morphological and cytoskeletal changes associated with overexpression of constitutively active c-Src. 


\section{Materials and Methods}

\section{Plasmids}

cDNA constructs encoding LA29 v-Src, c-Src, Src ${ }^{527 F}, Y 3^{527 F}, Y 2^{527 F}, Y 32^{527 F}$, Y4U32 $2^{527 F}, Y 4 U^{527 F}, Y 4^{527 F}$, and $\mathrm{YU}^{527 \mathrm{~F}}$ were generated within the Rous Sarcoma Virus (RSV) as described previously (Felice et al., 1990; Hoey et al., 2000; Summy et al., 2000).

\section{Cells}

Chicken embryo fibroblasts (CEF) were prepared as described previously from day 10 eggs (Spafas) (Flynn et al., 1993). Cells were passed 1:4 every 48 hours in Falcon $100 \mathrm{~mm}$ tissue culture dishes or Falcon $250 \mathrm{ml}$ vented-cap tissue culture flasks. CEF were transfected at one half confluence with $15 \mu \mathrm{g}$ of plasmid DNA using the Clontech Calphos kit, as per the protocol. Confluent cells were viewed through a Nikon Phase Contrast II microscope at 40x total magnification (Plan 2 filter) and photographed with a Nikon N 2000 camera using Kodak TMax 400 black and white film.

\section{Antibodies}

The rabbit polyclonal anti-Src antibody was raised against an epitope in the Src carboxy-terminus as described previously (Summy et al., 2000). This antibody was used at a 1:1000 dilution for western blot analysis. The anti-phosphotyrosine antibody was obtained from BD Transduction and was used at a 1:1000 dilution for western blot analysis. The rabbit anti-phospho- $\mathrm{Y}^{416}$ was obtained from Upstate Biotechnology and used at a dilution of 1:1000. The anti-Shc antibody is a rabbit polyclonal antibody commercially available from BD Transduction. It was used at a 1:1000 dilution for western blot analysis and a 1:200 dilution for immunoprecipitation. The anti-Grb2 
antibody was obtained from BD Transduction and used at a 1:5000 dilution for western blot analysis. The anti-phospho-c-Raf antibody was obtained from Biosource International. It recognizes c-Raf phosphorylated on tyrosines 340 and 341. It was used at a 1:1000 dilution for western blot analysis. The rabbit anti-c-Raf-1 antibody was obtained from BD Transduction. It was used at a 1:1000 dilution for western blot analysis. The monoclonal anti-phospho-MAP kinase antibody was obtained from Upstate Biotechnology. It is reactive against Erk 1 and Erk 2 phosphorylated at the pTE-pY motif and was used at a dilution of 1:1000 for western blot analysis. The monoclonal anti-MAP kinase antibody was obtained from Upstate Biotechnology. This antibody recognizes Erk 1 and 2 and was used at a 1:1000 dilution for western blot analysis. The rabbit anti-phospho-Akt antibody was obtained from Upstate Biotechnology. This antibody recognizes Akt1 phosphorylated at threonine 308. This antibody was used at a 1:1000 dilution for western blot analysis. The monoclonal antiAkt antibody was obtained from BD Transduction and used at a 1:500 dilution for western blot analysis. The rabbit anti-rat PI3K p85 antibody was obtained from Upstate Biotechnology and used at a dilution of 1:1000 for western blot analysis and 1:50 for immunoprecipitation. Anti-rabbit and anti-mouse horseradish peroxidase-conjugated secondary antibodies were obtained from Amersham Life Science and used at a dilution of $1: 1000$.

\section{Immunofluorescence}

Immunofluorescence was carried out as described previously (Qian et al., 1998). Briefly, CEF were split onto cover slips and fixed in 3.7\% formaldehyde at $50 \%$ confluence. The cells were washed three times in PBS, permeablized in $0.4 \%$ Triton X- 
100, washed, and stained with rhodamine-conjugated phalloidin $(2 \mu \mathrm{g} / \mu \mathrm{l}$ in $5 \%$

BSA/PBS). Cells were stained for 20 min, washed three times in PBS, and mounted on cover slips using Flouromount G (Southern Biotechnology Associates Inc). Cells were visualized using a Zeiss LSM 510 confocal microscope (63x objective).

\section{Western blot analysis}

Cells were lysed at confluence in RIPA buffer as described previously (Hoey et al., 2000). Cell lysates were quantitated for total protein content using the Pierce BCA assay as per the protocol. Thirty or fifty $\mu \mathrm{g}$ of cell lysates were boiled in Laemmli's sample buffer (LSB) and resolved by $8 \%$ SDS PAGE. The proteins were transferred to PVDF membrane and washed as described previously (Hoey et al., 2000). The membranes were blocked overnight in 1\% BSA formulated in Tris buffered saline with $1 \%$ Tween 20 (TBS-T) at $4^{\circ} \mathrm{C}$ or $5 \%$ non-fat milk in TBS-T for $30 \mathrm{~min}$ at room temperature. The membranes were probed with primary antibody (diluted in TBS-T) for 1 hour at room temperature or overnight in $5 \%$ milk/TBS-T at $4{ }^{\circ} \mathrm{C}$. Secondary antibodies were applied for 45 min in TBS-T. Bound antibodies were visualized by incubation with ECL reagents (Amersham Pharmacia), followed by X-ray film (Kodak) exposure (Hoey et al., 2000). Quantitation of western blots was performed using the Stratgene Eagle Eye II scanning densitometry software.

\section{Immunoprecipitation}

Five hundred $\mu \mathrm{g}$ of RIPA lysates were incubated with antibody for $1.5 \mathrm{hr}$ at $4^{\circ} \mathrm{C}$ with rotating. Twenty $\mu 1$ of Protein A/G agarose (Santa Cruz) was added for an additional $1.5 \mathrm{hr}$ at $4^{\circ} \mathrm{C}$ with rotation. The beads were centrifuged for $30 \mathrm{~s}$ at room temperature, followed by two washes in RIPA and two washes in TBS. Bound proteins 
were eluted by boiling in LSB and resolved by SDS-PAGE. Western blot analysis was carried out as described above.

\section{Cell Fractionation}

Cells were fractionated into membrane and cytosolic fractions as described previously (Resh and Erikson, 1985). Briefly, cells were rinsed twice with STE buffer (150 mM NaCl, $50 \mathrm{mM}$ Tris, 1mM EDTA, $\mathrm{pH}$ 7.2). Cells were scraped off in STE buffer using a rubber policeman and collected by low speed centrifugation. Cells were then resuspended in $800 \mu \mathrm{l} / 100 \mathrm{~mm}$ dish hypotonic buffer $(10 \mathrm{mM}$ Tris, $0.2 \mathrm{mM} \mathrm{MgCl}$ ) and lysed with a Dounce homogenizer. The homogenate was adjusted to $0.2 \mathrm{mM}$ sucrose and $1 \mathrm{mM}$ EDTA and spun at $1000 \mathrm{~g}$ for $10 \mathrm{~min}$ at $4^{\circ} \mathrm{C}$. The supernatant was removed and saved, and the pellet was resuspended in $0.25 \mathrm{M}$ sucrose, $1 \mathrm{mM}$ EDTA, $10 \mathrm{mM}$ Tris, $\mathrm{pH}$ 7.4 via Dounce homogenization. The homogenate was re-spun at $1000 \mathrm{~g}$ for $10 \mathrm{~min}$, and the supernatant was removed and pooled with that of the previous spin. The supernatants were then spun at $100,000 \mathrm{~g}$ for $30 \mathrm{~min}$ at $4^{\circ} \mathrm{C}$, separating the cellular material into cytosolic (S100 or supernatant) and membranous (P100 or pellet) fractions.

Cells were also separated into triton X-100 soluble and insoluble fractions as described previously (Hamaguchi and Hanafusa, 1987). Briefly, cells were washed twice with cold Tris buffered saline. Cells were then incubated with $1 \mathrm{ml}$ of cold CSK buffer (10 mM Pipes, ph 6.8, $100 \mathrm{mM} \mathrm{KCl,} 2.5 \mathrm{mM} \mathrm{MgCl} 2,1 \mathrm{mM} \mathrm{CaCl}_{2}, 0.3 \mathrm{M}$ sucrose, $1 \mathrm{mM}$ phenylmethylsulfonyl fluoride, $1 \mathrm{mM} \mathrm{Na}_{3} \mathrm{VO}_{4}, 1 \%$ triton $\mathrm{X}-100$ ) on ice with gentle rocking for 1,4 , or $10 \mathrm{~min}$. The soluble material was removed, and the remaining material was solubilized in $1 \mathrm{ml}$ of RIPA buffer as described previously. Lysates were clarified by 5 min centrifugation at $10,000 \mathrm{rpm}$ and $4^{\circ} \mathrm{C}$ in a Hermle Z $360 \mathrm{~K}$ bench-top 
centrifuge, and supernatants were quantitated for total protein content. Samples were prepared for western blot analysis as described above. Triton-soluble fractions were equilibrated to RIPA by addition of $1 \%$ sodium deoxycholate and $10 \mathrm{mM}$ Tris- $\mathrm{HCl}, \mathrm{pH}$ 8.0 prior to protein quantitation.

\section{PI3 Kinase Assay}

The PI3K assay was performed as described elsewhere (Jiang et al., 1998). Briefly, CEF were scraped from tissue culture flasks in cold PBS and pelleted at 1000 $\mathrm{rpm}$ and $4^{\circ} \mathrm{C}$ for $5 \mathrm{~min}$ in a Sorvall RT6000B bench-top centrifuge. Cells were then lysed and total protein concentration was determined. Four hundred $\mu \mathrm{g}$ of lysate were pre-cleared with $20 \mu \mathrm{l}$ of Protein $\mathrm{A} / \mathrm{G}$ agarose for $1 \mathrm{hr}$ at $4^{\circ} \mathrm{C}$. Lysates were immunoprecipitated with $2 \mu \mathrm{l}$ of anti-PI3K antibody for $1 \mathrm{hr}$ at $4{ }^{\circ} \mathrm{C}$. Twenty-five $\mu \mathrm{l}$ of protein $\mathrm{A} / \mathrm{G}$ agarose beads were added and incubated with rotation for an additional $1 \mathrm{hr}$ at $4^{\circ} \mathrm{C}$. The immunoprecipitations were washed with TNE buffer $(20 \mathrm{mM}$ Tris, $\mathrm{pH} 7.5$, $100 \mathrm{mM} \mathrm{NaCl}, 1 \mathrm{mM}$ EDTA), centrifuged, and the pellet was then resuspended in $50 \mu 1$ of PI3K assay buffer (20 mM Hepes pH7.5, $10 \mathrm{mM} \mathrm{MgCl}_{2}, 0.2 \mathrm{mg} / \mathrm{ml}$ phosphoinositol, $60 \mu \mathrm{M}$ ATP, $\left.2 \mu \mathrm{Ci}\left[\gamma_{-}{ }^{32} \mathrm{P}\right] \mathrm{ATP}\right)$. The reactions were incubated at room temperature for $15 \mathrm{~min}$. Following the reaction, the products were extracted by addition of $80 \mu \mathrm{l} 1 \mathrm{M} \mathrm{HCl}$ and $160 \mu \mathrm{l}$ chloroform/methanol. The upper phase was removed, and the lower phase, containing the lipid products, was dried. The pellets were then resuspended in chloroform and spotted on thin layer chromatography (TLC) plates. Once the buffer front had migrated to the top of the plate, the plates were removed, dried, and exposed via phosphorimaging. 


\section{Results}

\section{Expression of Src ${ }^{527 F} / c$-Yes chimeric constructs in CEF}

Chicken embryo fibroblasts were transfected at 50\% confluence with RSV constructs expressing Src ${ }^{527 \mathrm{~F}}, \mathrm{Y}^{527 \mathrm{~F}}, \mathrm{Y}^{527 \mathrm{~F}}, \mathrm{Y} 32^{527 \mathrm{~F}}$, or $\mathrm{Y} 4 \mathrm{U} 32^{527 \mathrm{~F}}$ (Figure 1). After 10 days, cells were lysed in RIPA, $30 \mu \mathrm{g}$ of cell lysates were resolved by SDS-PAGE, and expression of the constructs was verified by western blot analysis using an anti-Src antibody, reactive against all chimeras, as described previously. As seen in Figure 2A, all constructs were expressed successfully in CEF (Figure 2A, bottom panel); however, the Y4U32 $2^{527 \mathrm{~F}}$ chimera was expressed at somewhat lower steady-state levels than $\mathrm{Src}^{527 \mathrm{~F}}$ or the other $\mathrm{Src}^{527 \mathrm{~F}} / \mathrm{c}-$ Yes chimeras. In order to assess the functionality of these constructs, steady-state levels of phosphotyrosine were assessed by western blot analysis with a polyclonal anti-phosphotyrosine antibody. As seen in Figure 2A, all of the constructs induced comparable levels of phosphotyrosine (Figure 2A, top panel), with the exception of Y4U32 $2^{527 F}$, which induced somewhat lower levels of phosphotyrosine. These blots were stripped and re-probed with an antibody that binds specifically to the phosphorylated form of tyrosine 416, the c-Src autophosphorylation site. Immunoreactivity with this antibody is used as an indicator of kinase activation. As seen in Figure 2A, all chimeras were immunoreactive with the anti-phospho- $\mathrm{Y}^{416}$ antibody, although, the Y4U32 $2^{527 \mathrm{~F}}$ construct displayed reduced immunoreactivity (Figure 2A, middle panel). However, the reduced immunoreactivity with anti-phospho- $\mathrm{Y}^{416}$ correlated with and was likely due to the reduced expression levels of this chimera, relative to the other constructs. Collectively, these data indicate that these constructs displayed equivalent in vivo catalytic activity 
The Y4U32 $2^{527 F}$ chimera does not induce morphological changes or rearrangement of cytoskeletal actin.

We hypothesized that differences in one or more of the functional domains were responsible for the inability of c-Yes to compensate for c-Src in regulation of cellular pathways controlling actin cytoskeletal dynamics. We chose the chicken embryo fibroblast as a model system in these studies, as CEF have a well-defined system of actin filament stress fibers that undergo a characteristic rearrangement upon overexpression of constitutively active Src. Transfected cells were evaluated for the Src-transformed phenotype, the hallmarks of which include a rounded morphology, the lack of a wellorganized monolayer, and an absence of contact-dependent inhibition of cell growth. As seen in Figure $2 \mathrm{~B}$, the $\mathrm{Y} 4 \mathrm{U} 32^{527 \mathrm{~F}}$ chimera failed to induce changes in cell morphology, as the morphology of these cells was difficult to distinguish from that of mock-transfected cells. Y $32^{527 \mathrm{~F}}$, however, induced morphological changes similar to those induced by $\mathrm{Src}^{527 \mathrm{~F}}$ (Figure 2B), as did $\mathrm{Y} 3^{527 \mathrm{~F}}$ and $\mathrm{Y} 2^{527 \mathrm{~F}}$ (data not shown).

The change in cell morphology induced by constitutively active Src occurs concomitant with rearrangement of the actin cytoskeletal structure. Src-transformed cells display a loss of actin stress fibers and focal adhesions, with the actin repositioning into rosettes, lamellipodia, and filopodia. In order to determine the effects of the c-Yes functional domains on the ability of $\mathrm{Src}^{527 \mathrm{~F}}$ to exert its influence on the actin-based cytoskeleton, cells were fixed on cover slips, stained with rhodamine-conjugated phalloidin, and visualized via confocal laser microscopy. As can be seen in Figure 2C, cells expressing $\mathrm{Src}^{527 \mathrm{~F}}$ appeared more rounded, and actin staining was present largely in punctate rosette structures or in actin-based motility structures such as lamellipodia or 
filopodia. Similar actin staining was detected in cells expressing each of the $\mathrm{Src}^{527 \mathrm{~F}} / \mathrm{c}-$ Yes chimeras, again with the exception of Y4U32 ${ }^{527 F}$ (Figure 2C). Cells expressing this construct retained long, well-organized actin stress fibers, comparable to those in nontransfected cells (Figure 2C). Additionally, in contrast to Src-transformed cells, the cells appeared elongated with intact focal adhesion structures.

\section{The c-Yes SH4 and Unique domains are sufficient for the ablation of morphological} and cytoskeletal changes induced by $\mathrm{Src}^{527 F}$.

These initial results indicated that $\mathrm{Src}^{527 \mathrm{~F}} / \mathrm{c}$-Yes chimeras with the c-Yes SH4, Unique, $\mathrm{SH}$, and $\mathrm{SH} 2$ domains were unable to induce the actin filament rearrangements that typically occur concomitant with Src-transformation. The next question we sought to address was which functional domain or domains were responsible for the inability of $\mathrm{Y} 4 \mathrm{U} 32^{527 \mathrm{~F}}$ to induce changes in the actin cytoskeleton. As the Y32 $2^{527 \mathrm{~F}}$ construct induced morphological changes similar to those of $\mathrm{Src}^{527 \mathrm{~F}}$, we hypothesized that the SH4 and/or Unique domains of c-Yes were responsible for the inability of $\mathrm{Y} 4 \mathrm{U} 32^{527 \mathrm{~F}}$ to induce changes in actin filament integrity. In order to determine if the c-Yes SH4 and Unique domains, either together or individually, were sufficient to prevent cytoskeletal and morphological changes, CEF were transfected with $\mathrm{Src}^{527 \mathrm{~F}} / \mathrm{c}-\mathrm{Y}$ es chimeras in which the SH4 and Unique domains ( $\left.\mathrm{Y}^{4} \mathrm{U}^{527 \mathrm{~F}}\right)$, the $\mathrm{SH} 4$ domain alone $\left(\mathrm{Y}^{527 \mathrm{~F}}\right)$, or the Unique domain alone $\left(\mathrm{YU}^{527 \mathrm{~F}}\right)$ of $\mathrm{Src}^{527 \mathrm{~F}}$ were replaced by those of c-Yes. Rabbit anti-Src western blot analysis was again used to verify expression of the chimeric constructs (Figure 3A). As seen in Figure 3B, replacement of either the $\mathrm{Src}^{527 \mathrm{~F}} \mathrm{SH} 4$ or Unique domain individually with the corresponding c-Yes domain did not affect the ability of $\mathrm{Src}^{527 \mathrm{~F}}$ to induce morphological changes as extensively as did replacement of both 
domains. Cells expressing $\mathrm{Y}^{527 \mathrm{~F}}$ and $\mathrm{YU}^{527 \mathrm{~F}}$ demonstrate a loss of contact-dependent inhibition of cell growth and a loss of organization of the monolayer, however, the morphological changes are not as dramatic as those induced by $\mathrm{Src}^{527 \mathrm{~F}}$ (Figure 3B). The $\mathrm{Y}_{4} \mathrm{U}^{527 \mathrm{~F}}$ chimera, however, did not induce significant morphological changes in CEF (Figure 3B). Y44 $\mathrm{U}^{527 \mathrm{~F}}$ transfectants grew into a confluent, well-organized monolayer and retained contact-dependent inhibition of cell growth. The ability of these chimeras to effect repositioning of actin to rosettes and motility structures was also assessed through immunofluorescent confocal microscopy. Cells were fixed on cover slips, and stained with rhodamine-conjugated phalloidin. In Figure 3C, it can be seen that cells transfected with the $\mathrm{Y}^{527 \mathrm{~F}}$ and $\mathrm{YU}^{527 \mathrm{~F}}$ constructs were more rounded and demonstrated actin staining in rosette structures, although they retained some actin stress fibers. In cells transfected with $\mathrm{Y}_{4} \mathrm{U}^{527 \mathrm{~F}}$, actin was predominantly present in stress fibers and along the plasma membrane (Figure 3C). These results indicate that while both the c-Yes SH4 and Unique domains contribute, neither domain alone is sufficient to completely ablate the ability of $\mathrm{Src}^{527 \mathrm{~F}}$ to induce morphological changes and effect the repositioning of actin from stress fibers to rosettes and membranous motility structures.

\section{$\mathrm{Src}^{527 F} / \mathrm{c}$-Yes amino terminal chimeras are associated with the triton-insoluble}

\section{cytoskeletal fraction.}

We next set out to address why $\mathrm{Src}^{527 \mathrm{~F}} / \mathrm{c}$-Yes amino terminal chimeras (including both the SH4 and Unique domains) were unable to induce changes in the actin-based cytoskeletal architecture. Although Y4U32 $2^{527 F}$ produced relative autophosphorylation and total cellular phosphotyrosine levels that approached those induced by $\operatorname{Src}^{527 \mathrm{~F}}$, the reduced steady-state expression levels of $\mathrm{Y} 4 \mathrm{U} 32^{527 \mathrm{~F}}$ were considered as a possible 
explanation for the lack of morphological or cytoskeletal changes associated with this chimera. However, we observed that steady-state levels of the Y4U32 $2^{527 \mathrm{~F}}$ chimera were higher than those of LA29 v-Src, a temperature-sensitive variant of v-Src that is transformation competent at the permissive temperature of $36^{\circ} \mathrm{C}$ but does not transform cells at $41^{\circ} \mathrm{C}$ (Poste and Flood, 1979) (Figure 4). Thus, reduced steady-state expression alone may not be sufficient to account for the inability of $Y 4 U 32^{527 \mathrm{~F}}$ to induce changes in the integrity of the actin cytoskeleton.

In order to investigate the mechanisms associated with the inability of Y4U32 $2^{527 \mathrm{~F}}$ and $\mathrm{Y}_{4} \mathrm{U}^{527 \mathrm{~F}}$ to alter actin filament integrity, we next examined the subcellular distribution of these chimeric proteins. One of the hallmarks of transformationcompetent variants of Src is that they are associated with cellular membranes via their SH4 domains. Fractionation of cells into membrane and cytosolic preps revealed that $\mathrm{Src}^{527 \mathrm{~F}}$ and all $\mathrm{Src}^{527 \mathrm{~F}} / \mathrm{c}$-Yes chimeras were associated predominantly with the membrane fraction (data not shown). Thus the inability of Y4U32 $2^{527 \mathrm{~F}}$ to induce cytoskeletal rearrangements is not due to an inability to localize with cellular membranes. Another feature of transformation-competent variants of Src is that they associate predominantly with the triton X-100 insoluble cytoskeletal fraction, whereas endogenous c-Src is primarily triton-soluble. Thus, in order to determine if $\mathrm{Src}^{527 \mathrm{~F}} / \mathrm{c}$-Yes amino terminal chimeras were able to associate with the triton-insoluble fraction, mock-transfected CEF or cells expressing c-Src, Src ${ }^{527 \mathrm{~F}}$, Y4U32 $2^{527 \mathrm{~F}}$, or $\mathrm{Y}_{4} \mathrm{U}^{527 \mathrm{~F}}$ were separated into tritonsoluble and triton-insoluble fractions. Both endogenous c-Src from mock-transfected cells and overexpressed c-Src displayed a shift in solubility from the triton insoluble fraction to the triton soluble fraction after four minutes of incubation in CSK buffer, 
whereas $\mathrm{Src}^{527 \mathrm{~F}}$ and $\mathrm{Y} 4 \mathrm{U} 32^{527 \mathrm{~F}}$ remained predominantly associated with the tritoninsoluble fraction, even after 10 minutes of incubation. Similar results were obtained with $\mathrm{Y}_{4} \mathrm{U}^{527 \mathrm{~F}}$ (data not shown). These results indicate that the inability of $\mathrm{Y} 4 \mathrm{U} 32^{527 \mathrm{~F}}$ to effect actin redistribution is not due to an inability of the protein to partition into the triton-insoluble cytoskeletal fraction.

\section{The c-Yes amino terminal region does not prevent activation of the MAP kinase pathway.}

The inability of $\mathrm{Src}^{527 \mathrm{~F}} / \mathrm{c}-$ Yes amino terminal chimeras to induce rearrangement of the actin cytoskeleton may likely be attributed to failure to activate one or more downstream pathways that are normally upregulated in response to oncogenic Src. Thus, we next investigated the activation status of signaling proteins that function downstream of Src. The proteins chosen in this study can broadly be classified into two distinct yet overlapping categories: those that are involved in the mitogenic response to Src activation and those that are involved in mediating the effects of Src on the actin-based cytoskeleton.

The MAP kinase pathway, as illustrated in Figure 6, is one of the most wellcharacterized pathways activated in response to Src and is involved in the induction of a mitogenic response (Gupta et al., 1992; Howe et al., 1992; Cowley et al., 1994;

Whitmarsh and Davis, 1996; Klein and Schneider, 1997). The first step in the activation of the MAP kinase pathway downstream of Src is the formation of stable complex between Shc and Grb2 (Rozakis-Adcock et al., 1992). Thus in order to assess the effects of the c-Yes amino terminus on the ability of Src to induce activation of the MAP kinase pathway, we first assayed complex formation between Shc and Grb2. CEF lysates were 
immunoprecipitated with an anti-Shc monoclonal antibody, and the immunoprecipitates were resolved by SDS-PAGE. Western blot analysis was performed using an anti-Grb2 monoclonal antibody. Blots were stripped and re-probed with the anti-Shc antibody to demonstrate that equal amounts of Shc were immunoprecipitated (Figure 7A, bottom panel). Minimal complex formation was detected between Shc and Grb2 in lysates from mock-transfected cells. Robust complex formation was detected between Shc and Grb2 in $\mathrm{Src}^{527 \mathrm{~F}}$-transformed cells (Figure 7A, top panel). Cells expressing Y4U32 ${ }^{527 \mathrm{~F}}$ displayed increased Shc/Grb2 complex formation over mock-transfected CEF (approximately 2.5 fold); however, levels were almost 2 -fold lower than those detected in Src-expressing cells (Figure 7A, top panel). Cells expressing Y4U ${ }^{527 F}$ displayed levels of Shc/Grb2 complex formation more closely approximating those induced by $\operatorname{Src}^{527 \mathrm{~F}}(1.2$ fold lower) (Figure 7A, top panel). Similar results were obtained when immunoprecipitating with the anti-Grb2 antibody and probing with the anti-Shc antibody (data not shown). These data indicate that the c-Yes amino terminus alone is not sufficient to abrogate Src-induced Grb2/Shc complex formation.

We next looked further downstream at c-Raf activation. c-Raf activation was assessed by western blot analysis using an antibody against the phosphorylated form of cRaf. CEF lysates from mock-transfected cells, or cells expressing Src ${ }^{527 F}, Y 4 U 32^{527 F}$, or $\mathrm{Y}_{4} \mathrm{U}^{527 \mathrm{~F}}$ were separated by SDS-PAGE, and western blots were probed with the antiphospho-Raf antibody. As seen in Figure 7B, no phosphorylation of c-Raf was detected in mock-transfected cells; however, lysates from cells expressing $\mathrm{Src}^{527 \mathrm{~F}}$ were strongly immunoreactive with the anti-phospho-Raf antibody (Figure 7B, top panel). Y4U32 $227 \mathrm{~F}$ lysates were weakly immunoreactive with the anti-phospho-Raf antibody in comparison 
to $\mathrm{Src}^{527 \mathrm{~F}}$; however, $\mathrm{Y}_{4 \mathrm{U}^{527 \mathrm{~F}}}$-induced c-Raf phosphorylation more closely approximated levels induced by $\mathrm{Src}^{527 \mathrm{~F}}$. (Figure 7B, top panel). Blots were additionally probed with an anti-c-Raf antibody in order to determine relative levels of c-Raf present in the cell lysates (Figure 7B, bottom panel). The markedly lower levels of phospho-c-Raf present in $\mathrm{Y} 4 \mathrm{U} 32^{527 \mathrm{~F}}$ lysates were somewhat surprising. We have, however, previously noted functional differences in the SH3 and SH2 domains of c-Src and c-Yes, and thus the reduced c-Raf activation induced by $\mathrm{Y} 4 \mathrm{U} 32^{527 \mathrm{~F}}$ may be due to one or both of these domains (Summy et al., 2000). Nevertheless, these results indicate that the c-Yes amino terminus alone is not sufficient to prevent the activation of c-Raf downstream of Src.

We next assessed the effects of the c-Yes amino terminus on the ability of Src to induce activation of the MAP kinases Erk 1/2. In order to assess the activation of Erk $1 / 2$, western blot analysis was performed on lysates from mock-transfected CEF or cells expressing $\mathrm{Src}^{527 \mathrm{~F}}$, $\mathrm{Y} 4 \mathrm{U} 32^{527 \mathrm{~F}}$, or $\mathrm{Y} 4 \mathrm{U}^{527 \mathrm{~F}}$ using an anti-phospho-ERK 1/2 antibody, immunoreactive against the activated forms of Erk 1 and 2. As seen in Figure 7C, $\mathrm{Src}^{527 \mathrm{~F}}, \mathrm{Y} 4 \mathrm{U} 32^{527 \mathrm{~F}}$, and $\mathrm{Y} 4 \mathrm{U}^{527 \mathrm{~F}}$ each induced significant Erk activation above levels detected in mock-transfected cells (Figure 7C, top panel). Western blots were additionally probed with an anti-MAP kinase antibody, specific for Erk 1/2, to ensure that equal levels of protein were present in the lysates (Figure 7C, bottom panel). These results indicate that the presence of the c-Yes amino terminus is insufficient to abrogate Erk activation downstream of $\mathrm{Src}^{527 \mathrm{~F}}$. Thus the inability of chimeric proteins with the cYes amino terminus to induce rearrangement of the actin cytoskeleton and changes in cellular morphology do not correlate with an inability to activate the MAP kinase pathway. 


\section{$\mathrm{Src}^{527 F} / \mathrm{c}$-Yes chimeras with the c-Yes amino terminus fail to activate the PI3K/Akt pathway.}

While many proteins are known to be important for Src-mediated actin filament rearrangement, the precise pathway that regulates this process has not been defined. Phosphatidylinositol-3-kinase (PI3K), a lipid and protein kinase named for its ability to phosphorylate the 3' hydroxyl group of inositol phospholipids, may potentially mediate the effects of Src on the actin cytoskeleton, as it functions downstream of Src and is known to be involved in actin filament rearrangements (Penuel and Martin, 1999; Krasilnikov, 2000; Odajima et al., 2000; Sohara et al., 2001). We first assessed the activation of PI3 kinase indirectly, using the activation state of Akt as an indicator of PI3 kinase activity. Akt is a ser/thr kinase that is activated downstream of PI3K and an important mediator of cellular survival signals (Krasilnikov, 2000). In order to evaluate Akt activation, western blot analysis was performed, using an antibody against the phosphorylated and active form of Akt, on lysates from cells that were mock-transfected

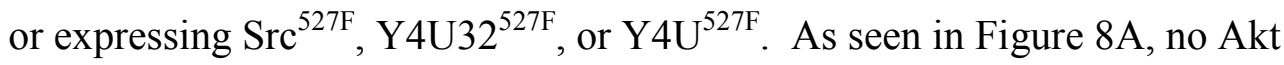
phosphorylation was detected in lysates of mock-transfected CEF; however, strong antiphospho-Akt immunoreactivity was detected in cell lysates expressing $\mathrm{Src}^{527 \mathrm{~F}}$ (Figure 8 A, top panel). Levels of anti-phospho-Akt reactivity from cells expressing Y4U32 $2^{527 F}$ or $\mathrm{Y}_{4} \mathrm{U}^{527 \mathrm{~F}}$ were only slightly higher than background (Figure $8 \mathrm{~A}$, top panel). These results indicate that the presence of the c-Yes amino terminus was sufficient to ablate the ability of $\mathrm{Src}^{527 \mathrm{~F}}$ to induce activation of Akt, presumably through PI3K. In order to directly assess the ability of these proteins to induce PI3 kinase activity, cell lysates were immunoprecipitated with an antibody against the $85 \mathrm{kDa}$ subunit of PI3K, and the 
immunoprecipitated proteins were subjected to a PI3 kinase assay. The radio-labeled kinase assay products were then spotted on thin layer chromatography plates for separation. The results were visualized using phosphorimager analysis. As can be seen in Figure 8B, little PI3 kinase activity was detected in lysates from mock-transfected cells, while PI3 kinase activity was readily detected in $\mathrm{Src}^{527 \mathrm{~F}}$-transfected cells (Figure 8B, top panel). Cells expressing Y4U32 ${ }^{527 F}$, however, displayed levels of PI3 kinase activity that were equivalent to background (Figure 8B, top panel). Western blot analysis of PI3K immunoprecipitates using an anti-PI3K p85 antibody revealed that equivalent amounts of PI3K were present (Figure 8B, bottom panel). These results indicate that Y4U $32^{527 F}$ is unable to induce activation of PI3K. Thus, the inability of this protein to induce the rearrangements of the actin cytoskeleton and the morphological changes that are characteristic of Src transformation may be due to an inability to activate PI3K. 


\section{Discussion}

c-Yes and c-Src are two of the most highly homologous members of the Src family of non-receptor tyrosine kinases, yet despite their significant similarity, specificity exists between the two proteins. The c-src and c-yes gene knockout mice and cells derived from them have proved useful in uncovering cellular processes and pathways in which these proteins function distinctly from one another. As mentioned above, several studies carried out in cells derived from the c-src -/- mice have indicated deficiencies in cellular processes that are dependent on dynamic regulation of the actin cytoskeleton. cYes, despite normal expression in these cells, is unable to compensate for c-Src in the regulation of these processes.

The experiments described in this report were undertaken in an effort to gain an understanding of the roles of the c-Yes functional domains in the apparent inability of cYes to regulate actin cytoskeletal rearrangements. In these experiments, the cytoskeletal and morphological changes that occur concomitantly with $\mathrm{Src}^{527 \mathrm{~F}}$-induced transformation of CEF were used as a model system. We discovered that replacement of the Src SH4, Unique, $\mathrm{SH} 3$, and $\mathrm{SH} 2$ domains with the corresponding c-Yes domains resulted in a loss of actin repositioning from stress fibers to punctate rosettes and actin-based membranous motility structures such as lamellipodia and filopodia. The inability to induce morphological and cytoskeletal changes was associated primarily with the c-Yes amino terminus ( $\mathrm{SH} 4$ and Unique domains), as the $\mathrm{Y} 32^{527 \mathrm{~F}}$ chimera was able to induce these phenotypic changes. However, replacement of the c-Src amino terminus with that of cYes eliminated the ability of $\mathrm{Src}^{527 \mathrm{~F}}$ to induce the phenotypic changes that are typically observed upon overexpression of the protein. 
Having identified the c-Yes amino terminus as the region responsible for the failure of these chimeric proteins to induce morphological and cytoskeletal changes, the focus shifts to the determination of why this is true. Failure to activate the appropriate signaling pathway or pathways would seem to be an obvious answer, but that raises the more difficult issue of identifying the pathway or pathways responsible. This is a particularly vexing issue, as there are many proteins that are important for Src-mediated actin filament rearrangement, and they do not necessarily act in one linear pathway. In fact, it is likely that the effectors of Src transformation act through multiple pathways, both parallel and overlapping.

One pathway that is activated downstream of Src and is essential for cell transformation by oncogenic Src is the MAP kinase pathway (Cowley et al., 1994). Erk 1/2 MAP kinases are activated downstream of Src through a pathway that can be initiated through Shc/Grb2 interaction (Rozakis-Adcock et al., 1992). Shc/Grb2 complex formation allows the Grb2/SOS complex to activate Ras, which is followed by activation of Raf, MEK1/2, and finally the MAP kinases themselves (Klein and Schneider, 1997). In these studies, the ability of $\mathrm{Src}^{527 \mathrm{~F}}$ to induce activation of the MAP kinase pathway was not ablated by the presence of the c-Yes amino terminus. Although Y4U32 $2^{527 \mathrm{~F}}$ did not induce the robust activation of members of the MAPK pathway that $\mathrm{Src}^{527 \mathrm{~F}}$ did, differences mediated by $\mathrm{Src}^{527 \mathrm{~F}}$ and $\mathrm{Y} 4 \mathrm{U}^{527 \mathrm{~F}}$ were less pronounced. The reduced levels of MAPK pathway activation induced by $\mathrm{Y} 4 \mathrm{U} 32^{527 \mathrm{~F}}$ may be due to the presence of the cYes SH3 and SH2 domains, which, as noted above, have been previously demonstrated to differ in their ligand-binding, and hence signaling, capacities (Sparks et al., 1996; Summy et al., 2000). While activation of MAP kinases are important for the mitogenic 
response to Src activation, the role that MAP kinase activation plays in rearrangement of the actin cytoskeleton downstream of Src is unclear. Fincham and colleagues demonstrated that inactivation of Rho, a key modulator of the actin cytoskeleton, downstream of Src may be independent of mitogenesis, thus indicating that separate pathways may be involved in inducing the cytoskeletal and mitogenic responses (Fincham et al., 1999).

PI3K is an important downstream mediator of Src and is involved in directing actin cytoskeletal rearrangements (Toker and Cantley, 1997; Penuel and Martin, 1999; Krasilnikov, 2000; Odajima et al., 2000; Sohara et al., 2001). It has been reported previously that PI3K may function in parallel with the MAP kinase pathway (Penuel and Martin, 1999; Susa et al., 2000; Odajima et al., 2000). The $85 \mathrm{kDa}$ subunit of PI3K is both a substrate and SH3 domain binding partner of Src, and the ability of Src to associate with PI3K correlates with its ability to induce cell transformation (Hamaguchi et al., 1993; Catling et al., 1994; Pleiman et al., 1994; Krasilnikov, 2000). Fincham et al. recently demonstrated that binding of the $\mathrm{v}$-Src $\mathrm{SH} 3$ domain to $\mathrm{PI} 3 \mathrm{~K}$ is important in targeting Src to focal adhesion structures (Fincham et al., 2000). The exact mechanism by which PI3K exerts its influence on the actin cytoskeleton remains unclear; however, it may be involved in the regulation of Rho family members, such as Rac-1, Cdc42, and RhoA (Reif et al., 1996). Preliminary data obtained in our laboratory indicate that $\mathrm{Src}^{527 \mathrm{~F}} / \mathrm{c}$-Yes amino terminal chimeras fail to inactivate, and in fact may induce activation of RhoA, which is responsible for formation of actin stress fibers (Summy and Qian, unpublished data). Additionally, activation of PI3K results in activation of the Ser/Thr kinase Akt (Krasilnikov, 2000). Akt activation contributes to cell survival and 
may also play a role in cell transformation (Krasilnikov, 2000). Our data indicate that $\mathrm{Src}^{527 \mathrm{~F}} / \mathrm{c}$-Yes amino terminal chimeras are incapable of efficiently inducing activation of Akt, as demonstrated by western blot analysis with the anti-phospho-Akt antibody. This result correlates with the inability of Y4U $32^{527 \mathrm{~F}}$ to induce activation of PI3K. We feel that the inability of $\mathrm{Src}^{527 \mathrm{~F}} / \mathrm{c}$-Yes amino terminal chimeras to activate the PI3K/Akt pathway may be responsible for their inability to induce actin filament rearrangement.

The investigation of one question invariably leads to the uncovering of another: in this case, why are $\mathrm{Src}^{527 \mathrm{~F}} / \mathrm{c}-$ Yes amino terminal chimeras unable to induce activation of PI3K? Traditionally, Src has been hypothesized to induce PI3K activation through direct binding and/or tyrosine phosphorylation (Pleiman et al., 1994; Krasilnikov, 2000). Binding of Src to PI3K occurs through an interaction between the Src SH3 domain and the $85 \mathrm{kDa}$ subunit of PI3K (Pleiman et al., 1994; Mak et al., 1996). Mutants of v-Src that fail to bind PI3K also fail to induce cell transformation (Catling et al., 1994). While there is no previous evidence of direct interaction between c-Yes and PI3K, there is little reason to believe that the c-Yes SH3 domain would be unable to bind to p85, as the SH3 domain residues that have been reported to be essential for p85 binding in other Src family members are conserved in c-Yes (Mak et al., 1996), and v-Yes is able to induce elevated PI3K activity (Fukui et al., 1991). Additionally, the $\mathrm{Y}^{4} \mathrm{U}^{527 \mathrm{~F}}$ chimera, which expresses the c-Src SH3 domain, was unable to induce efficient activation of Akt. This suggests that it is the c-Yes amino terminus itself that is responsible for the inability of these chimeras to induce activation of the PI3K/Akt pathway.

As mentioned above, the c-Yes amino terminus is composed of the $\mathrm{SH} 4$ and Unique domains. The c-Yes SH4 domain contains a palmitoylation site at Cys 3 that is 
not present in the c-Src SH4 domain (Resh, 1994). Palmitoylation is important for targeting Src family kinases to detergent-resistant membrane microdomains, or lipid rafts (Shenoy-Scaria et al., 1994; Resh, 1994; Robbins et al., 1995). It is possible that sequestration to the lipid raft fraction may be responsible for the inability of $\mathrm{Src}^{527 \mathrm{~F}} / \mathrm{c}-\mathrm{Yes}$ amino terminal chimeras to activate the PI3K pathway and thus induce morphological and cytoskeletal changes. This explanation would be in agreement with the ability of vYes to induce PI3K activation and cell transformation, as v-Yes is an N-terminal fusion of the Yes protein with the retroviral Gag protein and is not palmitoylated, relying instead on the Gag protein for membrane targeting (Ghysdael et al., 1981; Fukui et al., 1991). Raft localization cannot be the full explanation, however, as the palmitoylation site is sufficient for localization of Src family kinases to lipid rafts (Shenoy-Scaria et al., 1994), yet $\mathrm{Y}^{527 \mathrm{~F}}$ is able to induce actin filament rearrangement and morphological changes. It is possible that the Unique domain contributes to membrane compartmentalization, as occurs with Lck (Bijlmakers et al., 1997), or targets the kinase to proteins with which it would not normally interact. Conversely, the c-Yes Unique domain may prevent the interaction of $\mathrm{Src}^{527 \mathrm{~F}}$ with substrates or binding partners, such as PI3K, that are necessary for repositioning of cellular actin and induction of morphological changes. However, the ability of the $\mathrm{YU}^{527 \mathrm{~F}}$ chimera to induce actin filament rearrangement and morphological changes suggests that this is also not the complete story and that both the SH4 and Unique domains contribute to the inability of $\mathrm{Src}^{527 \mathrm{~F}} / \mathrm{c}-$ Yes amino terminal chimeras to induce morphological changes and actin filament rearrangement. The SH4 and Unique domains may act synergistically, both through sequestration to lipid raft fractions and through altered protein/protein and/or 
protein/substrate interactions. The function of the c-Yes Unique domain has not been previously explored.

It should also be noted that the inability of $\mathrm{Y} 4 \mathrm{U}^{527 \mathrm{~F}}$ and $\mathrm{Y} 4 \mathrm{U} 32^{527 \mathrm{~F}}$ to activate the PI3K/Akt pathway in CEF may be unrelated to direct interaction between the chimeric proteins and PI3K. Hakak et al. demonstrated that in Shp-2 knockout cells, the PI3K/Akt pathway was inefficiently activated by v-Src, and this correlated with reduced complex formation between $\mathrm{Cbl}$ and $\mathrm{p} 85$ (Hakak et al., 2000). The reason behind the

reduced activation of the PI3K/Akt pathway by $\mathrm{Src}^{527 \mathrm{~F}} / \mathrm{c}-$ Yes amino terminal chimeras is currently under investigation.

In summary, we have demonstrated that fully activated Src/Yes chimeras with the c-Yes amino terminus are unable to induce the cytoskeletal and morphological changes normally associated with expression of $\mathrm{Src}^{527 \mathrm{~F}}$ in CEF. The deficiency in actin cytoskeleton rearrangement correlates strongly with the inability of these chimeras to induce activation of the PI3K/Akt pathway. These results may provide insight into why c-Yes is unable to compensate for c-Src in the regulation of several cytoskeletal processes in c-Src knockout cells. Future studies, in which these chimeras are expressed in c-src-/-cells, may provide further insight into this problem.

\section{Acknowledgements}

The authors would like to thank Anne Guappone Koay for her invaluable technical assistance. This work was support by a grant from the NCI (CA60731) and a grant from the American Cancer Society (RPG-99-088-01-MBC) 


\section{$\mathrm{Src}^{527 \mathrm{~F}} / \mathrm{c}-$ Yes Chimeric Constructs}

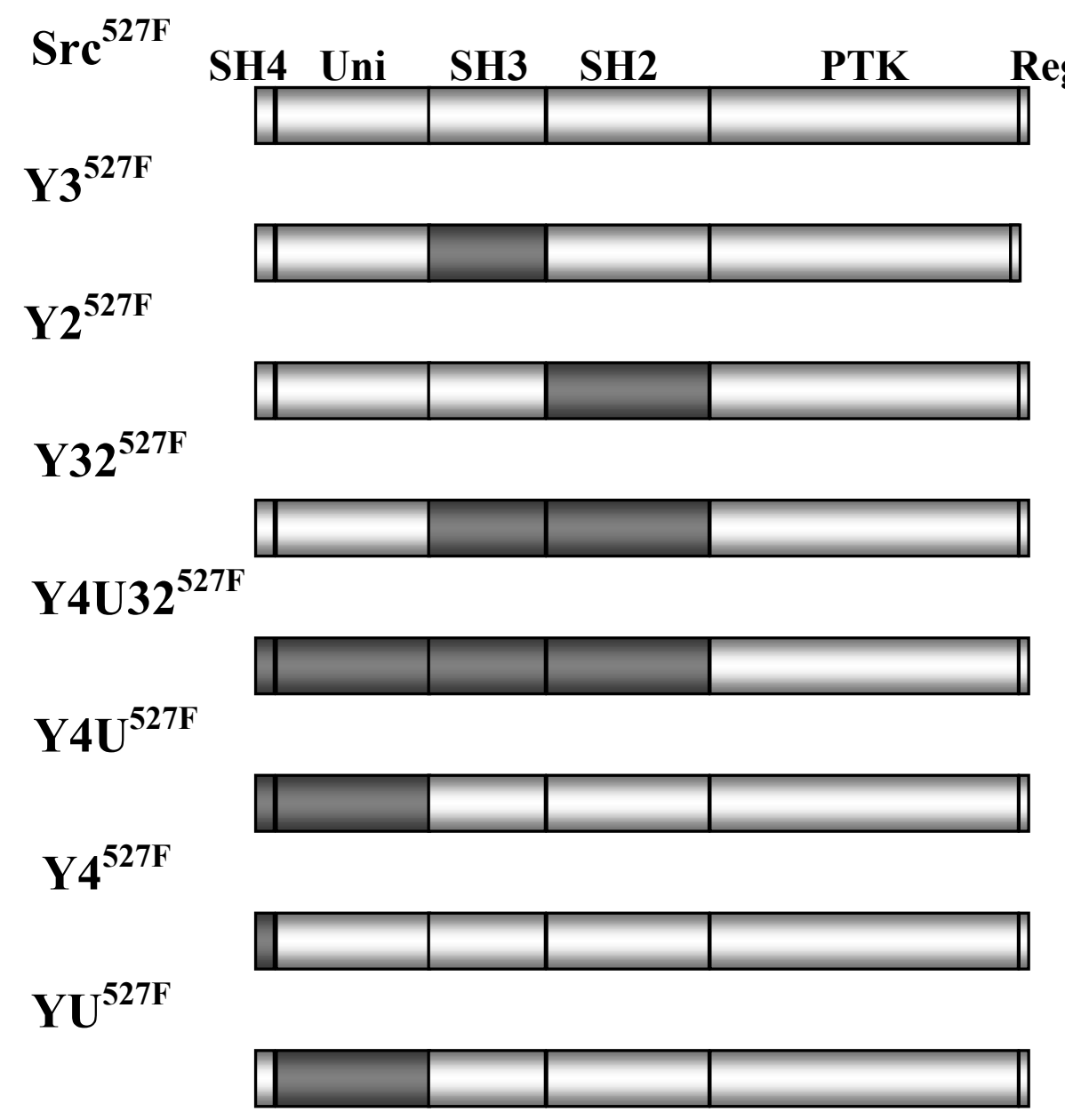

Figure 1. $\mathrm{Src}^{527 \mathrm{~F}} / \mathrm{c}$-Yes chimeric constructs. $\mathrm{Src}^{527 \mathrm{~F}} / \mathrm{c}$-Yes chimeras are depicted subdivided into the following functional domains: SH4 domain, Unique domain, SH3 domain, $\mathrm{SH} 2$ domain, protein tyrosine kinase domain, and regulatory sequence. Gray boxes represent domains from c-Yes; white boxes represent domains from $\mathrm{Src}^{527 F}$. The generation of the $\mathrm{Y}^{527 \mathrm{~F}}, \mathrm{Y}^{527 \mathrm{~F}}, \mathrm{Y} 32^{527 \mathrm{~F}}, \mathrm{Y} 4 \mathrm{U} 32^{527 \mathrm{~F}}, \mathrm{Y}_{4} \mathrm{U}^{527 \mathrm{~F}}, \mathrm{Y}^{527 \mathrm{~F}}$, and $\mathrm{YU}^{527 \mathrm{~F}}$ 
chimeric constructs was described previously. All proteins were expressed in CEF via the Rous Sarcoma Virus (RSV) vector. 
A

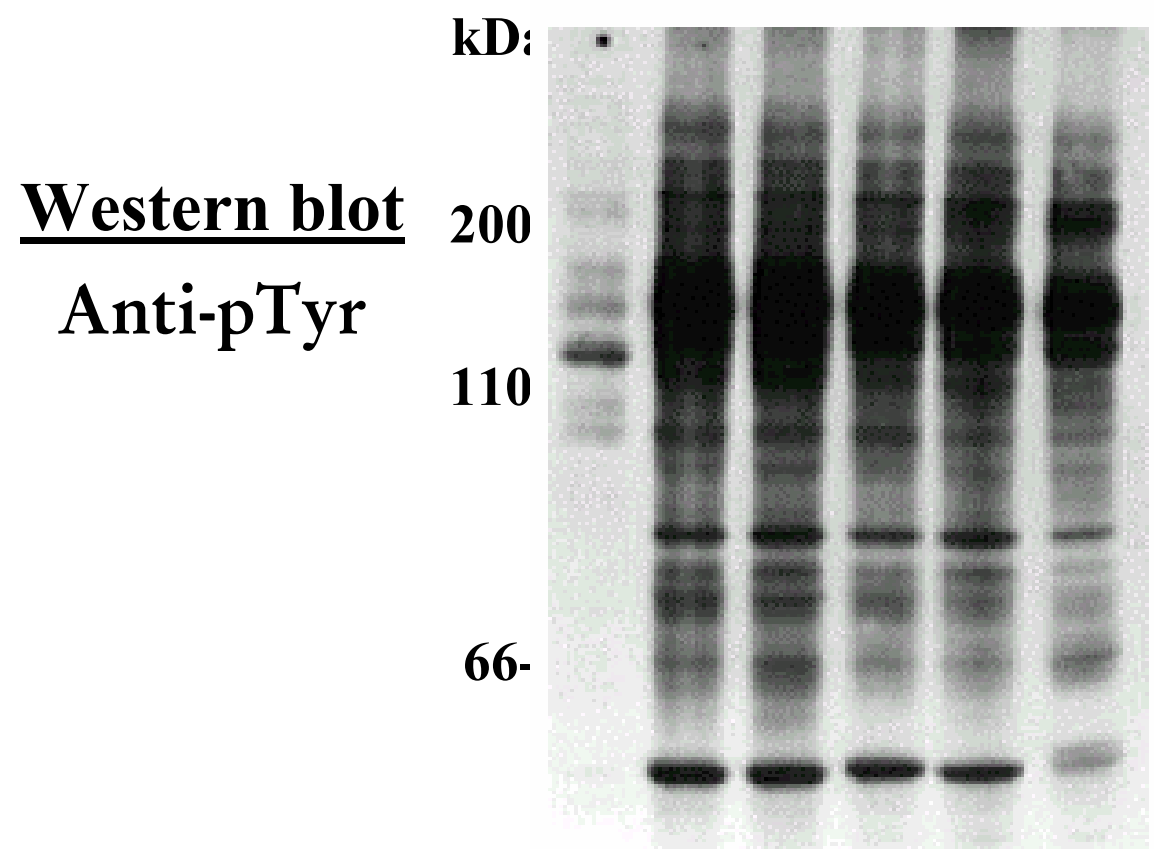

Anti-pY ${ }^{416}$

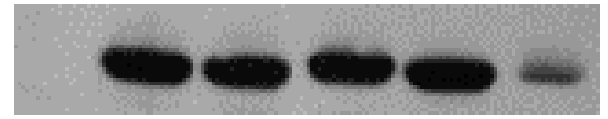

Anti-Src

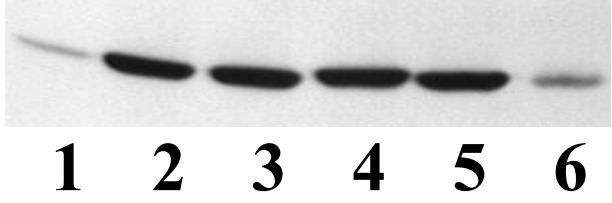


B
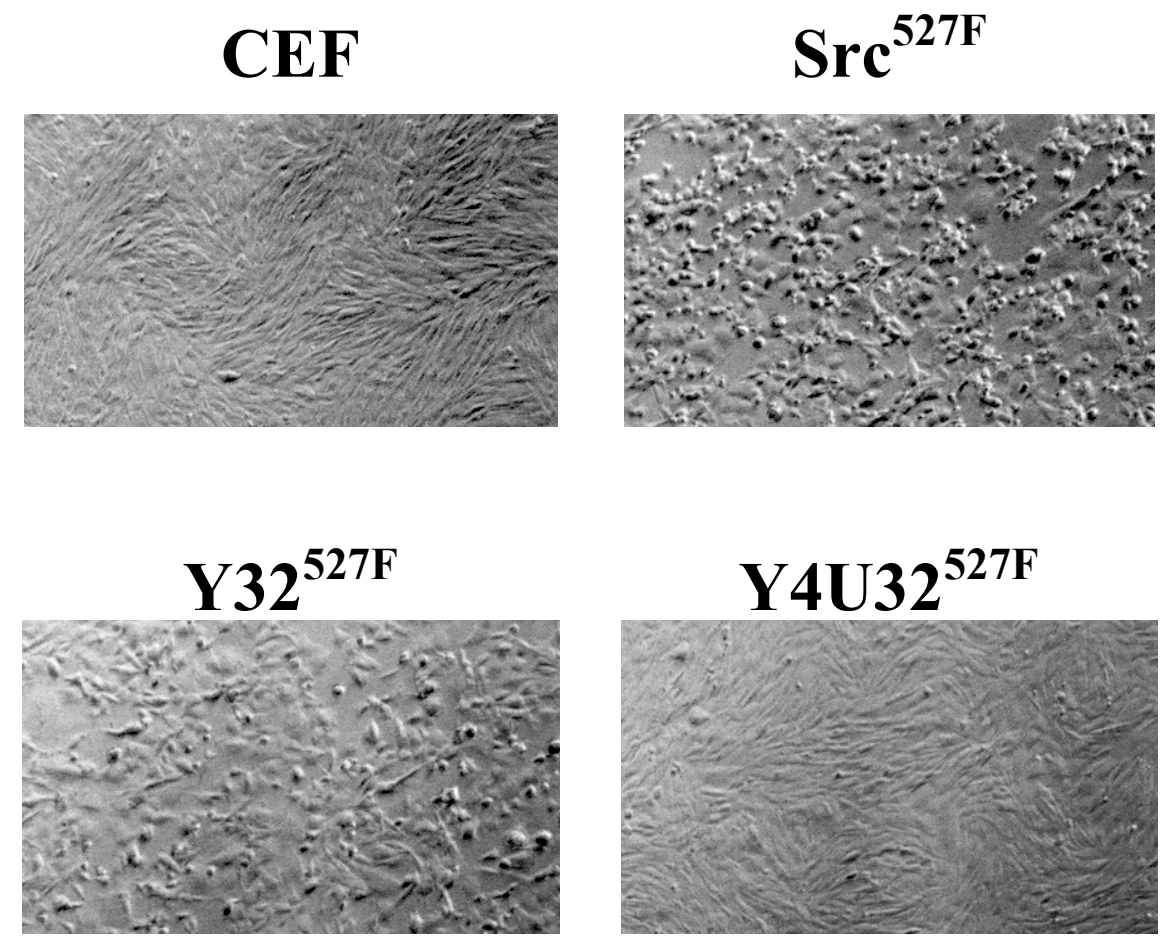

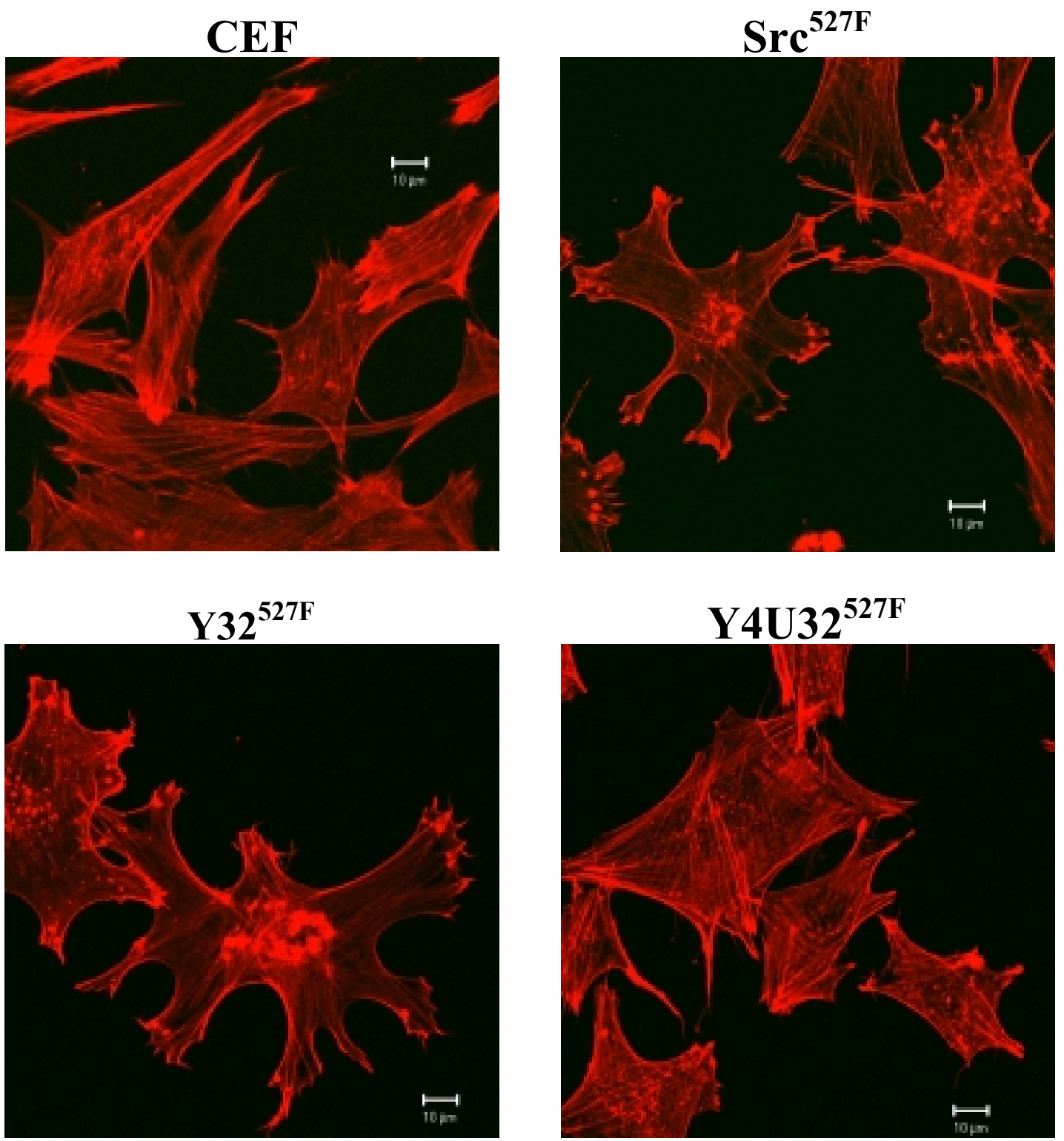

Figure 2. Effects of $\mathrm{Src}^{527 \mathrm{~F}} / \mathrm{c}-$ Yes chimeras on cellular phosphotyrosine, cell morphology, and the actin cytoskeleton. (A) Thirty $\mu$ g of day 12 RIPA lysates from mock-transfected CEF or cells expressing $\mathrm{Src}^{527 \mathrm{~F}}, \mathrm{Y}^{527 \mathrm{~F}}, \mathrm{Y} 2^{527 \mathrm{~F}}, \mathrm{Y} 32^{527 \mathrm{~F}}$, or Y4U32 $2^{527 \mathrm{~F}}$ were separated by $8 \%$ SDS PAGE. Lysates were transferred to PVDF membrane, 
blocked in $1 \% \mathrm{BSA}$, and probed with a rabbit anti-phosphotyrosine antibody (top panel), rabbit anti-phospho- $Y^{416}$ (middle panel), or rabbit anti-Src (bottom panel). Lane $1=$ $\mathrm{CEF}$; Lane $2=\mathrm{Src}^{527 \mathrm{~F}} ;$ Lane $3=\mathrm{Y} 3^{527 \mathrm{~F}} ;$ Lane $4=\mathrm{Y} 2^{527 \mathrm{~F}} ;$ Lane $5=\mathrm{Y} 32^{527 \mathrm{~F}} ;$ Lane $6=$ Y4U32 $2^{527 F}$. (B) Confluent CEF expressing Src ${ }^{527 F}, Y^{527 F}, Y^{527 F}, Y 32^{527 F}$, or Y4U32 $227 \mathrm{~F}$ were photographed at day 12 post-transfection in $100 \mathrm{~mm}$ tissue culture plates (Falcon). Cells were photographed at 40x total magnification using a Plan 2 filter. Mocktransfected CEF and cells expressing $\mathrm{Src}^{527 \mathrm{~F}}, \mathrm{Y} 32^{527 \mathrm{~F}}$, and $\mathrm{Y} 4 \mathrm{U} 32^{527 \mathrm{~F}}$ are shown. (C) Mock-transfected CEF and cells expressing Src ${ }^{527 \mathrm{~F}}, \mathrm{Y}^{527 \mathrm{~F}}, \mathrm{Y}^{527 \mathrm{~F}}, \mathrm{Y} 32^{527 \mathrm{~F}}$, or Y4U $32^{527 \mathrm{~F}}$ were fixed at $50 \%$ confluence on cover slips in $3.7 \%$ formaldehyde, permeablized in $0.4 \%$ triton X-100, and stained with rhodamine-phalloidin $(2 \mu \mathrm{g} / \mathrm{ml})$. Cells were visualized via Zeiss LSM 510 confocal microscopy (63x objective). Mock transfected CEF and cells expressing Src ${ }^{527 F}, Y_{32}^{527 F}$, or Y4U32 $2^{527 F}$ are shown. Bars represent $10 \mu \mathrm{m}$. (A-C) Results are representative of three independent experiments. 
A

\section{Western Blot \\ Rabbit Anti-Src}

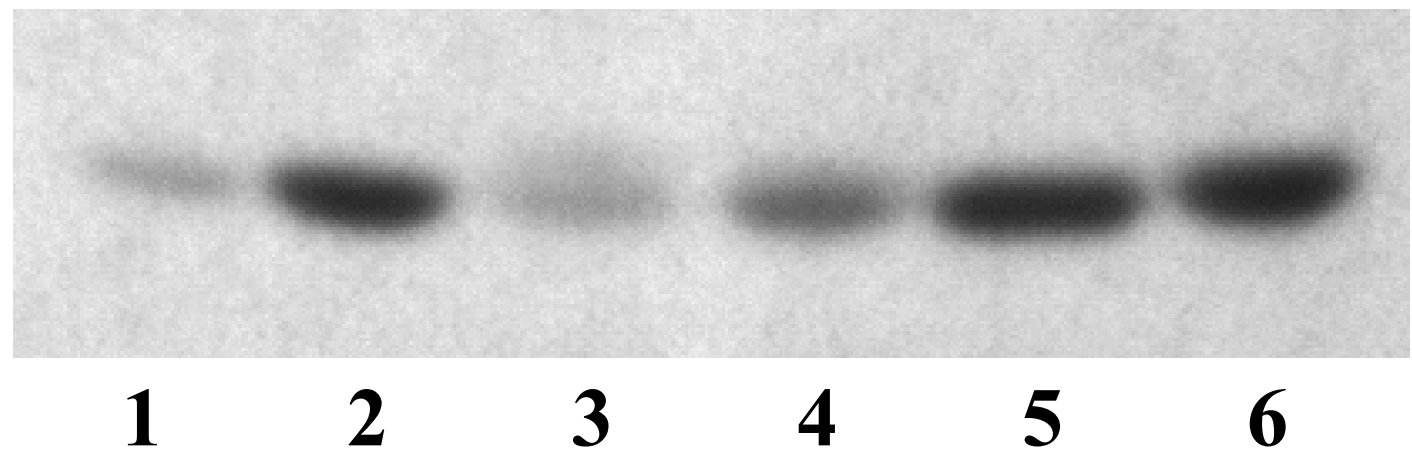

B

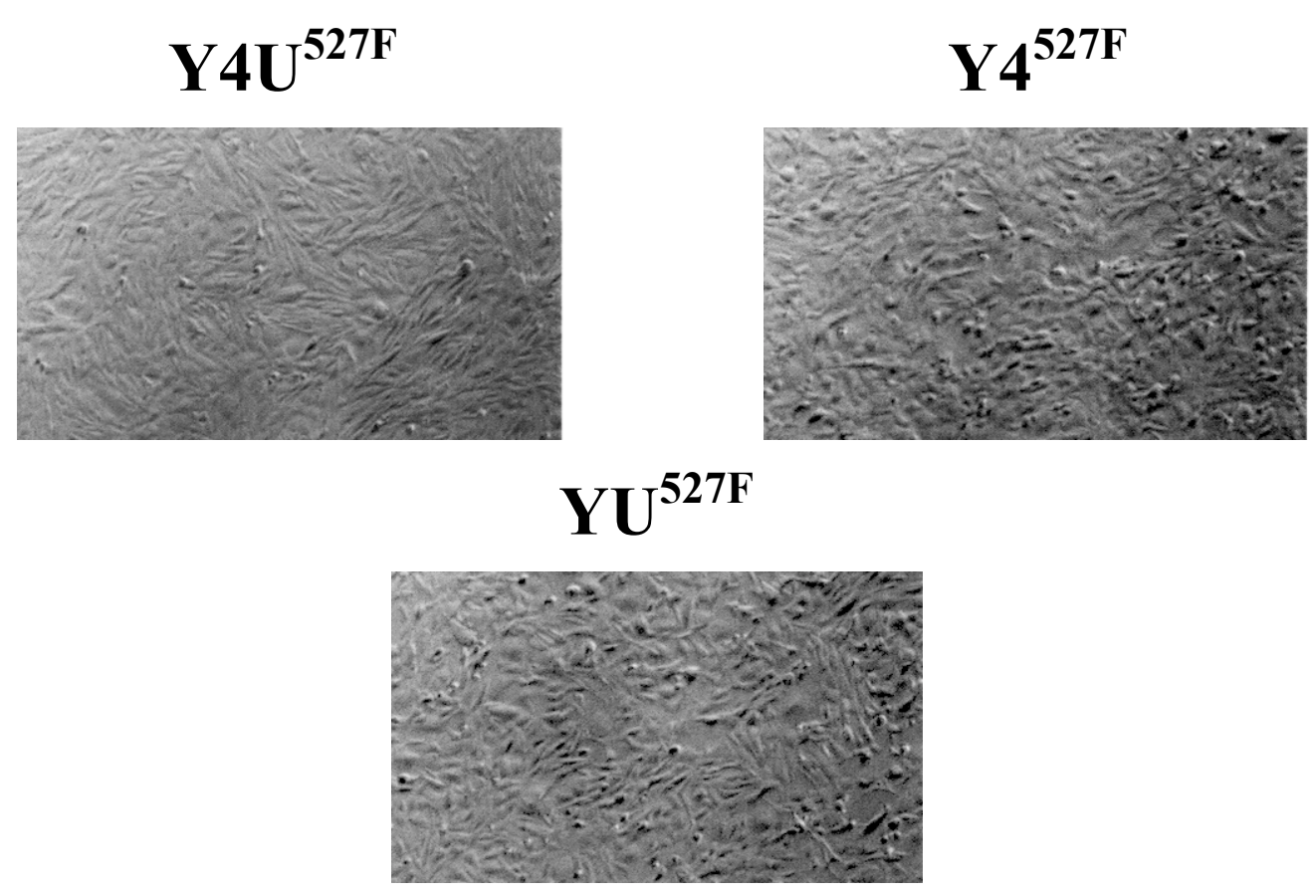



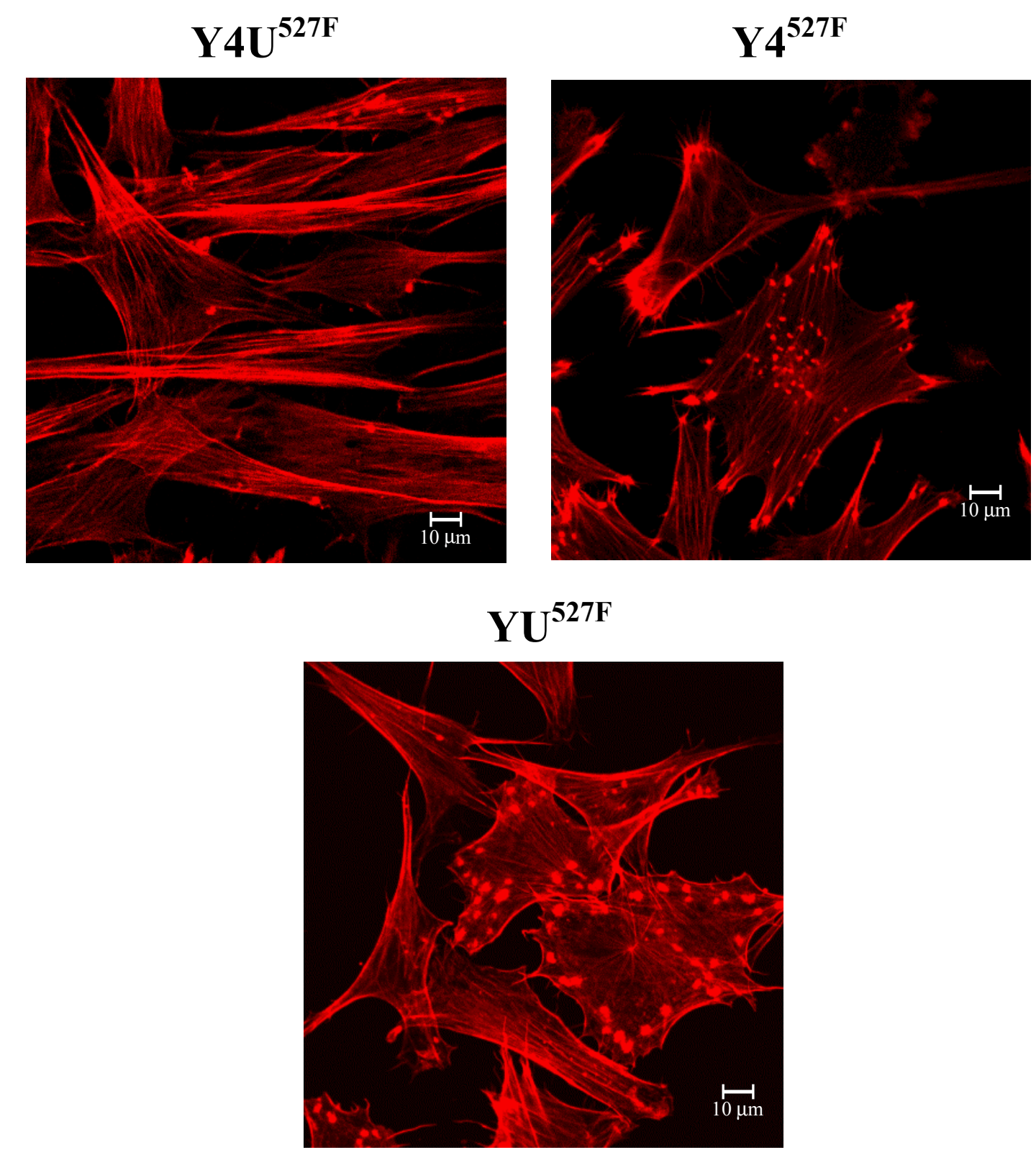

Figure 3. Expression of $\mathrm{Src}^{527 \mathrm{~F}} / \mathrm{c}-$ Yes amino terminal chimeras in $\mathrm{CEF}$ and their effects on cell morphology and the actin cytoskeleton. (A) Thirty $\mu \mathrm{g}$ of day 12 RIPA lysates from mock-transfected CEF or cells expressing $\mathrm{Src}^{527 \mathrm{~F}}$, Y4U32 $2^{527 \mathrm{~F}}, \mathrm{Y}_{4} \mathrm{U}^{527 \mathrm{~F}}, \mathrm{Y} 4^{527 \mathrm{~F}}$, or $\mathrm{YU}^{527 \mathrm{~F}}$ were separated via 8\% SDS PAGE. Lysates were transferred to PVDF 
membrane, blocked in 5\% milk/TBS-T, and probed with rabbit anti-Src. Lane $1=\mathrm{CEF}$; Lane $2=\mathrm{Src}^{527 \mathrm{~F}} ;$ Lane $3=\mathrm{Y} 4 \mathrm{U} 32^{527 \mathrm{~F}} ;$ Lane $4=\mathrm{Y}_{4} \mathrm{U}^{527 \mathrm{~F}} ;$ Lane $5=\mathrm{Y} 4^{527 \mathrm{~F}} ;$ Lane $6=$ $\mathrm{YU}^{527 \mathrm{~F}}$. (B) Confluent CEF expressing $\mathrm{Y}_{4} \mathrm{U}^{527 \mathrm{~F}}, \mathrm{Y}^{527 \mathrm{~F}}$ or $\mathrm{YU}^{527 \mathrm{~F}}$ were photographed at day 12 post-transfection in $100 \mathrm{~mm}$ tissue culture plates (Falcon). Cells were photographed at 40x total magnification using a Plan 2 filter. (C) CEF expressing $\mathrm{Y}_{4} \mathrm{U}^{527 \mathrm{~F}}, \mathrm{Y}^{527 \mathrm{~F}}$, or $\mathrm{YU}^{527 \mathrm{~F}}$ were fixed at $50 \%$ confluence on cover slips in $3.7 \%$ formaldehyde, permeablized in $0.4 \%$ triton X-100, and stained with rhodaminephalloidin $(2 \mu \mathrm{g} / \mathrm{ml})$. Cells were visualized via Zeiss LSM 510 confocal microscopy (63x objective). Bars represent $10 \mu \mathrm{m}$. (A-C) Results are representative of three independent experiments. 


\section{$\underline{\text { Western Blot }}$ Anti-p $Y^{416}$}

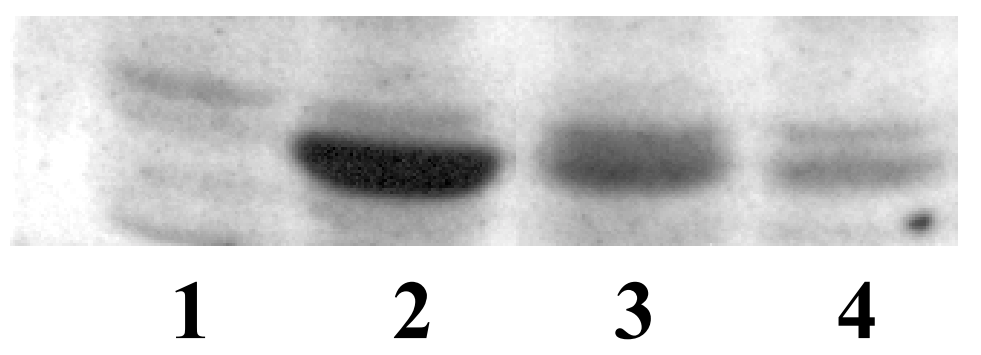

Figure 4. Y4U32 $2^{527 \mathrm{~F}}$ is expressed at higher steady state levels than LA29 v-Src. Fifty $\mu \mathrm{g}$ of day 12 RIPA lysates from mock-transfected CEF or cells expressing $\mathrm{Src}^{527 \mathrm{~F}}$, Y4U32 $2^{527 \mathrm{~F}}$, or LA29 v-Src were resolved by $8 \%$ SDS PAGE, transferred to PVDF membrane, blocked in 5\% milk/TBS-T, and probed with rabbit anti-phospho- $\mathrm{Y}^{416}$. Lane $1=\mathrm{CEF}$; Lane $2=\mathrm{Src}^{527 \mathrm{~F}}$; Lane $3=\mathrm{Y} 4 \mathrm{U} 32^{527 \mathrm{~F}}$; Lane $4=\mathrm{LA} 29 \mathrm{v}-\mathrm{Src}$. Results are representative of two independent experiments. 


\section{$\underline{\text { Western Blot }}$ \\ Anti-Src}
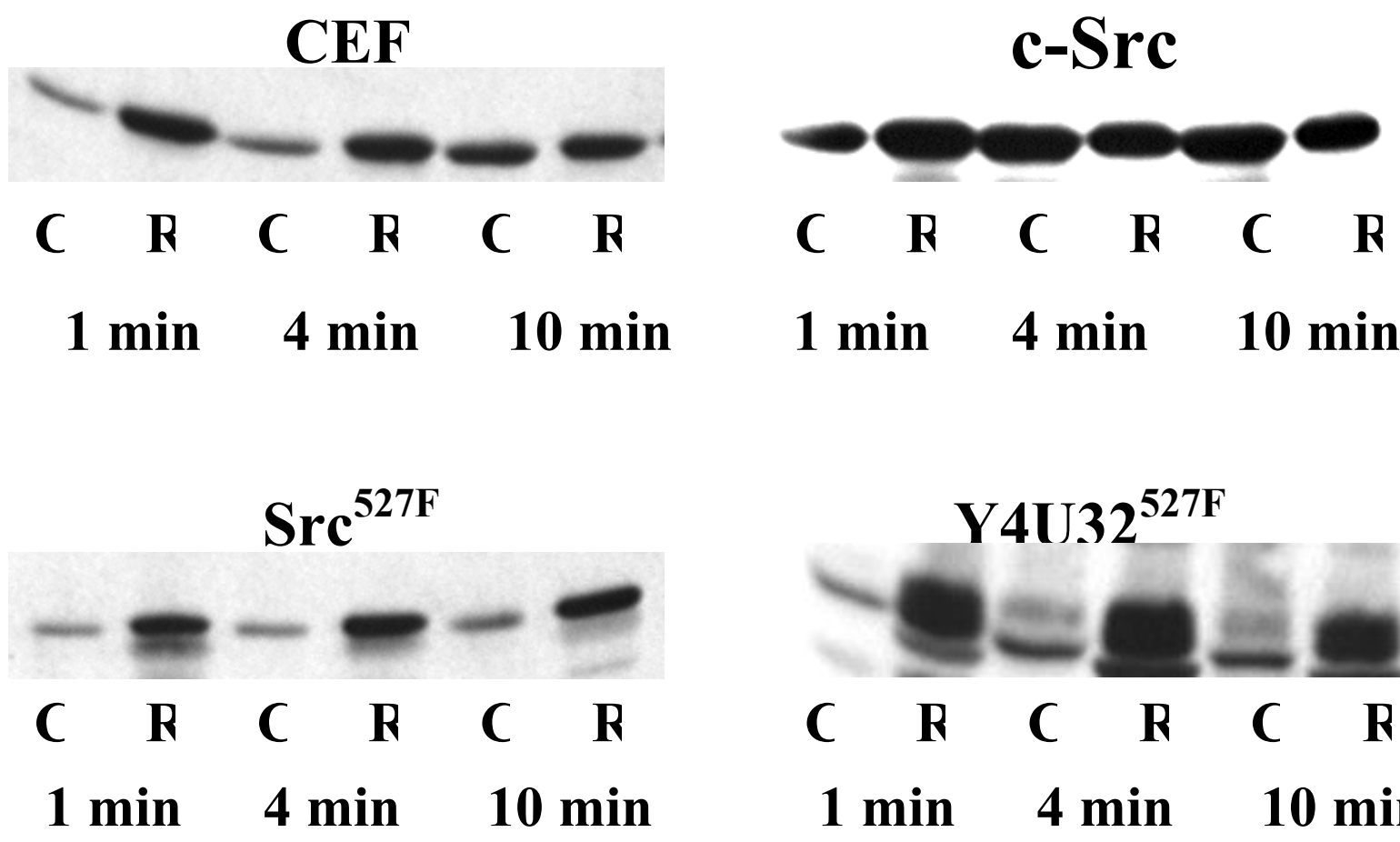

$1 \mathrm{~min} \quad 4 \mathrm{~min} \quad 10 \mathrm{~min}$

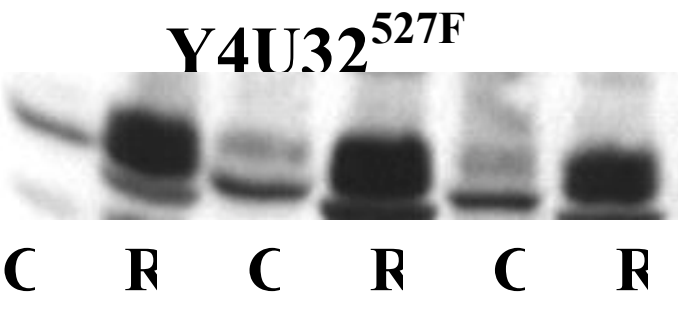

$1 \mathrm{~min} \quad 4 \mathrm{~min} 10 \mathrm{~min}$

Figure 5. Y4U $32^{527 \mathrm{~F}}$ is associated with the triton $\mathrm{X}-100$ insoluble cytoskeletal fraction. Mock-transfected CEF or cells expressing c-Src, Src ${ }^{527 F}$, Y4U32 ${ }^{527 F}$, or Y4U ${ }^{527 F}$ were grown to confluence in $100 \mathrm{~mm}$ dishes. Cells were incubated in $1 \mathrm{ml}$ of CSK buffer for 1, 4, or $10 \mathrm{~min}$. The triton-soluble fractions were collected, and the triton-insoluble material at each time-point was solublized in RIPA buffer. Fifty $\mu \mathrm{g}$ of cell lysates from each fraction were separated by $8 \%$ SDS PAGE, transferred to PVDF membrane, blocked with 5\% milk/TBS-T, and probed with rabbit anti-Src. Results are shown for mocktransfected CEF (top left panel), c-Src (top right panel), Src ${ }^{527 F}$ (bottom left panel), and Y4U32 $2^{527 F}$ (bottom right panel). $\mathrm{C}=\mathrm{CSK}$ buffer; $\mathrm{R}=\mathrm{RIPA}$ buffer. 


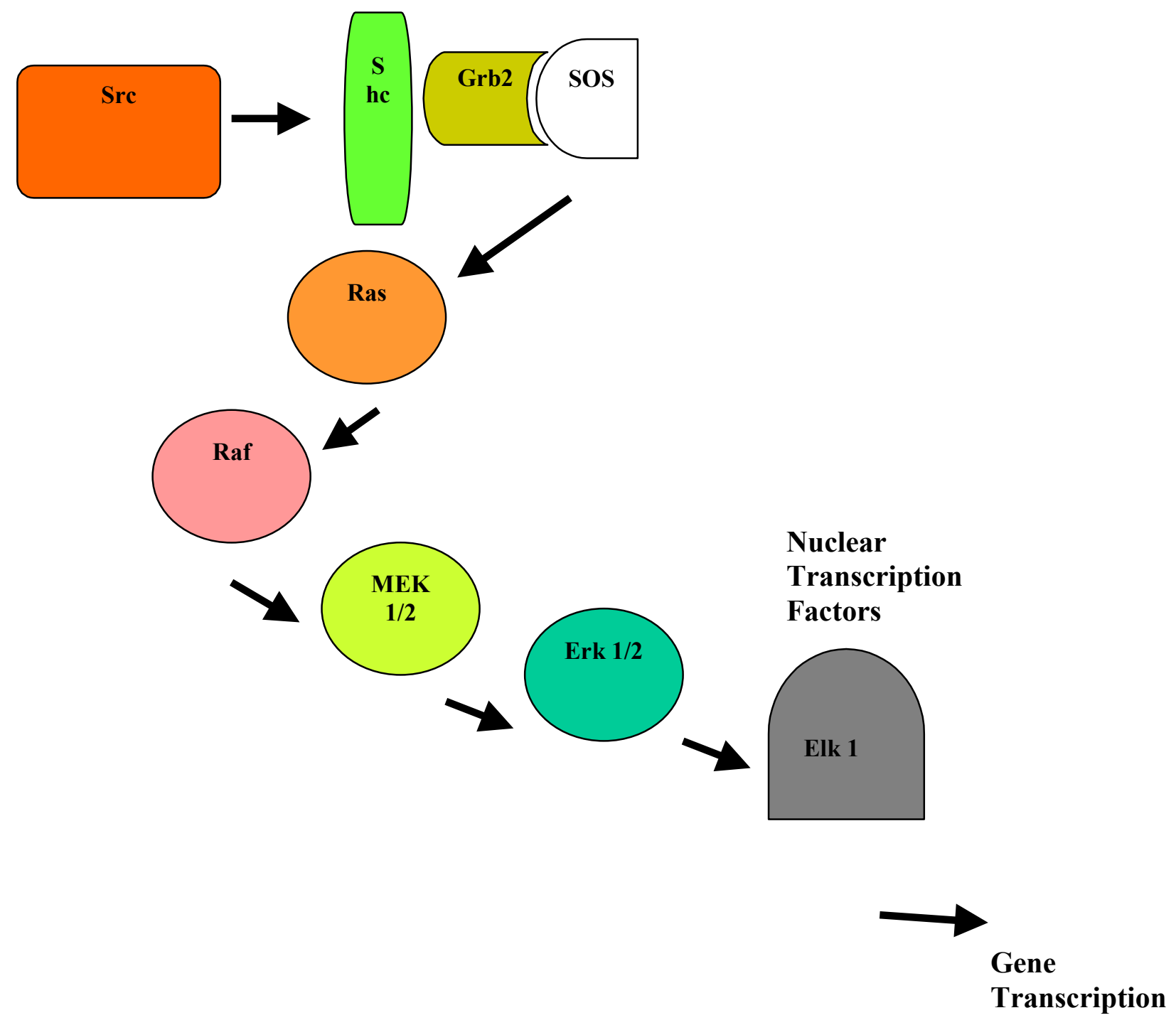

Figure 6. Src can activate the MAP kinase pathway. Activation of the MAPK pathway by Src begins with phosphorylation of the adaptor protein Shc. Phosphorylated Shc forms a stable complex with Grb2, which binds to the guanine nucleotide exchange factor SOS. SOS facilitates exchange of GTP for GDP, thereby resulting in activation of Ras. Activated Ras binds to and contributes to the activation of c-Raf. Activated c-Raf phosphorylates and activates MEK1/2, which in turn phosphorylate and activate Erk 1/2 
MAP kinases. The MAP kinases phosphorylate and activate nuclear transcription factors such as Elk 1 (Klein and Schneider, 1997). 
A

IP: Anti-Shc

Western Blot

Anti-Grb2

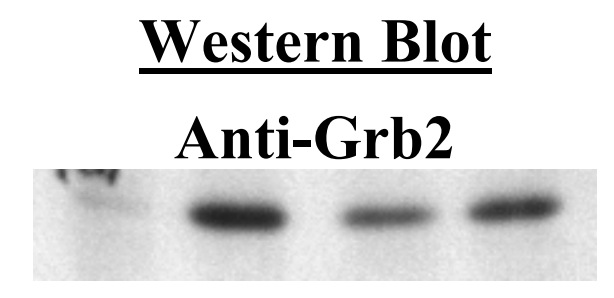

B
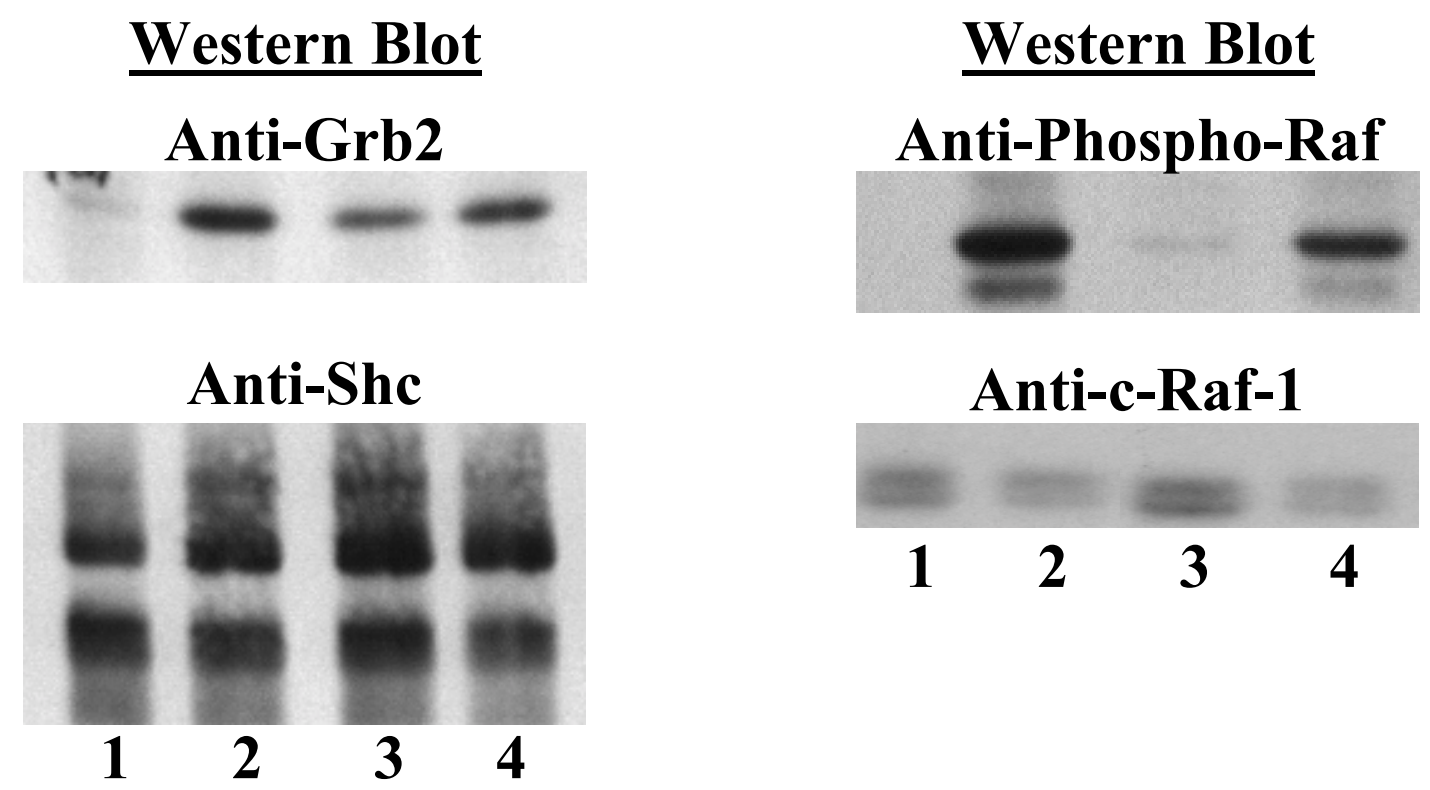

Anti-c-Raf-1

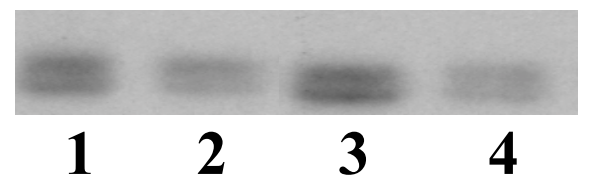

C

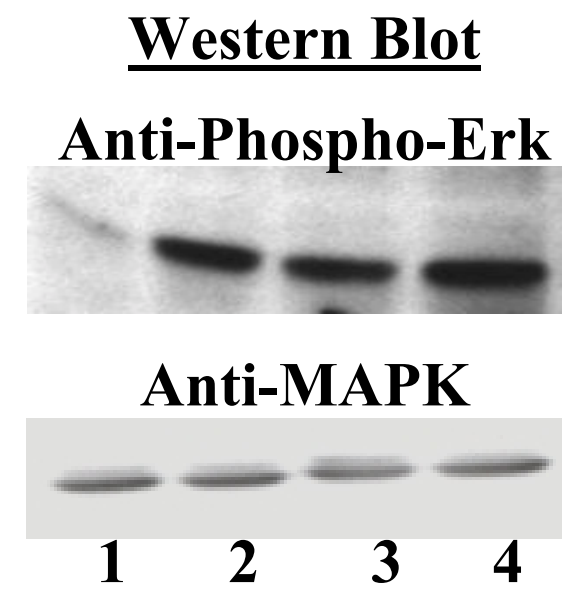

Figure 7. Activation of the MAP kinase pathway by $\mathrm{Src}^{527 \mathrm{~F}}$ and $\mathrm{Src}^{527 \mathrm{~F}} / \mathrm{c}-\mathrm{Y}$ es chimeras.

(A) Five hundred $\mu \mathrm{g}$ of RIPA lysates from mock-transfected CEF or cells expressing 
$\mathrm{Src}^{527 \mathrm{~F}}$, Y4U32 $2^{527 \mathrm{~F}}$, or $\mathrm{Y}_{4} \mathrm{U}^{527 \mathrm{~F}}$ were immunoprecipitated with an anti-Shc antibody and separated by $10 \%$ SDS PAGE. Immunoprecipitated proteins were transferred to PVDF membrane, blocked in 5\% milk/TBS-T and probed with an anti-Grb2 antibody (top panel). The blots were stripped and re-probed with the anti-Shc antibody, immunoreactive against the 46, 52, and $66 \mathrm{kDa}$ isoforms of Shc (bottom panel). Results are representative of two independent experiments. (B) Fifty $\mu \mathrm{g}$ of RIPA lysates from mock-transfected CEF or cells expressing $\mathrm{Src}^{527 \mathrm{~F}}$, Y4U32 ${ }^{527 \mathrm{~F}}$, or $\mathrm{Y}_{4} \mathrm{U}^{527 \mathrm{~F}}$ were resolved by $8 \%$ SDS PAGE, transferred to PVDF membrane, blocked in 5\% milk/TBS-T and probed with an anti-phospho-Raf antibody (top panel). Western blot analysis was also performed with an anti-c-Raf antibody to determine relative protein levels (bottom panel). Results are representative of two independent experiments. (C) Fifty $\mu g$ of RIPA lysates from mock-transfected CEF or cells expressing $\mathrm{Src}^{527 \mathrm{~F}}$, Y4U32 $2^{527 \mathrm{~F}}$, or $\mathrm{Y}_{4} \mathrm{U}^{527 \mathrm{~F}}$ were processed for western blot analysis as described above. Membranes were probed with an anti-phospho-Erk antibody (top panel) or an anti-p42/44 MAPK antibody to determine relative protein levels (bottom panel). Results are representative of two independent experiments. (A-C) Lane $1=\mathrm{CEF}$; Lane $2=\mathrm{Src}^{527 \mathrm{~F}}$; Lane $3=\mathrm{Y} 4 \mathrm{U} 32^{527 \mathrm{~F}}$; Lane $4=\mathrm{Y}_{4} \mathrm{U}^{527 \mathrm{~F}}$. 


\section{A}

\section{Western Blot Anti-Phospho-Akt

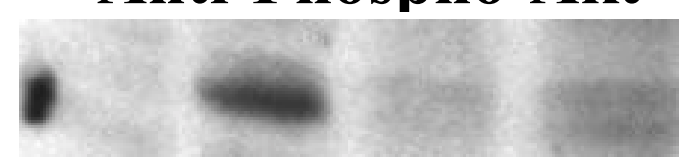

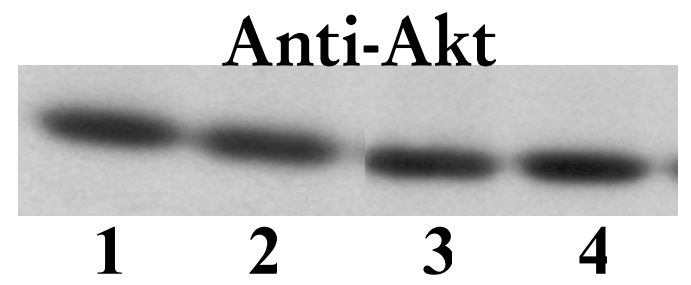

B

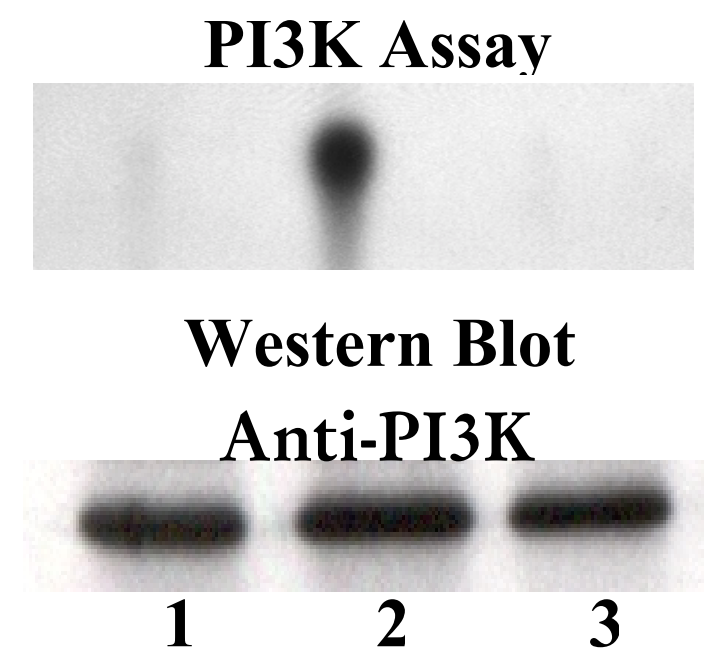

Figure $8 . \mathrm{Src}^{527 \mathrm{~F}} / \mathrm{c}$-Yes chimeras with the c-Yes amino terminus are unable to activate the PI3K/Akt pathway. (A) Fifty $\mu$ g of RIPA lysates from mock-transfected CEF or cells expressing Src ${ }^{527 \mathrm{~F}}$, Y4U32 $2^{527 \mathrm{~F}}$, or Y4U ${ }^{527 \mathrm{~F}}$ were resolved by $8 \%$ SDS PAGE, transferred to PVDF membrane, blocked with 5\% milk/TBS-T, and probed with an anti-phospho-Akt antibody (top panel) or with an anti-Akt antibody to determine relative protein levels (bottom panel). Lane $1=\mathrm{CEF}$; Lane $2=\mathrm{Src}^{527 \mathrm{~F}}$; Lane $3=\mathrm{Y} 4 \mathrm{U} 32^{527 \mathrm{~F}}$; Lane $4=\mathrm{Y} 4 \mathrm{U}^{527 \mathrm{~F}}$. Results are representative of two independent blots. (B) Four hundred $\mu \mathrm{g}$ of lysates from mock-transfected CEF or cells expressing $\mathrm{Src}^{527 \mathrm{~F}}$ or $\mathrm{Y} 4 \mathrm{U} 32^{527 \mathrm{~F}}$ were immunoprecipitated 
with an anti-PI3K antibody and subjected to PI3 kinase assay as described in materials and methods. Kinase assay products were resolved by thin layer chromatography and visualized by Phosphorimager analysis (top panel). Anti-PI3K immunoprecipitates were also resolved by $8 \%$ SDS PAGE, transferred to PVDF membrane, blocked in $5 \%$ milk/TBS-T, and probed with an anti-PI3K p85 antibody to verify equal amounts of PI3K in the lysates (bottom panel). Lane $1=\mathrm{CEF}$; Lane $2=\mathrm{Src}^{527 \mathrm{~F}}$; Lane $3=\mathrm{Y} 4 \mathrm{U} 32^{527 \mathrm{~F}}$. 


\section{References}

Arreaza,G., Melkonian,K.A., LaFevre-Bernt,M., Brown,D.A. (1994). Triton X-100resistant membrane complexes from cultured kidney epithelial cells contain the Src family protein tyrosine kinase p62yes. J.Biol.Chem. 269, 19123-19127.

Bijlmakers,M.J., Isobe-Nakamura,M., Ruddock,L.J., Marsh,M. (1997). Intrinsic signals in the unique domain target p56(lck) to the plasma membrane independently of CD4. J.Cell Biol. 137, 1029-1040.

Boyce,B.F., Yoneda,T., Lowe,C., Soriano,P., Mundy,G.R. (1992). Requirement of pp60c-src expression for osteoclasts to form ruffled borders and resorb bone in mice. J.Clin.Invest 90, 1622-1627.

Catling,A.D., Fincham,V.J., Frame,M.C., Haefner,B., Wyke,J.A. (1994). Mutations in vSrc SH3 and catalytic domains that jointly confer temperature-sensitive transformation with minimal temperature-dependent changes in cellular tyrosine phosphorylation.

J.Virol. 68, 4392-4399.

Ciesielski-Treska,J., Ulrich,G., Chasserot-Golaz,S., Aunis,D. (1995).

Immunocytochemical localization of protein kinases Yes and Src in amoeboid microglia in culture: association of Yes kinase with vimentin intermediate filaments. Eur.J.Cell Biol. 68, 369-376.

Courtneidge,S.A., Dhand,R., Pilat,D., Twamley,G.M., Waterfield,M.D., Roussel,M.F. (1993). Activation of Src family kinases by colony stimulating factor-1, and their association with its receptor. EMBO J. 12, 943-950.

Cowley,S., Paterson,H., Kemp,P., Marshall,C.J. (1994). Activation of MAP kinase kinase is necessary and sufficient for PC12 differentiation and for transformation of NIH 3T3 cells. Cell 77, 841-852.

Felice,G.R., Eason,P., Nermut,M.V., Kellie,S. (1990). pp60v-src association with the cytoskeleton induces actin reorganization without affecting polymerization status. Eur.J.Cell Biol. 52, 47-59.

Feshchenko,E.A., Langdon,W.Y., Tsygankov,A.Y. (1998). Fyn, Yes, and Syk phosphorylation sites in c-Cbl map to the same tyrosine residues that become phosphorylated in activated T cells. J.Biol.Chem. 273, 8323-8331.

Fincham,V.J., Brunton,V.G., Frame,M.C. (2000). The SH3 domain directs acto-myosindependent targeting of v-Src to focal adhesions via phosphatidylinositol 3-kinase. Mol.Cell Biol. 20, 6518-6536.

Fincham,V.J., Chudleigh,A., Frame,M.C. (1999). Regulation of p190 Rho-GAP by v-Src is linked to cytoskeletal disruption during transformation. J.Cell Sci. 112 ( Pt 6), 947-956. 
Flynn,D.C., Leu,T.H., Reynolds,A.B., Parsons,J.T. (1993). Identification and sequence analysis of cDNAs encoding a 110-kilodalton actin filament-associated pp60src substrate. Mol.Cell Biol. 13, 7892-7900.

Fuhrer,D.K., Yang,Y.C. (1996a). Activation of Src-family protein tyrosine kinases and phosphatidylinositol 3-kinase in 3T3-L1 mouse preadipocytes by interleukin-11. Exp.Hematol. 24, 195-203.

Fuhrer,D.K., Yang,Y.C. (1996b). Complex formation of JAK2 with PP2A, P13K, and Yes in response to the hematopoietic cytokine interleukin-11.

Biochem.Biophys.Res.Commun. 224, 289-296.

Fukui,Y., Saltiel,A.R., Hanafusa,H. (1991). Phosphatidylinositol-3 kinase is activated in $\mathrm{v}$-src, v-yes, and v-fps transformed chicken embryo fibroblasts. Oncogene 6, 407-411.

Ghysdael,J., Neil,J.C., Vogt,P.K. (1981). A third class of avian sarcoma viruses, defined by related transformation-specific proteins of Yamaguchi 73 and Esh sarcoma viruses. Proc.Natl.Acad.Sci.U.S.A 78, 2611-2615.

Gupta,S.K., Gallego,C., Johnson,G.L., Heasley,L.E. (1992). MAP kinase is constitutively activated in gip2 and src transformed rat 1a fibroblasts. J.Biol.Chem. 267, 7987-7990.

Guy,C.T., Muthuswamy,S.K., Cardiff,R.D., Soriano,P., Muller,W.J. (1994). Activation of the c-Src tyrosine kinase is required for the induction of mammary tumors in transgenic mice. Genes Dev. 8, 23-32.

Hakak,Y., Hsu,Y.S., Martin,G.S. (2000). Shp-2 mediates v-Src-induced morphological changes and activation of the anti-apoptotic protein kinase Akt. Oncogene 19, 3164-3171.

Hall,C.L., Lange,L.A., Prober,D.A., Zhang,S., Turley,E.A. (1996). pp60(c-src) is required for cell locomotion regulated by the hyaluronanreceptor RHAMM. Oncogene $13,2213-2224$.

Hamaguchi,M., Hanafusa,H. (1987). Association of p60src with Triton X-100-resistant cellular structure correlates with morphological transformation.

Proc.Natl.Acad.Sci.U.S.A 84, 2312-2316.

Hamaguchi,M., Xiao,H., Uehara,Y., Ohnishi,Y., Nagai,Y. (1993). Herbimycin A inhibits the association of p60v-src with the cytoskeletal structure and with phosphatidylinositol 3 ' kinase. Oncogene 8, 559-564.

Hoey,J.G., Summy,J., Flynn,D.C. (2000). Chimeric constructs containing the SH4/Unique domains of cYes can restrict the ability of $\mathrm{Src}(527 \mathrm{~F})$ to upregulate heme oxygenase-1 expression efficiently. Cell Signal. 12, 691-701.

Honda,Z., Suzuki,T., Kono,H., Okada,M., Yamamoto,T., Ra,C., Morita,Y., Yamamoto,K. (2000). Sequential requirements of the N-terminal palmitoylation site and 
SH2 domain of Src family kinases in the initiation and progression of FcepsilonRI signaling. Mol.Cell Biol. 20, 1759-1771.

Howe,L.R., Leevers,S.J., Gomez,N., Nakielny,S., Cohen,P., Marshall,C.J. (1992). Activation of the MAP kinase pathway by the protein kinase raf. Cell 71, 335-342.

Ignelzi,M.A., Jr., Miller,D.R., Soriano,P., Maness,P.F. (1994). Impaired neurite outgrowth of src-minus cerebellar neurons on the cell adhesion molecule L1. Neuron 12, 873-884.

Jiang,B.H., Zheng,J.Z., Vogt,P.K. (1998). An essential role of phosphatidylinositol 3kinase in myogenic differentiation. Proc.Natl.Acad.Sci.U.S.A 95, 14179-14183.

Kabouridis,P.S., Magee,A.I., Ley,S.C. (1997). S-acylation of LCK protein tyrosine kinase is essential for its signalling function in T lymphocytes. EMBO J. 16, 4983-4998.

Kamei,T., Hamlin,G.P., Chapman,B.M., Burkhardt,A.L., Bolen,J.B., Soares,M.J. (1997). Signaling pathways controlling trophoblast cell differentiation: Src family protein tyrosine kinases in the rat. Biol.Reprod. 57, 1302-1311.

Kaplan,K.B., Swedlow,J.R., Morgan,D.O., Varmus,H.E. (1995). c-Src enhances the spreading of src-/- fibroblasts on fibronectin by a kinase-independent mechanism. Genes Dev. 9, 1505-1517.

Kitamura,N., Kitamura,A., Toyoshima,K., Hirayama,Y., Yoshida,M. (1982). Avian sarcoma virus Y73 genome sequence and structural similarity of its transforming gene product to that of Rous sarcoma virus. Nature 297, 205-208.

Klein,N.P., Schneider,R.J. (1997). Activation of Src family kinases by hepatitis B virus HBx protein and coupled signaling to Ras. Mol.Cell Biol. 17, 6427-6436.

Kovacic,B., Ilic,D., Damsky,C.H., Gardner,D.G. (1998). c-Src activation plays a role in endothelin-dependent hypertrophy of the cardiac myocyte. J.Biol.Chem. 273, 3518535193.

Krasilnikov,M.A. (2000). Phosphatidylinositol-3 kinase dependent pathways: the role in control of cell growth, survival, and malignant transformation. Biochemistry (Mosc.) 65, 59-67.

Kypta,R.M., Goldberg,Y., Ulug,E.T., Courtneidge,S.A. (1990). Association between the PDGF receptor and members of the src family of tyrosine kinases. Cell 62, 481-492.

Landgren,E., Blume-Jensen,P., Courtneidge,S.A., Claesson-Welsh,L. (1995). Fibroblast growth factor receptor-1 regulation of Src family kinases. Oncogene 10, 2027-2035.

Luton,F., Verges,M., Vaerman,J.P., Sudol,M., Mostov,K.E. (1999). The SRC family protein tyrosine kinase p62yes controls polymeric IgA transcytosis in vivo. Mol.Cell 4, $627-632$. 
Mak,P., He,Z., Kurosaki,T. (1996). Identification of amino acid residues required for a specific interaction between Src-tyrosine kinase and proline-rich region of phosphatidylinositol-3' kinase. FEBS Lett. 397, 183-185.

Marchetti,D., Parikh,N., Sudol,M., Gallick,G.E. (1998). Stimulation of the protein tyrosine kinase c-Yes but not c-Src by neurotrophins in human brain-metastatic melanoma cells. Oncogene 16, 3253-3260.

Mukhopadhyay,D., Tsiokas,L., Zhou,X.M., Foster,D., Brugge,J.S., Sukhatme,V.P. (1995). Hypoxic induction of human vascular endothelial growth factor expression through c-Src activation. Nature 375, 577-581.

Muthuswamy,S.K., Muller,W.J. (1995). Activation of Src family kinases in Neu-induced mammary tumors correlates with their association with distinct sets of tyrosine phosphorylated proteins in vivo. Oncogene 11, 1801-1810.

Odajima,J., Matsumura,I., Sonoyama,J., Daino,H., Kawasaki,A., Tanaka,H., Inohara,N., Kitamura,T., Downward,J., Nakajima,K., Hirano,T., Kanakura,Y. (2000). Full oncogenic activities of $\mathrm{v}$-Src are mediated by multiple signaling pathways. Ras as an essential mediator for cell survival. J.Biol.Chem. 275, 24096-24105.

Park,J., Cartwright,C.A. (1995). Src activity increases and Yes activity decreases during mitosis of human colon carcinoma cells. Mol.Cell Biol. 15, 2374-2382.

Penuel,E., Martin,G.S. (1999). Transformation by v-Src: Ras-MAPK and PI3K-mTOR mediate parallel pathways. Mol.Biol.Cell 10, 1693-1703.

Pleiman,C.M., Hertz,W.M., Cambier,J.C. (1994). Activation of phosphatidylinositol-3' kinase by Src-family kinase SH3 binding to the p85 subunit. Science 263, 1609-1612.

Poste,G., Flood,M.K. (1979). Cells transformed by temperature-sensitive mutants of avian sarcoma virus cause tumors in vivo at permissive and nonpermissive temperatures. Cell 17, 789-800.

Qian,Y., Baisden,J.M., Westin,E.H., Guappone,A.C., Koay,T.C., Flynn,D.C. (1998). Src can regulate carboxy terminal interactions with AFAP-110, which influence selfassociation, cell localization and actin filament integrity. Oncogene 16, 2185-2195.

Reif,K., Nobes,C.D., Thomas,G., Hall,A., Cantrell,D.A. (1996). Phosphatidylinositol 3kinase signals activate a selective subset of Rac/Rho-dependent effector pathways. Curr.Biol. 6, 1445-1455.

Resh,M.D. (1994). Myristylation and palmitylation of Src family members: the fats of the matter. Cell 76, 411-413.

Resh,M.D., Erikson,R.L. (1985). Highly specific antibody to Rous sarcoma virus src gene product recognizes a novel population of pp60v-src and pp60c-src molecules. J.Cell Biol. 100, 409-417. 
Rickles,R.J., Botfield,M.C., Zhou,X.M., Henry,P.A., Brugge,J.S., Zoller,M.J. (1995). Phage display selection of ligand residues important for Src homology 3 domain binding specificity. Proc.Natl.Acad.Sci.U.S.A 92, 10909-10913.

Robbins,S.M., Quintrell,N.A., Bishop,J.M. (1995). Myristoylation and differential palmitoylation of the HCK protein- tyrosine kinases govern their attachment to membranes and association with caveolae. Mol.Cell Biol. 15, 3507-3515.

Roche,S., Fumagalli,S., Courtneidge,S.A. (1995). Requirement for Src family protein tyrosine kinases in G2 for fibroblast cell division. Science 269, 1567-1569.

Rozakis-Adcock,M., McGlade,J., Mbamalu,G., Pelicci,G., Daly,R., Li,W., Batzer,A., Thomas,S., Brugge,J., Pelicci,P.G., . (1992). Association of the Shc and Grb2/Sem5 SH2containing proteins is implicated in activation of the Ras pathway by tyrosine kinases. Nature 360, 689-692.

Sargiacomo,M., Sudol,M., Tang,Z., Lisanti,M.P. (1993). Signal transducing molecules and glycosyl-phosphatidylinositol-linked proteins form a caveolin-rich insoluble complex in MDCK cells. J.Cell Biol. 122, 789-807.

Schieffer,B., Paxton,W.G., Chai,Q., Marrero,M.B., Bernstein,K.E. (1996). Angiotensin II controls p21ras activity via pp60c-src. J.Biol.Chem. 271, 10329-10333.

Schieven,G.L., Kallestad,J.C., Brown,T.J., Ledbetter,J.A., Linsley,P.S. (1992).

Oncostatin $\mathrm{M}$ induces tyrosine phosphorylation in endothelial cells and activation of p62yes tyrosine kinase. J.Immunol. 149, 1676-1682.

Shenoy-Scaria,A.M., Dietzen,D.J., Kwong,J., Link,D.C., Lublin,D.M. (1994). Cysteine3 of Src family protein tyrosine kinase determines palmitoylation and localization in caveolae. J.Cell Biol. 126, 353-363.

Sohara,Y., Ishiguro,N., Machida,K., Kurata,H., Thant,A.A., Senga,T., Matsuda,S., Kimata,K., Iwata,H., Hamaguchi,M. (2001). Hyaluronan activates cell motility of v-Srctransformed cells via Ras- mitogen-activated protein kinase and phosphoinositide 3kinase-Akt in a tumor-specific manner. Mol.Biol.Cell 12, 1859-1868.

Soriano,P., Montgomery,C., Geske,R., Bradley,A. (1991). Targeted disruption of the csrc proto-oncogene leads to osteopetrosis in mice. Cell 64, 693-702.

Sparks,A.B., Rider,J.E., Hoffman,N.G., Fowlkes,D.M., Quillam,L.A., Kay,B.K. (1996). Distinct ligand preferences of Src homology 3 domains from Src, Yes, Abl, Cortactin, p53bp2, PLCgamma, Crk, and Grb2. Proc.Natl.Acad.Sci.U.S.A 93, 1540-1544.

Stein,P.L., Vogel,H., Soriano,P. (1994). Combined deficiencies of Src, Fyn, and Yes tyrosine kinases in mutant mice. Genes Dev. 8, 1999-2007.

Sudol,M., Hanafusa,H. (1986). Cellular proteins homologous to the viral yes gene product. Mol.Cell Biol. 6, 2839-2846. 
Sudol,M., Kieswetter,C., Zhao,Y.H., Dorai,T., Wang,L.H., Hanafusa,H. (1988).

Nucleotide sequence of a cDNA for the chick yes proto-oncogene: comparison with the viral yes gene. Nucleic Acids Res. 16, 9876.

Sugawara,K., Sugawara,I., Sukegawa,J., Akatsuka,T., Yamamoto,T., Morita,M., Mori,S., Toyoshima,K. (1991). Distribution of c-yes-1 gene product in various cells and tissues. Br.J.Cancer 63, 508-513.

Summy,J.M., Guappone,A.C., Sudol,M., Flynn,D.C. (2000). The SH3 and SH2 domains are capable of directing specificity in protein interactions between the non-receptor tyrosine kinases cSrc and cYes. Oncogene 19, 155-160.

Susa,M., Luong-Nguyen,N.H., Crespo,J., Maier,R., Missbach,M., McMaster,G. (2000). Active recombinant human tyrosine kinase c-Yes: expression in baculovirus system, purification, comparison to c-Src, and inhibition by a c-Src inhibitor. Protein Expr.Purif. 19, 99-106.

Suzuki,T., Kono,H., Hirose,N., Okada,M., Yamamoto,T., Yamamoto,K., Honda,Z. (2000). Differential involvement of Src family kinases in Fc gamma receptor- mediated phagocytosis. J.Immunol. 165, 473-482.

Tang,H., Zhao,Z.J., Landon,E.J., Inagami,T. (2000). Regulation of calcium-sensitive tyrosine kinase Pyk2 by angiotensin II in endothelial cells. Roles of Yes tyrosine kinase and tyrosine phosphatase SHP-2. J.Biol.Chem. 275, 8389-8396.

Thomas,S.M., Brugge,J.S. (1997). Cellular functions regulated by Src family kinases. Annu.Rev.Cell Dev.Biol. 13, 513-609.

Toker,A., Cantley,L.C. (1997). Signalling through the lipid products of phosphoinositide3-OH kinase. Nature 387, 673-676.

Toshima,J., Ohashi,K., Iwashita,S., Mizuno,K. (1995). Autophosphorylation activity and association with Src family kinase of Sky receptor tyrosine kinase.

Biochem.Biophys.Res.Commun. 209, 656-663.

Tsygankova,O.M., Peng,M., Maloney,J.A., Hopkins,N., Williamson,J.R. (1998). Angiotensin II induces diverse signal transduction pathways via both Gq and Gi proteins in liver epithelial cells. J.Cell Biochem. 69, 63-71.

Waltenberger,J., Claesson-Welsh,L., Siegbahn,A., Shibuya,M., Heldin,C.H. (1994). Different signal transduction properties of KDR and Flt1, two receptors for vascular endothelial growth factor. J.Biol.Chem. 269, 26988-26995.

Whitmarsh,A.J., Davis,R.J. (1996). Transcription factor AP-1 regulation by mitogenactivated protein kinase signal transduction pathways. J.Mol.Med. 74, 589-607. 
Zhao,Y., Uyttendaele,H., Krueger,J.G., Sudol,M., Hanafusa,H. (1993). Inactivation of cYes tyrosine kinase by elevation of intracellular calcium levels. Mol.Cell Biol. 13, 75077514.

Zhao,Y.H., Krueger,J.G., Sudol,M. (1990). Expression of cellular-yes protein in mammalian tissues. Oncogene 5, 1629-1635. 


\section{Chapter 5}

\section{General Discussion}


Src family tyrosine kinases are expressed in virtually all vertebrate tissues, and are involved in signal transduction pathways that govern a variety of biological processes, including cell cycle, cell spreading, motility, differentiation, survival, and death (Thomas and Brugge, 1997). While there is a wealth of data available on the functions of Src family kinases, the issue of specificity in signaling between Src family members has only been lightly addressed. With the exception of c-Src, c-Yes, and Fyn, Src family kinases are expressed only in limited subsets of hematopoietic cells (Thomas and Brugge, 1997). These kinases, including Lyn, Lck, Hck, Blk, Fgr, and Yrk, are well positioned to serve specific functions in signaling pathways unique to these cells. Examples of this include Fgr and Hck in the development and differentiation of monocytic cells and Lck in T-cell receptor signaling (Katagiri et al., 1991; Katagiri et al., 1992; Wong et al., 1998). Even in these cells, however, there are frequently multiple Src family kinases present, indicating that they either perform redundant functions, or that individual Src family kinases expressed in the same cells carry out unique functions. It should be noted, however, that these two possibilities are not mutually exclusive, and evidence exists to support both redundancy and specificity of function between Src family kinases (Brown and Cooper, 1996; Page et al., 1997).

The primary goal of these studies was the investigation of how c-Src and c-Yes are capable of sending specific signals. c-Src and c-Yes are two of the most highly homologous members of the Src family of tyrosine kinases. They share over $80 \%$ amino acid homology outside of their Unique domains and are expressed across a wide range of cells and tissues (Kitamura et al., 1982; Sudol et al., 1988; Zhao et al., 1990; Sugawara et al., 1991). The studies outlined in this thesis have focused on the contributions of the 
functional domains to signaling specificity between c-Src and c-Yes. All Src family kinases share a common functional domain architecture. These domains, with the exception of the amino terminal region (SH4 and Unique domains), each take on a known three-dimensional conformation and thus contribute, in a well-established fashion, to the overall fold of the protein (Sicheri et al., 1997; Xu et al., 1997). The independent folding of the functional domains permits exchange of homologous functional domains between Src family members without disrupting the overall protein conformation. Additionally, with the exception of the Unique domain, the functions of these domains, and thus their general contributions to Src family kinase signaling, have been well characterized.

The experiments described in this thesis have focused primarily on the roles of the non-catalytic functional domains in signaling specificity between c-Src and c-Yes. The non-catalytic domains were chosen for study due to the high homology between the kinase domains themselves. c-Src and c-Yes share 90\% amino acid homology in their kinase domains, including virtually complete identity in 11 sub-regions important for tyrosine kinase activity (Kitamura et al., 1982; Brickell, 1992). Additionally, there is little data available in the literature to suggest that substrate selectivity exists between the catalytic domains of Src family kinases. Thus the focus of this thesis was placed on the non-catalytic domains, including the $\mathrm{SH} 4$, Unique, $\mathrm{SH} 3$, and $\mathrm{SH} 2$ domains. Utilizing chimeras in which the c-Src or $\mathrm{Src}^{527 \mathrm{~F}}$ functional domains were replaced by the corresponding domains of c-Yes, signaling specificity between c-Src and c-Yes was studied at three interrelated yet distinct levels: protein/protein interactions, transcriptional activation, and cell biology. 
In comparison to c-Src, little is known of the function of c-Yes, thus the studies outlined in this thesis evolved into an assessment of the effects of the c-Yes functional domains on the signaling capacity of activated c-Src, at the three levels mentioned above. In the course of these experiments, each of the non-catalytic functional domains was implicated in signaling specificity. Src family kinase signaling is initiated at the level of protein/protein interactions. Upon kinase activation, the conformation shifts from the closed or assembled form to the open conformation, in which the intramolecular interactions between the $\mathrm{SH} 3$ domain and kinase linker and between the $\mathrm{SH} 2$ domain and the phosphorylated carboxy-terminal tyrosine are displaced (Xu et al., 1999). The kinase active site is then readily accessible for ATP and substrates. Substrate interactions may include both stable and transient associations with binding partners and phosphorylation of target proteins. It was in hypothesized in Chapter 2 that differences in the binding specificity of the $\mathrm{SH} 3$ and/or SH2 domains would result in differential protein/protein interactions at the level of stable complex formation and substrate selection. It has been demonstrated previously that functional $\mathrm{SH} 3$ and $\mathrm{SH} 2$ domains are necessary for efficient phosphorylation of SH3 and $\mathrm{SH} 2$ domain binding partners, and $\mathrm{SH} 2$ domain swapping can alter the profile of proteins phosphorylated by a tyrosine kinase (Kanner et al., 1991; Mayer and Baltimore, 1994; Weng et al., 1994; Guappone and Flynn, 1997). Collectively, these data indicate that $\mathrm{SH} 3$ and $\mathrm{SH} 2$ domains are able to select substrates through initiation of complex formation and presentation of bound proteins for phosphorylation. In the case of the $\mathrm{SH} 2$ domain, initial phosphorylation is a prerequisite for binding; however, this brings the kinase and substrate in closer proximity, facilitating subsequent phosphorylation events. Processive phosphorylation of Src family kinase 
SH2 domain binding partners has been demonstrated previously (Pellicena et al., 1998; Scott and Miller, 2000).

Kanner and colleagues observed that v-Yes, in comparison to v-Src, induced significantly lower levels of tyrosine-phosphorylation of several v-Src substrates (Kanner et al., 1990). These proteins included the SH3 and SH2 domain binding partners AFAP110 and p130 CAS, thus our selection of these proteins for study in Chapter 2. It was also demonstrated previously that mutants of activated Src deficient in SH3 domain binding were unable to efficiently induce tyrosine phosphorylation of AFAP-110, while SH2 domain mutants were deficient in phosphorylation of p130 CAS (Kanner et al., 1991). Hence our hypothesis that the inability of $\mathrm{v}$-Yes to induce efficient phosphorylation of these proteins was due to deficiencies in SH3- or SH2-mediated substrate presentation.

According to this hypothesis, replacement of the $\mathrm{Src}^{527 \mathrm{~F}} \mathrm{SH} 3$ domain with that of c-Yes was expected to disrupt the ability of active Src to associate with and select AFAP110 for phosphorylation, while the replacement of the $\mathrm{Src}^{527 \mathrm{~F}} \mathrm{SH} 2$ domain with that of cYes would do the same for interactions with p130 CAS. As reported in Chapter 2, the results did not support the hypothesis in regard to substrate selection. Replacement of the $\mathrm{Src}^{527 \mathrm{~F}} \mathrm{SH} 3$ and/or SH2 domains did not impede its ability to induce phosphorylation of either AFAP-110 or p130 CAS (Chapter 2, Figure 4A and 4B). The phosphorylation of several other unidentified Src SH3 and SH2 domain binding partners was also not affected by replacement of the $\mathrm{Src}^{527 \mathrm{~F}} \mathrm{SH} 3$ or $\mathrm{SH} 2$ domain with the corresponding domain from c-Yes, as determined by anti-pTyr western blot analysis of $\mathrm{SH} 3$ or $\mathrm{SH} 2$ domain affinity absorptions from lysates of cells expressing $\mathrm{Src}^{527 \mathrm{~F}}, \mathrm{Y}^{527 \mathrm{~F}}$, or Y $2^{527 \mathrm{~F}}$ 
(Figure 2, A and B). Additionally, neither the c-Yes SH3 nor SH2 domain, in the context of $\mathrm{Src}^{527 \mathrm{~F}}$, enhanced phosphorylation of proteins capable of binding specifically to either domain (Figure 2, A and B). These results indicate that there is functional redundancy between the c-Src and c-Yes SH3 and SH2 domains at the level of substrate selection; however it does not address the issue of specificity in protein binding.

Evidence for protein binding specificity was detected between both the SH3 and $\mathrm{SH} 2$ domains of c-Src and c-Yes. In vitro affinity absorptions indicated that AFAP-110 bound the c-Yes $\mathrm{SH} 3$ domain with much lower affinity than the c-Src SH3 domain (Chapter 2, Figure 1A). The c-Yes SH3 domain also failed to bind six tyrosinephosphorylated proteins (approximate molecular weights of 137, 108, 97, 91, 77, and 72 $\mathrm{kDa}$ ) that were affinity absorbed by the c-Src SH3 domain from lysates expressing $\mathrm{Src}^{527 \mathrm{~F}}$ or $\mathrm{Src}^{527 \mathrm{~F}} / \mathrm{c}-\mathrm{Y}$ es chimeras (Figure 2A). The c-Yes SH3 domain selectively bound to the $65 \mathrm{kDa}$ Yes associated protein (YAP 65) (Sudol, 1994), indicating that the GST$\mathrm{SH} 3{ }^{\text {Yes }}$ fusion protein was functional (Chapter 2, Figure 1B). Additionally, as mentioned above, chimeric proteins with the c-Yes SH3 domain, in contrast to $\mathrm{Src}^{527 \mathrm{~F}}$, did not efficiently co-immunoprecipitate with AFAP-110, however the c-Yes SH2 domain did not inhibit the co-immunoprecipitation of $\mathrm{Src}^{527 \mathrm{~F}} / \mathrm{c}$-Yes chimeras with AFAP-110 (Chapter 2, Figure 4D). Neither the c-Yes SH3 nor SH2 domain affected the ability of chimeric constructs to co-immunoprecipitate with p130 CAS. The c-Yes SH2 domain appeared to facilitate association of $\mathrm{Src}^{527 \mathrm{~F}} / \mathrm{c}$-Yes chimeras with an unidentified $87 \mathrm{kDa}$ tyrosine-phosphorylated protein (pp87), as only those chimeras with the c-Yes $\mathrm{SH} 2$ domain were found to efficiently co-immunoprecipitate with pp87 (Chapter 2, Figure 5). 
Differential protein binding between the c-Src and c-Yes SH3 domains was not unexpected. Differences in SH3 domain ligand specificity, to the amino or carboxy terminal sides of the core PXXP motif, between Src family members, including c-Src and c-Yes, have been shown previously using in vitro peptide binding studies (Rickles et al., 1994; Rickles et al., 1995; Sparks et al., 1996). The c-Src and c-Yes SH3 domains are very similar, however, differing at only 11 amino acid positions (Sudol et al., 1988; Xu et al., 1997), and these have not been definitively identified as crucial for ligand binding. In lieu of the homology between the c-Src and c-Yes SH3 domains, it is of little surprise that ligand specificity detected between the two was subtle (LXXRPLPXYP for Src, IXXRPLPXLP, where $\Psi$ represents an aliphatic residue, and X represents any amino acid) (Sparks et al., 1996). It was not determined if these differences in ligand specificity corresponded to actual differences in the ability of the c-Src and c-Yes SH3 domains to associate with full-length polypeptides, either in vitro or in vivo. The SH3 domains of cSrc, Fyn, and Lyn have previously demonstrated differential protein binding capacities in vitro (Weng et al., 1994), however this was not observed for the c-Src and c-Yes SH3 domains.

The data presented in Chapter 2 indicate that the differences in specificity between the c-Src and c-Yes SH3 domains are sufficient for differential protein/protein interactions both in vitro and in vivo. The individual amino acids responsible for ligand specificity, however, remain to be determined. Although systematic mutagenesis was not carried out to identify the individual residues responsible for imparting ligand specificity, they are likely to be localized to regions harboring non-homologous amino acid changes between the two SH3 domains. $\mathrm{Glu}^{97}$ and $\mathrm{Thr}^{98}$ in the c-Src SH3 domain, which 
correspond to $\mathrm{Thr}^{105}$ and $\mathrm{Asp}^{106}$ in the c-Yes SH3 domain, represent two nonhomologous amino acid differences between the c-Src and c-Yes SH3 domains. These residues lie within the RT loop, a region that connects two of the core beta sheets and contributes to ligand specificity (Noble et al., 1993; Erpel et al., 1995), thus identifying these amino acids as potentially important for directing SH3 domain specificity between c-Src and c-Yes. Further studies, in which these residues in the c-Src and c-Yes SH3 domains are mutated, will be necessary to fully assess their importance for ligand specificity between the two proteins.

While differences in ligand specificity were expected between the c-Src and cYes SH3 domains, the evidence for differential protein binding between the c-Src and cYes SH2 domains was a surprise. In vitro binding assays indicate that Src family kinases select the same cognate peptide ligand sequences (Songyang et al., 1993). The c-Src and c-Yes SH2 domains in particular have been demonstrated to bind the same sites within their cognate ligands (Alonso et al., 1995; Muthuswamy and Muller, 1995). While no significant differences in ligand specificity were detected between the c-Src and c-Yes SH2 domains in vitro (Figure 2B), an $87 \mathrm{kDa}$ tyrosine-phosphorylated protein (pp87) was observed to co-immunoprecipitate preferentially with $\mathrm{Src}^{527 \mathrm{~F}} / \mathrm{c}$-Yes chimeras with the cYes SH2 domain. This is strongly suggestive that pp 87 represents either a direct or indirect $\mathrm{SH} 2$ domain binding partner. Again, the question remains as to which amino acids dictate $\mathrm{SH} 2$ domain specificity between c-Src and c-Yes.

The SH2 domain is composed of two binding pockets separated by a large central beta sheet (Waksman et al., 1992; Eck et al., 1993). The two binding pockets accommodate phosphotyrosine and downstream residues within the cognate ligand 
respectively (Waksman et al., 1992; Eck et al., 1993). In the case of Src family kinases, the second ligand-binding pocket is typically occupied by a hydrophobic amino acid three residues downstream of the phosphotyrosine (pY+3) (Eck et al., 1993). As

phosphotyrosine binding is a conserved feature of all $\mathrm{SH} 2$ domains, and differences in the downstream binding pocket dictate ligand specificity between the various $\mathrm{SH} 2$ domain sub-classes, the $\mathrm{pY}+3$ pocket initially seemed the more attractive candidate for directing specificity between Src family kinases.

There are 27 amino acid differences between the c-Src and c-Yes SH2 domains, however, the most notable non-homologous differences between the SH2 domains, within the $\mathrm{pY}+3$ pocket, occur in the $\mathrm{B}$ helix, which forms the bottom of the pocket. These differences occur at $\mathrm{Gln}^{223}, \mathrm{Ala}^{228}$, and $\mathrm{Tyr}^{229}$ in $\mathrm{Src}^{527 \mathrm{~F}}$, corresponding to Lys, Lys, and His in c-Yes. However, the existing crystal structures of Src family SH2 domains (Sicheri et al., 1997; Xu et al., 1997) suggest that only His ${ }^{237}$ is likely to be directed toward the interior of the ligand-binding pocket (Waksman et al., 1992). Unfortunately, mutation of this residue to tyrosine did not affect the ability of $\mathrm{Y}^{527 \mathrm{~F}}$ to associate with pp87 (Figure 3, top panel). In a recent paper by Bradshaw et al., it was reported that $\mathrm{Cys}^{185}$ in the c-Src SH2 domain phosphotyrosine pocket, occupied by serine in all other Src family kinases ( $\mathrm{Ser}^{193}$ in c-Yes), imparts a reduced affinity for phosphotyrosine relative to serine (Bradshaw et al., 1999). Differences in phosphotyrosine affinity may represent a mechanism for dictating ligand specificity between the c-Src and c-Yes $\mathrm{SH} 2$ domains, as a non-consensus SH2 domain binding partner may be more readily accommodated by a higher affinity for phosphotyrosine. Mutation of this Ser, $\operatorname{Ser}^{185}$ in Y2 $2^{527 F}$, resulted in a mild loss of pp87 co- 
immunoprecipitation (Figure 3, top panel), however, this consistently corresponded with a decrease in the amount of Y $2^{527 F S 185 C}$ immunoprecipitated relative to the other $\mathrm{Src}$ 527F/cYes SH2 chimeric constructs (Figure 3, bottom panel), thus making it impossible to attribute the decreased co-immunoprecipitation of pp87 to mutation of residue 185 from Ser to Cys.

Differential phosphotyrosine affinity between the c-Src and c-Yes SH2 domains may also have implications for the relative abilities of these kinases to be activated in response to cellular signals. A higher affinity for phosphotyrosine may allow more efficient association between the phosphorylated tail and the $\mathrm{SH} 2$ domain, thus stabilizing the inactive, closed conformation. Interestingly, it was observed that c-Src/cYes chimeras with the c-Yes SH2 domain induced much lower levels of cellular phosphotyrosine and autophosphorylation than corresponding constructs with the c-Src SH2 domain (Figure 4). Mutation of Ser $^{185}$ to Cys in Y2, however, did not increase cellular phosphotyrosine or autophosphorylation of this kinase (Figure 5A and data not shown).

In an effort to determine why c-Src/c-Yes chimeric constructs with the c-Yes SH2 domain displayed reduced levels of cellular phosphotyrosine and autophosphorylation, the possibility that the closed conformation was stabilized by an ionic interaction between a positive-charged amino acid in the c-Yes $\mathrm{SH} 2$ domain ( $\mathrm{His}^{229}$ in $\left.\mathrm{Y} 2\right)$ and a negativecharged residue in the regulatory tail $\left(\mathrm{Glu}^{531}\right.$ in c-Src, $\mathrm{Asp}^{539}$ in c-Yes) was explored. Again, however, mutation of these residues to uncharged amino acids (His ${ }^{229}$ to Tyr, as in c-Src and $\mathrm{Glu}^{531}$ to Gln) did not result in increased kinase activation, as evidenced by autophosphorylation (Figure 5A, top panel) and phosphorylation of the regulatory 
tyrosine $\mathrm{Tyr}^{527}$ (Figure 5B, top panel). It thus appears that additional residues are involved in directing specificity between the c-Src and c-Yes SH2 domains; however, with no clues as to which amino acids might be responsible for $\mathrm{SH} 2$ domain specificity between the two kinases, a systematic series of SH2 domain mutations was deemed beyond the scope of these studies. Nevertheless, the results obtained in these studies indicate that the c-Src and c-Yes SH2 domains may contribute to signaling specificity between these proteins and may play a larger role in directing signaling specificity between Src family kinases than previously believed.

What are the functional implications of ligand specificity between the c-Src and cYes SH3 and SH2 domains? The results presented here do not suggest a strong influence on substrate selection. The tyrosine phosphorylation of AFAP-110 and other tyrosinephosphorylated SH3 domain binding partners induced by $\mathrm{Y}^{527 \mathrm{~F}}$ was surprising given the inefficient co-immunoprecipitation and in vitro binding between these proteins. As mentioned above, SH3 domain interactions are necessary for Src-induced tyrosine phosphorylation of AFAP-110 and other SH3 domain binding partners (Kanner et al., 1991; Weng et al., 1994; Guappone and Flynn, 1997). Mutations in either the SH3 domain binding site of AFAP-110 or the Src SH3 domain impair the ability of $\mathrm{Src}^{527 \mathrm{~F}}$ to induce tyrosine phosphorylation of AFAP-110 (Kanner et al., 1991; Guappone and Flynn, 1997). Due to the failure of the c-Yes SH3 domain to bind AFAP-110 efficiently in vitro or in vivo, a corresponding deficiency in the ability of $\mathrm{Y}^{527 \mathrm{~F}}$ to induce AFAP110 tyrosine phosphorylation was expected. This was not the case, however, as $\mathrm{Y} 3^{527 \mathrm{~F}}$ and $\mathrm{Src}^{527 F}$ induced comparable levels of AFAP-110 tyrosine phosphorylation. How are these seemingly contradictory results explained? One possible explanation is that the c- 
Yes SH3 domain, as opposed to a c-Src SH3 domain in which residues critical for ligand binding have been mutated, is capable of low-level association with AFAP-110. As seen in Chapter 2, there is modest association of the c-Yes SH3 domain with AFAP-110 in vitro, and this correlates with inefficient yet still detectable co-immunoprecipitation between $\mathrm{Y}^{527 \mathrm{~F}}$ and AFAP-110 in RIPA lysates. This relatively weak association between the c-Yes SH3 domain and AFAP-110 may allow a transient association between AFAP-110 and $\mathrm{Y}^{527 \mathrm{~F}}$ that is sufficient to permit tyrosine phosphorylation of AFAP-110 but not detectable co-immunoprecipitation between the two proteins.

The benefit of the more stable association between the c-Src or $\mathrm{Src}^{527 \mathrm{~F}} \mathrm{SH} 3$ domain and AFAP-110 remains unclear, as it does not result in a significant enhancement in tyrosine phosphorylation. Higher affinity association between the c-Src SH3 domain and AFAP-110 may allow formation of longer lived signaling complexes with distinct functions, including sub-cellular targeting, recruitment of signaling molecules, or alterations in the multimeric status of AFAP-110 itself. AFAP-110 has an intrinsic ability to bind actin filaments (Qian et al., 2000), and phosphorylation of AFAP-110 by PKC activates the ability of AFAP-110 to induce actin filament bundling in vitro (Qian et al., submitted). Thus, AFAP-110 may play a key role in remodeling the actin filament cytoskeleton in response to cellular signals, as occurs during embryonic development, cell division, and metastasis of cancer cells. $\mathrm{Src}^{527 \mathrm{~F}} / \mathrm{c}$-Yes chimeras with the c-Yes SH3 domain are capable of inducing actin filament remodeling in CEF comparable to $\mathrm{Src}^{527 \mathrm{~F}}$, thus it does not appear that stable association between $\operatorname{Src}^{527 \mathrm{~F}}$ and AFAP-110 is a requirement for induction of actin filament rearrangement. AFAP-110 association with active Src is also not sufficient to target Src to focal adhesion structures, as Fincham et al. 
demonstrated that mutants of Src that failed to localize to focal adhesions were still able to associate with AFAP-110 (Fincham et al., 2000).

Regardless of the biological importance of stable association between activated cSrc and AFAP-110, the inefficient association of c-Yes with AFAP-110 would presumably preclude the involvement of c-Yes in these signaling pathways. Conversely, stable association between pp87 and $\mathrm{Src}^{527 \mathrm{~F}} / \mathrm{c}$-Yes chimeras with the c-Yes $\mathrm{SH} 2$ domain, and theoretically activated c-Yes itself, may allow these proteins to participate in signaling pathways that do not involve c-Src. This may occur, as described above for Src/AFAP-110 interactions, through sub-cellular localization or formation of c-Yesspecific signaling complexes. Unfortunately, in comparison to c-Src, little is known about the biological functions of c-Yes, and there are few intermolecular interactions between c-Yes and its cellular binding partners that have demonstrated definitive functional implications. Association of c-Yes with YAP65 may facilitate localization of c-Yes to the apical surface in airway epithelial cells (Mohler et al., 1999), and it was recently demonstrated that recruitment of c-Yes to a signaling complex including betaarrestin 1 and the endothelin type-A receptor might allow c-Yes to participate in endothelin-stimulated glucose transport (Imamura et al., 2001). The only phenotype reported thus far as a result of loss of the c-yes gene is a deficiency in transcytosis mediated by the polyimmunoglobulin (pIg) receptor (Luton et al., 1999). Expression of the $\mathrm{Src}^{527 \mathrm{~F}} / \mathrm{c}-$ Yes chimeras in c-yes -/- cells may prove useful in uncovering why c-Src is unable to compensate for $\mathrm{c}-$ Yes in $\mathrm{pIg}$ receptor function and what role pp87 may play in this pathway. 
The affinity of the c-Src and c-Yes SH3 and SH2 domains for their cognate ligands also has implications for the activation of these kinases in response to cellular signals. The HIV-1 Nef protein is able to bind and activate Hck through SH3 domain interactions (Moarefi et al., 1997). Greenway and colleagues found that SH3 domain specificity between Src family kinases allows HIV-2 and SIV Nef to target the SH3 domains of Src and Fyn, as opposed to Hck (Greenway et al., 1999). Baisden et al. demonstrated that a mutant of AFAP-110 in which the leucine zipper motif is deleted is able to activate c-Src in an SH3 domain-dependent fashion, most likely through displacement of the intramolecular interaction between the SH3 domain and the kinase linker (Baisden et al., submitted). The low affinity interaction between AFAP-110 and the c-Yes SH3 domain may be insufficient to permit AFAP-110-induced activation of cYes in response to cellular signals. The functions of AFAP-110, both downstream and upstream of Src, remain the subject of ongoing investigations by others. It remains possible that pp87 binding contributes to the activation of c-Yes in a similar fashion, however, this will be difficult to determine experimentally until pp87 is cloned and identified.

In summary, the proteins studied in these experiments, including the known c-Src substrates p130 CAS and AFAP-110, as well as several unidentified tyrosine phosphorylated $\mathrm{SH} 3$ and $\mathrm{SH} 2$ domain binding partners, did not provide evidence for $\mathrm{SH} 3$ or SH2 domain-mediated substrate specificity between activated c-Src and c-Yes. While these results should not be over-interpreted to imply that SH3 and SH2 domain-mediated substrate selection between c-Src and c-Yes do not exist, the results imply that they may not be the primary means of generating signaling specificity. The SH3- and SH2- 
mediated specificity in protein binding observed in these experiments may contribute more to overall signaling specificity through differential signaling complex formation than through substrate selection.

In contrast to the differences in protein/protein interactions, differences in transcriptional activation and cell biology were primarily found to be due to differences in the $\mathrm{Src}^{527 \mathrm{~F}}$ and c-Yes amino terminal regions, including the $\mathrm{SH} 4$ and Unique domains. Chimeric proteins with the c-Yes amino terminus, $\mathrm{Y} 4 \mathrm{U} 32^{527 \mathrm{~F}}$ and $\mathrm{Y} 4 \mathrm{U}^{527 \mathrm{~F}}$, were deficient in upregulation of the heme oxygenase $1(\mathrm{HO}-1)$ gene product (Chapter 3, Figure 3B and Figure 6) and induction of the morphological and cytoskeletal changes that occur concomitant with overexpression of constitutively activated c-Src (Chapter 4, Figure 2B, 2C, 3B, 3C) despite the fact that they were fully active, as evidenced by antiphosphotyrosine and anti-phospho- $\mathrm{Y}^{416}$ western blot analysis (Chapter 4, Figure 2A). The decreased HO-1 induction and failure of these chimeras to induce rearrangement of the actin cytoskeleton was attributed to the presence of the c-Yes amino terminus, as $\mathrm{Y} 32^{527 \mathrm{~F}}$ was fully functional in regard to both of these processes. Both the SH4 and Unique domains were necessary in order to obtain these results, as chimeric proteins in which only the SH4 or Unique domain of $\mathrm{Src}^{527 \mathrm{~F}}$ was replaced by that of c-Yes induced actin filament rearrangement and efficient upregulation of HO-1 expression in CEF. In recent years, it has become clear that the amino terminal regions of Src family kinases do not simply localize these proteins to cellular membranes; they also regulate the compartmentalization of these kinases within cellular membranes. Specifically, it has been demonstrated that palmitoylation of Src family members dictates their inclusion into triton X-100 resistant membrane fractions, referred to as lipid rafts (Robbins et al., 1995). 
These are formed by aggregates of bulky lipids, including sphingolipids and cholesterol, and glycosylphosphatidyl inositol (GPI)-linked proteins (Brown and London, 1997). Several acylated signaling proteins, including many Src family kinases, are recruited to lipid raft fractions by virtue of their long chain fatty acid modifications. Fatty acylation is not necessarily a requirement for inclusion into lipid raft fractions, however, as several transmembrane receptors localize to lipid rafts, including the PDGF and Fce receptors (Brown and London, 1997; Honda et al., 2000).

As mentioned in Chapter 4, recruitment to lipid rafts is important for the participation of Src family kinases in several signaling pathways. The detection of c-Yes in caveolae, a sub-class of lipid rafts that are defined by the presence of caveolin, was among the first reports of Src family kinases in lipid rafts (Sugawara et al., 1991). The importance of c-Yes localization to caveolae, however, was not determined. ShenoyScaria et al. were among the first to observe that association between Src family kinases and a cellular binding partner was dependent on palmitoylation and localization to lipid rafts (Arreaza et al., 1994; Shenoy-Scaria et al., 1994). At a functional level, colocalization of the Fce receptor and Src family kinases in lipid raft fractions is essential for Fce receptor signaling (Honda et al., 2000; Suzuki et al., 2000). In this system, it was demonstrated that raft localization serves as a means of achieving signaling specificity, as c-Src was unable to reconstitute Fce receptor signaling unless a palmitoylation signal was included in the amino terminus (Honda et al., 2000; Suzuki et al., 2000). Palmitoylationdependent signaling is also observed for Lck, which is unable to transmit signals from the T-cell receptor in the absence of palmitoylation (Yurchak and Sefton, 1995). 
The results obtained in the present studies were particularly novel, in that the entire amino terminal region, including both the $\mathrm{SH} 4$ palmitoylation signal and the Unique domain, was required in order to achieve the differential effects on transcription and the actin cytoskeleton. This is of note in that previous studies have traditionally reported the functions of the SH4 and Unique domains individually, with little consideration given to the possibility that these domains may act in concert. The heterogeneity of the Unique domain across the Src family renders it virtually impossible to assign a generalized function. Lck associates with the CD4 and CD8 T cell coreceptors by virtue of its Unique domain (Shaw et al., 1989; Campbell et al., 1995), whereas the Unique domain of Lyn is responsible for mediating its association with the Fce receptor (Vonakis et al., 1997). The Unique domains of Fyn, c-Src, and c-Yes harbor phosphorylation sites that demonstrate some correlation with activation, however, the full importance of these phosphorylations remains unknown (Gould and Hunter, 1988; Morgan et al., 1989; Shenoy et al., 1989; Ariki et al., 1997; Hansen et al., 1997). Bijlmakers and colleagues reported that the Unique domain of Lck is sufficient for membrane localization, however, the construct used in those studies included the Lck SH4 domain (Bijlmakers et al., 1997).

Unlike the Unique domain, the function of the SH4 domain has been well established. Myristoylation, in conjunction with either palmitoylation or positivecharged amino acids, localize Src family kinases to cellular membranes (Resh, 1994). Palmitoylation then localizes Src family kinases to lipid raft fractions, allowing them to participate in signaling pathways originating in these membrane microenvironments. The requirement of the c-Yes $\mathrm{SH} 4$ domain for the inability of $\mathrm{Src}^{527 \mathrm{~F}} / \mathrm{c}-$ Yes chimeras to 
induce actin filament rearrangement and elevated HO-1 expression suggests that localization to lipid rafts is important in these results. However, the additional requirement for the c-Yes Unique domain complicates the issue. These results indicate that either the Unique domain participates in localization or that it, in conjunction with the SH4 domain, facilitates interaction with a protein or proteins that inhibit the ability of Y4U32 $2^{527 F}$ and $\mathrm{Y}^{4} \mathrm{U}^{527 \mathrm{~F}}$ to influence signaling pathways that induce HO-1 expression and actin filament rearrangement. Alternatively, the c-Yes Unique domain, again in conjunction with the SH4 domain, may prevent interaction with a Src substrate or binding partner that is necessary for initiation of these signaling events. Regardless, it is clear that both the c-Yes SH4 and Unique domains are required for the inability of proteins with the c-Yes amino terminus to efficiently induce elevated HO-1 expression and actin filament rearrangement. Thus, evidence is presented for a synergistic effect of the SH4 and Unique domains in c-Yes signaling.

What do these results reveal about the biological functions of c-Yes and the signaling pathways it utilizes? Unfortunately, they suggest more about what activated cYes cannot do than what it can. However, they may also provide insight as to why c-Yes is frequently unable to compensate for the absence of c-Src in c-src-/- cells. The c-Yes amino terminal region is necessary and sufficient to inhibit the ability of $\mathrm{Src}^{527 \mathrm{~F}} / \mathrm{c}-\mathrm{Yes}$ chimeras to participate in pathways that effect elevated induction of HO-1 and rearrangement of actin stress fibers into rosettes, lamellipodia, and filopodia. These results correlate well with data in the literature that indicate that c-Yes is unable to participate in related signaling pathways. Heme oxygenase 1 is an enzyme that cleaves the heme molecule into iron, carbon monoxide, and biliverdin (Maines, 1997; 
Montellano, 2000). HO-1 is expressed in a wide range of tissues in response to diverse cellular stimuli, including hypoxia (Maines, 1997), heavy metals (Masuya et al., 1998), Ras (Seko et al., 1996), MAP kinases (Koong et al., 1994; Seko et al., 1997), NFkB (Koong et al., 1994), Hypoxia-Inducible Transcription Factor 1 (HIF-1) (Lee et al., 1997), and, was shown in Chapter 3, Src activation. The ability of activated Src to induce HO-1 expression was not surprising in lieu of the fact that tyrosine kinase inhibitors block HO-1 induction in response to heavy metals (Masuya et al., 1998) and given the ability of v-Src to induce HIF-1 expression (Jiang et al., 1997). In fact, the reduced induction of $\mathrm{HO}-1$ by $\mathrm{Y} 4 \mathrm{U} 32^{527 \mathrm{~F}}$ and $\mathrm{Y}_{4} \mathrm{U}^{527 \mathrm{~F}}$ may be due to a failure to induce expression of HIF-1.

It was demonstrated in Chapter 4 that chimeric proteins with the c-Yes amino terminus failed to induce activation of the PI3K/Akt pathway (Chapter 4, Figure 8A and 8B). Several recent studies have indicated that activation of PI3K and/or Akt are necessary for induction of HIF-1 (Sandau et al., 2000; Zhong et al., 2000; Jiang et al., 2001). Failure to activate PI3K may prevent $\mathrm{Y} 4 \mathrm{U} 32^{527 \mathrm{~F}}$ and $\mathrm{Y} 4 \mathrm{U}^{527 \mathrm{~F}}$ from efficiently activating an oxidative stress response pathway that involves HIF-1 expression and subsequent expression of HO-1. These results suggest that $\mathrm{c}-\mathrm{Y}$ es, by virtue of its amino terminal region, may not participate in this oxidative stress response pathway. In agreement with this hypothesis, it was previously observed that c-Src, but not c-Yes, is activated in response to hypoxia, and results in expression of vascular endothelial growth factor, which is also induced in response to HIF-1 (Mukhopadhyay et al., 1995).

The inability of $\mathrm{Y} 4 \mathrm{U} 32^{527 \mathrm{~F}}$ and $\mathrm{Y} 4 \mathrm{U}^{527 \mathrm{~F}}$ to induce actin cytoskeletal rearrangement and morphological changes is also in agreement with results reported 
previously. As mentioned in Chapters 1 and 4, cells lacking the c-src gene are deficient in several processes that are dependent on the dynamic regulation of the actin cytoskeleton. These include cell migration (Hall et al., 1996), cell spreading (Kaplan et al., 1995), neurite extension (Ignelzi, Jr. et al., 1994), membrane ruffle and ring formation (Boyce et al., 1992), and osteoclast-mediated bone resorption (Soriano et al., 1991). The results reported in Chapter 4 suggest that the c-Yes amino terminus may prevent $\mathrm{Y} 4 \mathrm{U} 32^{527 \mathrm{~F}}$ and $\mathrm{Y} 4 \mathrm{U}^{527 \mathrm{~F}}$, and by extension activated c-Yes, from inducing remodeling of the actin cytoskeleton. Cells transfected with $\mathrm{Y} 4 \mathrm{U} 32^{527 \mathrm{~F}}$ or $\mathrm{Y} 4 \mathrm{U}^{527 \mathrm{~F}}$ retained a normal CEF morphology, characterized by intact focal adhesions and long actin stress fibers. In contrast, cells expressing $\mathrm{Src}^{527 \mathrm{~F}}$ and the other activated $\mathrm{Src}^{527 \mathrm{~F}} / \mathrm{c}$ Yes chimeras displayed a fully transformed morphology and a repositioning of actin from stress fibers into rosettes and actin-based membranous motility structures, such as lamellipodia and filopodia.

Investigation of signaling pathways downstream of activated Src revealed that $\mathrm{Src}^{527 \mathrm{~F}} / \mathrm{c}$-Yes amino terminal chimeras were able to induce activation of the MAPK pathway, as evidenced by Shc/Grb2 complex formation and activation of Raf-1 and Erk. These results are in agreement with published data that indicate that the mitogenic effects of Src activation may be separable from the effects on the actin cytoskeleton (Fincham et al., 1999). In contrast to their effects on the MAPK pathway, $\mathrm{Src}^{527 \mathrm{~F}} / \mathrm{c}-\mathrm{Y}$ es amino terminal chimeras were unable to induce activation of the PI3K/Akt pathway, as determined by activation-specific Akt phosphorylation and PI3K assay. Interestingly, Y4U32 ${ }^{527 \mathrm{~F}}$ was able to induce a transformed morphology and cytoskeletal rearrangements in a chemically immortalized CEF cell line (Figure 6A). In these cells, 
activation-specific Akt phosphorylation levels were comparable to those detected in cells expressing $\operatorname{Src}^{527 \mathrm{~F}}$ (Figure 6B). These data indicate a strong correlation between the ability of $\mathrm{Src}^{527 \mathrm{~F}} / \mathrm{c}$-Yes chimeras to induce activation of the PI3K/Akt pathway and their ability to cause disruption of actin filament structures.

PI3K is an important mediator of actin cytoskeletal rearrangement in Srctransformed cells and in response to a variety of other stimuli, however, it is not clear how PI3K mediates its effects on the cytoskeleton (Penuel and Martin, 1999; Krasilnikov, 2000; Odajima et al., 2000; Sohara et al., 2001). Akt may play a role in actin rearrangement mediated through PI3K, as may members of the Rho family of small GTPases, including RhoA, Rac-1 and Cdc42 (Krasilnikov, 2000). Although there is still controversy as to where Rho family members fall in the pathway leading to actin filament rearrangement in response to activated c-Src or PI3K, they appear to play a key role in these processes (Reif et al., 1996; Ren and Schwartz, 1998; Mackay and Hall, 1998; Aspenstrom, 1999; Cantrell, 2001). RhoA induces actin filament stress fibers; Rac-1 activation results in lamellipodia formation; and $\mathrm{Cdc} 42$ causes the formation of filopodia (Mackay and Hall, 1998). The loss of actin stress fibers in Src-transformed cells is accompanied by activation of 190 Rho-GAP, a GTPase activating protein and negative regulator of the RhoA G protein (Fincham et al., 1999). In preliminary results from CEF expressing $\mathrm{Y} 4 \mathrm{U} 32^{527 \mathrm{~F}}$ and $\mathrm{Y} 4 \mathrm{U}^{527 \mathrm{~F}}$, RhoA activity was not decreased, but in fact increased by a factor of approximately 1.5 (Figure 7). Thus, the inability of Y4U32 $2^{527 \mathrm{~F}}$ and $\mathrm{Y}_{4} \mathrm{U}^{527 \mathrm{~F}}$ to induce disruption and rearrangement of actin stress fibers may be due to a failure to activate PI3K and to inactivate RhoA. Whether RhoA acts downstream or upstream of PI3K in these cells is at this point unknown. Regardless, our results suggest 
the possibility that the amino terminal region prevents c-Yes from participating in dynamic regulation of the actin cytoskeleton by preventing activation of PI3K and inactivation of RhoA. This explanation is in agreement with the ability of $\mathrm{v}$-Yes to induce cell transformation and activation of PI3K (Fukui et al., 1991), as the v-Yes amino terminus is fused with the viral Gag sequence and is not palmitoylated (Beemon and Mattingly, 1986). Expression of these chimeric constructs in c-src-/- cells may aid in the determination of the validity of this model outside of the chicken embryo fibroblast system. As mentioned above, the only observed defect in c-yes -/- cells is a deficiency in transcytosis of IgA mediated by the pIg receptor (Luton et al., 1999). Expression of these chimeras in c-yes -/- cells may aid in the determination of why c-Src is unable to compensate for c-Yes in this pathway and whether this may also be attributed to amino terminal differences between the two proteins.

The results obtained in these experiments raise questions about the relative contributions of c-Src and c-Yes to the onset and progression of human cancers. The transition of a cell from the normal to the cancerous state is a multi-step process, and while the biochemical pathways utilized to achieve full transformation may vary, there are certain phenotypic changes that are almost universally present. The experiments outlined in these studies directly and indirectly touch on four of these: cell proliferation, resistance to apoptosis, rearrangement of the cytoskeletal architecture, and the ability to survive in the face of oxidative stress. Cancerous cells are characterized by unchecked cell division (Molinari, 2000), and remodeling of the actin cytoskeleton allows them to invade surrounding tissue and metastasize (Pawlak and Helfman, 2001). Resistance to apoptosis allows the continued survival of the tumor in the face of DNA damage and 
removal from its normal cellular milieu (Howell, 2000). Resistance to oxidative damage allows cancerous cells to survive oxidative threats from the body's defense system and hypoxic conditions encountered in the interior of a tumor in the absence of vascularization (Pugh et al., 2001). The studies presented in this thesis, along with those in the literature, either directly demonstrate or suggest that c-Src activation is able to induce all of these effects.

In Chapter 4, it was demonstrated that $\mathrm{Src}^{527 \mathrm{~F}}$ expression results in activation of the MAPK pathway, which in turn induces cell cycle progression (Roussel, 1998). It was also shown that $\mathrm{Src}^{527 \mathrm{~F}}$ induces efficient rearrangement of the actin cytoskeleton, repositioning actin from stress fibers to actin based motility structures. c-Src activation also induces activation of the Akt/PI3K pathway, which in addition to its effects on the cytoskeleton, is an important mediator of cell survival and resistance to apoptosis (Krasilnikov, 2000). Finally, it was demonstrated that $\mathrm{Src}^{527 \mathrm{~F}}$ induces high levels of HO1 expression, a protein that is involved in the resistance to hypoxic stress (Maines, 1997).

In the present studies, proteins with the c-Yes amino terminus were only able to induce one of the effects mentioned above, at levels that approached those achieved by $\mathrm{Src}^{527 \mathrm{~F}}$ : activation of the MAPK pathway. Unfortunately, due to the lack of a constitutively activated c-Yes, there is currently no data available in the literature on the phenotype of cells expressing this protein and how they differ from cells expressing active c-Src. Y4U32 $2^{527 \mathrm{~F}}$ should functionally approximate constitutively active c-Yes $\left(\mathrm{Yes}^{535 \mathrm{~F}}\right)$, as the only differences between the two proteins occur in their highly homologous tyrosine kinase domains. c-Yes is frequently activated in a subset of human cancers, most notably colon carcinoma and melanoma (Loganzo, Jr. et al., 1993; Park et 
al., 1993; Pena et al., 1995; Marchetti et al., 1998). In these cancers, the level of c-Yes activation correlates with the metastatic potential of the cells. How then does activated cYes contribute to the cancerous phenotype? Activation of the MAPK pathway may allow c-Yes to induce mitogenesis and thereby contribute to cell transformation. Tsygankova et al. demonstrated the importance of c-Yes in activation of the MAPK pathway in response to angiotensin II treatment of liver epithelial cells (Tsygankova et al., 1998). Recent evidence also suggests that c-Yes may be important in regulation of cell adhesions (Owens et al., 2000) and VEGF-induced vascular permeability (Eliceiri et al., 1999). c-Yes is most frequently activated in cancers of epithelial origin, thus c-Yes activation may contribute to metastasis through disruption of tight junctions and/or through an increase in vascular permeability that would enhance angiogenesis.

While the data presented in this thesis suggest that the c-Yes amino terminus prevents its participation in pathways that regulate actin filament rearrangement, it should be noted that palmitoylation of Src family kinases is a reversible process (Yurchak and Sefton, 1995; Bano et al., 1998). As the SH4 domain is essential for the loss of function associated with the c-Yes amino terminus, regulated de-palmitoylation of c-Yes in cancerous cells may allow the protein to move out of lipid raft fractions and participate in signaling pathways that were previously inaccessible. As mentioned above, $\mathrm{v}$-Yes is not palmitoylated and is capable of inducing PI3K activation, CEF transformation, and tumor formation in chickens (Beemon and Mattingly, 1986; Toyoshima et al., 1987; Fukui et al., 1991). The palmitoylation status of activated c-Yes in cancerous cells has not been reported. Nevertheless, the results presented here indicate that the c-Yes amino terminus, including the SH4 palmitoylation signal and the Unique domain, are crucial for the 
inability of activated $\mathrm{Src} /$ Yes chimeras to induce actin filament rearrangement, activation of the PI3K/Akt pathway, and induction of HO-1 expression. The amino terminal region may thus limit the ability of c-Yes itself to contribute to the onset and progression of the metastatic phenotype.

The experiments outlined in this thesis have examined the contributions of the non-catalytic functional domains to signaling specificity between the c-Src and c-Yes tyrosine kinases. The results indicate that each non-catalytic functional domain contributes to some aspect of signaling specificity. These results allow the proposal of a working model for specificity in signaling between c-Src and c-Yes (Figure 8). In this model, after synthesis, the two proteins are rapidly localized to cellular membranes. Upon membrane localization, c-Src and c-Yes differentially partition into detergent soluble and insoluble regions, respectively, as dictated by differences in their amino termini. This may be the most important contribution to signaling specificity between cSrc and c-Yes, as it determines the subset of proteins available for intermolecular interactions. Protein/protein interactions mediated by the Unique domain may contribute to membrane compartmentalization or stable complex formation with intermolecular binding partners that allow initiation of downstream signaling events. Protein/protein interactions or phosphorylation events mediated by the Unique domains may also contribute to differential activation of c-Src and c-Yes, through destabilization of the closed conformation. Signaling specificity is further fine-tuned through intermolecular interactions mediated by the $\mathrm{SH} 3$ and $\mathrm{SH} 2$ domains. These regions serve to select substrates, and perhaps more importantly, direct stable associations with protein binding partners that may influence sub-cellular localization, activation state, and formation of 
multi-protein signaling complexes through which specific signals are sent. This model for signaling specificity does not exclude the ability of c-Src and c-Yes to function redundantly. Src family kinases are rapidly $(5 \mathrm{~min})$ localized to cellular membranes after synthesis, however, it was observed for Fyn that localization to detergent resistant lipid rafts occurs after a 10-20 min lag time (van't Hof and Resh, 1997). c-Yes and c-Src may thus interact with overlapping subsets of proteins before c-Yes partitions into lipid rafts. Additionally, regulated de-palmitoylation of c-Yes, and partitioning of other proteins between raft and non-raft fractions, may bring c-Src and c-Yes into contact with overlapping sets of proteins.

This model for signaling specificity between c-Src and c-Yes may be more broadly applicable to signaling specificity between Src family kinases in general. Understanding how these kinases are capable of sending specific signals will be important in the overall understanding of the function of these proteins, and in their possible usage as targets for rational drug design. Src family kinase inhibitors have shown promise as anti-cancer drugs due to their ability to block cell proliferation, however, most of these compounds do not distinguish between Src family members (Lawrence and Niu, 1998; Moasser et al., 1999; Al Obeidi and Lam, 2000). Studies in mice lacking one or more Src family members have revealed that loss of individual Src family kinases is more readily tolerated than loss of multiple Src family members (Stein et al., 1994). Thus, non-specific inhibition of Src family kinases may have deleterious effects as a result of disruption of multiple signaling pathways. A more ideal treatment strategy would involve inhibition of only the kinase or kinases that were abnormally activated in a particular tumor. A comprehensive knowledge of the roles of the 
functional domains in generating signaling specificity may allow the design of drugs specific for individual Src family kinases that would avoid the potentially deleterious effects of global Src family kinase inhibition. 


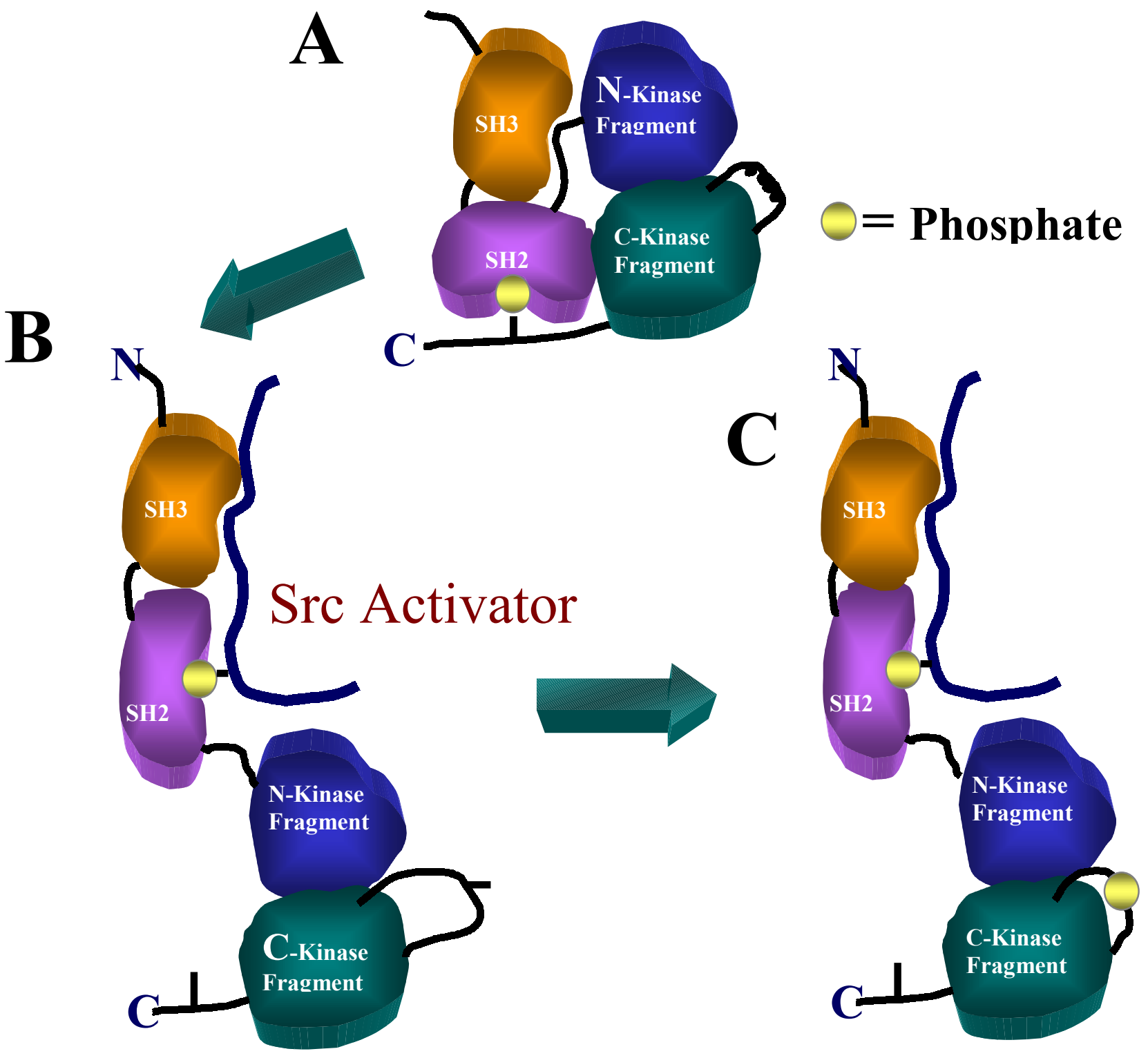

Figure 1. Src family kinase activation. (A) In the inactive state, Src family kinases exist in the closed or assembled conformation. This structure is stabilized primarily by two intramolecular interactions: association of the SH2 domain with the phosphorylated tail tyrosine ( $\mathrm{Y}^{527}$ in $\mathrm{c}-\mathrm{Src}$ ) and binding of the $\mathrm{SH} 3$ domain to the $\mathrm{SH} 2 /$ kinase linker, which 
forms a left-handed type II helix in the closed conformation. (B) SH3 and SH2 domain binding partners may displace the SH3/linker and/or SH2/carboxy terminal tyrosine interactions, thus shifting the conformation of the protein from closed to open. The transition to the open conformation allows access of ATP and substrates to the kinase active site. (C) Activation of the kinase is accompanied and enhanced by autophosphorylation at a key tyrosine residue $\left(\mathrm{Y}^{416}\right.$ in c-Src) in the activation loop. (Cartoon provided by Amanda Gatesman). 
A

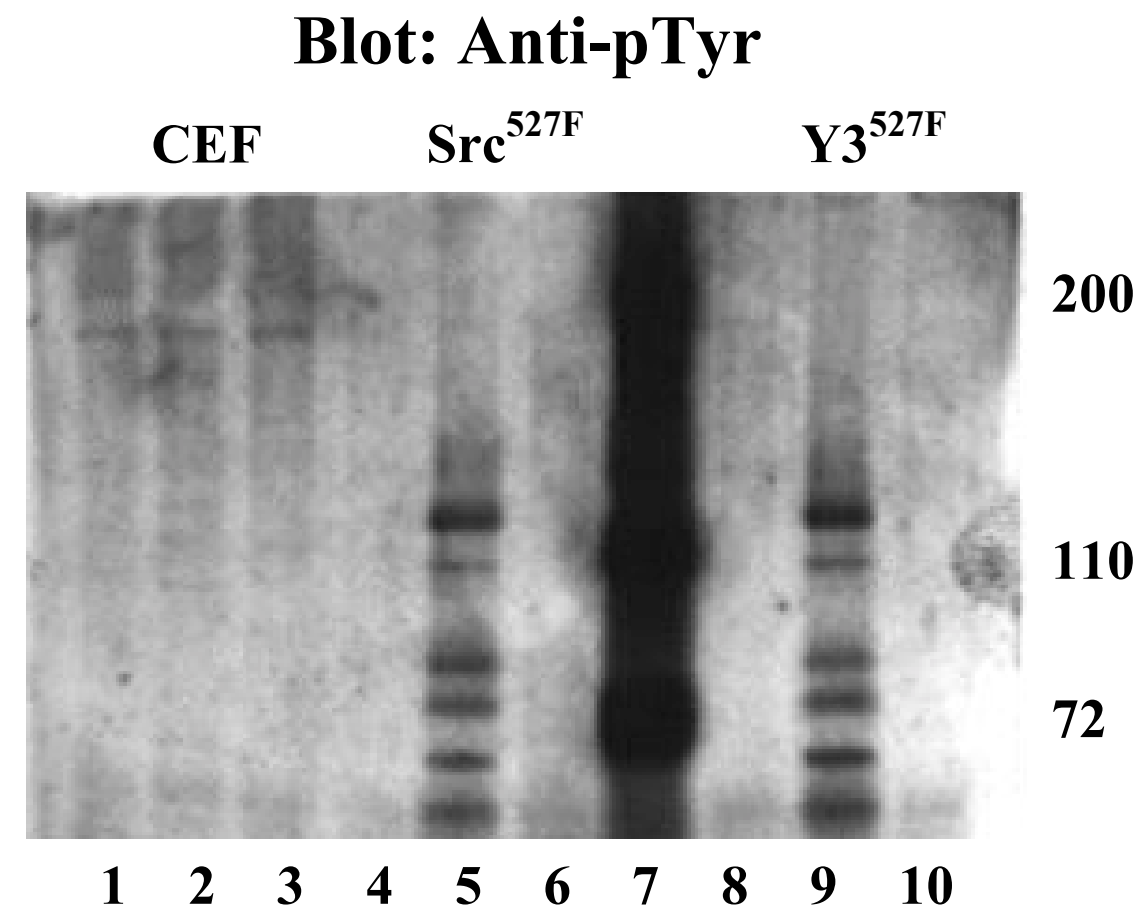

B

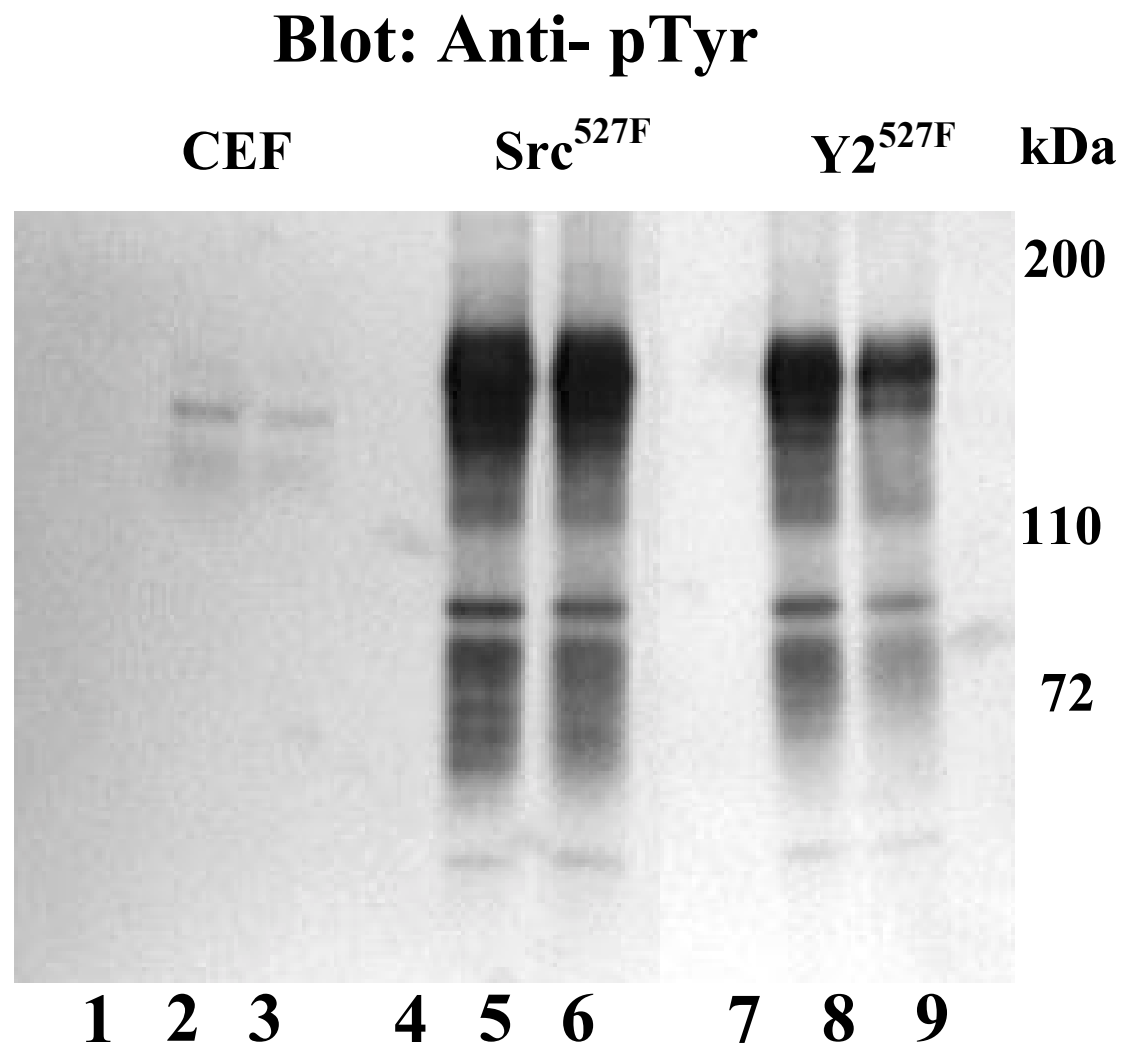


Figure 2. The c-Yes SH3 and SH2 domains do not affect tyrosine phosphorylation of cSrc SH3 and SH2 domain binding partners. (A) Mock-transfected CEF or cells expressing Src ${ }^{527 \mathrm{~F}}, \mathrm{Y}^{527 \mathrm{~F}}, \mathrm{Y}^{527 \mathrm{~F}}, \mathrm{Y} 32^{527 \mathrm{~F}}$, or Y4U32 $2^{527 \mathrm{~F}}$ were lysed in RIPA buffer, and five hundred $\mu \mathrm{g}$ of cell lysates were absorbed with GST, GST-SH3 ${ }^{\text {Src }}$, or GST-SH3 ${ }^{\text {Yes }}$ bound to glutathione-sepharose beads. Bound proteins were eluted by boiling in Laemmli's sample buffer (LSB), and resolved by $8 \%$ SDS-PAGE. After transfer to PVDF membrane, proteins were blocked in $1 \% \mathrm{BSA} / \mathrm{TBS}-\mathrm{T}$ and probed with a rabbit anti-phosphotyrosine antibody. Results are shown for mock-transfected CEF and cells expressing $\mathrm{Src}^{527 \mathrm{~F}}$ and $\mathrm{Y}^{527 \mathrm{~F}}$. Lanes 1, 4, $8=\mathrm{GST}$; Lanes 2, 5, $9=\mathrm{GST}-\mathrm{SH} 3^{\mathrm{Src}}$; Lanes 3, 6, $10=$ GST-SH3 ${ }^{\text {Yes. }}$ Lane $7=$ Molecular weight marker. (B) Experiments were performed as in (A), however, lysates were absorbed with GST, GST-SH2 ${ }^{\mathrm{Src}}$, or GST$\mathrm{SH} 2{ }^{\text {Yes }}$. Results are shown for mock-transfected CEF and cells expressing $\mathrm{Src}^{527 \mathrm{~F}}$ and $\mathrm{Y}^{527 \mathrm{~F}}$. Lanes 1, 4, $7=\mathrm{GST}$; Lanes 2, 5, $8=\mathrm{GST}_{-\mathrm{SH}} 2^{\text {Src }}$; Lanes 3, 6, $9=\mathrm{GST}-\mathrm{SH} 2^{\text {Yes }}$. 


\section{IP: Anti-Src \\ Blot: Anti-pTyr}

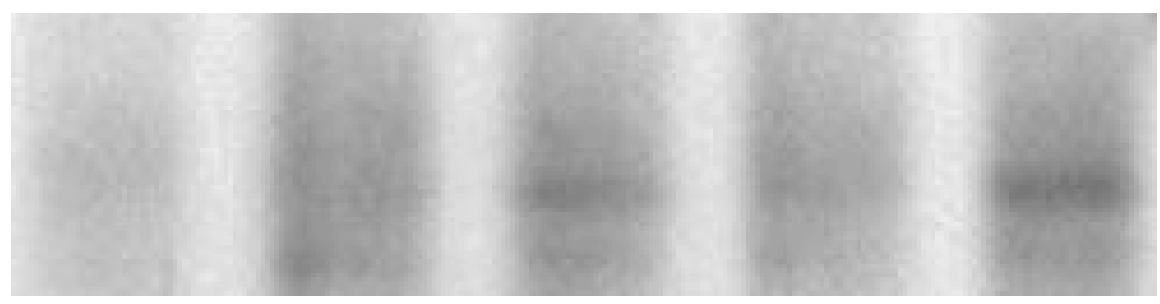

\section{Blot: Anti-Src}

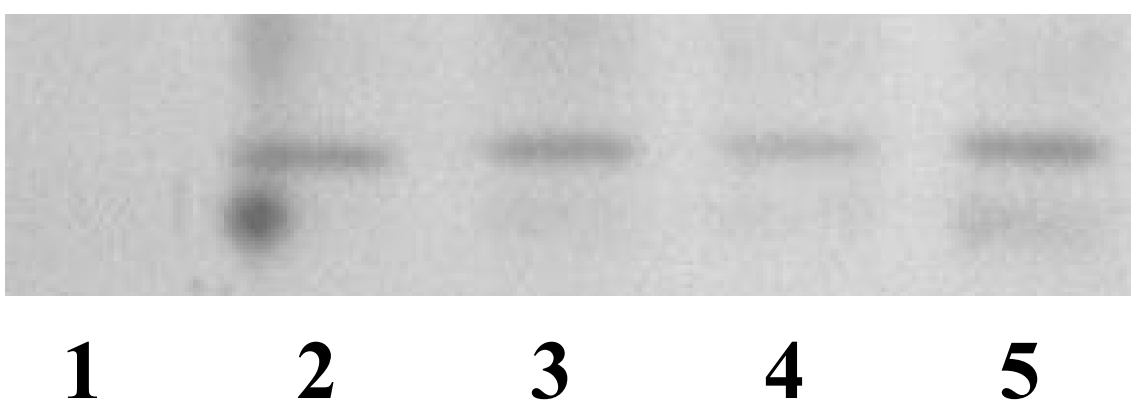

Figure 3. Association of $\mathrm{Src}^{527 \mathrm{~F}}$ and $\mathrm{Y} 2^{527 \mathrm{~F}}$ mutants with pp87. $\mathrm{Y}^{\mathrm{S} 185 \mathrm{C}}, \mathrm{Y}^{\mathrm{H} 229 \mathrm{Y}}$, and $\mathrm{Y}^{\mathrm{E} 531 \mathrm{Q}}$ mutants were generated via mutation of $\mathrm{Ser}^{185}$ to Cys (TCC $\rightarrow \mathrm{TGC}$ ), $\mathrm{His}^{229}$ to Tyrosine $(\mathrm{CAC} \rightarrow \mathrm{TAC})$, or $\mathrm{Glu}^{531}$ to $\mathrm{Gln}(\mathrm{GAG} \rightarrow \mathrm{CAG})$ in $\mathrm{Y} 2$. Mutagenesis was verified via DNA sequencing. Constitutive activation of the $\mathrm{Y}^{\mathrm{S} 185 \mathrm{C}}$ and $\mathrm{Y}^{\mathrm{H} 229 \mathrm{Y}}$ mutants was achieved via replacement of the c-Src tyrosine kinase domain coding-sequence with that of $\mathrm{Src}^{527 \mathrm{~F}}$ as described in Chapter 2. Mock-transfected CEF or cells expressing $\mathrm{Src}^{527 \mathrm{~F}}, \mathrm{Y}^{527 \mathrm{~F}}, \mathrm{Y}^{527 \mathrm{FS} 185 \mathrm{C}}$, or Y $2^{527 \mathrm{FH} 229 \mathrm{Y}}$ were lysed in RIPA, and $500 \mu \mathrm{g}$ of lysates were immunoprecipitated with the rabbit anti-Src antibody. Co-immunoprecipitated 
proteins were eluted via boiling in LSB and resolved by $8 \%$ SDS-PAGE. Proteins were transferred to PVDF, blocked in 1\% BSA/TBS-T and probed with a rabbit antiphosphotyrosine antibody. Blots were stripped and re-probed with rabbit anti-Src to assess the relative levels of immunoprecipitated protein. Lane $1=\mathrm{CEF}$; Lane $2=\mathrm{Src}^{527 \mathrm{~F}}$; Lane $3=\mathrm{Y} 2^{527 \mathrm{~F}}$; Lane $4=\mathrm{Y} 2^{527 \mathrm{FS} 185 \mathrm{C}}$; Lane $5=\mathrm{Y} 2^{527 \mathrm{FH} 229 \mathrm{Y}}$. Western blots are representative of three independent experiments. 

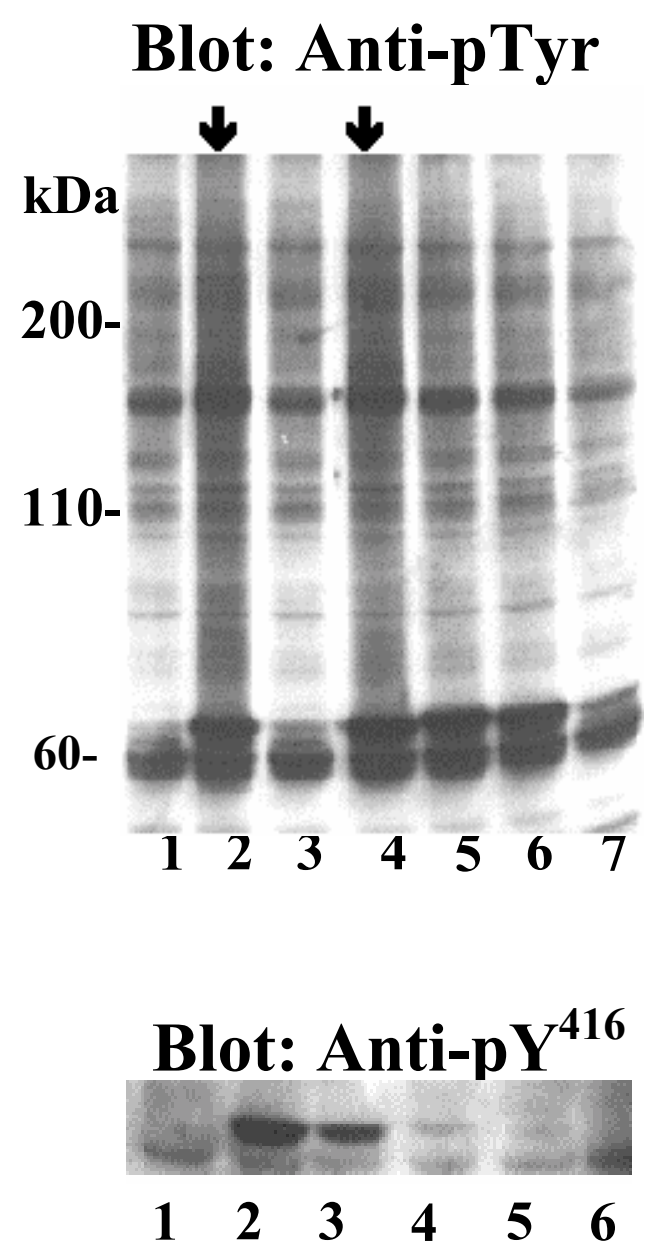

Figure 4. Induction of cellular phosphotyrosine and autophosphorylation of c-Src/c-Yes chimeras. Mock-transfected CEF or cells expressing c-Src, c-Yes, Y3, Y2, Y32, or Y4U32 were lysed in RIPA buffer, and $30 \mu \mathrm{g}$ of lysates were resolved by $8 \%$ SDSPAGE, transferred to PVDF, blocked in $1 \%$ BSA/TBS-T, and probed with a rabbit antiphosphotyrosine antibody. Lane 1 = CEF; Lane 2 =c-Src; Lane 3 = c-Yes; Lane 4 = Y3; Lane 5 =Y2; Lane $6=\mathrm{Y} 32$; Lane $7=\mathrm{Y} 4 \mathrm{U} 32$. In the bottom panel, CEF, c-Src, Y3, Y2, Y32, or Y4U32 lysates were prepared for western blot analysis as described above and 
probed with a rabbit anti-phospho- $\mathrm{Y}^{416}$ antibody. Lane $1=\mathrm{CEF}$; Lane 2 = c-Src; Lane 3 $=\mathrm{Y} 3$; Lane $4=\mathrm{Y} 2$; Lane $5=\mathrm{Y} 32$; Lane $6=\mathrm{Y} 4 \mathrm{U} 32$. Western blots are representative of three independent experiments. 
A

$$
\text { Blot: Anti-pY } Y^{416}
$$

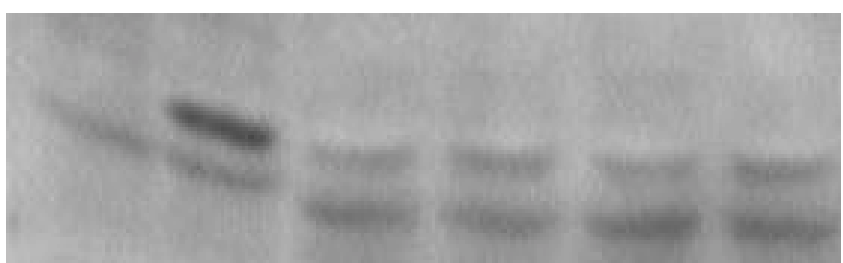

Blot: EC10

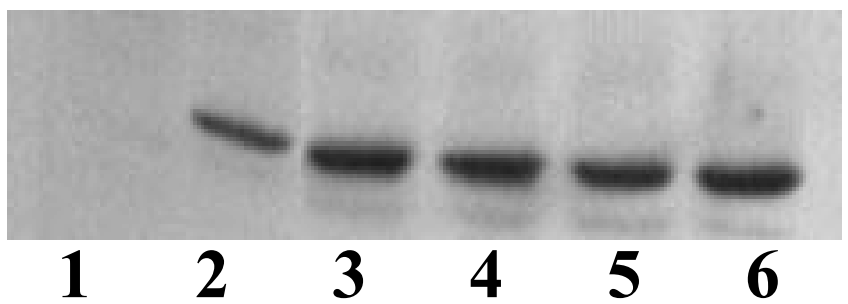

B

$$
\text { Blot: Anti-pY } Y^{527}
$$

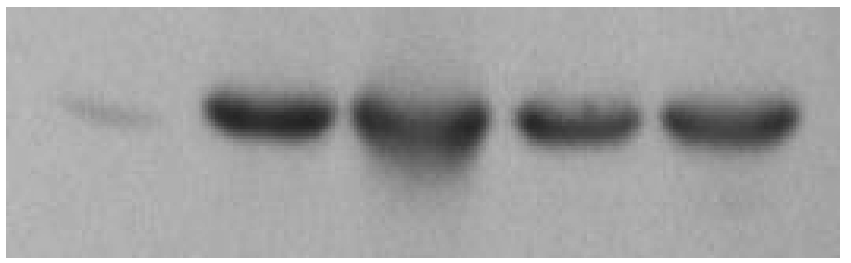

\section{Blot: EC10}

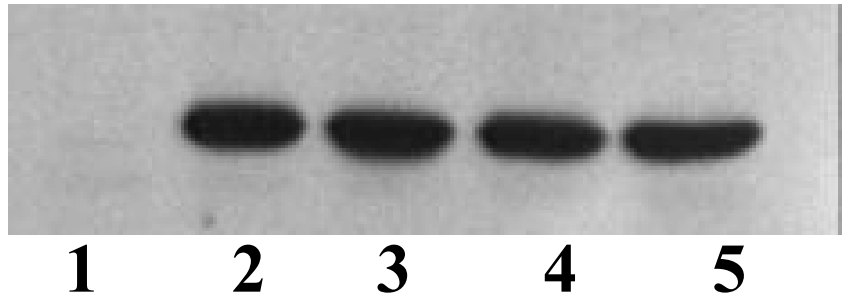


Figure 5. Activation state of c-Src, Y2, and Y2 mutants in CEF. Mock-transfected CEF or cells expressing c-Src, Y2, Y2 ${ }^{\mathrm{S} 185 \mathrm{C}}, \mathrm{Y} 2^{\mathrm{H} 229 \mathrm{Y}}$, or $\mathrm{Y} 2^{\mathrm{E} 531 \mathrm{Q}}$ were lysed in RIPA buffer, and $50 \mu \mathrm{g}$ of lysates were resolved by $8 \%$ SDS-PAGE, transferred to PVDF, blocked in $5 \%$ milk/TBS-T, and probed with either a rabbit anti-phospho- $\mathrm{Y}^{416}$ antibody (A, top panel) or a rabbit anti-phospho- $\mathrm{Y}^{529}$ antibody (B, top panel). In the bottom panels, blots were stripped and re-probed with rabbit anti-Src. (A) Lane 1=CEF; Lane 2 = c-Src; Lane $3=\mathrm{Y} 2$; Lane $4=\mathrm{Y} 2^{\mathrm{S} 185 \mathrm{C}} ;$ Lane $5=\mathrm{Y} 2^{\mathrm{H} 229 \mathrm{Y}}$; Lane $6=\mathrm{Y} 2^{\mathrm{E} 531 \mathrm{Q}}$. (B) Lane $1=\mathrm{CEF}$; Lane $2=\mathrm{Y} 2$; Lane $3=\mathrm{Y} 2^{\mathrm{S} 185 \mathrm{C}}$; Lane $4=\mathrm{Y} 2^{\mathrm{H} 229 \mathrm{Y}}$; Lane $5=\mathrm{Y} 2^{\mathrm{E} 531 \mathrm{Q}}$. 
A
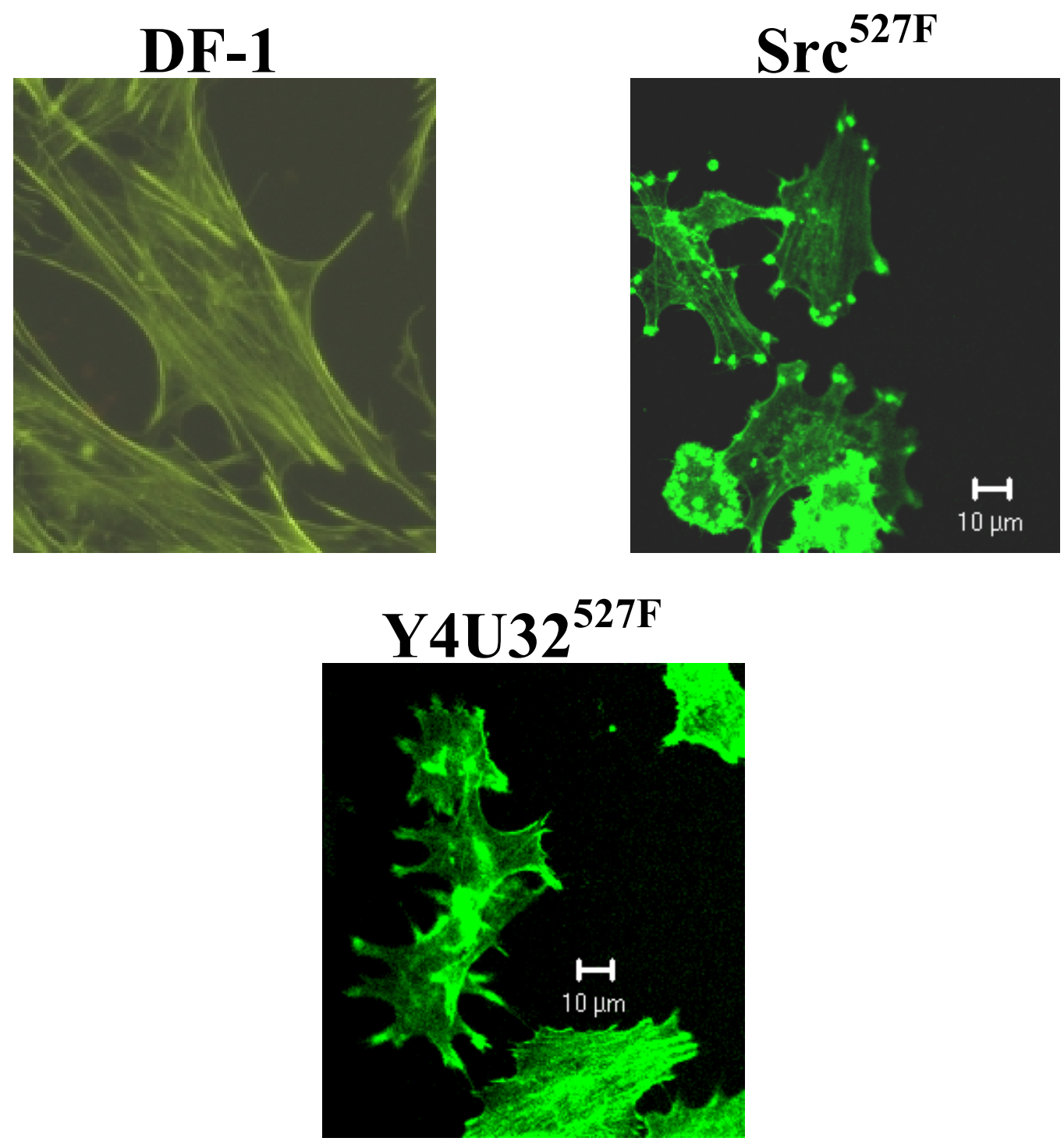

B

Blot: Anti-phospho-Akt

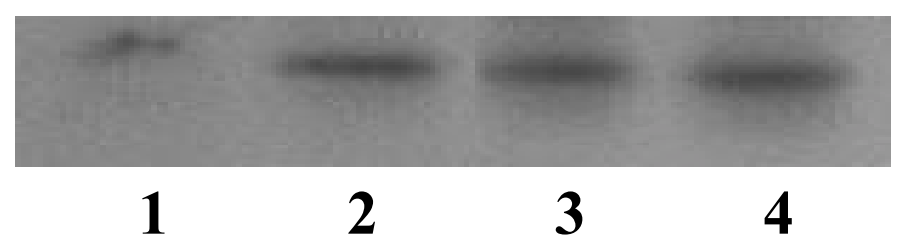


Figure 6. $\mathrm{Y} 4 \mathrm{U} 32^{527 \mathrm{~F}}$ induces actin filament rearrangement and Akt activation in DF-1 cells. (A) Mock-transfected DF-1 or cells expressing Src ${ }^{527 \mathrm{~F}}$ or Y4U32 $2^{527 \mathrm{~F}}$ were fixed at $50 \%$ confluence on cover slips for $15 \mathrm{~min}$ in $3.7 \%$ formaldehyde, followed by three washes in PBS. Cells were permeablized via incubation for 4 min with $0.4 \%$ triton X100. After three PBS washes, cells were stained with FITC-phalloidin $(5 \mu \mathrm{g} / \mathrm{ml})$, mounted on slides, and visualized via Zeiss LSM 510 confocal microscopy (63x objective). These results are representative of two independent experiments. (B) Mocktransfected DF-1 or cells expressing $\mathrm{Src}^{527 \mathrm{~F}}$, Y4U32 $2^{527 \mathrm{~F}}$, or $\mathrm{Y}_{4} \mathrm{U}^{527 \mathrm{~F}}$ were lysed in RIPA, and $50 \mu \mathrm{g}$ of lysates were resolved by $8 \%$ SDS-PAGE, transferred to PVDF, blocked with 5\% milk/TBS-T, and probed with an anti-phospho-Akt antibody (Upstate Biotechnology). Lane $1=$ Mock-transfected DF-1; Lane $2=\mathrm{Src}^{527 F} ;$ Lane $3=$ $\mathrm{Y} 4 \mathrm{U} 32^{527 \mathrm{~F}} ;$ Lane $4=\mathrm{Y}_{4} \mathrm{U}^{527 \mathrm{~F}}$. 


\section{$\underline{\text { Rho Activity Assay }}$}

\section{Blot: Anti-Rho}

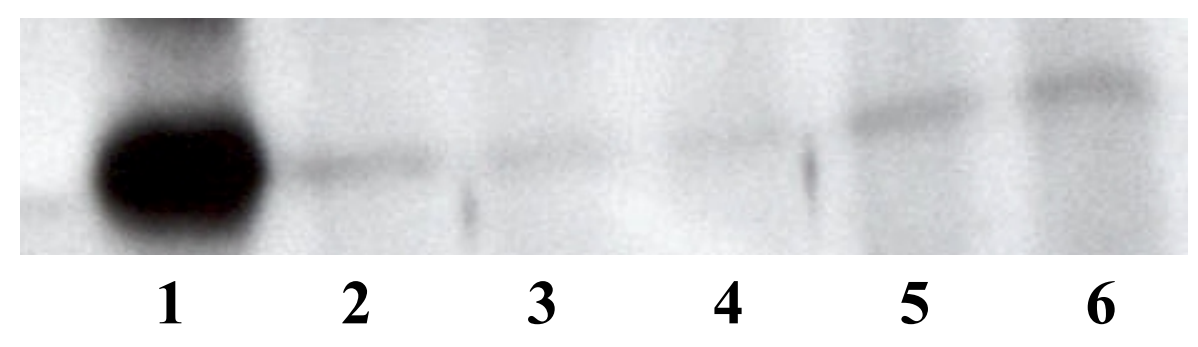

Figure 7. $\mathrm{Src}^{527 \mathrm{~F}} / \mathrm{c}-$ Yes chimeras with the c-Yes amino terminus fail to inactivate Rho. The Rho activation assay kit was obtained from Upstate Biotechnology and performed as described in the protocol. Briefly, mock-transfected CEF, or cells expressing $\mathrm{Src}^{527 \mathrm{~F}}$, $\mathrm{Y} 32^{527 \mathrm{~F}}$, Y4U32 $2^{527 \mathrm{~F}}$, or Y4U ${ }^{527 \mathrm{~F}}$ were lysed in Rho lysis buffer, and quantitated for total protein content. Fifty $\mu$ l of Rhotekin Rho binding domain-conjugated agarose beads were added for each $500 \mu \mathrm{l}$ of cell lysates, followed by gentle rocking for $45 \mathrm{~min}$ at $4{ }^{\circ} \mathrm{C}$. Beads were collected by centrifugation, and bound proteins were eluted by boiling in sample buffer. Bound proteins were separated by $12 \%$ SDS-PAGE, transferred to PVDF, blocked in 3\% milk/PBS, and probed with an anti-Rho antibody (Upstate Biotechnology). Lane 1 = Anti-Rho immunoprecipitation from CEF lysates; Lane 2 = $\mathrm{CEF}$; Lane $3=\mathrm{Src}^{527 \mathrm{~F}}$; Lane $4=\mathrm{Y} 32^{527 \mathrm{~F}}$; Lane $5=\mathrm{Y} 4 \mathrm{U} 32^{527 \mathrm{~F}}$; Lane $6=\mathrm{Y}^{2} \mathrm{U}^{527 \mathrm{~F}}$. 


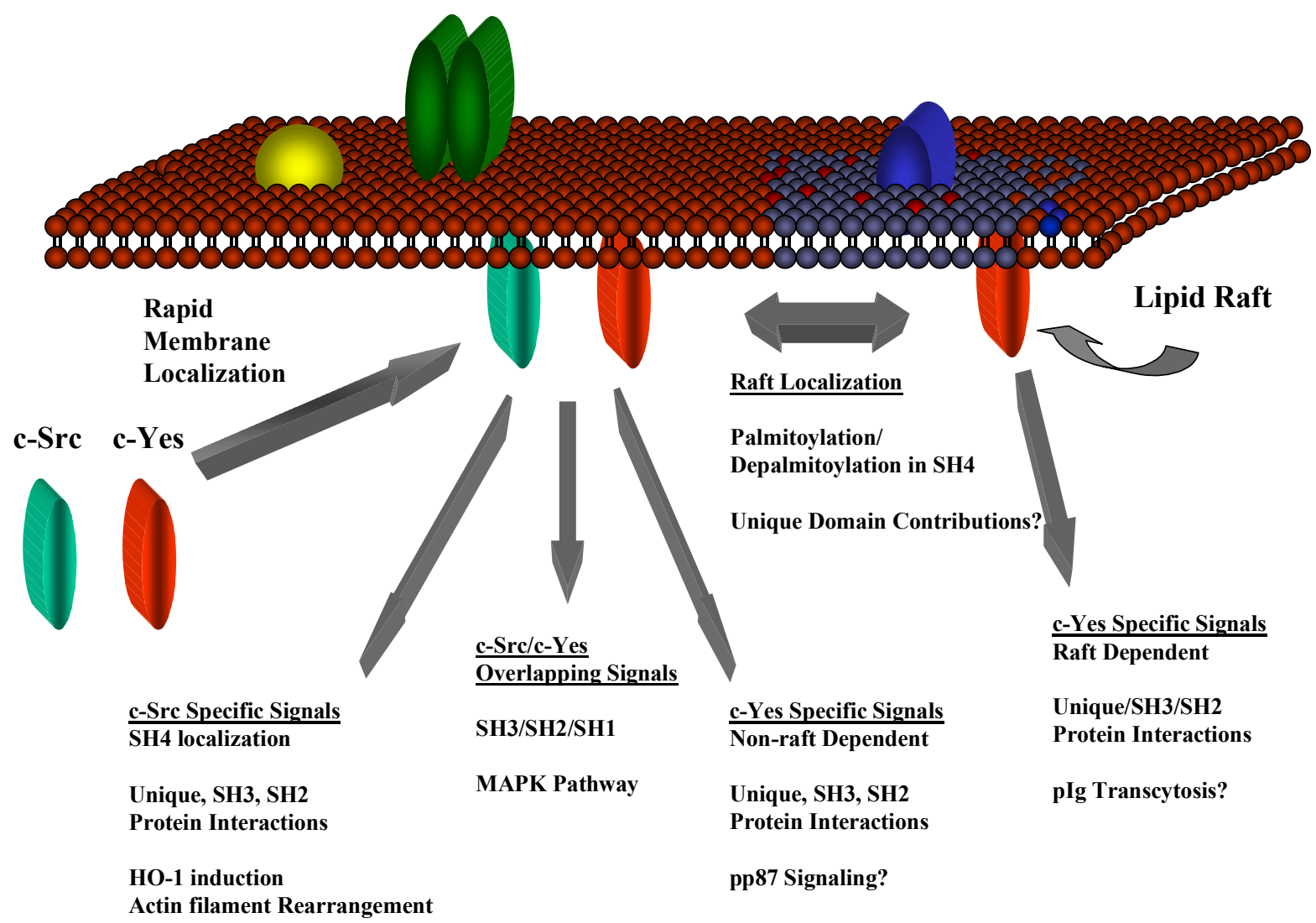

Figure 8. Model for Signaling Specificity between c-Src and c-Yes. In this model, after synthesis, c-Src and c-Yes are rapidly localized to cellular membranes. At the membrane, subtle differences in signaling between the two proteins may be mediated by differential protein/protein interactions through the $\mathrm{SH} 3, \mathrm{SH} 2$, and Unique domains. These protein/protein interactions may serve to affect subcellular localization, direct stable signaling complex formation, or select substrates for phosphorylation. The SH3, SH2, and SH1 domains may also serve to transmit overlapping signals between the kinases. After membrane localization, c-Yes partitions into lipid raft fractions. The reversible nature of palmitoylation may allow c-Yes to traffic in and out of lipid rafts. 
Sequestration into lipid rafts may contribute significantly to c-Yes specific signaling by dictating the sub-set of proteins available for intermolecular interactions. The Unique domain may also contribute to localization. Once inside lipid rafts, c-Yes-specific signals may be dictated by protein/protein interactions mediated through the Unique, SH3, and SH2 domains. (Membrane cartoon provided by Amanda Gatesman). 


\section{References}

Al Obeidi,F.A., Lam,K.S. (2000). Development of inhibitors for protein tyrosine kinases. Oncogene 19, 5690-5701.

Alonso,G., Koegl,M., Mazurenko,N., Courtneidge,S.A. (1995). Sequence requirements for binding of Src family tyrosine kinases to activated growth factor receptors. J.Biol.Chem. 270, 9840-9848.

Ariki,M., Tanabe,O., Usui,H., Hayashi,H., Inoue,R., Nishito,Y., Kagamiyama,H., Takeda,M. (1997). Identification of autophosphorylation sites in c-Yes purified from rat liver plasma membranes. J.Biochem.(Tokyo) 121, 104-111.

Arreaza,G., Melkonian,K.A., LaFevre-Bernt,M., Brown,D.A. (1994). Triton X-100resistant membrane complexes from cultured kidney epithelial cells contain the Src family protein tyrosine kinase p62yes. J.Biol.Chem. 269, 19123-19127.

Aspenstrom,P. (1999). Effectors for the Rho GTPases. Curr.Opin.Cell Biol. 11, 95-102.

Bano,M.C., Jackson,C.S., Magee,A.I. (1998). Pseudo-enzymatic S-acylation of a myristoylated yes protein tyrosine kinase peptide in vitro may reflect non-enzymatic Sacylation in vivo. Biochem.J. 330 ( Pt 2), 723-731.

Beemon,K., Mattingly,B. (1986). Avian sarcoma virus gag-fps and gag-yes transforming proteins are not myristylated or palmitylated. Virology 155, 716-720.

Bijlmakers,M.J., Isobe-Nakamura,M., Ruddock,L.J., Marsh,M. (1997). Intrinsic signals in the unique domain target p56(lck) to the plasma membrane independently of CD4.

J.Cell Biol. 137, 1029-1040.

Boyce,B.F., Yoneda,T., Lowe,C., Soriano,P., Mundy,G.R. (1992). Requirement of pp60c-src expression for osteoclasts to form ruffled borders and resorb bone in mice. J.Clin.Invest 90, 1622-1627.

Bradshaw,J.M., Mitaxov,V., Waksman,G. (1999). Investigation of phosphotyrosine recognition by the SH2 domain of the Src kinase. J.Mol.Biol. 293, 971-985.

Brickell,P.M. (1992). The p60c-src family of protein-tyrosine kinases: structure, regulation, and function. Crit Rev.Oncog. 3, 401-446.

Brown,D.A., London,E. (1997). Structure of detergent-resistant membrane domains: does phase separation occur in biological membranes? Biochem.Biophys.Res.Commun. 240, $1-7$.

Brown,M.T., Cooper,J.A. (1996). Regulation, substrates and functions of src. Biochim.Biophys.Acta 1287, 121-149. 
Campbell,K.S., Buder,A., Deuschle,U. (1995). Interactions between the amino-terminal domain of p56lck and cytoplasmic domains of CD4 and CD8 alpha in yeast.

Eur.J.Immunol. 25, 2408-2412.

Cantrell,D.A. (2001). Phosphoinositide 3-kinase signalling pathways. J.Cell Sci. 114, 1439-1445.

Eck,M.J., Shoelson,S.E., Harrison,S.C. (1993). Recognition of a high-affinity phosphotyrosyl peptide by the Src homology-2 domain of p56lck. Nature 362, 87-91.

Eliceiri,B.P., Paul,R., Schwartzberg,P.L., Hood,J.D., Leng,J., Cheresh,D.A. (1999). Selective requirement for Src kinases during VEGF-induced angiogenesis and vascular permeability. Mol.Cell 4, 915-924.

Erpel,T., Superti-Furga,G., Courtneidge,S.A. (1995). Mutational analysis of the Src SH3 domain: the same residues of the ligand binding surface are important for intra- and intermolecular interactions. EMBO J. 14, 963-975.

Fincham,V.J., Brunton,V.G., Frame,M.C. (2000). The SH3 domain directs acto-myosindependent targeting of v-Src to focal adhesions via phosphatidylinositol 3-kinase. Mol.Cell Biol. 20, 6518-6536.

Fincham,V.J., Chudleigh,A., Frame,M.C. (1999). Regulation of p190 Rho-GAP by v-Src is linked to cytoskeletal disruption during transformation. J.Cell Sci. 112 ( Pt 6), 947-956.

Fukui,Y., Saltiel,A.R., Hanafusa,H. (1991). Phosphatidylinositol-3 kinase is activated in v-src, v-yes, and v-fps transformed chicken embryo fibroblasts. Oncogene 6, 407-411.

Gould,K.L., Hunter,T. (1988). Platelet-derived growth factor induces multisite phosphorylation of pp60c-src and increases its protein-tyrosine kinase activity. Mol.Cell Biol. 8, 3345-3356.

Greenway,A.L., Dutartre,H., Allen,K., McPhee,D.A., Olive,D., Collette,Y. (1999). Simian immunodeficiency virus and human immunodeficiency virus type 1 nef proteins show distinct patterns and mechanisms of Src kinase activation. J.Virol. 73, 6152-6158.

Guappone,A.C., Flynn,D.C. (1997). The integrity of the SH3 binding motif of AFAP-110 is required to facilitate tyrosine phosphorylation by, and stable complex formation with, Src. Mol.Cell Biochem. 175, 243-252.

Hall,C.L., Lange,L.A., Prober,D.A., Zhang,S., Turley,E.A. (1996). pp60(c-src) is required for cell locomotion regulated by the hyaluronanreceptor RHAMM. Oncogene $13,2213-2224$.

Hansen,K., Alonso,G., Courtneidge,S.A., Ronnstrand,L., Heldin,C.H. (1997). PDGFinduced phosphorylation of Tyr28 in the N-terminus of Fyn affects Fyn activation. Biochem.Biophys.Res.Commun. 241, 355-362. 
Honda,Z., Suzuki,T., Kono,H., Okada,M., Yamamoto,T., Ra,C., Morita,Y., Yamamoto,K. (2000). Sequential requirements of the N-terminal palmitoylation site and $\mathrm{SH} 2$ domain of Src family kinases in the initiation and progression of FcepsilonRI signaling. Mol.Cell Biol. 20, 1759-1771.

Howell,S.B. (2000). Resistance to apoptosis in prostate cancer cells. Mol.Urol. 4, 225229.

Ignelzi,M.A., Jr., Miller,D.R., Soriano,P., Maness,P.F. (1994). Impaired neurite outgrowth of src-minus cerebellar neurons on the cell adhesion molecule L1. Neuron 12, 873-884.

Imamura,T., Huang,J., Dalle,S., Ugi,S., Usui,I., Luttrell,L.M., Miller,W.E., Lefkowitz,R.J., Olefsky,J.M. (2001). \{beta\}-arrestin-mediated recruitment of the Src family kinase Yes mediates endothelin-1-stimulated glucose transport. J.Biol.Chem.

Jiang,B.H., Agani,F., Passaniti,A., Semenza,G.L. (1997). V-SRC induces expression of hypoxia-inducible factor 1 (HIF-1) and transcription of genes encoding vascular endothelial growth factor and enolase 1: involvement of HIF-1 in tumor progression. Cancer Res. 57, 5328-5335.

Jiang,B.H., Jiang,G., Zheng,J.Z., Lu,Z., Hunter,T., Vogt,P.K. (2001).

Phosphatidylinositol 3-kinase signaling controls levels of hypoxia- inducible factor 1.

Cell Growth Differ. 12, 363-369.

Kanner,S.B., Reynolds,A.B., Vines,R.R., Parsons,J.T. (1990). Monoclonal antibodies to individual tyrosine-phosphorylated protein substrates of oncogene-encoded tyrosine kinases. Proc.Natl.Acad.Sci.U.S.A 87, 3328-3332.

Kanner,S.B., Reynolds,A.B., Wang,H.C., Vines,R.R., Parsons,J.T. (1991). The SH2 and SH3 domains of pp60src direct stable association with tyrosine phosphorylated proteins p130 and p110. EMBO J. 10, 1689-1698.

Kaplan,K.B., Swedlow,J.R., Morgan,D.O., Varmus,H.E. (1995). c-Src enhances the spreading of src-/- fibroblasts on fibronectin by a kinase-independent mechanism. Genes Dev. 9, 1505-1517.

Katagiri,K., Katagiri,T., Kajiyama,K., Uehara,Y., Yamamoto,T., Yoshida,T. (1992). Modulation of monocytic differentiation of HL-60 cells by inhibitors of protein tyrosine kinases. Cell Immunol. 140, 282-294.

Katagiri,K., Katagiri,T., Koyama,Y., Morikawa,M., Yamamoto,T., Yoshida,T. (1991). Expression of src family genes during monocytic differentiation of HL- 60 cells. J.Immunol. 146, 701-707.

Kitamura,N., Kitamura,A., Toyoshima,K., Hirayama,Y., Yoshida,M. (1982). Avian sarcoma virus $\mathrm{Y} 73$ genome sequence and structural similarity of its transforming gene product to that of Rous sarcoma virus. Nature 297, 205-208. 
Koong,A.C., Chen,E.Y., Mivechi,N.F., Denko,N.C., Stambrook,P., Giaccia,A.J. (1994). Hypoxic activation of nuclear factor-kappa B is mediated by a Ras and Raf signaling pathway and does not involve MAP kinase (ERK1 or ERK2). Cancer Res. 54, 52735279.

Krasilnikov,M.A. (2000). Phosphatidylinositol-3 kinase dependent pathways: the role in control of cell growth, survival, and malignant transformation. Biochemistry (Mosc.) 65, 59-67.

Lawrence,D.S., Niu,J. (1998). Protein kinase inhibitors: the tyrosine-specific protein kinases. Pharmacol.Ther. 77, 81-114.

Lee,P.J., Jiang,B.H., Chin,B.Y., Iyer,N.V., Alam,J., Semenza,G.L., Choi,A.M. (1997). Hypoxia-inducible factor-1 mediates transcriptional activation of the heme oxygenase-1 gene in response to hypoxia. J.Biol.Chem. 272, 5375-5381.

Loganzo,F., Jr., Dosik,J.S., Zhao,Y., Vidal,M.J., Nanus,D.M., Sudol,M., Albino,A.P. (1993). Elevated expression of protein tyrosine kinase c-Yes, but not c-Src, in human malignant melanoma. Oncogene 8, 2637-2644.

Luton,F., Verges,M., Vaerman,J.P., Sudol,M., Mostov,K.E. (1999). The SRC family protein tyrosine kinase p62yes controls polymeric IgA transcytosis in vivo. Mol.Cell 4, 627-632.

Mackay,D.J., Hall,A. (1998). Rho GTPases. J.Biol.Chem. 273, 20685-20688.

Maines,M.D. (1997). The heme oxygenase system: a regulator of second messenger gases. Annu.Rev.Pharmacol.Toxicol. 37, 517-554.

Marchetti,D., Parikh,N., Sudol,M., Gallick,G.E. (1998). Stimulation of the protein tyrosine kinase c-Yes but not c-Src by neurotrophins in human brain-metastatic melanoma cells. Oncogene 16, 3253-3260.

Masuya,Y., Hioki,K., Tokunaga,R., Taketani,S. (1998). Involvement of the tyrosine phosphorylation pathway in induction of human heme oxygenase-1 by hemin, sodium arsenite, and cadmium chloride. J.Biochem.(Tokyo) 124, 628-633.

Mayer,B.J., Baltimore,D. (1994). Mutagenic analysis of the roles of SH2 and SH3 domains in regulation of the Abl tyrosine kinase. Mol.Cell Biol. 14, 2883-2894.

Moarefi,I., LaFevre-Bernt,M., Sicheri,F., Huse,M., Lee,C.H., Kuriyan,J., Miller,W.T. (1997). Activation of the Src-family tyrosine kinase Hck by SH3 domain displacement. Nature 385, 650-653.

Moasser,M.M., Srethapakdi,M., Sachar,K.S., Kraker,A.J., Rosen,N. (1999). Inhibition of Src kinases by a selective tyrosine kinase inhibitor causes mitotic arrest. Cancer Res. 59, 6145-6152. 
Mohler,P.J., Kreda,S.M., Boucher,R.C., Sudol,M., Stutts,M.J., Milgram,S.L. (1999). Yesassociated protein 65 localizes p62(c-Yes) to the apical compartment of airway epithelia by association with EBP50. J.Cell Biol. 147, 879-890.

Molinari,M. (2000). Cell cycle checkpoints and their inactivation in human cancer. Cell Prolif. 33, 261-274.

Montellano,P.R. (2000). The mechanism of heme oxygenase. Curr.Opin.Chem.Biol. 4, 221-227.

Morgan,D.O., Kaplan,J.M., Bishop,J.M., Varmus,H.E. (1989). Mitosis-specific phosphorylation of p60c-src by p34cdc2-associated protein kinase. Cell 57, 775-786.

Mukhopadhyay,D., Tsiokas,L., Zhou,X.M., Foster,D., Brugge,J.S., Sukhatme,V.P. (1995). Hypoxic induction of human vascular endothelial growth factor expression through c-Src activation. Nature 375, 577-581.

Muthuswamy,S.K., Muller,W.J. (1995). Activation of Src family kinases in Neu-induced mammary tumors correlates with their association with distinct sets of tyrosine phosphorylated proteins in vivo. Oncogene 11, 1801-1810.

Noble,M.E., Musacchio,A., Saraste,M., Courtneidge,S.A., Wierenga,R.K. (1993). Crystal structure of the SH3 domain in human Fyn; comparison of the three-dimensional structures of SH3 domains in tyrosine kinases and spectrin. EMBO J. 12, 2617-2624.

Odajima,J., Matsumura,I., Sonoyama,J., Daino,H., Kawasaki,A., Tanaka,H., Inohara,N., Kitamura,T., Downward,J., Nakajima,K., Hirano,T., Kanakura,Y. (2000). Full oncogenic activities of $\mathrm{v}$-Src are mediated by multiple signaling pathways. Ras as an essential mediator for cell survival. J.Biol.Chem. 275, 24096-24105.

Owens,D.W., McLean,G.W., Wyke,A.W., Paraskeva,C., Parkinson,E.K., Frame,M.C., Brunton,V.G. (2000). The catalytic activity of the Src family kinases is required to disrupt cadherin-dependent cell-cell contacts. Mol.Biol.Cell 11, 51-64.

Page,S.T., van Oers,N.S., Perlmutter,R.M., Weiss,A., Pullen,A.M. (1997). Differential contribution of Lck and Fyn protein tyrosine kinases to intraepithelial lymphocyte development. Eur.J.Immunol. 27, 554-562.

Park,J., Meisler,A.I., Cartwright,C.A. (1993). c-Yes tyrosine kinase activity in human colon carcinoma. Oncogene 8, 2627-2635.

Pawlak,G., Helfman,D.M. (2001). Cytoskeletal changes in cell transformation and tumorigenesis. Curr.Opin.Genet.Dev. 11, 41-47.

Pellicena,P., Stowell,K.R., Miller,W.T. (1998). Enhanced phosphorylation of Src family kinase substrates containing SH2 domain binding sites. J.Biol.Chem. 273, 15325-15328. 
Pena,S.V., Melhem,M.F., Meisler,A.I., Cartwright,C.A. (1995). Elevated c-yes tyrosine kinase activity in premalignant lesions of the colon. Gastroenterology 108, 117-124.

Penuel,E., Martin,G.S. (1999). Transformation by v-Src: Ras-MAPK and PI3K-mTOR mediate parallel pathways. Mol.Biol.Cell 10, 1693-1703.

Pugh,C.W., Gleadle,J., Maxwell,P.H. (2001). Hypoxia and oxidative stress in breast cancer. Hypoxia signalling pathways. Breast Cancer Res. 3, 313-317.

Qian,Y., Baisden,J.M., Zot,H.G., Van Winkle,W.B., Flynn,D.C. (2000). The carboxy terminus of AFAP-110 modulates direct interactions with actin filaments and regulates its ability to alter actin filament integrity and induce lamellipodia formation. Exp.Cell Res. $255,102-113$.

Reif,K., Nobes,C.D., Thomas,G., Hall,A., Cantrell,D.A. (1996). Phosphatidylinositol 3kinase signals activate a selective subset of Rac/Rho-dependent effector pathways.

Curr.Biol. 6, 1445-1455.

Ren,X.D., Schwartz,M.A. (1998). Regulation of inositol lipid kinases by Rho and Rac. Curr.Opin.Genet.Dev. 8, 63-67.

Resh,M.D. (1994). Myristylation and palmitylation of Src family members: the fats of the matter. Cell 76, 411-413.

Rickles,R.J., Botfield,M.C., Weng,Z., Taylor,J.A., Green,O.M., Brugge,J.S., Zoller,M.J. (1994). Identification of Src, Fyn, Lyn, PI3K and Ab1 SH3 domain ligands using phage display libraries. EMBO J. 13, 5598-5604.

Rickles,R.J., Botfield,M.C., Zhou,X.M., Henry,P.A., Brugge,J.S., Zoller,M.J. (1995). Phage display selection of ligand residues important for Src homology 3 domain binding specificity. Proc.Natl.Acad.Sci.U.S.A 92, 10909-10913.

Robbins,S.M., Quintrell,N.A., Bishop,J.M. (1995). Myristoylation and differential palmitoylation of the HCK protein- tyrosine kinases govern their attachment to membranes and association with caveolae. Mol.Cell Biol. 15, 3507-3515.

Roussel,M.F. (1998). Key effectors of signal transduction and G1 progression. Adv.Cancer Res. 74, 1-24.

Sandau,K.B., Faus,H.G., Brune,B. (2000). Induction of hypoxia-inducible-factor 1 by nitric oxide is mediated via the PI $3 \mathrm{~K}$ pathway. Biochem.Biophys.Res.Commun. 278, 263-267.

Scott,M.P., Miller,W.T. (2000). A peptide model system for processive phosphorylation by Src family kinases. Biochemistry 39, 14531-14537.

Seko,Y., Takahashi,N., Tobe,K., Kadowaki,T., Yazaki,Y. (1997). Hypoxia and hypoxia/reoxygenation activate p65PAK, p38 mitogen- activated protein kinase (MAPK), 
and stress-activated protein kinase (SAPK) in cultured rat cardiac myocytes. Biochem.Biophys.Res.Commun. 239, 840-844.

Seko,Y., Tobe,K., Takahashi,N., Kaburagi,Y., Kadowaki,T., Yazaki,Y. (1996). Hypoxia and hypoxia/reoxygenation activate Src family tyrosine kinases and p21 ras in cultured rat cardiac myocytes. Biochem.Biophys.Res.Commun. 226, 530-535.

Shaw,A.S., Amrein,K.E., Hammond,C., Stern,D.F., Sefton,B.M., Rose,J.K. (1989). The lck tyrosine protein kinase interacts with the cytoplasmic tail of the CD4 glycoprotein through its unique amino-terminal domain. Cell 59, 627-636.

Shenoy-Scaria,A.M., Dietzen,D.J., Kwong,J., Link,D.C., Lublin,D.M. (1994). Cysteine3 of Src family protein tyrosine kinase determines palmitoylation and localization in caveolae. J.Cell Biol. 126, 353-363.

Shenoy,S., Choi,J.K., Bagrodia,S., Copeland,T.D., Maller,J.L., Shalloway,D. (1989). Purified maturation promoting factor phosphorylates pp60c-src at the sites phosphorylated during fibroblast mitosis. Cell 57, 763-774.

Sicheri,F., Moarefi,I., Kuriyan,J. (1997). Crystal structure of the Src family tyrosine kinase Hck. Nature 385, 602-609.

Sohara,Y., Ishiguro,N., Machida,K., Kurata,H., Thant,A.A., Senga,T., Matsuda,S., Kimata,K., Iwata,H., Hamaguchi,M. (2001). Hyaluronan activates cell motility of v-Srctransformed cells via Ras- mitogen-activated protein kinase and phosphoinositide 3kinase-Akt in a tumor-specific manner. Mol.Biol.Cell 12, 1859-1868.

Songyang,Z., Shoelson,S.E., Chaudhuri,M., Gish,G., Pawson,T., Haser,W.G., King,F., Roberts,T., Ratnofsky,S., Lechleider,R.J., . (1993). SH2 domains recognize specific phosphopeptide sequences. Cell 72, 767-778.

Soriano,P., Montgomery,C., Geske,R., Bradley,A. (1991). Targeted disruption of the csrc proto-oncogene leads to osteopetrosis in mice. Cell 64, 693-702.

Sparks,A.B., Rider,J.E., Hoffman,N.G., Fowlkes,D.M., Quillam,L.A., Kay,B.K. (1996). Distinct ligand preferences of Src homology 3 domains from Src, Yes, Abl, Cortactin, p53bp2, PLCgamma, Crk, and Grb2. Proc.Natl.Acad.Sci.U.S.A 93, 1540-1544.

Stein,P.L., Vogel,H., Soriano,P. (1994). Combined deficiencies of Src, Fyn, and Yes tyrosine kinases in mutant mice. Genes Dev. 8, 1999-2007.

Sudol,M. (1994). Yes-associated protein (YAP65) is a proline-rich phosphoprotein that binds to the SH3 domain of the Yes proto-oncogene product. Oncogene 9, 2145-2152.

Sudol,M., Kieswetter,C., Zhao,Y.H., Dorai,T., Wang,L.H., Hanafusa,H. (1988).

Nucleotide sequence of a cDNA for the chick yes proto-oncogene: comparison with the viral yes gene. Nucleic Acids Res. 16, 9876. 
Sugawara,K., Sugawara,I., Sukegawa,J., Akatsuka,T., Yamamoto,T., Morita,M., Mori,S., Toyoshima,K. (1991). Distribution of c-yes-1 gene product in various cells and tissues. Br.J.Cancer 63, 508-513.

Suzuki,T., Kono,H., Hirose,N., Okada,M., Yamamoto,T., Yamamoto,K., Honda,Z. (2000). Differential involvement of Src family kinases in Fc gamma receptor- mediated phagocytosis. J.Immunol. 165, 473-482.

Thomas,S.M., Brugge,J.S. (1997). Cellular functions regulated by Src family kinases. Annu.Rev.Cell Dev.Biol. 13, 513-609.

Toyoshima,K., Yamamoto,T., Kawai,S., Yoshida,M. (1987). Viral oncogenes, v-yes and v-erbB, and their cellular counterparts. Adv.Virus Res. 32, 97-127.

Tsygankova,O.M., Peng,M., Maloney,J.A., Hopkins,N., Williamson,J.R. (1998). Angiotensin II induces diverse signal transduction pathways via both Gq and Gi proteins in liver epithelial cells. J.Cell Biochem. 69, 63-71.

van't Hof,W., Resh,M.D. (1997). Rapid plasma membrane anchoring of newly synthesized p59fyn: selective requirement for NH2-terminal myristoylation and palmitoylation at cysteine-3. J.Cell Biol. 136, 1023-1035.

Vonakis,B.M., Chen,H., Haleem-Smith,H., Metzger,H. (1997). The unique domain as the site on Lyn kinase for its constitutive association with the high affinity receptor for IgE. J.Biol.Chem. 272, 24072-24080.

Waksman,G., Kominos,D., Robertson,S.C., Pant,N., Baltimore,D., Birge,R.B., Cowburn,D., Hanafusa,H., Mayer,B.J., Overduin,M., . (1992). Crystal structure of the phosphotyrosine recognition domain $\mathrm{SH} 2$ of $\mathrm{v}$ - src complexed with tyrosinephosphorylated peptides. Nature 358, 646-653.

Weng,Z., Thomas,S.M., Rickles,R.J., Taylor,J.A., Brauer,A.W., Seidel-Dugan,C., Michael,W.M., Dreyfuss,G., Brugge,J.S. (1994). Identification of Src, Fyn, and Lyn SH3-binding proteins: implications for a function of SH3 domains. Mol.Cell Biol. 14, 4509-4521.

Wong,J., Straus,D., Chan,A.C. (1998). Genetic evidence of a role for Lck in T-cell receptor function independent or downstream of ZAP-70/Syk protein tyrosine kinases. Mol.Cell Biol. 18, 2855-2866.

Xu,W., Doshi,A., Lei,M., Eck,M.J., Harrison,S.C. (1999). Crystal structures of c-Src reveal features of its autoinhibitory mechanism. Mol.Cell 3, 629-638.

Xu,W., Harrison,S.C., Eck,M.J. (1997). Three-dimensional structure of the tyrosine kinase c-Src. Nature 385, 595-602. 
Yurchak,L.K., Sefton,B.M. (1995). Palmitoylation of either Cys-3 or Cys-5 is required for the biological activity of the Lck tyrosine protein kinase. Mol.Cell Biol. 15, 69146922.

Zhao,Y.H., Krueger,J.G., Sudol,M. (1990). Expression of cellular-yes protein in mammalian tissues. Oncogene 5, 1629-1635.

Zhong,H., Chiles,K., Feldser,D., Laughner,E., Hanrahan,C., Georgescu,M.M., Simons,J.W., Semenza,G.L. (2000). Modulation of hypoxia-inducible factor 1alpha expression by the epidermal growth factor/phosphatidylinositol 3-

kinase/PTEN/AKT/FRAP pathway in human prostate cancer cells: implications for tumor angiogenesis and therapeutics. Cancer Res. 60, 1541-1545. 


\section{CURRICULUM VITAE \\ Justin Summy, Ph.D. (anticipated, December 2001) \\ Personal and Professional}

\section{Personal}

Born: Mount Pleasant, PA

Marital Status: Single

Citizenship: US citizen. SSN: 457-81-5256

Current Home: 113 Mountaineer Village, Morgantown WV, 26508

Current Work: 2813 MBR Cancer Center, West Virginia University, Morgantown,

WV 26506-9300, phone: 304-293-0501

\section{Education}

1992-1996 - West Virginia University B.S., Biology. With honors, summa cum laude.

1996-2001 - West Virginia University Ph.D., Microbiology \& Immunology

Thesis: Specificity in signaling by cYes (mentor, Daniel C. Flynn, Ph.D.).

\section{Professional Experience}

1994-1995: Undergraduate Research Fellow, Lisa Salati, PhD. West Virginia University

1996-1997: Teaching Assistant, Department of Microbiology \& Immunology, West Virginia University

1997-2001: Research Assistant, Mary Babb Randolph Cancer Center, West Virginia University

2001 - present: Post-doctoral fellow, Dr. Gary Gallick, MD Anderson Cancer Center.

\section{Active Society Membership}

1. American Society for Cell Biology (ASCB): Student Member.

\section{Honors}

1. Presidential Scholar (full scholarship). West Virginia University. 1992-1996.

2. Golden Key Honor Society. 1994

3. Beta Beta Beta, National Biology Honor Society. 1995

4. Phi Beta Kappa. 1996

5. Swiger Graduate Student Fellowship. 1997-2000.

6. Outstanding Graduate Student Award - WVU Health Sciences Center. 1997. 
7. Student Travel Award - American Society for Cell Biology, $38^{\text {th }}$ National Meeting, San Francisco, CA December 1998.

Area of Research Expertise: Cancer, signal transduction, tyrosine kinases.

\section{Funding Obtained:}

\section{RESEARCH}

Active/Pending/Expired expired

Project Number (Principal Investigator): (Justin M. Summy)

Source: $\quad$ Swiger Foundation

Title of Project (and/or Subproject): Specificity in signaling by cYes

Dates of Approved/Proposed Project:8/1/1997 to 7/31/00

Annual Direct Costs / Percent Effort: \$15,000 / 100\% effort

The major goals of this project are...A graduate student fellowship award that paid the salary for JMS.

Active/Pending/Expired expired

Project Number (Principal Investigator): $\quad$ (Daniel C. Flynn, PhD)

Source: $\quad$ Emmet G. and Brownie E. McDowell Fund

Title of Project (and/or Subproject): Activation of telomerase by Src, Yes and Myb proto-oncogenes

Dates of Approved/Proposed Project:3/1/98 to 2/28/99

Annual Direct Costs / Percent Effort: \$20,000 / 100\% effort

The major goals of this project are...This grant supported the research project of J.M.

Summy. Proposal was written by JMS and submitted on his behalf by DCF.

\section{PUBLICATIONS}

1. Qian, Y., A.C. Guappone, J.M. Baisden, M.W. Hill, J.M. Summy, and D.C. Flynn. 1999. Monoclonal Antibodies Directed Against AFAP-110 Recognize Speciesspecific and Conserved Epitopes. Hybridoma 18:167-175.

2. Summy, J.M.., A.C. Guappone, M.Sudol, and D.C. Flynn. 2000. SH2 and SH3 interactions can dictate specificity in substrate selection between cSrc and cYes. Oncogene, 19:155-160.

3. Summy J.M., J. Hoey, and D.C. Flynn. 2000. Chimeric constructs containing the SH4/Unique domains of cYes can restrict the ability of $\mathrm{Src}^{527 \mathrm{~F}}$ to efficiently upregulate Heme Oxygenase-1 expression. Cell. Signaling, 12:887-897.

4. Summy, J. M. D.C. Flynn and M. Sudol. Src family tyrosine kinases in growth control. Invited Review, Frontiers in Biochemistry, Submitted. 
5. Baisden J.M., L. Cherezova, Y. Qian, J.M. Summy, A. Guappone-Koay, B. Han, M. Liu, X. Shi and D.C. Flynn. PKC alters actin filament integrity and directs activation of cSrc through interactions with the Src-binding partner, AFAP-110. Submitted.

6. Summy, J.M., B.-H. Jiang and D.C. Flynn. The c-Yes amino terminal SH4 and Unique domains prevent actin filament rearrangement and Phosphatidylinositol-3kinase activation by $\mathrm{Src}^{527 \mathrm{~F}} / \mathrm{c}$-Yes chimeric proteins. Manuscript in preparation.

7. Summy J.M. and D.C. Flynn. Differential responses to activated cYes in CEF and DF-1 cells. Manuscript in preparation.

\section{ABSTRACTS}

1. J.M. Summy and D.C. Flynn. Role of the functional domains in directing signaling specificity between Src and Yes. American Society for Cell Biology, 1998.

2. J.M. Summy, A.C. Guappone, and D.C. Flynn. Roles of the c-Src and c-Yes functional domains in directing signaling specificity. American Association for Cancer Research, 1998.

3. J.M. Summy and D.C. Flynn. The c-Yes amino terminus inhibits the ability of fully activated c-Src/c-Yes chimeras to induce cell transformation in chicken embryo fibroblasts. Meeting on Oncogenes, 2000.

\section{Research statement:}

Src family kinases represent key components of a wide variety of cellular signal transduction pathways, contributing to the regulation of such diverse events as vesicular trafficking, cell division, survival, motility, adhesion, and spreading. Two of these kinases, c-Src and c-Yes are abnormally activated in a variety of human cancers, and thus may contribute to tumor development or progression. c-Src and c-Yes may in turn represent potential targets for anti-tumor therapy. However, as many tumors only harbor abnormal activation of one of these proteins, it may be beneficial to target the proteins individually. In order to accomplish this, one must have an understanding of how these proteins are different and able to send specific signals. We have sought to understand the contributions of the functional domains to specificity in signaling between Src and Yes.

In order to shed light on this issue, we have generated $\mathrm{Src} / Y$ es chimeras in which the $\mathrm{SH} 3, \mathrm{SH} 2, \mathrm{SH} 3$ and $\mathrm{SH} 2$, or SH4, Unique, $\mathrm{SH}$, and $\mathrm{SH} 2$ domains of c-Src or fully activated $\mathrm{Src}^{527 \mathrm{~F}}$ were replaced by the corresponding domains from c-Yes. Upon expressing these constructs in chicken embryo fibroblasts (CEF), we have determined that, while the Yes SH3 and SH2 domains do not appear to affect Src substrate selection, they do alter the profile of proteins with which Src is able to form stable complexes in vivo. Replacement of the Src SH3 domain with that of Yes results in a loss of ability of Src to co-immunoprecipitate with AFAP-110. Replacement of the Src SH2 domain with that of c-Yes results in a gain of ability of Src to co-immunoprecipitate with an unknown $87 \mathrm{kDa}$ phosphoprotein. pp 87 may represent an important component of a heretofore unidentified Yes-specific signaling pathway. 
Replacement of the Src amino terminus (SH4 and Unique domains) with those of c-Yes results in a loss of ability of $\mathrm{Src}^{527 \mathrm{~F}}$ to induce CEF transformation. This loss of transformation capacity seems to require both the SH4 and Unique domains, as replacement of either domain individually still allows for cell transformation. We hypothesize that the c-Yes SH4 and Unique domains may cooperatively serve to sequester Src away from key substrates or signaling partners necessary for activation of a pathway necessary for cell transformation.

Understanding the roles of the functional domains in allowing these extremely homologous kinases to send specific signals will be important in understanding the biology of these proteins and may contribute to the overall understanding of signaling specificity between Src family members. In addition, knowledge of how Src and Yes are able to generate unique signals may facilitate the design of compounds that can selectively inhibit signals sent by each kinase individually. Such compounds would further our understanding of the biological roles of these proteins and may prove useful as chemotherapeutic agents for cancers in which an individual Src family kinase is abnormally activated.

\title{
References
}

\author{
Dr. Daniel C. Flynn, PhD \\ Associate Professor \\ Department of Microbiology, Immunology, and Cell Biology \\ West Virginia University School of Medicine \\ PO Box 9300 \\ Mary Babb Randolph Cancer Center \\ Morgantown, WV 26506 \\ 304-293-6966 \\ dflynn@hsc.wvu.edu \\ Dr. Thomas A. Elliott, PhD \\ Professor \\ Department of Microbiology, Immunology, and Cell Biology \\ West Virginia University School of Medicine \\ PO Box 9177 Health Sciences Center North \\ Morgantown WV 26506 \\ 304-293-2676 \\ telliott@wvu.edu \\ telliott@hsc.wvu.edu
}

Dr. Stephen G. Graber, PhD

Associate Professor

Department of Pharmacology and Toxicology 
West Virginia University School of Medicine

PO Box 9223

Health Sciences Center North

Morgantown, WV 26506

304-293-2305

sgraber@wvu.edu

sgraber@hsc.wvu.edu

Dr. Bing-Hua Jiang, PhD

Assisstant Professor

Department of Microbiology, Immunology, and Cell Biology

West Virginia University School of Medicine

PO Box 9300

Mary Babb Randolph Cancer Center

Morgantown WV 26506

304-293-0493

bhjiang@hsc.wvu.edu

Dr. Lisa M. Salati, PhD

Associate Professor

Department of Biochemistry

West Virginia University School of Medicine

PO Box 9142 Health Sciences Center North

Morgantown WV 26506

304-293-7759

1salati@hsc.wvu.edu

Dr. Eric Westin, MD

Deputy Clinical Director and Chief, Section of Hematology/Oncology

Laboratory of Clinical Investigation

National Institute on Aging, NIH

Gerontology Research Center

Johns Hopkins Medical Center

Baltimore, MD 21224-6825

WestinE@grc.nia.nih.gov

Dr. John B. Barnett, PhD

Chairman, Department of Microbiology, Immunology, and Cell Biology

West Virginia University School of Medicine

PO Box 9177 Health Sciences Center North

Morgantown WV 26506

304-293-2649

jbarnett@hsc.wvu.edu 